
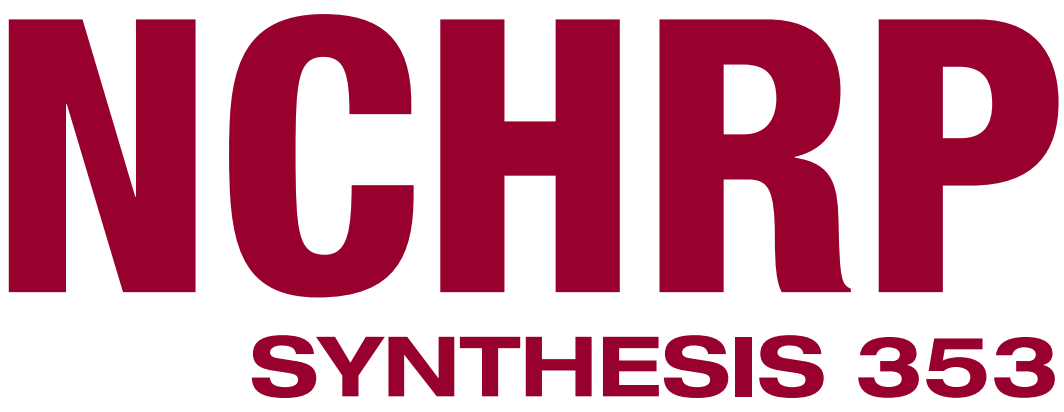

NATIONAL cOOPERATIVE HIGHWAY RESEARCH PROGRAM

\title{
Inspection and Maintenance of Bridge Stay Cable Systems
}

A Synthesis of Highway Practice 
TRANSPORTATION RESEARCH BOARD EXECUTIVE COMMITTEE 2005 (Membership as of November 2005)

\section{OFFICERS}

Chair: John R. Njord, Executive Director, Utah DOT

Vice Chair: Michael D. Meyer, Professor, School of Civil and Environmental Engineering, Georgia Institute of Technology

Executive Director: Robert E. Skinner, Jr., Transportation Research Board

\section{MEMBERS}

MICHAEL W. BEHRENS, Executive Director, Texas DOT

ALLEN D. BIEHLER, Secretary, Pennsylvania DOT

LARRY L. BROWN, SR., Executive Director, Mississippi DOT

DEBORAH H. BUTLER, Vice President, Customer Service, Norfolk Southern Corporation and Subsidiaries, Atlanta, GA

ANNE P. CANBY, President, Surface Transportation Policy Project, Washington, DC

JOHN L. CRAIG, Director, Nebraska Department of Roads

DOUGLAS G. DUNCAN, President and CEO, FedEx Freight, Memphis, TN

NICHOLAS J. GARBER, Professor of Civil Engineering, University of Virginia, Charlottesville

ANGELA GITTENS, Vice President, Airport Business Services, HNTB Corporation, Miami, FL

GENEVIEVE GIULIANO, Director, Metrans Transportation Center, and Professor, School of Policy, Planning, and Development,

USC, Los Angeles

BERNARD S. GROSECLOSE, JR., President and CEO, South Carolina State Ports Authority

SUSAN HANSON, Landry University Professor of Geography, Graduate School of Geography, Clark University

JAMES R. HERTWIG, President, CSX Intermodal, Jacksonville, FL

GLORIA JEAN JEFF, Director, Michigan DOT

ADIB K. KANAFANI, Cahill Professor of Civil Engineering, University of California, Berkeley

HERBERT S. LEVINSON, Principal, Herbert S. Levinson Transportation Consultant, New Haven, CT

SUE MCNEIL, Professor, Department of Civil and Environmental Engineering, University of Delaware, Newark

MICHAEL R. MORRIS, Director of Transportation, North Central Texas Council of Governments

CAROL A. MURRAY, Commissioner, New Hampshire DOT

MICHAEL S. TOWNES, President and CEO, Hampton Roads Transit, Hampton, VA

C. MICHAEL WALTON, Ernest H. Cockrell Centennial Chair in Engineering, University of Texas, Austin

LINDA S. WATSON, Executive Director, LYNX_Central Florida Regional Transportation Authority

MARION C. BLAKEY, Federal Aviation Administrator, U.S.DOT (ex officio)

JOSEPH H. BOARDMAN, Federal Railroad Administrator, U.S.DOT (ex officio)

REBECCA M. BREWSTER, President and COO, American Transportation Research Institute, Smyrna, GA (ex officio)

GEORGE BUGLIARELLO, Chancellor, Polytechnic University, and Foreign Secretary, National Academy of Engineering (ex officio)

J. RICHARD CAPKA, Acting Administrator, Federal Highway Administration, U.S.DOT (ex officio)

THOMAS H. COLLINS (Adm., U.S. Coast Guard), Commandant, U.S. Coast Guard (ex officio)

JAMES J. EBERHARDT, Chief Scientist, Office of FreedomCAR and Vehicle Technologies, U.S. Department of Energy (ex officio)

JACQUELINE GLASSMAN, Deputy Administrator, National Highway Traffic Safety Administration, U.S.DOT (ex officio)

EDWARD R. HAMBERGER, President and CEO, Association of American Railroads (ex officio)

DAVID B. HORNER, Acting Deputy Administrator, Federal Transit Administration, U.S. DOT (ex officio)

JOHN C. HORSLEY, Executive Director, American Association of State Highway and Transportation Officials (ex officio)

JOHN E. JAMIAN, Acting Administrator, Maritime Administration, U.S.DOT (ex officio)

EDWARD JOHNSON, Director, Applied Science Directorate, National Aeronautics and Space Administration (ex officio)

ASHOK G. KAVEESHWAR, Research and Innovative Technology Administrator, U.S.DOT (ex officio)

BRIGHAM MCCOWN, Deputy Administrator, Pipeline and Hazardous Materials Safety Administration, U.S.DOT (ex officio)

WILLIAM W. MILLAR, President, American Public Transportation Association (ex officio)

SUZANNE RUDZINSKI, Director, Transportation and Regional Programs, U.S. Environmental Protection Agency (ex officio)

ANNETTE M. SANDBERG, Federal Motor Carrier Safety Administrator, U.S.DOT (ex officio)

JEFFREY N. SHANE, Under Secretary for Policy, U.S.DOT (ex officio)

CARL A. STROCK (Maj. Gen., U.S. Army), Chief of Engineers and Commanding General, U.S. Army Corps of Engineers (ex officio)

\section{NATIONAL COOPERATIVE HIGHWAY RESEARCH PROGRAM}

\section{Transportation Research Board Executive Committee Subcommittee for NCHRP}

J. RICHARD CAPKA, Federal Highway Administration JOHN R. NJORD, Utah DOT (Chair)

JOHN C. HORSLEY, American Association of State Highway and Transportation Officials
MICHAEL D. MEYER, Georgia Institute of Technology ROBERT E. SKINNER, JR., Transportation Research Board MICHAEL S. TOWNES, Hampton Roads Transit, Hampton, VA C. MICHAEL WALTON, University of Texas, Austin 


\title{
NCHRP SYNTHESIS 353
}

\section{Inspection and Maintenance of Bridge Stay Cable Systems}

\section{A Synthesis of Highway Practice}

\author{
Consultant \\ HABIB TABATABAI \\ University of Wisconsin-Milwaukee
}




\section{NATIONAL COOPERATIVE HIGHWAY RESEARCH PROGRAM}

Systematic, well-designed research provides the most effective approach to the solution of many problems facing highway administrators and engineers. Often, highway problems are of local interest and can best be studied by highway departments individually or in cooperation with their state universities and others. However, the accelerating growth of highway transportation develops increasingly complex problems of wide interest to highway authorities. These problems are best studied through a coordinated program of cooperative research.

In recognition of these needs, the highway administrators of the American Association of State Highway and Transportation Officials initiated in 1962 an objective national highway research program employing modern scientific techniques. This program is supported on a continuing basis by funds from participating member states of the Association and it receives the full cooperation and support of the Federal Highway Administration, United States Department of Transportation.

The Transportation Research Board of the National Academies was requested by the Association to administer the research program because of the Board's recognized objectivity and understanding of modern research practices. The Board is uniquely suited for this purpose as it maintains an extensive committee structure from which authorities on any highway transportation subject may be drawn; it possesses avenues of communications and cooperation with federal, state, and local governmental agencies, universities, and industry; its relationship to the National Research Council is an insurance of objectivity; it maintains a full-time research correlation staff of specialists in highway transportation matters to bring the findings of research directly to those who are in a position to use them.

The program is developed on the basis of research needs identified by chief administrators of the highway and transportation departments and by committees of AASHTO. Each year, specific areas of research needs to be included in the program are proposed to the National Research Council and the Board by the American Association of State Highway and Transportation Officials. Research projects to fulfill these needs are defined by the Board, and qualified research agencies are selected from those that have submitted proposals. Administration and surveillance of research contracts are the responsibilities of the National Research Council and the Transportation Research Board.

The needs for highway research are many, and the National Cooperative Highway Research Program can make significant contributions to the solution of highway transportation problems of mutual concern to many responsible groups. The program, however, is intended to complement rather than to substitute for or duplicate other highway research programs.

NOTE: The Transportation Research Board of the National Academies, the National Research Council, the Federal Highway Administration, the American Association of State Highway and Transportation Officials, and the individual states participating in the National Cooperative Highway Research Program do not endorse products or manufacturers. Trade or manufacturers' names appear herein solely because they are considered essential to the object of this report.

\section{NCHRP SYNTHESIS 353}

Project 20-5 FY 2003 (Topic 35-07)

ISSN 0547-5570

ISBN 0-309-09760-6

Library of Congress Control No. 2005933207

(c) Transportation Research Board

Price $\$ 17.00$

\section{NOTICE}

The project that is the subject of this report was a part of the National Cooperative Highway Research Program conducted by the Transportation Research Board with the approval of the Governing Board of the National Research Council. Such approval reflects the Governing Board's judgment that the program concerned is of national importance and appropriate with respect to both the purposes and resources of the National Research Council.

The members of the technical committee selected to monitor this project and to review this report were chosen for recognized scholarly competence and with due consideration for the balance of disciplines appropriate to the project. The opinions and conclusions expressed or implied are those of the research agency that performed the research, and, while they have been accepted as appropriate by the technical committee, they are not necessarily those of the Transportation Research Board, the National Research Council, the American Association of State Highway and Transportation Officials, or the Federal Highway Administration, U.S. Department of Transportation.

Each report is reviewed and accepted for publication by the technical committee according to procedures established and monitored by the Transportation Research Board Executive Committee and the Governing Board of the National Research Council.

Published reports of the

NATIONAL COOPERATIVE HIGHWAY RESEARCH PROGRAM

are available from:

Transportation Research Board

Business Office

500 Fifth Street, NW

Washington, DC 20001

and can be ordered through the Internet at:

http://www.national-academies.org/trb/bookstore

Printed in the United States of America 


\section{THE NATIONAL ACADEMIES Advisers to the Nation on Science, Engineering, and Medicine}

The National Academy of Sciences is a private, nonprofit, self-perpetuating society of distinguished scholars engaged in scientific and engineering research, dedicated to the furtherance of science and technology and to their use for the general welfare. On the authority of the charter granted to it by the Congress in 1863, the Academy has a mandate that requires it to advise the federal government on scientific and technical matters. Dr. Ralph J. Cicerone is president of the National Academy of Sciences.

The National Academy of Engineering was established in 1964, under the charter of the National Academy of Sciences, as a parallel organization of outstanding engineers. It is autonomous in its administration and in the selection of its members, sharing with the National Academy of Sciences the responsibility for advising the federal government. The National Academy of Engineering also sponsors engineering programs aimed at meeting national needs, encourages education and research, and recognizes the superior achievements of engineers. Dr. William A. Wulf is president of the National Academy of Engineering.

The Institute of Medicine was established in 1970 by the National Academy of Sciences to secure the services of eminent members of appropriate professions in the examination of policy matters pertaining to the health of the public. The Institute acts under the responsibility given to the National Academy of Sciences by its congressional charter to be an adviser to the federal government and, on its own initiative, to identify issues of medical care, research, and education. Dr. Harvey V. Fineberg is president of the Institute of Medicine.

The National Research Council was organized by the National Academy of Sciences in 1916 to associate the broad community of science and technology with the Academy's purposes of furthering knowledge and advising the federal government. Functioning in accordance with general policies determined by the Academy, the Council has become the principal operating agency of both the National Academy of Sciences and the National Academy of Engineering in providing services to the government, the public, and the scientific and engineering communities. The Council is administered jointly by both the Academies and the Institute of Medicine. Dr. Ralph J. Cicerone and Dr. William A. Wulf are chair and vice chair, respectively, of the National Research Council.

The Transportation Research Board is a division of the National Research Council, which serves the National Academy of Sciences and the National Academy of Engineering. The Board's mission is to promote innovation and progress in transportation through research. In an objective and interdisciplinary setting, the Board facilitates the sharing of information on transportation practice and policy by researchers and practitioners; stimulates research and offers research management services that promote technical excellence; provides expert advice on transportation policy and programs; and disseminates research results broadly and encourages their implementation. The Board's varied activities annually engage more than 5,000 engineers, scientists, and other transportation researchers and practitioners from the public and private sectors and academia, all of whom contribute their expertise in the public interest. The program is supported by state transportation departments, federal agencies including the component administrations of the U.S. Department of Transportation, and other organizations and individuals interested in the development of transportation. www.TRB.org

www.national-academies.org 
NCHRP COMMITTEE FOR PROJECT 20-5

\section{CHAIR}

GARY D. TAYLOR, CTE Engineers

\section{MEMBERS}

THOMAS R. BOHUSLAV, Texas DOT DONN E. HANCHER, University of Kentucky

DWIGHT HORNE, Federal Highway Administration YSELA LLORT, Florida DOT

WESLEY S.C. LUM, California DOT

JAMES W. MARCH, Federal Highway Administration JOHN M. MASON, JR., Pennsylvania State University CATHERINE NELSON, Oregon DOT

LARRY VELASQUEZ, New Mexico DOT

PAUL T. WELLS, New York State DOT

\section{FHWA LIAISON}

WILLIAM ZACCAGNINO

\section{TRB LIAISON}

MARK R. NORMAN
COOPERATIVE RESEARCH PROGRAM STAFF

ROBERT J. REILLY, Director, Cooperative Research Programs CRAWFORD F. JENCKS, Manager, NCHRP

EILEEN DELANEY, Director of Publications

\section{NCHRP SYNTHESIS STAFF}

STEPHEN R. GODWIN, Director for Studies and Information Services JON WILLIAMS, Manager, Synthesis Studies

DONNA L. VLASAK, Senior Program Officer DON TIPPMAN, Editor

CHERYL KEITH, Senior Secretary

\section{TOPIC PANEL}

DARRELL K. DUDGEON, Kentucky Transportation Cabinet GILL GAUTREAU, Louisiana Department of Transportation and Development

AL GHORBANPOOR, University of Wisconsin-Milwaukee DAVID GOODYEAR, T.Y. Lin International FRANK N. LISLE, Transportation Research Board STEPHEN E. PUTZ, Illinois Department of Transportation KEITH L. RAMSEY, Texas Department of Transportation JOHN TUNG, Florida Department of Transportation HAROLD BOSCH, Federal Highway Administration (Liaison) BENJAMIN M. TANG, Federal Highway Administration (Liaison) 
FOREWORD By Staff

Transportation

Research Board
Highway administrators, engineers, and researchers often face problems for which information already exists, either in documented form or as undocumented experience and practice. This information may be fragmented, scattered, and unevaluated. As a consequence, full knowledge of what has been learned about a problem may not be brought to bear on its solution. Costly research findings may go unused, valuable experience may be overlooked, and due consideration may not be given to recommended practices for solving or alleviating the problem.

There is information on nearly every subject of concern to highway administrators and engineers. Much of it derives from research or from the work of practitioners faced with problems in their day-to-day work. To provide a systematic means for assembling and evaluating such useful information and to make it available to the entire highway community, the American Association of State Highway and Transportation Officials-through the mechanism of the National Cooperative Highway Research Program-authorized the Transportation Research Board to undertake a continuing study. This study, NCHRP Project 20-5, "Synthesis of Information Related to Highway Problems," searches out and synthesizes useful knowledge from all available sources and prepares concise, documented reports on specific topics. Reports from this endeavor constitute an NCHRP report series, Synthesis of Highway Practice.

This synthesis series reports on current knowledge and practice, in a compact format, without the detailed directions usually found in handbooks or design manuals. Each report in the series provides a compendium of the best knowledge available on those measures found to be the most successful in resolving specific problems.

This synthesis identifies and explains various inspection and maintenance techniques for bridge stay cable systems. It discusses both short- and long-term approaches. Topics covered included methods for inspections and assessments, including nondestructive testing and evaluation procedures; repair and retrofit; methods for control of cable vibrations, including rain-wind vibrations; stay cable fatigue and failure; effectiveness of various inspection and repair methods; limitations of available technologies; and trends and recommendations for future study.

This synthesis effort was based on a comprehensive review of domestic and international literature on the inspection, repair, testing, and design of stay cable. On-line sources of information as well as engineering databases were examined. A questionnaire was distributed to all state and provincial departments of transportation in the United States and Canada to determine current state of the practice. Also, contacts were made with a number of knowledgeable individuals for information. Additional information was gathered from the examination of test reports and condition assessments from inspections of cable-stayed bridges, a review of a limited number of maintenance and inspection manuals for cablestayed bridges, and a patent search using the U.S. Patent and Trademark Office database.

Habib Tabatabai, University of Wisconsin-Milwaukee, collected and synthesized the information and wrote the report. The members of the topic panel are acknowledged on the preceding page. This synthesis is an immediately useful document that records the practices that were acceptable within the limitations of the knowledge available at the time of its preparation. As progress in research and practice continues, new knowledge will be added to that now at hand. 


\section{CONTENTS}

1 SUMMARY

CHAPTER ONE INTRODUCTION

Background, 3

Objectives and Scope, 4

Questionnaire, 5

8

CHAPTER TWO STAY CABLE SYSTEMS AND MATERIALS

Stay Cable Systems, 8

Stay Cable Materials, 13

Stay Cable Design Challenges, 22

Fabrication and Erection of Stay Cables, 36

CHAPTER THREE INSPECTION AND MONITORING TECHNIQUES

Short-Term Evaluation and Monitoring, 37

Long-Term Evaluation and Monitoring, 46

CHAPTER FOUR MAINTENANCE AND REPAIR OF STAY CABLES

Repair and Retrofit Strategies and Methods, 50

Mitigation of Stay Cable Vibrations, 51

Challenges in Maintenance, Repair, and Retrofit, 58

FUTURE TRENDS

60

CHAPTER SIX

CONCLUSIONS AND FUTURE RESEARCH NEEDS

63

REFERENCES

68 APPENDIX A SURVEY QUESTIONNAIRE 


\section{INSPECTION AND MAINTENANCE OF BRIDGE STAY CABLE SYSTEMS}

In this synthesis effort, a worldwide search of information on inspection, repair, testing, and design of stay cable, was undertaken. On-line sources of information as well as engineering databases were examined. Contacts were made with a number of knowledgeable individuals for information. A questionnaire was prepared and distributed to all state and provincial departments of transportation in the United States and Canada. Completed questionnaires were received from $75 \%$ ( 27 of 36 ) of all known U.S. cable-stayed bridges and $81 \%$ (13 of 16) known cable-stayed bridges in Canada. Based on this information, various methods, approaches, and practices are explained in detail and their strengths and weaknesses identified. Specific approaches to inspection and repair are presented and discussed.

Challenges in the inspection and maintenance of cable-stayed bridges are significant. The main tension elements (MTEs) within a cable bundle are, in most cases, hidden from the view of inspectors. Access to cables for visual inspections or nondestructive testing is generally difficult and, in the case of the anchorage zones, nearly impossible. Those who are responsible for the inspection and maintenance of stay cables are faced with challenges for which proven and accepted methodologies and tools are limited and, in many cases, very costly.

There are 36 cable-stayed bridges in the United States and 16 such bridges in Canada. As of 2005, the average age of cable-stayed bridges in the United States was 11.4 years. As these bridges age, the need for effective inspection and maintenance methods and tools becomes more acute.

The following list cites some of the issues involved in the inspection, maintenance, and repair of stay cables, presents methods identified in the literature to address these issues, and briefly summarizes their known pros and cons and other factors. Detailed descriptions and discussions of these methods are given throughout this report.

General inspections (visual)—Visual inspections are, in the great majority of cases, the only method used for cable-stayed bridges.

Assessment of MTE condition in free length (magnetic flux leakage) - This system has a long history in the inspection of industrial cables and ropes.

Assessment of MTE condition (cable force measurements) - This approach is the most widely used, and sometimes misunderstood, nondestructive evaluation method.

Assessment of MTE condition (ultrasonic testing) — This method has been used on a few bridges to evaluate the condition of MTEs in Hi-Am-type anchorages.

Assessment of MTE condition (radiography) - Theoretically, this method has the potential to successfully assess conditions of cable anchorages where there is access to the perimeter.

Detection of wire breaks as they happen (acoustic monitoring)—Test laboratories performing qualification fatigue tests of stay cables have long used this method to detect wire breaks in the cable specimens as they happen.

Detection of grout voids inside high-density polyethylene (HDPE) pipe sheathing (impulse radar)-Hand-held impulse radar equipment can be placed over the cable and moved longitudinally to identify potential grout voids inside the cable sheathing. 
Repair of large grout voids (vacuum grouting) — This method has long been used in posttensioning tendon applications.

Cable force measurements (vibration-based using laser vibrometer)—A laser vibrometer is used to measure small vibrations of the cable from a large distance.

Cable force measurements (vibration-based using accelerometer) - Similar to the laserbased method described previously.

Cable force measurements (based on measurement of cable sag) —Although the tension in a cable is related to the square of the fundamental frequency, it is also inversely proportional to the cable sag; therefore, measurements of the cable sag can also be used to estimate cable tension.

Detection of hidden splits in HDPE (infrared thermography)—Hand-held infrared thermography equipment can be used to detect splits in HDPE pipes that are hidden under the protective tape.

Detection of damage to polyvinyl fluoride tape (infrared thermography)—Similar to the method discussed for the detection of hidden splits in HDPE.

Assessment of cable vibrations (long-term monitoring using accelerometers)—When cable vibration problems are suspected, sensors (accelerometers) can be mounted on select cables to monitor vibrations over a period of several weeks, months, or years.

Assessment of cable vibrations (video cameras on bridge) - There are no known instances of using video cameras to monitor vibrations on cable-stayed bridges. This option was discussed for two bridges in the path of hurricanes, but was not implemented.

Assessment of cable damping (vibration decay method) - There are different approaches to measuring cable damping. In one, an accelerometer is first attached on the cable.

There is no single method that would provide answers for all the questions regarding the condition of stay cables. In most cases, it is the combination of nondestructive testing techniques together with the experience, knowledge, and judgment of engineers, inspectors, and technicians that could lead to the appropriate answer. The effectiveness and accuracy of many of the methods might be significantly enhanced if baseline comparative measurements are available when the bridge is known to be defect free. 


\section{INTRODUCTION}

\section{BACKGROUND}

With the popularity and rapid growth in the use of cable-stayed bridges in the United States and worldwide, issues related to inspection and maintenance of stay cables are taking on added significance. Examples of problems that could affect stay cable performance include excessive vibrations, corrosion, fatigue, and the general inability to reliably ascertain the internal condition of the cables, especially in the critical anchorage zones. Many of the assessment and repair methods are still in early development and information on reliable, proven techniques is not readily available. Bridge owners and engineers are faced with selecting and using a number of new technologies or approaches for cable assessments without the benefit of knowing their degree of effectiveness. Although some valuable data are available, they are generally not readily accessible. Therefore, this synthesis project aims to collect and synthesize such information into a single document.

Cable-stayed and suspension bridges are the two prominent types of cable-supported bridges. In both systems, cables are supported on pylons. In cable-stayed bridges, the cables are inclined and directly support the deck on the pylon(s). In suspension bridges, vertical suspender cables transfer loads from the deck to the main catenary-shaped cables. The main cables in suspension bridges are typically anchored at massive anchorages at the two ends of the bridge, whereas stay cables are anchored to the deck itself.

In their basic form and concept, cable-stayed bridges have existed for centuries. In 1823, French engineer C.L. Navier presented some of his concepts for bridges supported by wrought iron chains, as shown in Figure 1 (Gimsing 1999). Although these sketches strikingly resemble the modern cable-stayed bridges, Navier envisioned ground-anchored backstays only.

The next phase involved design of combined suspension and stayed systems. A prominent example is the Brooklyn Bridge, designed in the 19th century by John A. Roebling. The first modern cable-stayed bridge was the Strömsund Bridge built in 1955 in Sweden, which was designed by Franz Dischinger. It had a main span of 182.6 m (599 ft) (Gimsing 1999).

The first major cable-stayed bridge made of concrete pylons and girders was the Maracaibo Bridge in Venezuela, built in 1962. As will be discussed later in this report, the cables of this bridge were subsequently replaced as a result of corrosion.

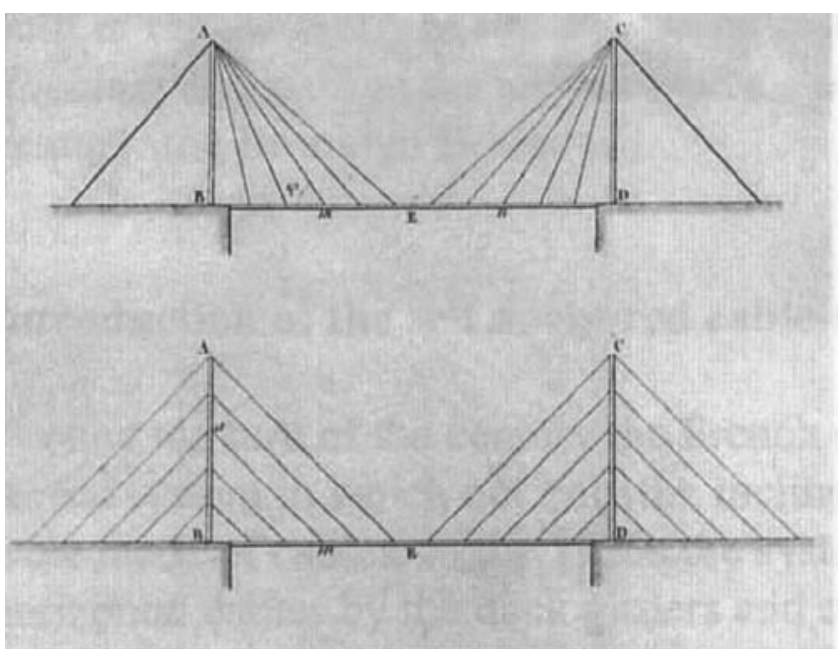

FIGURE 1 Bridge systems envisioned by Navier (Gimsing 1999).

The early bridges all had only a few stay cables, which provided support at locations where piers would have otherwise existed (Walther et al. 1999). This concept of using cables with large spacing did not fully realize the structural (and economic) potential of cable-stayed bridges. In 1967, H. Homberg used closely spaced stays (or the multi-stay system) on the Friedrich Ebert Bridge in Germany (Walther et al. 1999). The Brotonne Bridge in France used closely spaced stays, and the cable system was based on post-tensioning technology in which parallel seven-wire strands were encased in steel pipes and grouted (Gimsing 1999). The Zarate-Brazo Largo Bridges in Argentina were the first cable-stayed bridges designed to carry railroad and automobile traffic. As will be discussed later, one of the Argentine bridges had a complete failure of one of the stays after fewer than 20 years of service.

The oldest cable-stayed bridge in the United States is the Sitka Harbor Bridge in Alaska, built in 1970 (see Figure 2). The oldest cable-stayed bridge in North America is believed to be the North Romaine River railroad bridge in Québec, Canada, which was built in 1960. The oldest highway cablestayed bridges in Canada are the Longs Creek \#1 and Hawkshaw bridges in New Brunswick, built in 1966 and 1967, respectively. Other early and prominent cable-stayed bridges in North America include the Papineau Bridge in Montreal (1969) and the Pasco-Kennewick Bridge in Washington State (1978). 


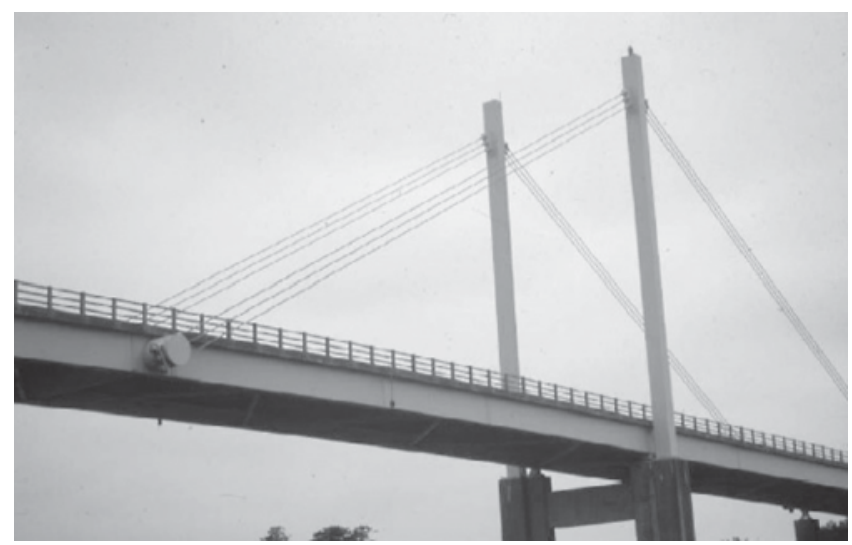

FIGURE 2 Sitka Harbor Bridge in Alaska, the oldest cablestayed bridge in the United States (Frank and Breen 2004).

The pace of construction of new cable-stayed bridges in the United States grew rapidly in the 1990s and early 2000s. Today, cable-stayed bridges have entirely replaced truss bridges on new medium- to long-span crossings. For example, all new crossings of the Mississippi River in the last 15 to 20 years have been with cable-stayed bridges, whereas these spans were exclusively truss bridges before that time. The essential factor is the cost-effectiveness of the system, aided by its elegance.

The total number of cable-stayed bridges in the United States recently surpassed 35, with several other bridges in planning or under construction. These include bridges in the planning stages in New York City, St. Louis, and one spanning the Mississippi River between Mississippi and Arkansas. The St. Louis bridge, if implemented, would have a main span of $610 \mathrm{~m}(2,000 \mathrm{ft})$, and will be the longest cable-stayed span in the Western Hemisphere (Brown 2001b). The world record for cable size will belong to the Maumee River Bridge in Toledo, Ohio, scheduled for completion in late 2006 (DSI 2004). This bridge incorporates stays with 156 seven-wire strands $15.2 \mathrm{~mm}$ (0.6 in.) in diameter and cable diameters of up to $508 \mathrm{~mm}$ (20 in.) (Marsh 2003). The longest span cable-stayed bridge in the world is the Tatara Bridge in Ehime, Japan, with a main span of $890 \mathrm{~m}$ (2,920 ft). However, the Stonecutters Bridge in Hong Kong will surpass Tatara with a span of $1018 \mathrm{~m}$ $(3,339 \mathrm{ft})$ when it is completed in 2008 (Brown 2001a).

The Millau Bridge in France (Viaduc de Millau) is the world's tallest bridge and spans France's Tarn River Valley. It consists of multiple cable-stayed spans with span lengths of approximately $340 \mathrm{~m}$ and a total length of approximately $2.5 \mathrm{~km}$. The deck is approximately $270 \mathrm{~m}$ above the valley and the pylons reach $343 \mathrm{~m}$ above the ground.

The challenges in inspection and maintenance of cablestayed bridges are enormous. The main tension elements (MTEs) within a cable bundle are, in most cases, hidden from the view of inspectors. Access to cables for visual inspections or nondestructive testing (NDT) is generally difficult, and in the case of the anchorage zones, nearly impossible. Those who are tasked with the inspection and maintenance of stay cables face challenges for which proven and accepted methodologies and tools are limited and often very costly. For example, the internal deterioration and failure of an Argentine stay cable in 1996 was not detected beforehand by visual means.

This synthesis report will present the latest information available on inspection and maintenance of stay cables, explains various tools and methods available, and examines their track record or future potential in addressing stay cable evaluations. To better understand the applicability and complexities of various methods and approaches, a brief overview of different stay cable designs and materials is also presented.

\section{OBJECTIVES AND SCOPE}

The objective of this synthesis is to identify and explain effective and promising inspection and maintenance techniques for stay cables in cable-stayed bridges. Both short- and longterm approaches are discussed. This synthesis is based on the following:

- A comprehensive review of domestic and international literature to identify various techniques and their track records, as well as documented problems and case studies;

- Formal and informal surveys of state and provincial departments of transportation (DOTs) in the United States and Canada, cable suppliers, testing companies, bridge designers, researchers, and contractors to determine the current state of practice and identify future trends in condition assessments and repair and retrofit of stay cables. These surveys were conducted by means of a questionnaire and through meetings, telephone conversations, and e-mail exchanges with knowledgeable individuals;

- Examination of test reports and condition assessment results from major inspections and cable-stayed bridges;

- Review of a limited number of maintenance and inspection manuals for cable-stayed bridges; and

- A patent search using the U.S. Patent and Trademark Office database.

This synthesis includes the following types of information:

- Methods for inspections and assessments including NDT methods,

- Repair methods,

- Methods for control of cable vibrations including rainwind vibrations,

- Control of moisture from internal or external sources,

- Fatigue in stay cables,

- Case studies of stay cable failures,

- Repair and retrofit issues and details,

- Effectiveness and costs of various inspection and repair methods,

- Limitations of available technologies, 
- Future trends and promising technologies, and

- Recommendations for future research.

\section{QUESTIONNAIRE}

A questionnaire (see Appendix A) was prepared and distributed to all state and provincial DOTs in the United States and Canada. The same questionnaire was also sent to all members of the Post-Tensioning Institute's (PTI) Cable-Stayed Bridge Committee, as well as major U.S. and Mexican stay cable suppliers and testing companies. Table 1 cites those states and provinces that responded and the number of bridges reported by each agency. A completed questionnaire was also received from one stay cable supplier. Table 2 is a list of all known cablestayed bridges in the United States and Canada. The information contained in the completed surveys, published literature, a paper by Podolny (1992), and a report by Kumarasena et al. (2004) were used to assemble this list.

In the United States, 43 state DOTs (86\%) responded to the survey, 24 of which did not have any cable-stayed bridges under their jurisdiction. One city (Milwaukee, Wisconsin) is maintaining two recently completed cable-stayed bridges. A completed questionnaire for one of the two new cable-stayed bridges in Ohio (Maumee River Bridge) was provided by the designer of the bridge.

A completed survey for one of the two cable-stayed bridges in Florida, the Dame Point Bridge in Jacksonville, was received. In addition, the Indiana DOT provided responses on two bridges, one a cable-stayed bridge and the other an arch bridge that incorporated stay cables. Table 1 lists only one cable-stayed bridge in Indiana, but the analyses of questionnaire results include both Indiana bridges.

In the United States, completed questionnaires were received for $75 \%$ of all known cable-stayed bridges (i.e., 27 of 36 cable-stayed bridges, with one additional arch bridge). It should be noted that four of the bridges listed in the U.S. inventory are pedestrian bridges. Therefore, the responses covered $84 \%$ of all highway bridges in the United States. No responses on U.S. pedestrian bridges were received. Questionnaires were not received for several other major cablestayed bridges in the United States including the Sunshine Skyway Bridge in Florida, two bridges in West Virginia (East Huntington and Weirton-Steubenville), and the recently completed La Plata River Bridge in Puerto Rico.

In Canada, responses were obtained from 5 of the 13 provinces, representing 13 of the 16 known cable-stayed bridges in Canada $(81 \%)$. The five cable-stayed bridges in Alberta/ Calgary are all pedestrian bridges. Responses were not received for the ALRT Fraser River Bridge in British Columbia, and Bridge of the Isles and North Romaine railroad bridge in Quebec. In some states and Canadian provinces, different agencies controlled maintenance of different cable-stayed bridges, thus making the task of identifying the proper agencies difficult.
TABLE 1

SUMMARY OF RESPONSES RECEIVED FROM STATES/ PROVINCES IN THE UNITED STATES AND CANADA

\begin{tabular}{|c|c|c|c|c|c|}
\hline States/Provinces & 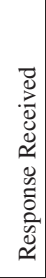 & 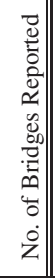 & States/Provinces & 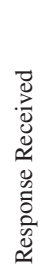 & 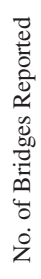 \\
\hline \multicolumn{6}{|c|}{ United States } \\
\hline Alabama & $\mathrm{Y}$ & 1 & Missouri & $\mathrm{Y}$ & 1 \\
\hline Alaska & $\mathrm{Y}$ & 2 & Mississippi $^{\mathrm{a}}$ & - & 0 \\
\hline Arizona & $\mathrm{Y}$ & 0 & Montana & $\mathrm{Y}$ & 0 \\
\hline Arkansas $^{\mathrm{a}}$ & - & 1 & North Carolina & $\mathrm{Y}$ & 0 \\
\hline California & $\mathrm{Y}$ & $1^{\mathrm{f}}$ & North Dakota & $\mathrm{Y}$ & 0 \\
\hline Colorado & $\mathrm{Y}$ & $0^{\mathrm{e}}$ & New Hampshire & $\mathrm{Y}$ & 0 \\
\hline Connecticut & $\mathrm{Y}$ & 0 & New Jersey & $\mathrm{Y}$ & 0 \\
\hline Delaware & $\mathrm{Y}$ & 1 & New Mexico & $\mathrm{Y}$ & 0 \\
\hline Florida $^{\mathrm{b}}$ & - & 1 & Nevada & $\mathrm{Y}$ & 0 \\
\hline Georgia & $\mathrm{Y}$ & 2 & New York & $\mathrm{Y}$ & 0 \\
\hline Hawaii & $\mathrm{Y}$ & 0 & Ohio $^{c}$ & - & 2 \\
\hline Idaho & $\mathrm{Y}$ & 0 & Pennsylvania & $\mathrm{Y}$ & 0 \\
\hline Illinois & $\mathrm{Y}$ & 2 & Rhode Island & $\mathrm{Y}$ & 0 \\
\hline Indiana & $\mathrm{Y}$ & 2 & South Carolina & $\mathrm{Y}$ & 1 \\
\hline Iowa & $\mathrm{Y}$ & 1 & Tennessee & $\mathrm{Y}$ & 0 \\
\hline Kansas & $\mathrm{Y}$ & 0 & Texas & $\mathrm{Y}$ & 2 \\
\hline Kentucky & $\mathrm{Y}$ & 2 & Utah & $\mathrm{Y}$ & 0 \\
\hline Louisiana & $\mathrm{Y}$ & 1 & Virginia & $\mathrm{Y}$ & 1 \\
\hline Massachusetts & $\mathrm{Y}$ & 1 & Washington & $\mathrm{Y}$ & 2 \\
\hline Maryland & $\mathrm{Y}$ & 0 & Wisconsin & $\mathrm{Y}$ & 2 \\
\hline Michigan & $\mathrm{Y}$ & 0 & Wyoming & $\mathrm{Y}$ & 0 \\
\hline Minnesota & $\mathrm{Y}$ & 0 & & & \\
\hline \multicolumn{6}{|c|}{ Canada } \\
\hline Alberta/Calgary $^{\mathrm{d}}$ & - & 5 & New Brunswick & $\mathrm{Y}$ & 3 \\
\hline British Columbia & $\mathrm{Y}$ & 1 & Ontario & $\mathrm{Y}$ & 0 \\
\hline Manitoba/ Winnipeg & $\mathrm{Y}$ & 1 & Québec & $\mathrm{Y}$ & 3 \\
\hline
\end{tabular}

${ }^{\mathrm{a}}$ Mississippi and Arkansas share a bridge that is under construction and will be maintained by Arkansas.

${ }^{b}$ The survey for one of the two Florida cable-stayed bridges was received.

${ }^{\mathrm{c}}$ The Ohio DOT reported two cable-stayed bridges under construction and the questionnaire for one bridge was received.

d All cable-stayed bridges reported for Calgary in Alberta, Canada, are pedestrian bridges.

${ }^{\mathrm{e}}$ There are two pedestrian cable-stayed bridges in downtown Denver, Colorado.

Information was not available on these bridges at the time of the writing of this report.

${ }^{\mathrm{f}}$ There is a pedestrian cable-stayed bridge in Redding, California. Information for this

bridge became available only after the completion of this report

Using the data in Table 2, Figures 3 and 4 show the number of cable-stayed bridges built (i.e., opened to traffic) in the United States and Canada from 1955 to 2005 in 10-year increments. In the United States, there has been a substantial increase in the number and the rate of construction of cablestayed bridges. From 1996 to 2005, 17 cable-stayed bridges were built in the United States, representing $47 \%$ of all such bridges built since 1970. The average age of cable-stayed bridges in the U.S. inventory (as of 2005) was 11.4 years, whereas the average age in Canada was 27 years.

The early Canadian bridge, the 217-m Hawkshaw Bridge built in 1967, had galvanized bridge strands with the stay cable wrapped with galvanized wire $5 \mathrm{ft}$ above the deck and then coated with protective paste. This approach is somewhat 
TABLE 2

CABLE-STAYED BRIDGES IN THE UNITED STATES AND CANADA

\begin{tabular}{|c|c|c|c|c|}
\hline No. & Bridge Name & State & Span, $\mathrm{m}(\mathrm{ft})$ & Year \\
\hline \multicolumn{5}{|c|}{ United States } \\
\hline 1 & Cooper River Bridge & South Carolina & $472(1,546)$ & 2005 \\
\hline 2 & Greenville Bridge, US 82 over Mississippi & Mississippi & $420(1,378)$ & 2005 \\
\hline 3 & Dame Point Bridge & Florida & $397(1,300)$ & 1989 \\
\hline 4 & Fred Hartman/Houston Ship Channel & Texas & $381(1,250)$ & 1995 \\
\hline 5 & Sidney Lanier Bridge, Brunswick & Georgia & $381(1,250)$ & 2003 \\
\hline 6 & Hale Boggs/Luling Bridge & Louisiana & $373(1,222)$ & 1984 \\
\hline 7 & Sunshine Skyway Bridge & Florida & $366(1,200)$ & 1987 \\
\hline 8 & William Natcher/Owensboro Bridge & Kentucky & $366(1,200)$ & 2002 \\
\hline 9 & Bill Emerson/Cape Girardeau Bridge & Missouri & $351(1,150)$ & 2003 \\
\hline 10 & Talmadge Memorial Bridge, Savannah & Georgia & $336(1,100)$ & 1991 \\
\hline 11 & William Harsha Bridge, Maysville & Kentucky & $320(1,050)$ & 2000 \\
\hline 12 & Pasco-Kennewick Bridge, Gum Street & Washington & $299(981)$ & 1978 \\
\hline 13 & East Huntington Bridge & West Virginia & $275(900)$ & 1985 \\
\hline 14 & Quincy/Bayview Bridge & Illinois & $275(900)$ & 1986 \\
\hline 15 & US Grant, Portsmouth & Ohio & $267(875)$ & 2004 \\
\hline 16 & Weirton-Steubenville & West Virginia & $250(820)$ & 1990 \\
\hline 17 & Cochrane Africatown Bridge & Alabama & $238(780)$ & 1991 \\
\hline 18 & Clark Bridge, Alton & Illinois & $230(756)$ & 1994 \\
\hline 19 & C\&D Canal Bridge & Delaware & $229(750)$ & 1995 \\
\hline 20 & L.P. Zakim Bunker Hill, Charles River & Massachusetts & $227(745)$ & 2002 \\
\hline 21 & Burlington Bridge, Burlington & Iowa & $201(660)$ & 1995 \\
\hline 22 & Veterans Memorial/Neches River Bridge & Texas & $195(640)$ & 1991 \\
\hline 23 & Varina-Enon Bridge/James River & Virginia & $192(630)$ & 1990 \\
\hline 24 & Maumee River Crossing & Ohio & $187(613)$ & 2005 \\
\hline 25 & PR 148 over LaPlata River & Puerto Rico & $160(525)$ & 2005 \\
\hline 26 & SR 46/East Fork White River & Indiana & $142(466)$ & 1999 \\
\hline 27 & Sitka Harbor/John O'Connel Bridge & Alaska & $137(450)$ & 1970 \\
\hline 28 & Tea Foss Waterway Bridge, Tacoma & Washington & $114(375)$ & 1996 \\
\hline 29 & Captain William Moore/Skagway & Alaska & $83(271)$ & 1975 \\
\hline 30 & Milwaukee Art Museum/Calatrava Bridge $^{\mathrm{a}}$ & Wisconsin & $70(231)$ & 2003 \\
\hline 31 & Menomonee Falls ${ }^{\mathrm{a}}$ & Wisconsin & $66(217)$ & 1971 \\
\hline 32 & Sixth Street Viaduct-North & Wisconsin & $59(195)$ & 2003 \\
\hline 33 & Sixth Street Viaduct_-South & Wisconsin & $59(195)$ & 2003 \\
\hline 34 & Sacramento River (Meridian) ${ }^{b}$ & California & $55(180)$ & 1977 \\
\hline 35 & Rockefeller University Campus $^{\mathrm{a}}$ & New York & $38(123)$ & 1999 \\
\hline 36 & Old Plank Road Trail Bridge ${ }^{a}$ & Illinois & $35(114)$ & 1999 \\
\hline \multicolumn{5}{|c|}{ Canada } \\
\hline 1 & Alex Fraser (Annacis) Bridge & British Columbia & $465(1,526)$ & 1986 \\
\hline 2 & ALRT Fraser River Bridge & British Columbia & $340(1,115)$ & 1988 \\
\hline 3 & Papineau-Leblanc & Quebec & $241(790)$ & 1969 \\
\hline 4 & Hawkshaw & New Brunswick & $218(713)$ & 1967 \\
\hline 5 & Longs Creek \#1 & New Brunswick & $218(713)$ & 1966 \\
\hline 6 & Price & Quebec & $137(450)$ & 1972 \\
\hline 7 & Esplanade Riel, Manitoba & Winnipeg & $106(348)$ & 2003 \\
\hline 8 & Bridge of the Isles & Quebec & $105(344)$ & 1967 \\
\hline 9 & Stoney Trail $^{\mathrm{a}}$ & Alberta/Calgary & $102(335)$ & 1998 \\
\hline 10 & Galipeault & Quebec & $94(308)$ & 1963 \\
\hline 11 & Carburn Park $^{\mathrm{a}}$ & Alberta/Calgary & $80(262)$ & 1982 \\
\hline 12 & Prince's Island $^{\mathrm{a}}$ & Alberta/Calgary & $67(220)$ & 1972 \\
\hline 13 & Nackawic River & New Brunswick & $66(216)$ & 1967 \\
\hline 14 & North Romaine River & Quebec & $61(200)$ & 1960 \\
\hline 15 & McMahon*** & Alberta/Calgary & $47(154)$ & 1987 \\
\hline 16 & Fox Hollow*** & Alberta/Calgary & $45(148)$ & 1996 \\
\hline
\end{tabular}

Notes: Bridges are cited in order of span length, from longest to shortest. After the completion of this report, three additional, recently built pedestrian cable-stayed bridges were identified in the United States; two in downtown Denver, Colorado, and one in Redding, California. These three bridges are not included in the analysis.

${ }^{\mathrm{a}}$ Pedestrian.

${ }^{\mathrm{b}}$ Swing movable bridge.

${ }^{\mathrm{c}}$ Railroad bridge. 


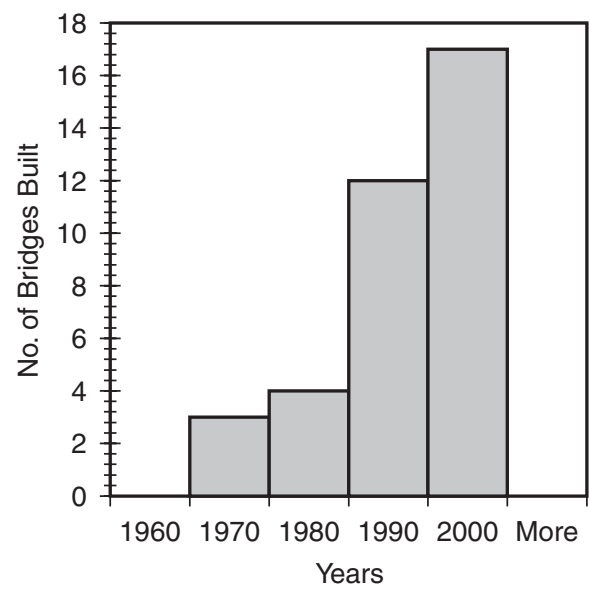

FIGURE 3 Number of cable-stayed bridges built in the United States.

similar to the suspension bridge main cables. The Papineau Bridge in Montreal (1969) incorporated galvanized bridge strands covered with polyethylene (PE) sheathing. The Sitka Harbor Bridge in Alaska (1970) also used galvanized bridge strands as cables, but without the PE sheathing. The PascoKennewick (or Gum Street-Kennewick) Bridge in Washington State (1978) was the first cable-stayed bridge in the United States to use parallel nongalvanized (bare) wires encased in high-density polyethylene (HDPE) pipe wrapped with polyvinyl chloride (PVC) tape and grouted with cement grout. This was a fundamental shift from the earlier designs based on the industrial and suspension cable technologies involving galvanized wires and strands toward grouted cables based on the post-tensioning technology. As will be discussed later, this grouted cable approach was first implemented in Europe, most notably on the Brotonne Bridge in France, before its implementation on the Pasco-Kennewick Bridge. This approach of using HDPE pipes filled with cement grout began the "grout era" in the United States, which dominated the U.S. stay cable designs for nearly two decades until the late 1990s. The Canadians, the Germans, and the Japanese among others have primarily

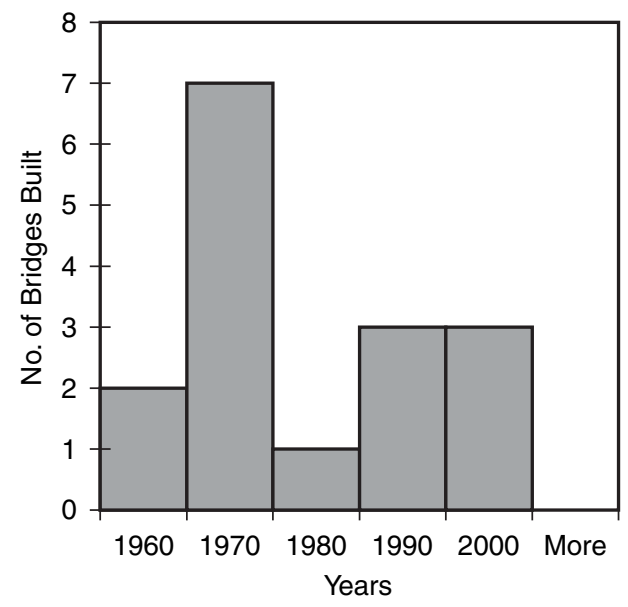

FIGURE 4 Number of cable-stayed bridges built in Canada. avoided the grouted cable approach. The Pasco-Kennewick Bridge was also the first of its kind in the United States to use a larger number of cables (i.e., reduce cable spacing).

In Canada, the 465-m Alex Fraser Bridge (1986) included long-lay galvanized bridge strands that were jacketed with PE filled with petroleum wax blocking compound. The first and only cable-stayed bridge in the United States that uses steel bars (or threadbars) is the Dame Point Bridge in Jacksonville, Florida (1989). In that bridge, the nongalvanized bars are encased in steel pipe and grouted. There are four pedestrian bridges in Calgary, Canada, that use bar stay cables, all galvanized without HDPE or grouting. The bars are anchored through threaded couplers. The first stay cables with epoxy-coated seven-wire strands were installed on the Quincy/Bayview Bridge in Quincy, Illinois (1986).

In the last 20 years, the design of stay cables including the corrosion/fatigue protection systems have significantly and continuously evolved and been modified. In the 1990s, systems offered by all of the major stay cable suppliers were rarely (if ever) left unchanged between consecutive projects despite economic incentives to limit such changes. This was primarily because the designers, cable suppliers, and owners learned from their experiences and the performances of the earlier stay cable systems during qualification testing and construction.

Since 2000, a tentative convergence of approaches emerged among some of the stay cable systems offered by various suppliers in the United States. All major U.S. stay cable suppliers began offering at least one system involving parallel seven-wire strands that were individually greased-andsheathed (or waxed-and-sheathed), encased in an ungrouted HDPE pipe, and anchored with wedges. Individual stressing of strands, as opposed to simultaneous stressing of all strands with large hydraulic jacks, was commonly used. Some of the more recent systems reportedly allow periodic removal of individual strands for inspection and sometimes provide room for future additions of strands into the cables.

Following this introductory chapter, chapter two provides an overview of various stay cable systems, touching on design, materials, fabrication, and erection. Chapter three describes short- and long-term inspection and monitoring techniques. Chapter four discusses the maintenance and repair of stay cables, chapter five briefly discusses future trends, and chapter six summarizes the findings and provides suggestions for future research.

The survey questionnaire is included as Appendix A. Appendix B provides detailed statistical tabular summaries of the answers to each of the multiple-choice questions as provided by the respondents for all bridges. The answers are categorized as U.S. responses, Canadian responses, and all responses. Appendix $\mathrm{C}$ is a web-only section of the report that provides detailed question-by-question results of each bridge surveyed and comparative tables of the the different responses to each question. This appendix can be found at: http://trb.org/publications/nchrp/nchrp_syn_353.pdf. 
CHAPTER TWO

\section{STAY CABLE SYSTEMS AND MATERIALS}

\section{STAY CABLE SYSTEMS}

An overview of various stay cable systems is presented in this section to familiarize readers with the terminology and technical aspects of various cable designs, and the issues related to inspection and maintenance of stay cables in cablestayed bridges. In very general terms, a stay cable can be described as a tension element composed of a single or multiple longitudinal MTEs, which is connected at one end to the bridge pylon and anchored at the other end at the bridge deck.

Over the years, there have been two fundamentally different and competing philosophies regarding design of stay cables. In the first approach, which dominated early German, British, and Japanese designs, the stay cables were designed based on the well-developed suspension bridge technologies; that is, those of the main suspension cables and the hanger cables, and wire rope technology from industrial applications. In the second approach, which more or less began with the Brotonne Bridge in France and dominated the U.S. stay cable designs until late 1990s, the cables were designed based on the post-tensioning tendon technologies. There were also variations in each of the two main philosophies. The concepts underlying these philosophies and their significant evolution over the last 30 to 40 years will be discussed later in this chapter. The motivations for these system evolutions were based on the field performance of the systems, technology developments and, above all, economic factors.

\section{Main Tension-Resisting Elements}

There are several different arrangements of the MTE components in the free length of the cable. The free length refers to areas of the cable that are not in the vicinity of the anchorages. The MTE could be a single bar, multiple parallel bars, multiwire helical strands (wire ropes or bridge strands), a bundle of parallel wires, or a bundle of parallel seven-wire strands. Figure 5 shows some of the MTE systems.

The locked coil cable was very common in early European and Japanese cable-stayed bridges. There is a central core of parallel round wires surrounded by spirally wrapped layers of interlocking z-shaped (and in some cases trapezoidal) wires. This arrangement makes a denser more compact cable (with reduced voids), with a smooth outer surface and less sensitivity to side pressures (Walton 1996; Ito 1999). Helical wire ropes have been popular in the United Kingdom. The spiral wires reduce the modulus of elasticity and strength of cable compared with equivalent parallel wire cables, but are much easier to handle (Ito 1999). The locked coil cable and spiral strands are examples of applications of suspension cable technology to stay cables.

The single or multiple bar system typically consists of one or more thread bars with a diameter of 26 to $36 \mathrm{~mm}$ (1-1.375 in.). The Dame Point Bridge in Florida and four pedestrian bridges in Calgary include bar cables. Worldwide it is believed that three other cable-stayed bridges with bars have been built; one each in Malaysia, Germany, and Chile. The parallel wire cables are typically made of 5 to $7 \mathrm{~mm}$ (0.19-0.27 in.) wires. Unlike the main suspension cables, the parallel wire stay cables do not include closely wrapped external spiral wires to maintain the shape of cable. The Pasco-Kennewick Bridge in Washington State and the Hale Boggs/Luling Bridge in Louisiana are examples of parallel wire cables in the United States.

The parallel seven-wire strand system is the most common MTE used in the United States. The survey results indicated that $75 \%$ of U.S. bridges included parallel seven-wire strands (see Figure 6). In contrast, only one bridge in the Canadian survey had seven-wire strands. The only Canadian bridge with parallel strands is also the newest one (opened to traffic in 2003), pointing to a possible move toward parallel strands. The majority of the Canadian bridges surveyed $(54 \%)$ have steel wires. There are however four bridges with parallel bars in Canada. The guaranteed ultimate tensile strength of seven-wire strands is $1860 \mathrm{MPa}(270 \mathrm{ksi})$.

The wire and strand stays are continuous from anchorage to anchorage because they are produced in long lengths and transported on reels, but bar systems require splicing with couplers, because the maximum length of individual bars is on the order of $18 \mathrm{~m}$ (60 ft). Figure 7 shows a bar cable with couplers.

The factors that typically drive the decision on the choice of MTEs have generally included the geographic preferences of the designers, suppliers, and owners (based on adopted design philosophies and available materials), perceived notions of long-term durability (i.e., potential for corrosion and fatigue), and cost. More recently however, issues related to inspectability, feasibility for nondestructive evaluation (NDE), and possibilities for MTE replacements and additions have also entered 


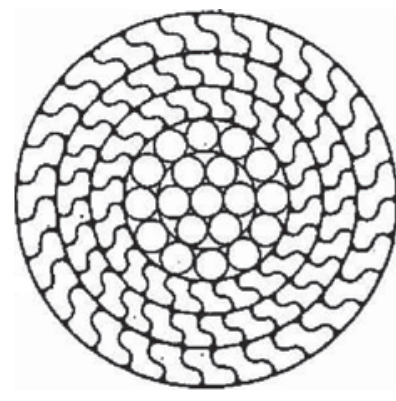

(a)

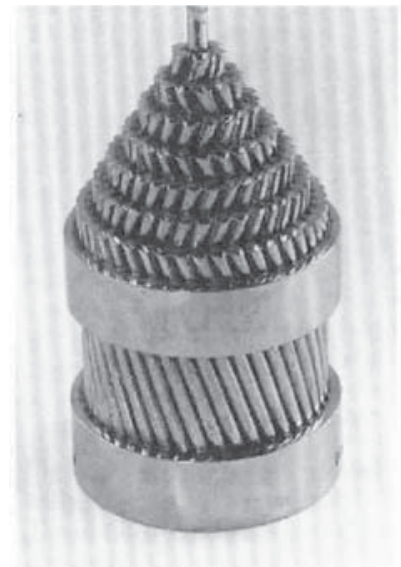

(b)
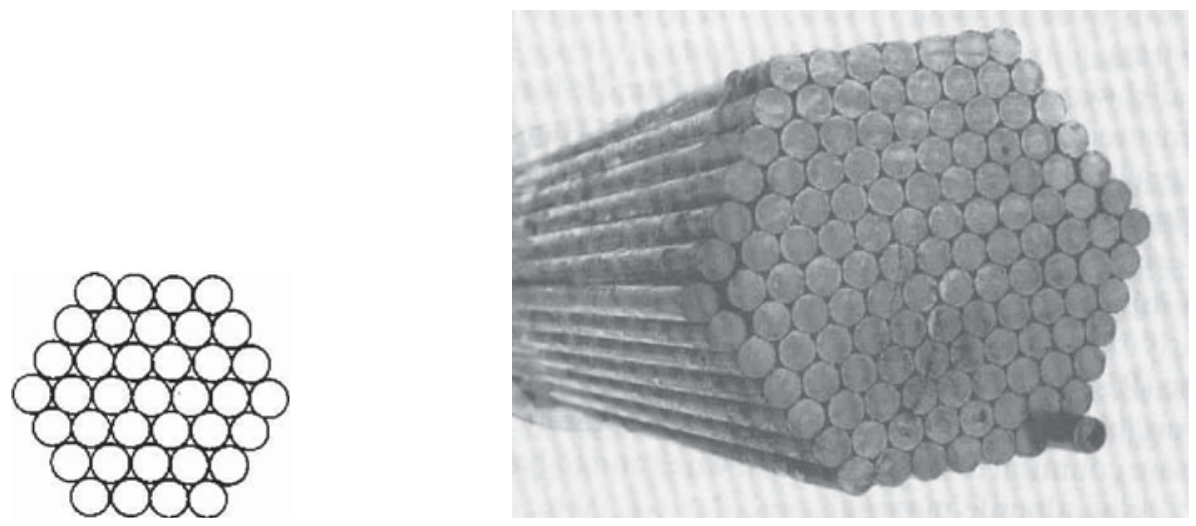

(c)

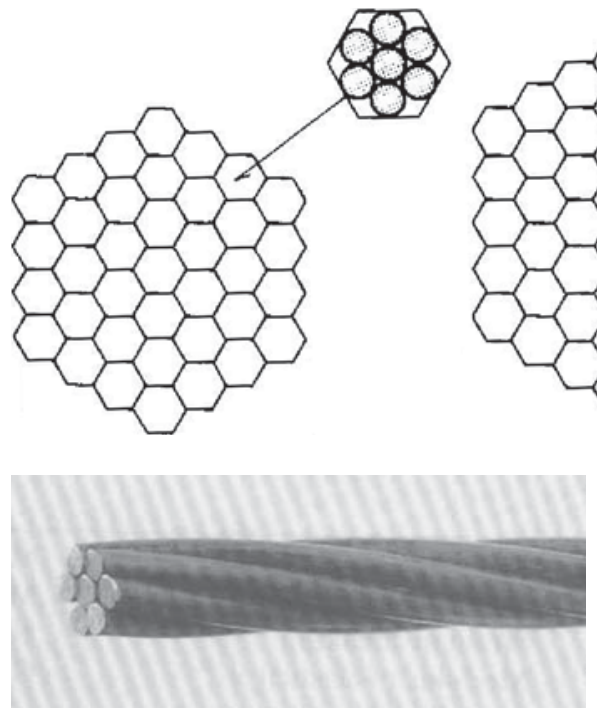

(d)

FIGURE 5 Various MTE cross sections: (a) locked coil, $(b)$ helical strand, $(c)$ parallel wire, (d) parallel seven-wire strands (Gimsing 1998). 


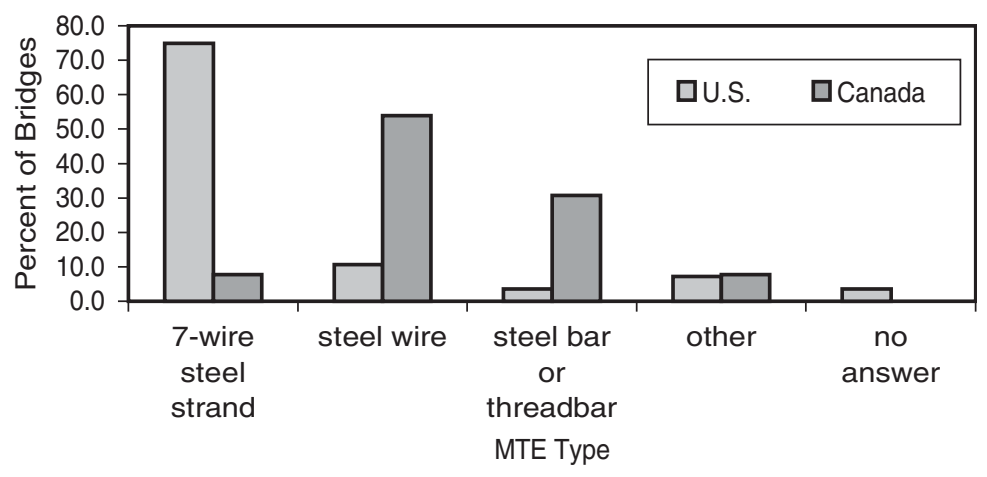

FIGURE 6 Types and frequency of main tension elements used.

the decision process. The arguments that are generally made for, or against, one MTE system or another involve some of the factors listed here:

- Cost,

- Implications of corrosion exposure including surfaceto-volume ratio,

- Fatigue performance including implications of crack propagation,

- Redundancy,

- Interwire fretting,

- Notching at anchorages,

- Stiffness,

- Tightness of MTE bundle (void areas),

- Implications of vibrations,

- Ability to adjust MTE force, and

- Ability to remove and augment MTE.

\section{Anchorage Systems}

There is a great variety of anchorage systems used for stay cables, depending on the choice of the MTE and the cable

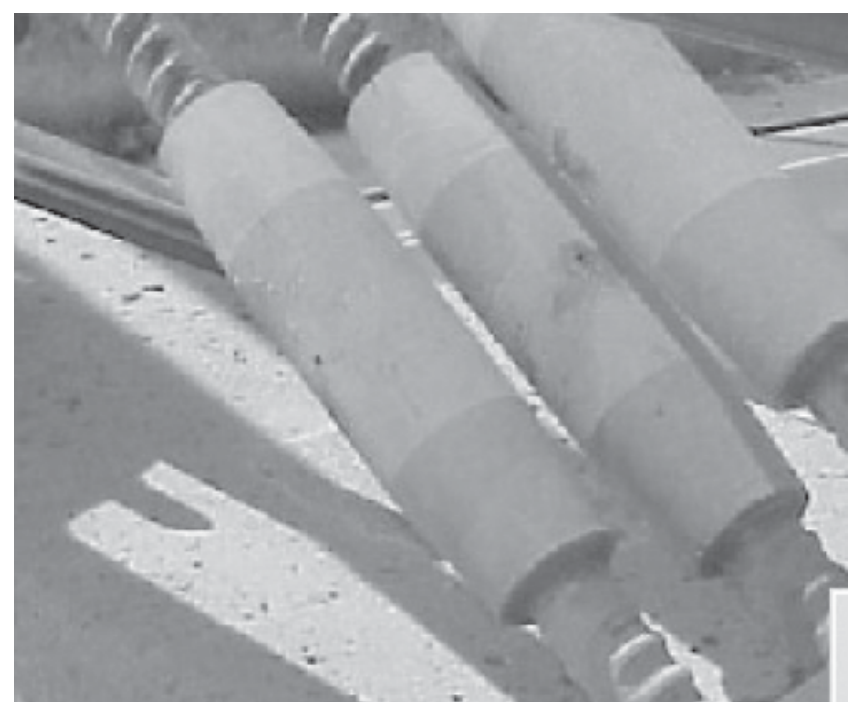

FIGURE 7 Typical bar couplers in stay cables. manufacturer. In bar systems, threaded nuts (matching the large threads on the bars) and anchor plates are used for anchorage. In this section, a brief discussion of generic categories of cable anchorages for parallel wires and strand cables is presented. For the sake of brevity, only anchorage systems common to the United States are discussed. However, such systems are commonly used worldwide. In the cable free length, the parallel wires or strands are bundled together, thus making contact with each other. As the cable approaches an anchorage, the wires or strands must separate from each other to achieve proper anchorage. The distance from the point that the strands (or wires) splay out to the anchorage point is generally referred to as the anchorage length.

There are three fundamental approaches to cable anchorage design. The first is to individually anchor each splayed wire or strand at a single point on an anchorage plate. That anchorage point would exclusively carry all dead and live loads imposed. The second is to transfer all loads through a conical steel socket. The force in the MTE transfers by bond through a filler material inside the conical socket. The third is a combination of the first two approaches; that is, transfer dead loads through the anchorage point and carry live loads through the socket action.

\section{Point Anchorages}

Figure 8 shows the point anchorage concept. Typically, a twoor three-piece conical wedge with a toothed center hole grabs on the outside of the seven-wire strand and anchors it. This is essentially a modified version of the wedge system used in post-tensioning applications. Examples of this type of anchorage include the Charles River Bridge in Boston and the C\&D Canal Bridge in St. Georges, Delaware. When individual wires are used, they are generally terminated at a "button head" that is formed at the ends.

In the multistrand system with point anchorages, the cable can be assembled in the field by stressing all strands at the same time, or it can be stressed one strand at a time (using a system to ensure equal distribution of stress). The gripping wedges create notches on the strands, which could become fatigue initiation points. However, stay cable systems 


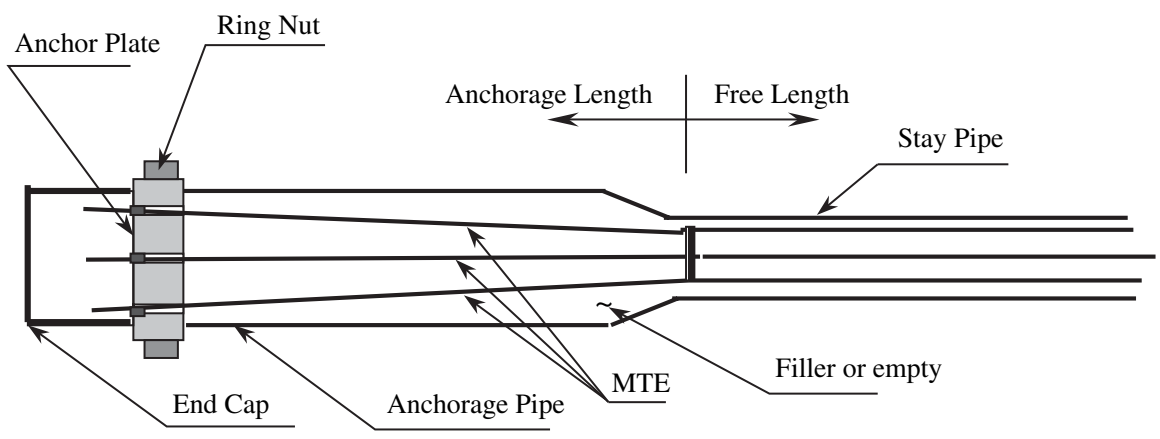

FIGURE 8 Point (wedge) anchorage concept.

go through fatigue qualification tests that they must meet. The other consideration regarding point anchorage systems is the performance of such systems in a rapidly detensioning cable during an earthquake. The concern is that in such a case the wedges could potentially exit the anchorage plate, resulting in the loss of anchorage. There have not been however any reported cases of such an occurrence, and there is no information available regarding cable performance in such scenarios.

\section{“Hi-Am”-Type Anchorages}

Figure 9 shows a "Hi-Am"-type socket. The strands or wires splay out at the entrance to a steel socket that is cylindrical on the outside and conical on the inside. The socket is typically filled with epoxy and small steel balls as well as zinc dust. The MTEs terminate at a locking plate. An example of this type of design is the Luling Bridge in Louisiana.

This type of anchorage has to be assembled to the right length at a plant and brought to the site, usually on reels. The load transfer between MTE and socket occurs over the length of the socket and not at a single point. The cable must be stressed as a whole.

\section{Bond Socket-Type Anchorages}

Figure 10 shows a bond socket anchorage. In this type of anchorage the strands are terminated at an anchorage plate with wedges, but there also exists a conical pipe (conical outside and inside) that is filled with either cement grout or epoxy compound. Examples of this type of anchorage include the
Clark Bridge in Illinois (with grout-filled socket) and the Cochrane Bridge in Alabama (with epoxy-filled socket). When cement grout is used, the wedges carry the initial stresses on the cable before grouting (or epoxy filling) operations are completed (similar to point anchorage). Following grouting, the socket would be expected to resist changes in cable load. Therefore, the intent of this system is to minimize stress changes at the point anchorages. This type of anchorage can be assembled in the field if the grout or epoxy compound is injected after the initial installation of strands and stressing.

Figure 11 shows the results of the survey as related to the types of anchorage systems. In the United States, the conical socket with wedges and the point (wedge) system were dominant. It is clear however that the respondents did not similarly understand the anchorage characterizations, and some misidentifications may have occurred.

\section{Recent Trends in Anchorage Design}

In recent years, the differences between the approaches to anchorage design of various cable manufacturers' have narrowed to some extent. Currently (in 2005), all of the major stay cable manufacturers in the United States have at least one system that more or less falls within the point anchorage system described in Figure 8.

\section{Shop or Field Cable Fabrications}

There are two different approaches regarding the assembly and erection of stay cables. In one approach, the stay cables

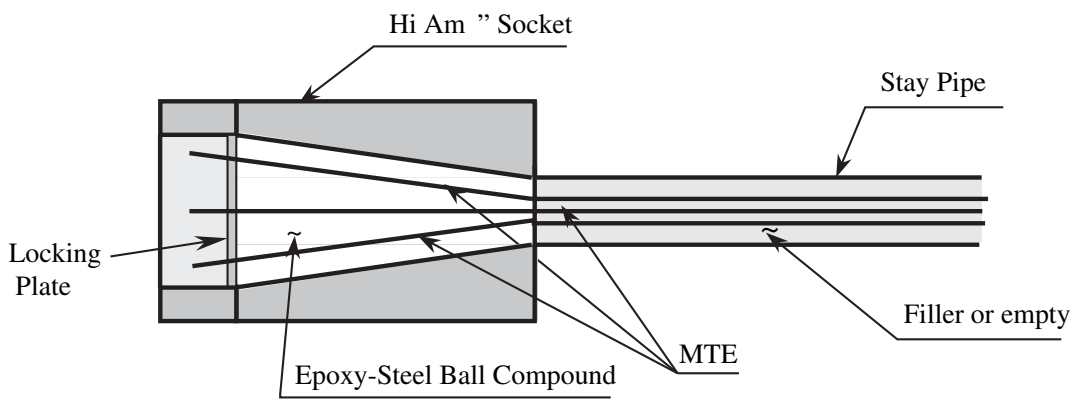

FIGURE 9 "Hi-Am" type anchorage. 


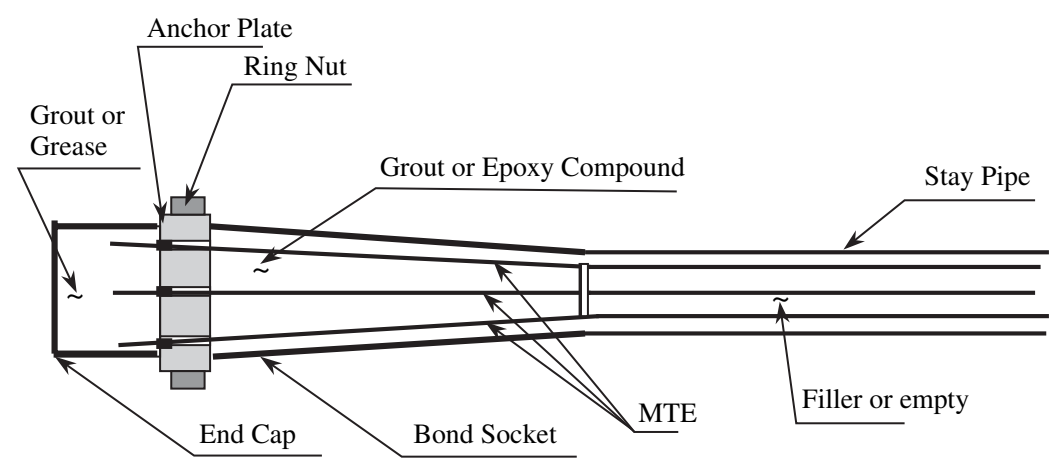

FIGURE 10 Bond socket anchorage system.

are shop-fabricated and installed in the field as a unit. This is typical of the Hi-Am-type anchorages. However, field fabrications have become more common in the United States, especially in the last decade. For field assembly, the cable sheathings are first welded together on the bridge and lifted into place (Figure 12a). Then, strands are typically individually inserted into the anchor plates at the bottom anchorage and fed through the stay pipes towards the top anchor plate (Figure 12b).

The strands can be collectively stressed with large hydraulic jacks or, as is more commonly done today, they are individually stressed with small jacks as they are inserted in the cable. Different cable suppliers have their own procedures and methods to achieve equal force in all strands. Shop fabrications are still very common in Japan. The Alex Fraser (Annacis) Bridge in British Columbia has shop-fabricated cables (Saul and Svensson 1991). The Burlington Bridge in Iowa and the Luling Bridge in Louisiana are examples of shop-fabricated cables in the United States.

\section{Saddles}

The costliest components of a stay cable are the anchorages. Therefore, some designers elect to eliminate anchorages at the pylon by providing a continuous cable through the pylon. The curved saddle at the pylon is typically a steel pipe that redirects the cable force through the pylon. Another reason given is that the pylon can be smaller (narrower) when there are no anchorages (Figure 13). However, large transverse forces are generated on the cable and individual strands in the saddles, especially at the entrances to the pylon. As the strands enter the saddle, they begin to move to the bottom of the pipe and large interstrand forces can develop, particularly when bare strands are used. Changes in cable tension can result in fretting and fatigue. Such fatigue fractures have been observed on at least one qualification test of a saddle system (Tabatabai et al. 1995). In that test, bare strands were used and fractures were initiated at oval-shaped fretting marks at interstrand contact points.

To address these issues and reduce interstrand contact, coated strands (such as epoxy-coated) have sometimes been used. In the case of the Maumee River Bridge in Ohio, the engineer designed a "cradle" system in which each strand passes through its own stainless steel sleeve within the cradle assembly (Harris 2002).

An FHWA Technical Advisory released in 1994 ("Cable Stays ..." 1994) discussed a number of factors related to saddles and discouraged the use of saddles at that time. However, the use of saddles has continued in the United States. Among the factors cited by the FHWA advisory were:

- Stressing of cables with saddles requires simultaneous stressing from both anchorages (during and after construction);

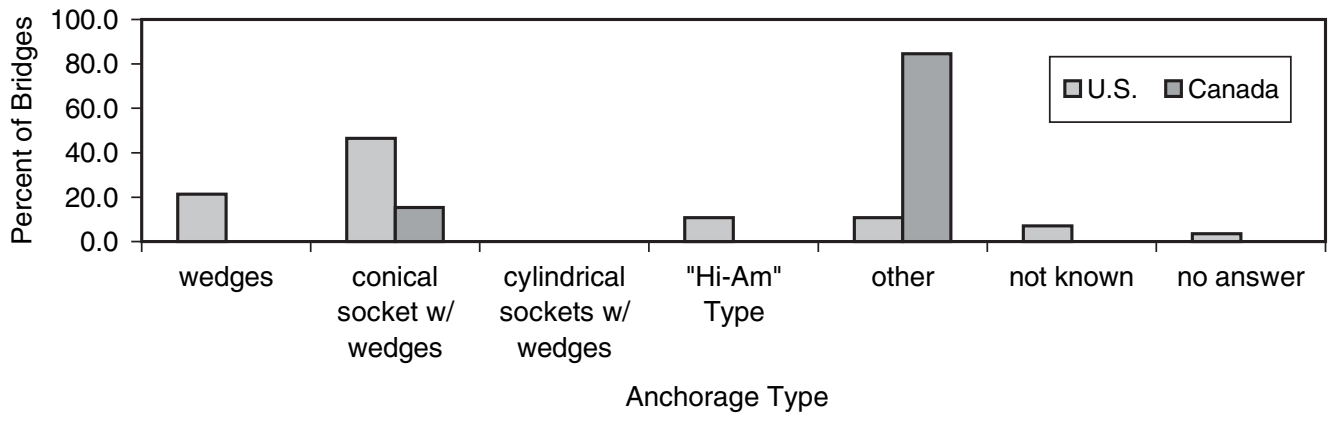

FIGURE 11 Type and frequency of anchorage used. 


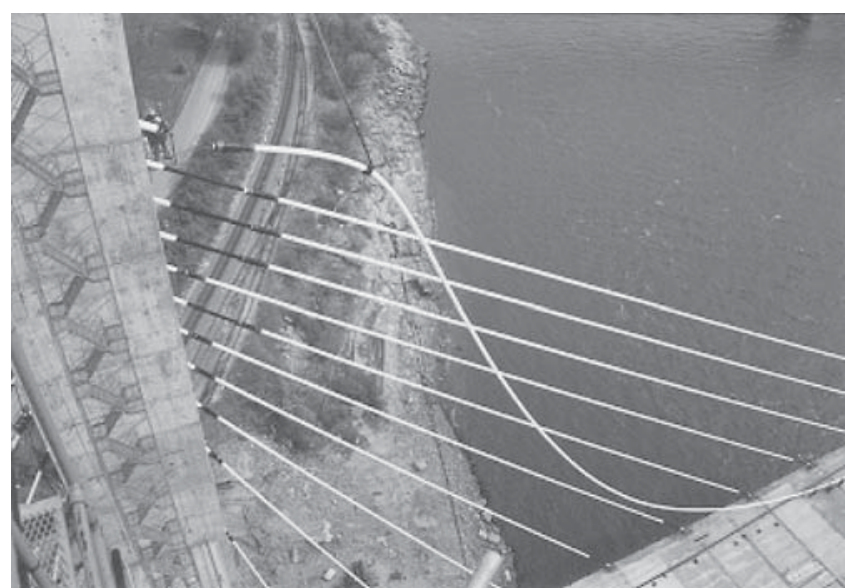

(a)

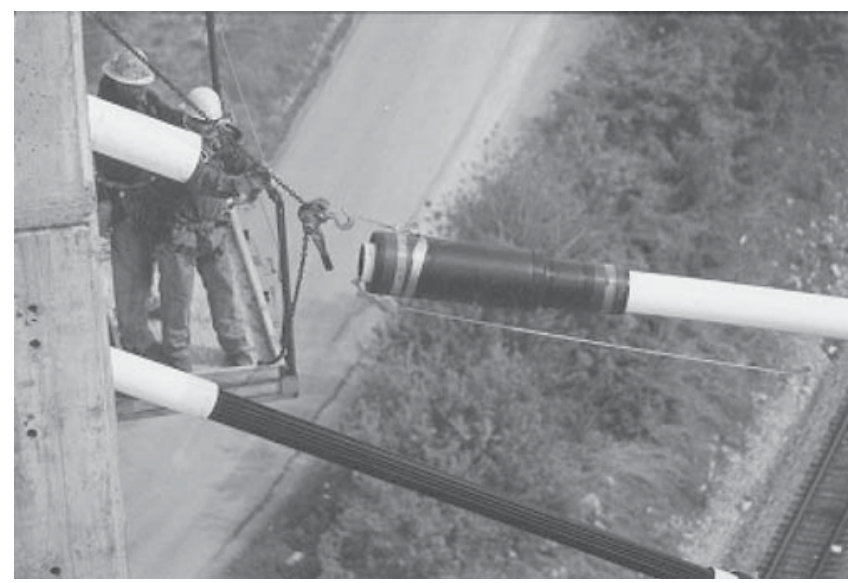

(b)

FIGURE 12 Field assembly of cables for the Cape Girardeau Bridge (courtesy: Missouri DOT).

- A more difficult cable removal and replacement process would be required should that become necessary;

- Precluding slip at the saddles would require special considerations;

- In large single saddles, the application of protective tape may become difficult in the vicinity of large single saddles as spaces between cables are reduced;

- Steel pipe at large single saddles should not participate in load transfer to the pylon (i.e., tension in the steel pipe controlled); and

- Geometric control through cable length would be more difficult.

In 1993, a worldwide survey of stay cable practitioners by Hamilton and Breen (1995) indicated that the majority of respondents did not favor the use of saddles, with European respondents having the highest rate of objections at $76 \%$. The results of the questionnaire in this study showed a total of seven bridges with saddles (21\%), six of which were in the United States and one in Canada (Figure 14).

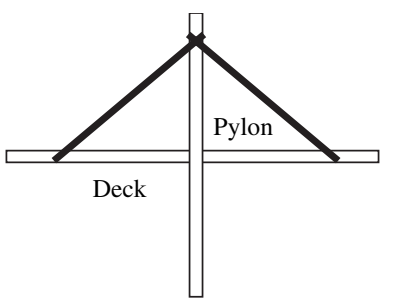

Cable terminated at pylon

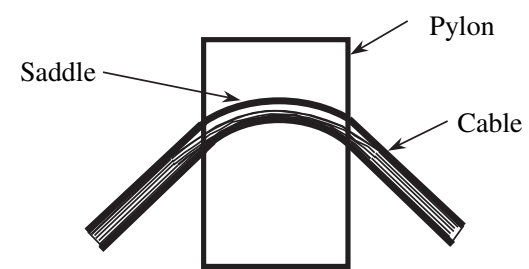

FIGURE 13 Saddles in stay cables.

\section{STAY CABLE MATERIALS}

In this section, the materials used in cable systems are discussed, and the importance of detailing and issues of material suitability and compatibility are presented.

\section{MTE Materials}

Steel

Today, steel is the predominant MTE material used for stay cables (100\% of cable-stayed bridges in the United States and Canada). According to the latest edition of the PTI Recommendations for Stay Cable Design, Testing and Installation (2001), steel wires used as MTEs must conform to the requirements of ASTM A421/A421M, Standard Specification for Uncoated Stress-Relieved Steel Wire for Prestressed Concrete, Type BA. Strands must conform to ASTM A416/ A416M, Standard Specification for Steel Strand, Uncoated Seven-Wire for Prestressed Concrete, and must be weldless, low-relaxation grade. Bars must conform to ASTM A722/ A722M, Standard Specification for Uncoated High-Strength Steel Bar for Prestressing Concrete.

\section{Fiber-Reinforced Polymers}

In recent years, a number of exploratory efforts have focused on the use of fiber-reinforced polymers (FRPs) in prestressing applications and stay cables. These investigations have generally focused on glass, aramid, or carbon fiber-reinforced polymers (GFRP, AFRP, and CFRP). Epoxy-based resins are typically used as the matrix for the composite, and the FRP is made using a pultrusion process. Fisher and Bassett (1997), Christoffersen et al. (1999), Roos and Noisternig (1999), and Noro et al. (2001) provided information on the properties of FRP composites and their comparison to steel. 


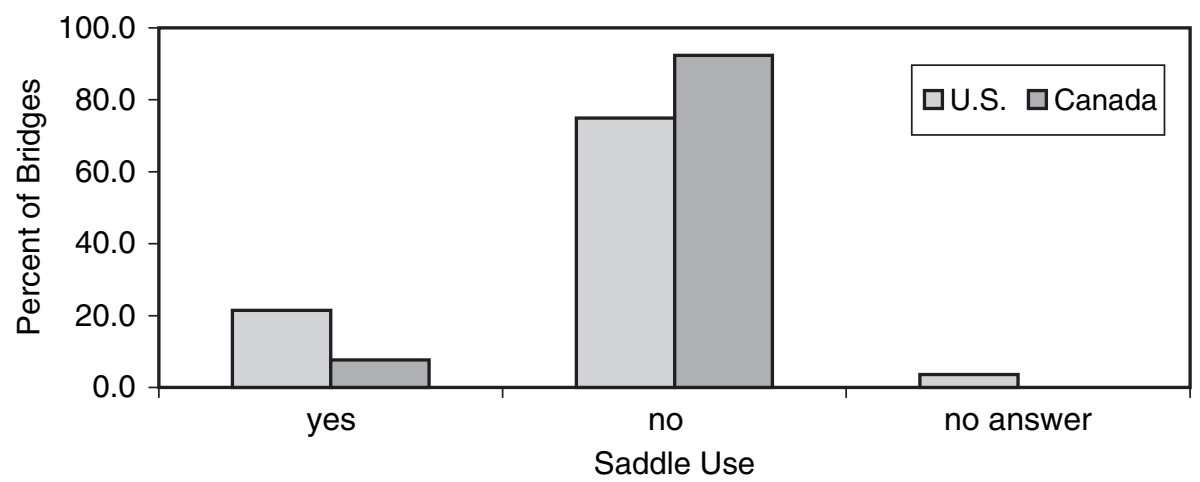

FIGURE 14 Use of saddles.

Tables 3 and 4 show reported comparisons of different material properties.

The main advantages of FRP composite cables are corrosion resistance and lighter weight. For CFRP, the coefficient of thermal expansion is much lower than steel (approximately one-sixtieth), and the strain at rupture is reported to be $1.6 \%$ as compared with $6 \%$ for steel (Roos and Noisternig 1999). The main disadvantages of FRP composites are their high cost and very low shear strength (both transverse and interlaminar shear strengths). The low shear strength seriously affects the gripping ability at anchorages (Christoffersen et al. 1999). Fisher and Bassett (1997) reported that although composite materials do not rust, "they can corrode when integrated into structures with incompatible materials." They report that carbon fiber can be subjected to galvanic corrosion with metals and thus should be insulated from metallic anchorage components. Similarly, glass fiber prestressing tendons "can be susceptible to corrosion under sustained loads when exposed to water or salt water."

Various manufacturers have devised anchorage solutions. These solutions, an example of which is shown in Figure 15, are typically based on a conical steel socket filled with a potting material such as epoxy. However, a wedge-type anchorage system for the carbon fiber composite cables of a pedestrian bridge (the Laroin Bridge in southern France) has been devel- oped. There is a cushioning layer used between the jaws and the rods (Bridge Design and Engineering 2005).

A number of demonstration projects have been built with FRPs. However, there are currently no known cable-stayed bridges in the United States and Canada with FRP cables. According to Seible and Burgueno (1997), the first all-composite cable-stayed pedestrian bridge was built in Aberfeldy, Scotland, in 1993, with aramid fiber stay cables. These authors also reported on the design of a vehicular cablestayed composite bridge on the campus of the University of California, San Diego (I5/Gilman). However, this bridge has not been constructed.

Christoffersen et al. (1999) reported on the construction of a CFRP cable-stayed bridge in Denmark. To protect against possible damage to cables from fire, impact, or vandalism (saw cutting), the designers used stainless steel sheathing over an extruded HDPE sheath. The design was also based on the ability to sustain static failures of two adjacent cables or a sudden failure of one cable. Provisions were made for periodic replacement of an original cable at 5-year intervals.

The Storchenbrücke (Stork) Bridge in Winterthur, Switzerland, incorporates two CFRP stay cables, each consisting of 241 parallel pultruded CFRP rods of 5 to $6 \mathrm{~mm}$ in diameter (Hooks et al. 1997). The other 22 stay cables on this bridge

TABLE 3

TYPICAL PROPERTIES OF THE MOST COMMON FRP MATERIALS AND STEEL

\begin{tabular}{lccc}
\hline Material & $\begin{array}{c}\text { Tensile Strength } \\
\text { ksi (MPa) }\end{array}$ & $\begin{array}{c}\text { Young's Modulus } \\
\text { ksi (GPA) }\end{array}$ & $\begin{array}{c}\text { Density } \\
1 \mathrm{~b} / \mathrm{ft}^{3}\left(\mathrm{~kg} / \mathrm{m}^{3}\right)\end{array}$ \\
\hline CFRP (carbon) & $245-435(1700-3000)$ & $20300-43500(140-300)$ & $100(1600)$ \\
AFRP (aramid) & $175-305(1200-2100)$ & $7250-17400(50-120)$ & $81(1300)$ \\
GFRP (glass) & $218(1500)$ & $7250(50)$ & $150(2400)$ \\
Steel & $270(1860)$ & $29000(200)$ & $490(7850)$ \\
\hline
\end{tabular}

Source: Christoffersen et al. (1999). 
TABLE 4

QUALITATIVE COMPARISON OF FRP PROPERTIES

\begin{tabular}{lccc}
\hline Properties & GFRP & AFRP & CFRP \\
\hline Environmental resistance & - & + & + \\
Tensile strength & + & + & ++ \\
Fatigue strength & 0 & - & ++ \\
Young's modulus & - & - & ++ \\
Creep/relaxation & - & 0 & ++ \\
Stress fatigue & - & - & ++ \\
Density & + & ++ & ++ \\
Material price & ++ & - & - \\
\hline
\end{tabular}

Notes: $-=$ not good, $0=$ neutral,$+=$ good, $++=$ very good .

Source: Christoffersen et al. (1999).

have steel MTEs. The stiffness of the anchorage filler material was varied along the length of the anchorage by adding aluminum oxide pellets with varying thicknesses of epoxy coating. The cables passed qualification fatigue and static testing (Hooks et al. 1997).

Roos and Noisternig (1999) reported on fatigue and static testing of CFRP stay cables with up to 91 wires using PTI recommendations. The cable sustained two million cycles of fatigue loading without wire failure, but reached only a maximum of $78 \%$ of nominal capacity and thus did not meet the requirements.

\section{MTE Coatings}

Various MTE coatings are available worldwide. These coatings are mainly provided for the corrosion protection of MTE. In earlier stay cable designs when uncoated strands and cement grouts were used, it was assumed that grout would provide the necessary protection. However, given that the time between stressing of strands and grouting could be several months or years, it soon became clear that the strands would be left unprotected and could corrode within that time period. One of the early steps taken to address this issue was to use watersoluble oil sprays on the strands (Funahashi 1995). Later, a protective/lubricant coating (a petroleum microcrystalline wax based product) was applied to the strands.

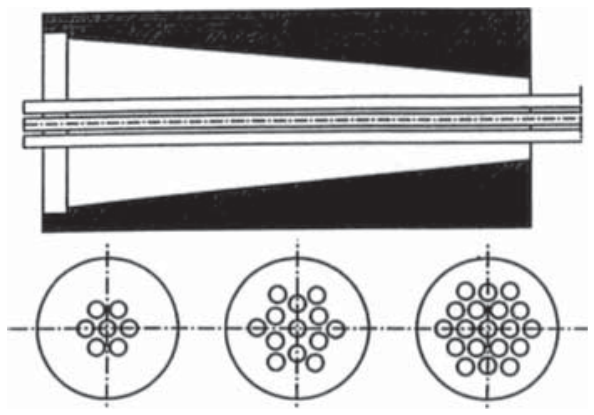

FIGURE 15 One type of CFRP anchorage (Roos and Noisternig 1999).
Figure 16 shows the results of the survey with respect to the type of MTE coatings used, if any, on bridges in the United States and Canada. Strands and wires that are coated with temporary protection oils, as described previously, are considered bare in the survey. Cables with bare MTEs represent $43 \%$ of the survey bridges in the United States, whereas no Canadian bridges use bare MTEs.

\section{Galvanizing}

A very common coating for strands that is used extensively in Europe and Japan is zinc coating (hot dip galvanizing). Galvanizing is a sacrificial form of cathodic protection against corrosion and can be consumed with time, especially in an aggressive environment. In the United States, however, galvanized MTEs have not been used very often for stay cables, except for the Sacramento River (Meridian) Bridge in California and the two early bridges in Alaska, including the oldest cable-stayed bridge in the United States, the Sitka Harbor Bridge. The main concern has been that the galvanizing process, especially with strands in contact with grout, could lead to hydrogen embrittlement. Corrosion and other electrochemical processes can lead to evolution of hydrogen. Absorbed hydrogen can reduce the ductility of steel, through a phenomenon known as hydrogen embrittlement (Barton et al. 2000). On the other hand, $61 \%$ of Canadian bridges in the survey used galvanized MTE members. However, none of the Canadian bridges included galvanized MTE in contact with cement grout.

It was also believed that the process of galvanizing would degrade the tensile strength of strand and its fatigue life ("Cable Stays ..."1994). The concern for contact between galvanized strand and cement is widely held (Ito 1999). However, PTI recommendations state that "galvanized prestressing strand may be used in contact with cement grout provided the steel has been manufactured in accordance with the latest ASTM A416, BS 5896, or EN 10138 standard. Experience has shown that strand manufactured to these standards is not susceptible to hydrogen embrittlement" (Recommendations for Stay Cable Design . . 2001). The PTI document does not refer to other references that form the basis for that statement.

The PTI recommendations also include the following:

Galvanized strand is made from either as-galvanized wires (in
Japan) or drawn-galvanized wires (in Europe). The advantage of
as-galvanized wire is heavier coating weight $\left(300 \mathrm{~g} / \mathrm{m}^{2}\right)$ or more
for better corrosion protection. The advantage of drawn-galvanized
wire, on the other hand, is improved fatigue performance and
tighter control on tolerance.

In Europe, galvanized wires and strands are routinely used for ungrouted stay cables, and special manufacturing processes are adopted that reportedly ensure compliance with the strength and fatigue requirements including those of the standards listed by the PTI document. In the United States, the market 


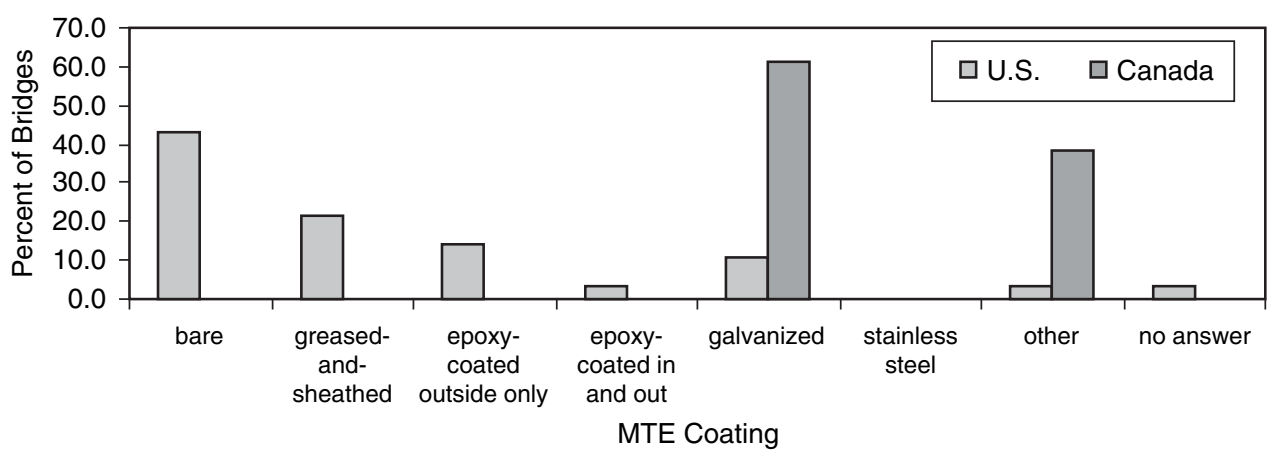

FIGURE 16 Types of MTE coatings used.

conditions have reportedly not yet justified local production of galvanized strands of sufficient quality (fatigue and strength) for use in stay cables. The Buy America Act enacted by the U.S. Congress in 1933 has so far effectively prevented the importation of stay cable-quality galvanized strands. According to the Buy America Act, all federal construction contracts that are undertaken within the United States must use domestic construction materials, subject to a few exceptions. Therefore, galvanized wires and strands are currently not being used in U.S. stay cables.

Suzumura and Nakamura (2004) studied environmental factors affecting corrosion of galvanized steel wires for suspension bridges. They concluded that galvanized steel wires did not corrode when kept in an environment with a relative humidity of less than $60 \%$. The corrosion rate increased significantly with temperature. They reported that for a wire kept in a wet environment the zinc layer $\left(350 \mathrm{~g} / \mathrm{m}^{2}\right)$ would be consumed within 10 years. In $100 \%$ and $60 \%$ relative humidity environments, the consumption of zinc would be complete in 34 years and 211 years, respectively. Figure 17 shows the effects of relative humidity and sodium chloride on the corrosion rate. Figure 18 shows the effect of temperature on the corrosion rate.

Tarui et al. (2001) reported that galvanized wires with strengths of $256 \mathrm{ksi}(1770 \mathrm{MPa})$ for $7 \mathrm{~mm} / 0.276 \mathrm{in}$. wires and

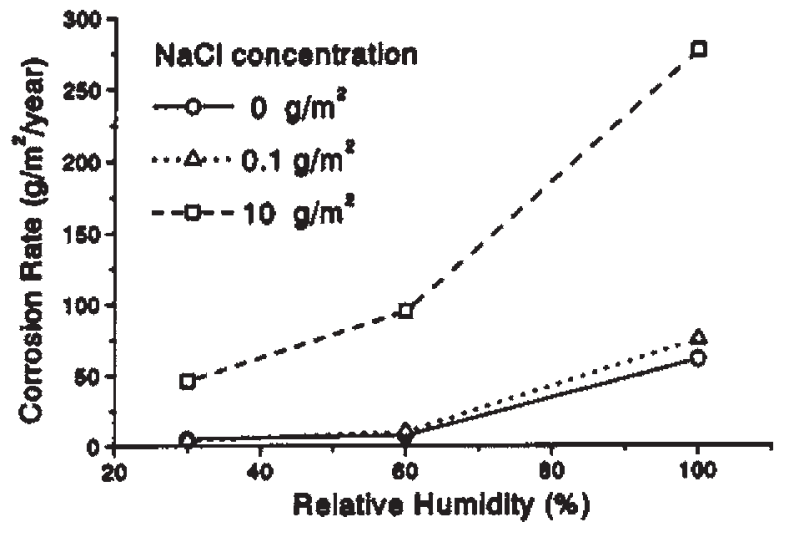

FIGURE 17 Corrosion rate for galvanized wire (Suzumura and Nakamura 2004).
$284 \mathrm{ksi}(1960 \mathrm{MPa})$ for $5 \mathrm{~mm} / 0.197 \mathrm{in}$. wires have been developed in Japan. They reported good fatigue and lowtemperature response and elongations of $6 \%$ to $7 \%$. Tauri et al. (2001) attributed the loss of strength in galvanized wires to the "spheroidizing of cementite, resulting in the collapse of the lamellar structure of ferrite and cementite." They reported that the silicon and chromium elements can suppress this loss of strength.

It should be noted that galvanized strands individually sheathed with HDPE are also available and have been used overseas. According to a worldwide survey of the stay cable industry performed by Hamilton and Breen (1995), the galvanized-and-sheathed strand is the most highly rated by the respondents.

\section{Individually Sheathed Strands with Corrosion Inhibiting Coating}

PTI provides detailed recommendations for such strands, which are typically referred to as greased-and-sheathed or waxed-and-sheathed strands (Recommendation for Stay Cable Design . . 2001). The grease or wax is believed to reduce potential for fretting fatigue resulting from interwire contact (Frank and Breen 2004). These strands are individually coated and then covered with HDPE or high-density polypropylene

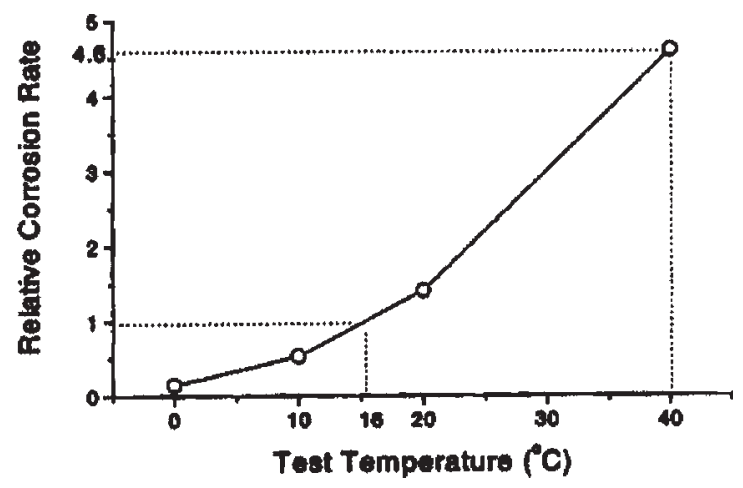

FIGURE 18 Relative corrosion rate-wet condition without chloride exposure (Suzumura and Nakamura 2004). 
(HDPP) that is extruded over the strand. These systems have been common in all recently constructed cable-stayed bridges in the United States. Examples of bridges using these types of strands are the Cape Girardeau Bridge in Missouri and the Sixth Street Viaduct Bridges in Wisconsin.

\section{Epoxy Coating}

The use of epoxy-coated strands became popular in the United States in the early to mid-1990s, and was used on at least four bridges in the United States in that decade. Three types of such strands were originally available for stay cables. In one, an epoxy coating with a smooth surface was applied on the outside perimeter of the seven-wire strands, thus leaving air voids in the interstitial spaces between the six outside wires and the center wire (Figure 19). The second type of epoxy-coated strand produced was similar to the first, except for a gritimpregnated surface to improve bond with grout. The third type of strand had epoxy in all interstitial spaces in addition to the outside surface. The FHWA advisory ("Cable Stays ..." 1994) and the current PTI provisions (Recommendation for Stay Cable Design ... 2001) recommend that only epoxycoated strands with filled interstices should be used for stay cables.

Qualification tests in the early 1990s on unfilled strands indicated that pressurized grout water could infiltrate the void spaces inside the strands and remain there as free water, resulting in extensive corrosion and fatigue fractures in the time period of the test (Tabatabai et al. 1995). Although a complete determination of the path of water was not made, it was clear that one likely source was the penetration (and breach) of the epoxy coating at the wedges. Corrosion tests by Hamilton et al. (1998b) also showed corrosion inside unfilled epoxy-coated strands, but no corrosion was found in the filled strands.

Saul and Svensson (1991) reported that during the installation of stay cables for the Quincy Bridge in Illinois, "it became apparent that the ends of the strands must be sealed with an epoxy coating in order to prevent moisture rising due to capillary pressure through the full height of the cables in the interstices between the individual seven wires forming each

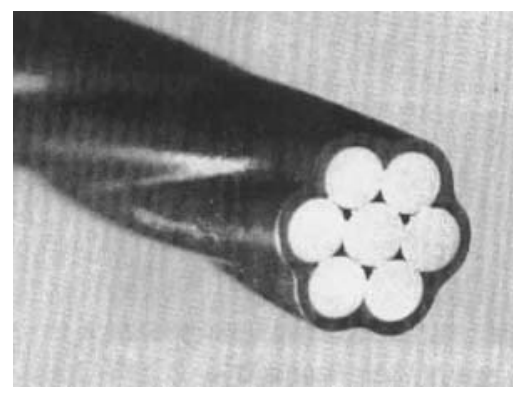

FIGURE 19 Epoxy-coated strand (Funahashi 1995). strand." According to the questionnaire response received, moisture has been found in the cable anchorages on this bridge.

\section{Cable Sheathings and Wraps}

Options for cable sheathings include HDPE, steel, stainless steel, or aluminum (Ito 1999). The most common cable sheathing is HDPE (Figure 20). Seventeen U.S. cable-stayed bridges included in the survey responses $(61 \%)$ have HDPE pipes around the cables. However, other bridges such as the Dame Point Bridge (Florida), Maumee River Bridge (Ohio), and the Sunshine Skyway Bridge (Florida) have steel pipes. The new Maumee River Bridge is designed with stainless steel pipes. The cable sheathing, when used, serves as the first line of defense, a barrier against damage or intrusion of harmful substances from the outside. In cases where grout or other fillers are used, the sheathing also serves as a container for the filler. The survey indicates that three bridges in the United States and nine bridges in Canada do not have any external sheathing.

The HDPE pipes include approximately $2 \%$ to $3 \%$ carbon to protect against ultraviolet radiation (Saul and Svensson 1991; Ito 1999). However, considering that the coefficient of thermal expansion of HDPE is much higher than the grout or steel (Funahashi 1995), and that the basic color of HDPE with carbon is black, the issue of increased surface temperatures had to be addressed. Saul and Svensson (1991) reported that the surface temperature of black pipes can reach more than $149^{\circ} \mathrm{F}\left(65^{\circ} \mathrm{C}\right)$ owing to direction solar radiation, whereas the surface of a white pipe under the same condition would reach only $104^{\circ} \mathrm{F}\left(40^{\circ} \mathrm{C}\right)$. Paint does not adhere well to HDPE. Until recently, new HDPE-covered cables were commonly wrapped with a light color self-adhesive polyvinyl fluoride (PVF) tape (mostly referred to by the commercial name Tedlar(), which was spirally wrapped around the HDPE pipe. Typically, a $50 \%$ overlap is provided.

Some damage has been reported on wrapped tapes in some bridges (based on the survey results). In one case, the PascoKennewick Bridge in Washington State, the damage was reported to be extensive. In that case, polyvinyl chloride (PVC) tapes were first used over the pipes, and these tapes became brittle after several years and began to flake off (Saul and Svensson 1991). In other cases, the damage was reported to be minor. A laminated tape consisting of a translucent Tedlar tape with a color PVC tape backing was also developed (Saul and Svensson 1991). In recent years, coextruded HDPE pipes with bright surface colors have entered the market, and recently constructed bridges use this approach in lieu of the PVF tape. Figure 21 shows the results of the survey with respect to damage to the protective tape.

In tests performed by Hamilton et al. (1998), clear HDPE sheathing was used to allow assessment of grout condition inside the sheathing. There is no information available that would indicate if clear HDPE sheathing has ever been used 


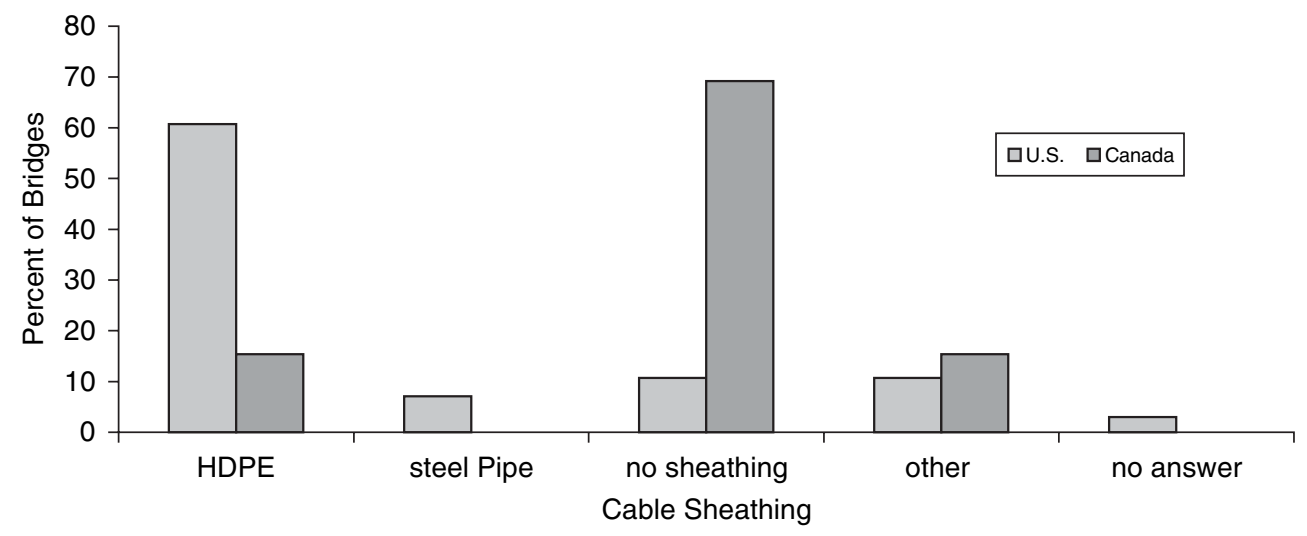

FIGURE 20 Types of cable sheathing used.

on stay cables in the field to facilitate inspections. An important challenge would be the required resistance to ultraviolet radiation.

Figure 22 shows the results of the survey with respect to the cracking of cable sheathing or sheathing connections. Four bridges or 14\% of the respondents in the United States (and none in Canada) reported problems with the sheathing or connections. In the C\&D Canal Bridge in St. Georges, Delaware, cracking of the steel sheathing was noted on one of the stay cables. This cracking was attributed to the position of a grout vent hole at a high-stress location near a pylon. The respondents to the questionnaire also identified two bridges that had splitting of HDPE [Quincy (Illinois) and Luling (Louisiana)].

In field-fabricated cables, the HDPE pipe segments are typically assembled and welded together (HDPE welding) by special machines on the bridge deck before being lifted into place. In some shop-fabricated cable systems, the cable assemblies (including HDPE) are assembled, coiled, and then shipped on large reels. The coiling and uncoiling of HDPE pipes at low temperatures can lead to cracking (Funahashi 1995). In newer shop-fabricated Japanese cable systems, the HDPE is extruded over the MTE bundle, thus creating a tight fit between the sheathing and MTE.

When a cable with HDPE sheathing is grouted, the pipe must resist grouting pressures. This would increase the required thickness of the pipe. On some of the early bridge projects, such as the Zarate-Brazo Largo Bridges in Argentina and the Luling Bridge in Louisiana, there have been problems with grouting operation that reportedly contributed to the cracking of the HDPE pipe (Saul and Svensson 1991). The authors discussed HDPE stresses as a result of coiling and uncoiling, effects of grouting pressures, and effects of high temperatures at the time of grouting.

Steel pipe segments are typically welded together in the field. The external pipe is generally bolted to the anchorage pipe. The axial and flexural stiffness of the steel pipe is far greater than that of the HDPE. In a grouted system, sufficient bond between the grout and the steel pipe can be developed, thus transmitting some of the fluctuating cable stresses into the sheathing (owing to strain compatibility). In some qualification tests, steel sheathing connections developed fatigue fractures as a result of this unintended effect (Tabatabai et al. 1995). Saul and Svensson (1991) also reported that "some welded connections have failed in the past" without elaborating. Steel sheathings must also be periodically painted to protect against corrosion.

\section{Fillers and Blocking Compounds}

Fillers refer to materials placed inside the sheathing and around the MTE. In United States practice, the most common

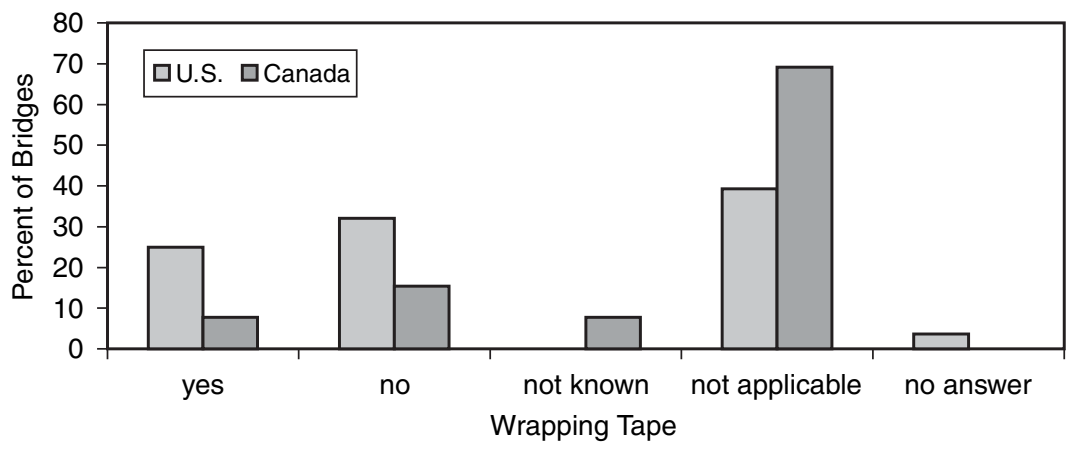

FIGURE 21 Damage to wrapping tape. 


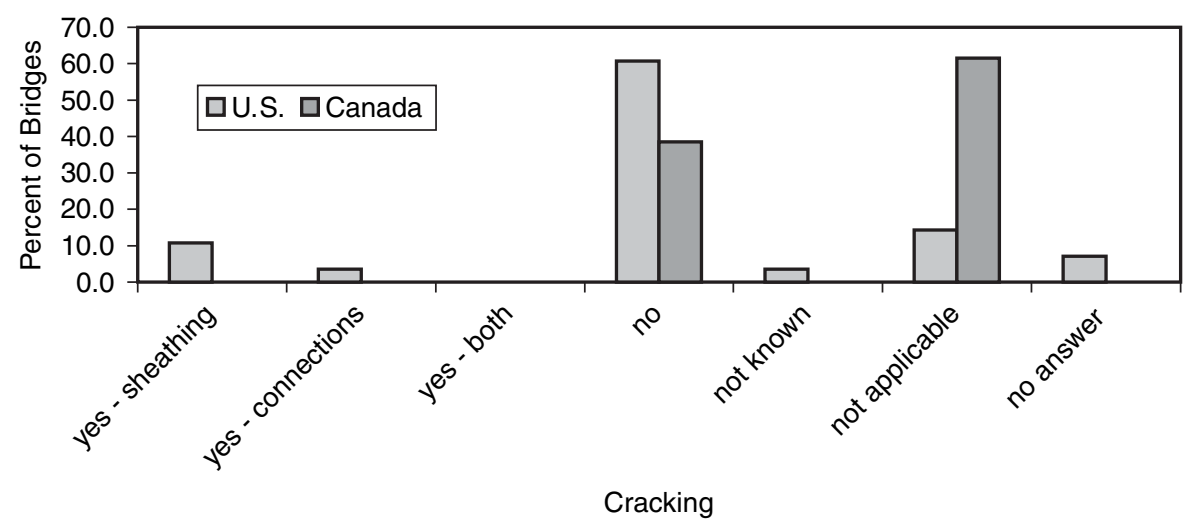

FIGURE 22 Cracking of cable sheathing and connections.

type of filler within the HDPE pipe and the MTE has been the cement grout. Table 5 shows the results of the survey with respect to the type of fillers used, if any, in the stay cables. Fifty-four percent of U.S. bridges in the survey include some type of cement grout in the free length of the cable. None of the Canadian bridges use cement grout. Table 6 shows responses to the survey with respect to the filler materials used in the anchorage zones.

\section{Portland Cement Grout}

There have been a variety of opinions on the merits of cement grouts for stay cables. As stated earlier, the practice of grouting stay cables comes from the post-tensioning technology, and not from the suspension cable technology. Grouting has not, in general, been very popular in Europe (Hamilton and Breen 1995). The main advantages typically given for cement grout in stay cables are:

- Cement grout provides a physical barrier for the MTE that is not easily breached.

- Grout provides an alkali environment for the bare steel and protects it against corrosion.

TABLE 5

SURVEY RESULTS-TYPE OF GROUT USED? (Question 4.7)

\begin{tabular}{lccccc}
\hline & U.S. & $\%$ U.S. & Canada & \% Canada & $\%$ total \\
\hline Grout not used & 6 & 21.4 & 12 & 92.3 & 43.9 \\
Cement-water & 5 & 17.9 & 0 & 0.0 & 12.2 \\
$\begin{array}{l}\text { Cement-water- } \\
\quad\end{array}$ & 9 & 32.1 & 0 & 0.0 & 22.0 \\
$\quad$ admixtures & & & & & \\
Commercial pre- & 1 & 3.6 & 0 & 0.0 & 2.4 \\
$\quad$ packaged grouts & & & & & \\
Not known & 6 & 21.4 & 0 & 0.0 & 14.6 \\
Not applicable & 0 & 0.0 & 1 & 7.7 & 2.4 \\
No answer & 1 & 3.6 & 0 & 0.0 & 2.4 \\
\hline
\end{tabular}

- The increased mass owing to the grout helps with damping and vibration control.

The disadvantages are:

- Stress fluctuations in the cable and grout shrinkage can result in the cracking of the grout. This cracking can lead to intrusion of moisture if the external sheathing is breached.

- Grouting adds to the cost of cables.

- Grouting could complicate many types of NDT and inspections.

- Grout water and bleed water could present internally driven corrosion danger when not properly controlled. Voids could be introduced inside grouted ducts.

Tabatabai et al. (1995) performed qualification tests on some grouted stay cable specimens with uncoated (bare) strands. The dissection of cable specimens after fatigue and static tests indicated transverse cracking in the grout. Corrosion was noted on the strand at the intersection of the grout cracks and the strand, some with surface pitting. Fatigue fractures were also noted at those locations, thus establishing that the cracking occurred early in the fatigue test and not in the subsequent static test. Figure 23 shows corrosion at the location of grout cracking. Ito (1999) refers to the presence of grout cracks and how they may be associated with potential for "fretting corrosion" of steel wires.

TABLE 6

SURVEY RESULTS-ARE FILLER MATERIALS USED IN THE ANCHORAGE ZONE? (Question 4.8)

\begin{tabular}{lrrccc}
\hline & U.S. & \% U.S. & Canada & \% Canada & \% total \\
\hline Yes_-grout & 6 & 21.4 & 0 & 0.0 & 14.6 \\
Yes_-grease & 10 & 35.7 & 0 & 0.0 & 24.4 \\
Yes_other & 7 & 25.0 & 2 & 15.4 & 22.0 \\
No filler & 0 & 0.0 & 11 & 84.6 & 26.8 \\
Not known & 4 & 14.3 & 0 & 0.0 & 9.8 \\
No answer & 1 & 3.6 & 0 & 0.0 & 2.4 \\
\hline
\end{tabular}




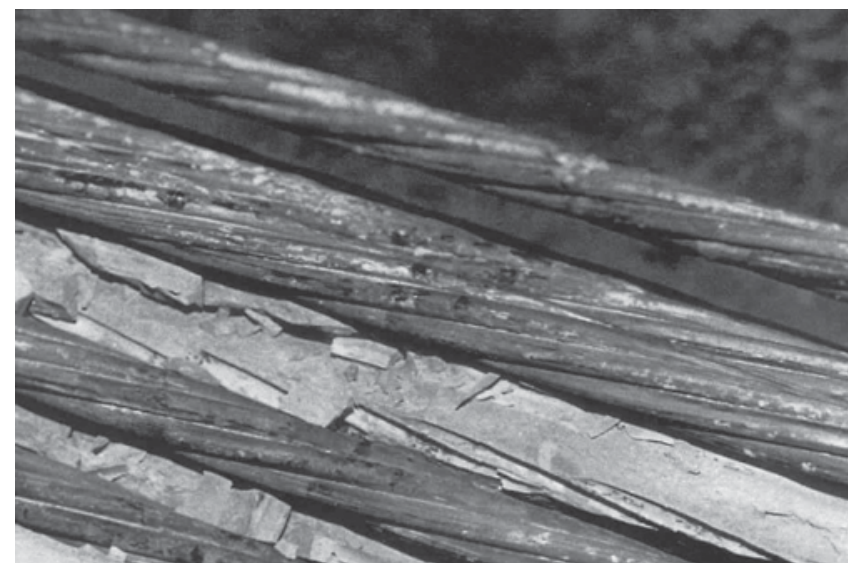

FIGURE 23 Corrosion of strand at transverse crack in grout.

There are conflicting results from examination of grout conditions on four bridges. In these bridges, the Cochrane Bridge (Alabama), Pasco-Kennewick Bridge (Washington State), Talmadge Memorial (Georgia), and the Fred Hartman Bridge (Texas), the HDPE sheathing was partially removed (windows cut) during inspections to allow examination of the condition of grout and wires (Grant 1991; Tabatabai et al. 1998; Dowd et al. 2001; and survey results). In the Cochrane Bridge, no cracking of grout or corrosion of MTE was reported (Tabatabai et al. 1998a). Grant (1991) also reported no grout cracks for the Pasco-Kennewick Bridge. However, Frank and Breen (1994) reported that in the Pasco-Kennewick Bridge there were small, closely spaced grout cracks perpendicular to the stay (Figure 24). The inspection of grout for the Fred Hartman Bridge indicated "fine, intersecting transverse and longitudinal cracks, with spacing between 12 and $19 \mathrm{~mm}$." These cracks were not readily evident.

It is not known whether longitudinal cracking of HDPE pipes in some bridges (such as Zarate-Brazo Largo in Argentina) affected the integrity of the grout, because no examination of the grout was reported in the literature for

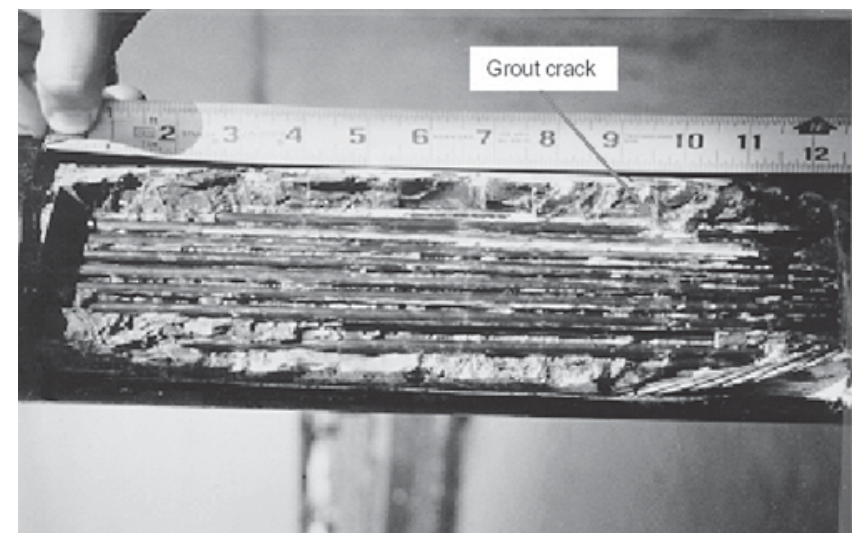

FIGURE 24 Exposed cable on the Pasco-Kennewick Bridge (Frank and Breen 1994). these bridges. Ito (1999) reported that grout cracking has been observed on some cable-stayed bridges, but does not provide additional information. Saul and Svensson (1991) also reported grout cracking on cable test specimens.

Hamilton et al. (1998a,b) reported on accelerated corrosion tests done on eight grouted stay cable specimens, five of which were uncoated (bare) strands, one with epoxy-coated strands (some filled and some unfilled), one with a galvanized strand, and one with a greased-and-sheathed strand. These specimens were loaded and grouted inside clear pipes to allow visual examination of grout surface. Windows were cut into the pipes to simulate damage to the HDPE. Wet and dry saltwater ponding cycles were initiated to represent longterm ingress of chloride-laden air and moisture through the openings. The main objective was to determine if the cement grout can provide positive secondary protection if the first protective layer (HDPE) is breached. Hamilton et al. (1998a,b) concluded that a relatively low level of loading above the grout injection load would result in grout cracking. The salt solution was able to reach almost any location in the specimens, and the primary mechanism for corrosion was cracking of grout at sheathing breaks. According to the authors, galvanized, greased-and-sheathed, and filled epoxy-coated strands provided vast improvement over the bare strands. Corrosion was observed inside the unfilled epoxy-coated strands. Therefore, the authors concluded that the traditional grout-bare-strand HDPE system could no longer be considered a redundant system. Frank and Breen (2004) concluded that the use of portland cement grout has not proven to be an effective corrosion protection barrier.

When wires of bare strands are encased in grout fracture, the force in the broken wire redevelops a relatively short distance away from the fracture. Some qualification tests have shown multiple fractures on the same wire over a length of a few inches (Tabatabai et al. 1995). Therefore, the overall cable axial stiffness would not necessarily change when limited numbers of individual wire breaks occur, especially when those breaks are spread over some distance. This can be viewed as both positive and negative; positive because cross-section strength at locations away from fracture would remain unchanged and negative because monitoring of cable force changes (or deck profile deflection changes) would not indicate loss of section because stiffness has not been affected substantially. The global stiffness of the cable would remain essentially unchanged even when moderate wire section losses occur.

\section{Other Fillers}

Ito (1999) reported that cement grout plasticized with polyurethane has been used in some bridges. A synthetic resin material based on polybutadiene was used on two Japanese bridges (Ito 1999). Grease and wax have also been used. In the Alex Fraser (Annacis) Bridge in British Columbia, petroleum wax blocking compound was used inside the sheathing. 
Wax is injected at high temperatures and solidifies when cooled, resulting in shrinkage and cracking. Ito (1999) reported that a type of petroleum wax that could be applied at ambient temperature has been developed.

Hemmert and Sczyslo (1999) reported that red lead is commonly used in locked coil cables. A coating of paint is sometimes used over the locked coil cables.

One option is not to have any fillers inside the HDPE pipe. That is the approach used on the Charles River Crossing Bridge in Boston, Maumee River Bridge in Ohio, Sixth Street Viaduct Bridges in Wisconsin, and Cooper River Bridge in South Carolina, where individually coated and sheathed strands (or epoxy-coated strands) are used inside HDPE pipe without cement grout. The Charles River Bridge is believed to be the first ungrouted parallel strand stay cable system built in the United States and marks a major shift in the stay cable technology in this country. In response to the questionnaire, the cable manufacturer for the Charles River Bridge, Freyssinet LLC, stated that the ungrouted system would improve inspectability and allows for future replacements. All of the major cable suppliers in the United States currently offer cable systems with the no-grout option.

Little et al. (2001) discussed fungal-influenced corrosion of post-tensioned tendons. They reported that bacteria have been implicated in corrosion of tendons in structures. Their experiments showed the fungal degradation of lubricating grease, which produced formic and acetic acids resulting in corrosion of steel cables. Fusarium sp., Penicillium sp., and Hormoconis sp. were isolated from corroding tendons in a post-tensioned structure and used in testing. The test specimens were coated with "metal soap hydrocarbon grease" before insertion into PVC sheathing. There were no indications of chlorides in the energy-dispersive X-ray analysis system spectra of the grease. This article did not refer specifically to stay cables.

\section{Neoprene Rings}

A stay cable is subjected to lateral movements as a result of vibrations. These vibrations create bending stresses at the two ends of the cable, thus increasing the potential for fatigue. To address this issue, most cable-stayed bridges in the United States have what are termed neoprene rubber "washers," "rings," or "donuts" placed around the HDPE pipe within the guide pipe (anchor pipe) near the ends of the cables. Figure 25, a diagram of the anchorage for the Cochrane Bridge in Alabama, shows the typical position of the neoprene washer with respect to the other components of cable anchorage.

In addition to reducing bending stresses at the anchorages, the neoprene rings also contribute to the vibration damping of the cables. Although the level of damping (attributed to the

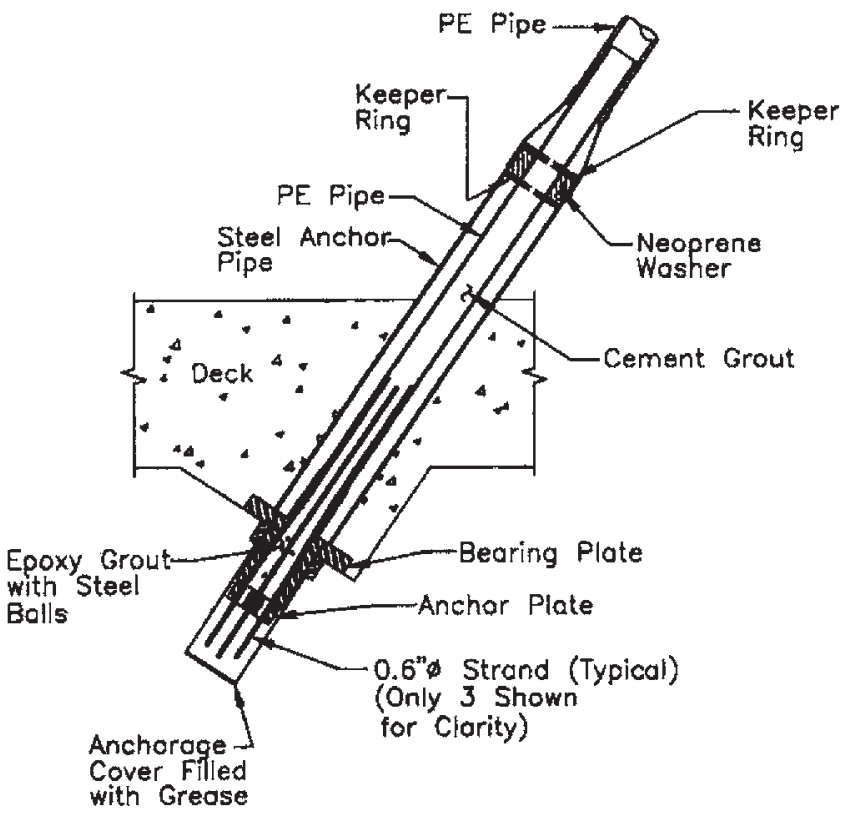

FIGURE 25 Anchorage detail including neoprene washers for the Cochrane Bridge (Alabama) (Telang et al. 2000).

neoprene ring) and its reliability is subject to debate, it is clear that problems with neoprene rings can exacerbate cable vibration problems. Telang et al. (2000) reported on problems with the washers on the Cochrane Bridge that likely contributed to excessive rain-wind vibrations. The cable was not centrally located in the middle of the steel anchor pipe (or the guide pipe); thus, the thickness of neoprene around the HDPE was variable. Also, there were gaps between the neoprene ring and the cable along the perimeter (see Figure 26). This would reduce the effectiveness of the washer both in reducing bending stresses and in damping vibrations.

The steel rings that typically hold the washers in place ("keeper rings") can fail and result in the dislocation and misalignment of the neoprene ring (Figure 27).

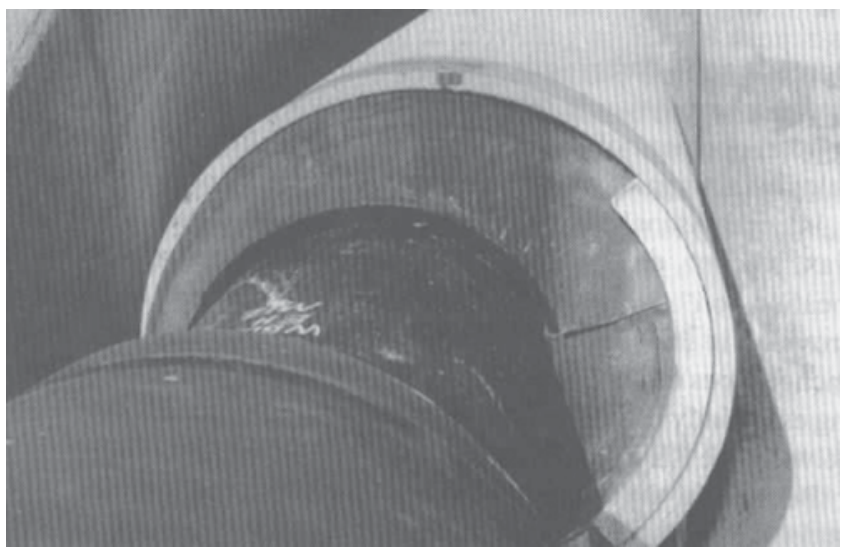

FIGURE 26 Cap between cable and neoprene washer (Telang et al. 2000). 


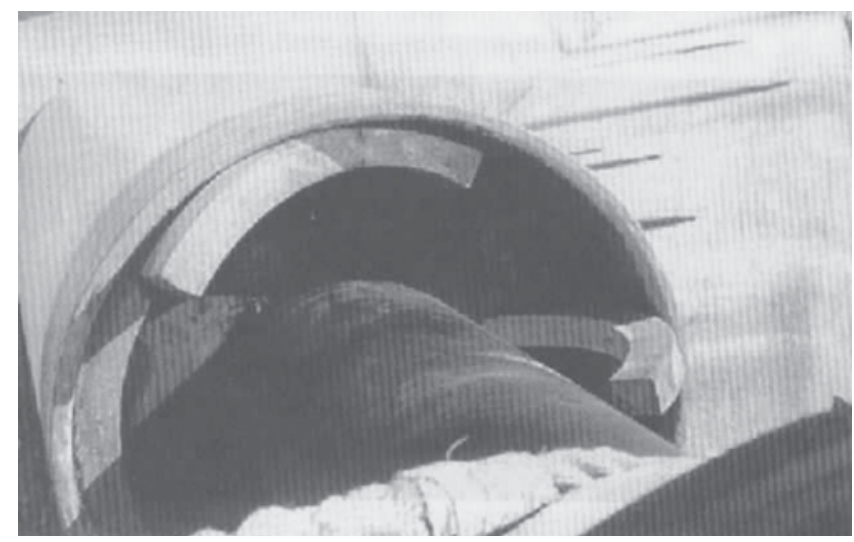

FIGURE 27 Failure of the keeper ring and dislocation of neoprene washer (Telang et al. 2000).

Figure 28 shows the results of the survey with respect to the use of neoprene rings. Most cable-stayed bridges in the United States $(64 \%)$ use neoprene rings, whereas $31 \%$ of Canadian bridges have neoprene rings.

Responses to the questionnaire indicated that seven bridges in the United States and two bridges in Canada had problems with movements of the rings out of position for various reasons, indicating that this is a relatively common problem (see Figure 29).

At least one cable supplier has developed a proprietary viscoelastic damping system that also serves the purposes of the neoprene washer. The topic of vibration damping is discussed later in this report.

\section{Neoprene Boot}

Neoprene boots are generally used to cover the gap between the cable sheathing and the end of the guide pipe near the neoprene ring. Figure 30 shows a typical neoprene boot that is in good working condition. Typically, hose clamps are used to tighten the boots against the sheathing and the guide pipe. In some cases, it has been observed that the clamps become displaced and rainwater can enter the guide pipes. Bloomstine and Stoltzner (1999) reported on water intrusion into the top and bottom neoprene boots. They recommended using silicone filler under the boot before clamping. Responses to the questionnaire for at least three bridges indicated problems with neoprene boots.

Table 7 shows the survey responses related to problems with neoprene boots. Four bridges in the United States and one in Canada reported problems with neoprene boots. However, two of the four U.S. cases referred to neoprene boots that are not as described above.

\section{STAY CABLE DESIGN CHALLENGES}

Aside from structural strength, the design of stay cables also must address the challenges of corrosion, fatigue, vibration, inspectability, and maintainability. More recently, consideration of extreme events such as fire, ice, blasts, impacts, and earthquakes are attracting more attention in the design of stay cables. In this section, the mechanisms for corrosion, fatigue, and vibrations (including rain-wind vibrations) are first discussed, followed by a discussion of the challenges of designing stay cables for inspectability and maintainability. The PTI recommendations, including qualification tests, are reviewed. Finally, a brief outline of issues related to extreme events is discussed.

It should be noted that although these issues are presented separately, they are highly interrelated and cannot be considered independent. For example, corrosion and vibrations could have major negative influence on fatigue performance. The ability to inspect and maintain also influences durability of cables in all areas. These major structures must safely carry traffic for a long time. Therefore, a clear understanding of the durability limits and issues is very important.

\section{Corrosion}

Corrosion protection for stay cables is understandably one of the primary concerns of designers, suppliers, and owners involved in cable-stayed bridges. According to the PTI Recommendations for Stay Cable Design, Testing, and Installation (2001), a minimum of "two nested qualified barriers"

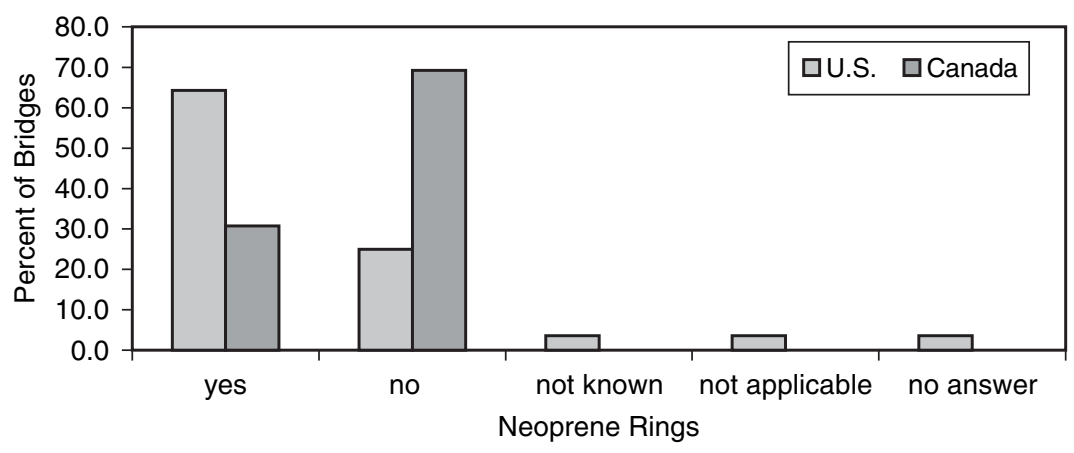

FIGURE 28 Use of neoprene rings. 


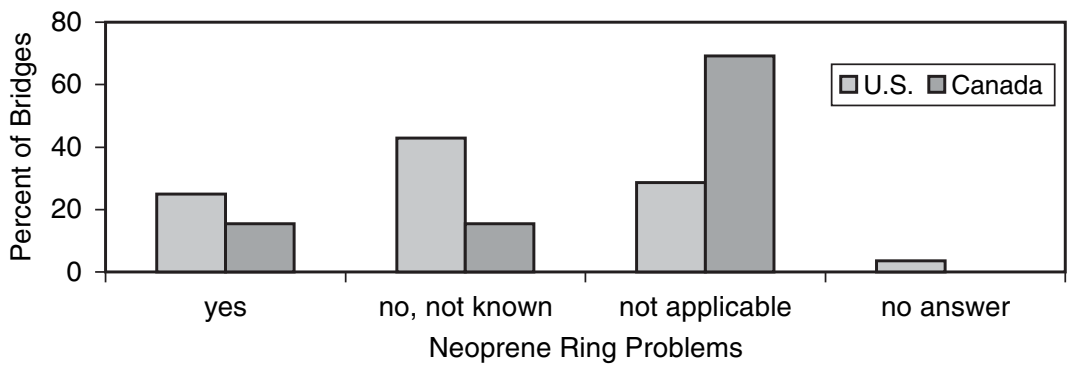

FIGURE 29 Movements of neoprene rings out of position.

must be provided for the corrosion protection of the MTE. By clearly specifying minimum acceptable levels of protection and setting performance requirements with respect to corrosion, these provisions are a major departure from earlier practices. A two-tier system is established in which the individual barriers must first be qualified through testing, followed by the testing of the nested barriers as a system. As the number of nested qualified barriers (that are compatible with each other) increase, the system redundancy and reliability is expected to improve.

It is important to realize that corrosion can be either internally or externally driven. The primary mode of protection has naturally and rightly been against externally driven corrosion (i.e., moisture and other harmful substances entering from outside). However, internally driven corrosion mechanisms have also been observed and must be addressed in design and maintenance. Examples of these corrosion mechanisms include corrosion resulting from the presence of free grout water in different components of cables.

Design of cable components for corrosion resistance should consider, when applicable, the effects of extreme temperatures, solar radiation, shrinkage or expansion of fillers, age, vibration, and fatigue on the effectiveness of the system. As will be seen later in this report, recent trends have been toward

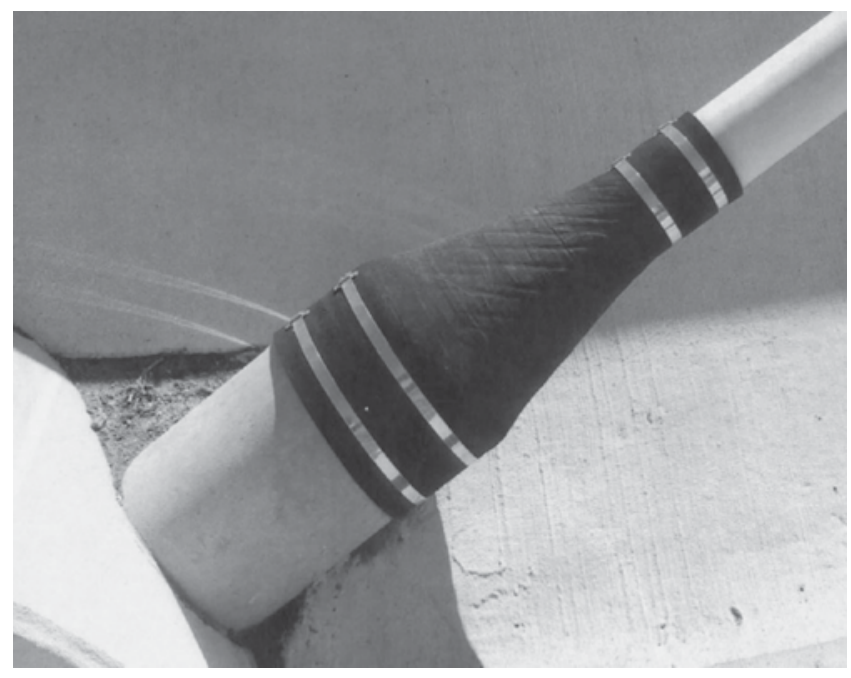

FIGURE 30 Neoprene boot (courtesy: Indiana DOT). inclusion of additional features such as vibration control and force measurements as part of the cable design. This constitutes a "system approach" to the design of stay cables. Embedded corrosion monitoring systems can also be considered as technology develops further.

There have been a number of debates over the years on the issues of corrosion and the overall health of stay cables. In a 1988 article, "Cables in Trouble," Watson and Stafford (1988) presented an alarming picture of the condition of stay cables, indicating that cable-stayed bridges were in serious danger as a result of corrosion. The authors pointed to corrosion (of the Kurt Schumaker Bridge in Germany), vibration (of the Brottone Bridge in France), intersliding of wires, and long-term creep behavior of cables as evidence of serious challenges for cable protection. In response, in a 1991 article, "Cables Not in Trouble," Grant (1991) countered that cablestayed bridges were not in danger of failure from corrosion of cables. Grant reported tests on the Sitka Harbor Bridge in Alaska involving removal of six galvanized structural strand cables and their examination by magnetic, ultrasonic, radiographic, and X-ray methods. All cables were reported in "nearly new condition." Tests were also performed on the Meridian Bridge in California and the Pasco-Kennewick Bridge (Washington State), and the steel elements were reportedly found to be without corrosion.

Saul and Svensson (1991) discussed some of the damage observed on cable-stayed bridges. In the case of the Kohlbrand Bridge in Germany, they reported on the detection during inspections of 25 broken wires on the nongalvanized locked coil cables that were protected with red lead and linseed oil

TABLE 7

SURVEY RESULTS—PROBLEMS WITH NEOPRENE BOOTS (Question 4.24)

\begin{tabular}{lrrccc}
\hline & U.S. & \% U.S. & Canada & \% Canada & \% total \\
\hline Yes & 4 & 14.3 & 1 & 7.7 & 12.2 \\
No & 19 & 67.9 & 6 & 46.2 & 61.0 \\
Not known & 1 & 3.6 & 0 & 0.0 & 2.4 \\
Not applicable & 1 & 3.6 & 3 & 23.1 & 9.8 \\
Other & 2 & 7.1 & 0 & 0.0 & 4.9 \\
No answer & 1 & 3.6 & 3 & 23.1 & 9.8 \\
\hline
\end{tabular}


(Figure 31). The bridge was under construction between 1969 and 1974, and the wire breaks were found in 1976. The authors attributed failures to many factors including misalignment of cables, missing protection at the sockets, cable vibrations, and possible effects of deicing salts.

The Lake Maracaibo Bridge in Venezuela also suffered corrosion of its galvanized locked coil cables after fewer than 18 years of service, and all of its cables were subsequently replaced in 1980 ("Cable Stays ..." 1994). Saul and Svensson (1991) reported that the causes included inadequate maintenance and painting in the hot marine climate and a mistake made in not reinstalling neoprene boots during inspections, which resulted in a humid microclimate. Figure 32 shows the fracture of wires on the Lake Maracaibo Bridge.

Sarcos-Portillo et al. (2003) reported that inspections carried out in 1997-1999 revealed "corrosion in both cables and sockets, as well as considerable settling in the sockets" of the new cables. A "significant" amount of water was also found in most sockets. Vibration-based tension force measurements indicated major force changes. Deck profile changes were also noted. The cables were retensioned, and they recommended painting the cables and waterproofing and lubricating the sockets.
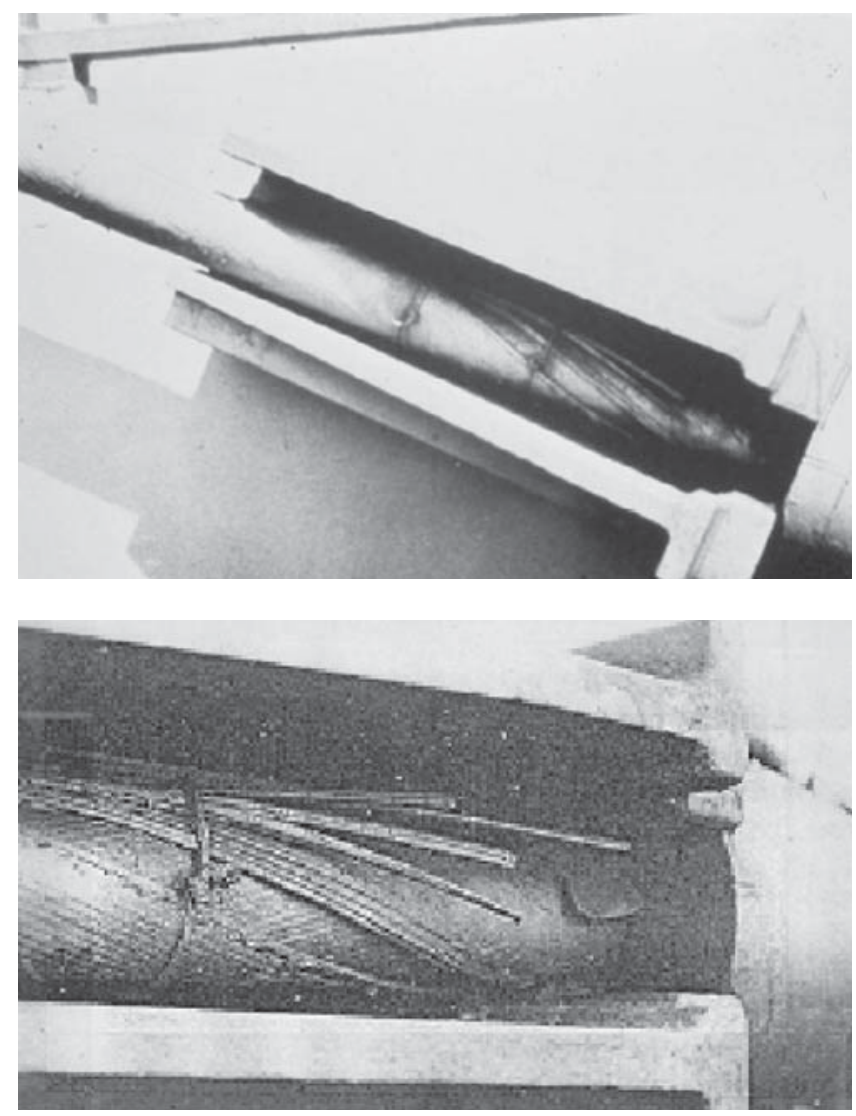

FIGURE 31 Corrosion and rupture of locked coil cable on the Kohlbrand Bridge in Germany (Frank and Breen 2004).
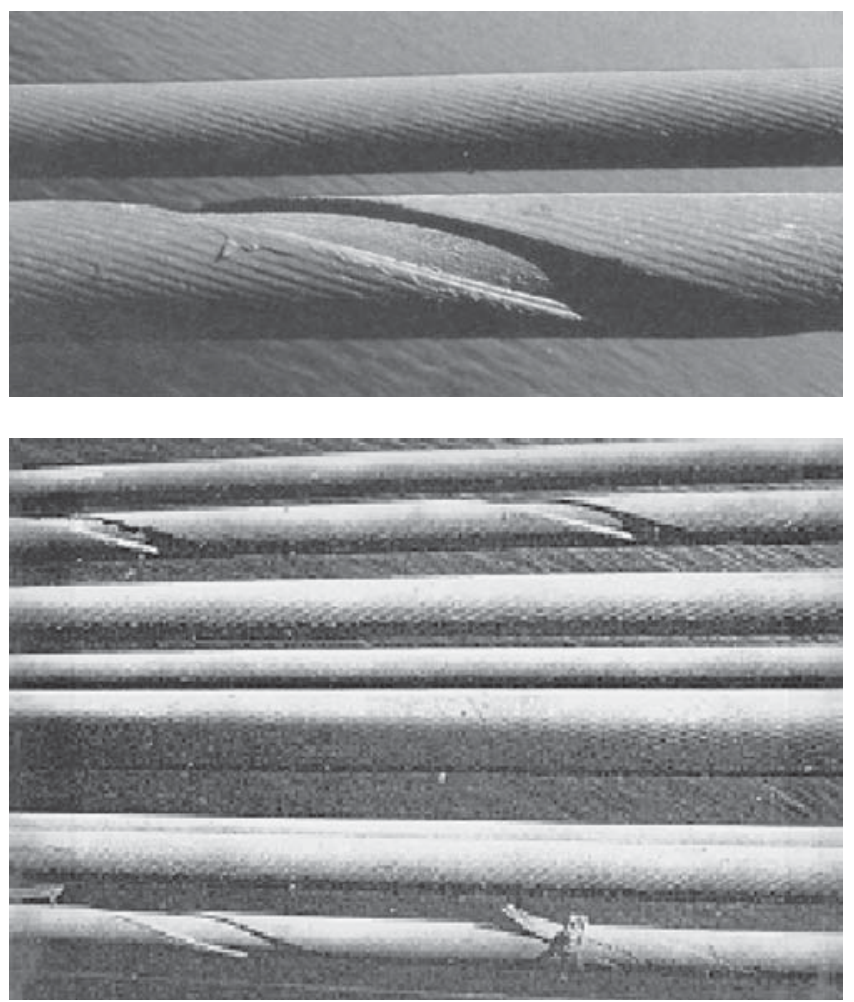

FIGURE 32 Corrosion of locked coil cables of the Lake Maracaibo Bridge in Venezuela (Frank and Breen 2004).

The response to the questionnaire for the Fox Hollow pedestrian bridge in Calgary, Canada, indicated failures of two galvanized bars used as MTEs, and replacement of a third bar. There were no sheathings or grout used on these cables. On further inquiry, the respondent reported that the failures were without any sign of prior problems. An evaluation has reportedly been performed by outside experts and the failure mode was reported as "corrosion induced fatigue." The remaining bars were examined and a third bar was identified with a corrosion pit and replaced. Wire rope cross cables were installed after the failures. No further information was available at this time.

As discussed earlier, Saul and Svensson (1991) reported on the cracking of the grouted HDPE pipes on the Luling Bridge in Louisiana and the twin Zarate-Brazo Largo Bridges in Argentina. The longitudinal cracks in the pipes were attributed to high strains owing to grouting during hot temperatures. Subsequent cooling against hardened grout creates stresses in the pipe. Both bridges used shop-fabricated cables that were delivered on reels. In the case of the Argentine bridges, they were left on reels for up to 3 years. In the case of the Luling Bridge, failures of the butt welds between HDPE segments were also noted, which were attributed to malfunctioning welding equipment and uncoiling at low temperatures. Repair of HDPE in both of these bridges included filling cracks with polyurethane grout and wrapping them with filament tape and PVF tape (Saul and Svensson 1991). 
Telang et al. (2004) reported on inspections of the cables of the Luling Bridge in 2002 and 2004. They reported that, at least in one location, exposed and rusted stay cable wires were detected. The original "epoxy repair" had deteriorated and resulted in the rupture of the protective tape and filler grout and corrosion of wires. Extensive water leakage inside sockets of deck level anchorages was observed. Water dripping from the split rings and shims was observed at most locations. It was suggested that rainwater entered the steel box at the cable exit locations through gaps in neoprene washers. It should be noted that the neoprene washers on the Luling Bridge are different from those described earlier. They surround the sheathing and are caulked to the opening at the top of the box girder (Figure 33).

The caulk that was used around the washers was weathered, cracked, or missing at some locations. Neoprene washers were removed and a video boroscope (videoscope) examination was performed. Accumulated water was found surrounding the cable inside the box. The end caps of sockets were removed to expose the button end of the wires. Figure 34 shows water
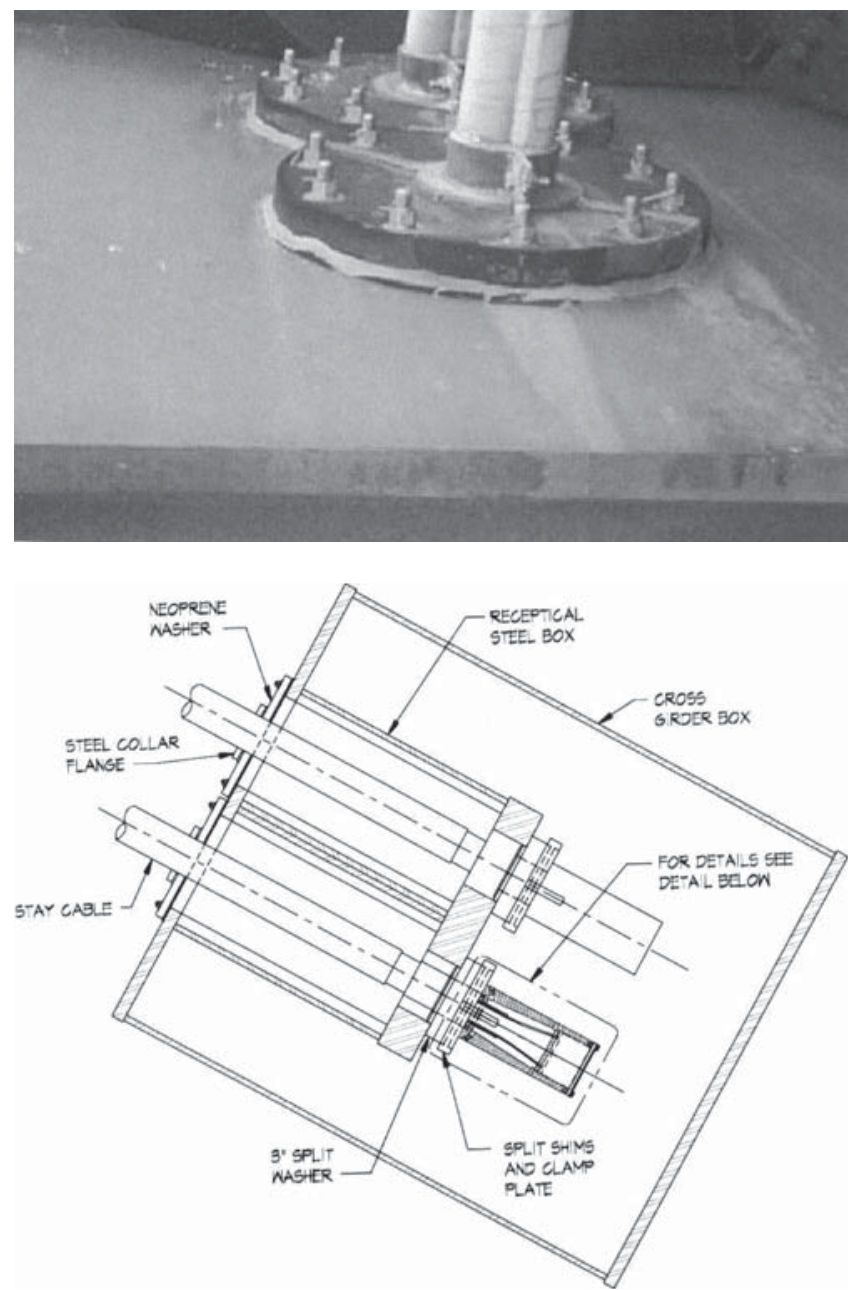

FIGURE 33 Neoprene washers on the Luling Bridge at the exit point of cables from the steel box (Telang et al. 2004).

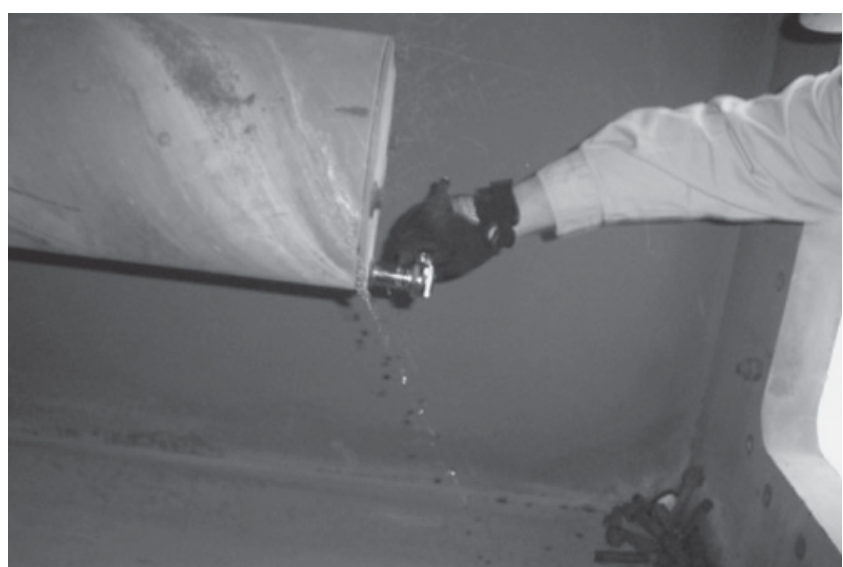

FIGURE 34 Water exiting the end cap of one anchorage (Telang et al. 2004).

coming out of one end cap as bolts are loosened. Various degrees of corrosion were noted in the cables (see Figure 35).

Telang et al. (2004) concluded, based on vibration-based measurements of cable forces, that "the cables have not suffered any significant damage." They do not however discuss whether corrosion damage would necessarily result in global stiffness changes in grouted cables resulting in force changes. Further testing is planned for the Luling Bridge.

In the case of the Zarate-Brazo Largo Bridges, Saul and Svensson (1991) stated "five years after the repair the cables were inspected by the Argentine Federal Highway Administration and found in good condition." It is estimated that the inspection was probably performed around 1987.

In November 1996, the first ever rupture and complete failure of a parallel wire stay cable occurred on the Guazu Bridge in Argentina, one of the two Zarate-Brazo Largo Bridges (Andersen et al. 1999). These bridges were built in the early

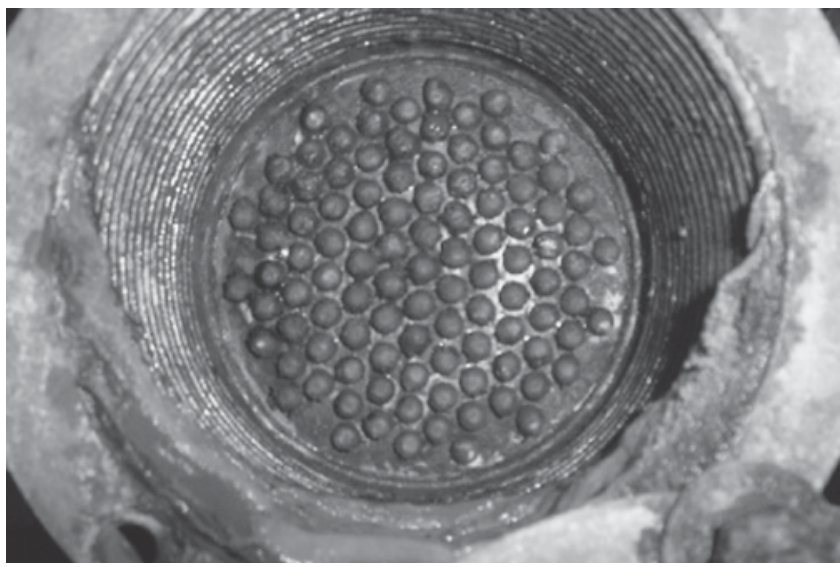

FIGURE 35 Corrosion at the end plate of one socket with wire button ends (Telang et al. 2004). 
1970s. The cable consisted of grouted nongalvanized parallel wires within HDPE pipes and anchored within Hi-Am-type sockets (Andersen et al. 1999). According to the authors, "a combination of corrosion and fatigue has been found to be the cause. The corrosion has taken place due to insufficient corrosion protection of the non-galvanized wires. The likely cause is that the cement grout, which was supposed to be the main corrosion protection, was insufficient in the anchorage zone due to the presence of a non-protecting epoxy tar." They also stated that "following intrusion of water through defects in the PE pipe or due to condensation of water inside the PE pipe, corrosion has been initiated." A complete rehabilitation of the bridge was planned for 1999/2000.

The cable had failed in an area near the entrance to the bottom anchorage. Subsequent ultrasonic testing on other anchorages revealed damage to other cables, with up to $62 \%$ wire breaks. The cable with $62 \%$ wire breaks had adjacent cables with $41 \%$ and $20 \%$ breaks. Damage to bottom anchorages was significantly greater than to top anchorages. Cable force measurements reportedly indicated that forces in the cables had changed by as much as $20 \%$ when compared with forces at the inauguration of the bridge. This however appears to have included the effect of the lost cable, and it is not clear whether the forces at the inauguration of the bridge were actually measured or estimated by the designer. Large amplitude cable vibrations (reportedly not rain-wind vibrations) had taken place on this bridge. During emergency repairs, 13 cables were replaced.

Prato et al. (1997, 1998) reported on the replacement of all locked coil cables of the Chaco-Corrientes Bridge in Argentina. The locked coil cables had external galvanized wires. This bridge was built in 1973. Failure of several Z-shaped wires (in the external layer of wires) on four cables occurred in 1986 and the cables were replaced in 1996.

Reinholdt et al. (1999) reported on the replacement of all wire rope cables of the Luangwa Bridge in Zambia in 1997. The bridge was built in 1968. The shop-fabricated cables were originally made longer than required resulting in a dip in bridge deck surface. This was addressed by installation of "cable clamps" to reduce cable length by approximately $135 \mathrm{~mm}$ (5.3 in.). Severe corrosion and pitting of cables was noted in 1997, resulting in replacement of all cables.
There has been some work done on the corrosion and embrittlement of high-strength wires for suspension bridges, which can be relevant to stay cables as well. Laboratory work by Barton et al. (2000) reported that "corrosion degradation of high-strength wires exceeds mere loss of load-bearing material." Wire strength was reduced more than the cross-sectional area suggesting that "cracking or pitting effects may be present, whether induced by corrosion or by hydrogen interaction, or both." Their studies indicated that hydrogen was absorbed into the corroded wire, with hydrogen retention being higher in galvanized wire. Corrosion results in higher embrittlement of both galvanized and nongalvanized wires.

Mayrbaurl and Camo (2004) reported on a study of structural safety of suspension bridge parallel-wire cables. They discussed issues related to corrosion of galvanized wires, including categorization of wire corrosion in four stages. They also presented cable strength models based on field assessments of wire data. However, unlike stay cables, the primary tool for inspection in main suspension cables is the removal of outside wrapped wire and the physical opening of the cable (insertion of wood wedges) to visually inspect the interior of the cable. Despite some similarities, suspension main cables and stay cable have major differences in design, materials, inspection processes, deterioration mechanisms, and anchorage systems. However, information related to long-term deterioration of galvanized wires is still valuable to the stay cable community.

In 1992, the U.S. Patent and Trademark Office issued Patent No. 5,173,982 to inventors T.G. Lovett and S.L. Stroh for a corrosion protection system for stay cables ("Immersion of Stays . . ."1993). It is designed to keep the stay cable immersed in a lightweight, corrosion-resistant fluid within the cable sheathing. It is not known if this concept has been used on any actual stay cables.

Kitagawa et al. (2001) reported on a dry-air injection system used to reduce humidity levels inside the main cables of the Akashi Kaikyo Suspension Bridge and other bridges in Japan. The system includes salt filters to remove chlorides. Humidity measurements inside the cable reportedly show the effectiveness of the system.

Figure 36 shows survey responses with respect to moisture found inside the stay cable components. Respondents for $25 \%$

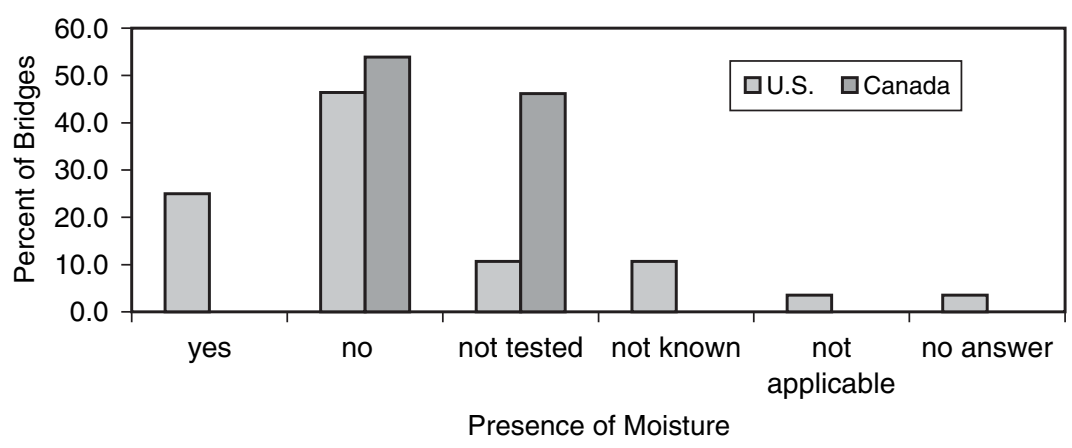

FIGURE 36 Occurrences of moisture inside stay cables. 
of bridges in the United States indicated that moisture has been found inside cables. Another $21 \%$ either have not tested or do not know if moisture exists. Figure 37 shows survey responses with respect to MTE corrosion. Only one U.S. bridge and two Canadian bridges were reported to have evidence of MTE corrosion. The corrosion status of five other U.S. bridges and three Canadian bridges was reported to be unknown. As will be discussed later, assessments of MTE corrosion in cablestayed bridges are, in many cases, very difficult.

\section{Fatigue}

The PTI Recommendations for Stay Cable Design, Testing, and Installation (2001) provide detailed fatigue and static qualification testing requirements for stay cables. Three cable specimens are typically tested for each bridge. These tests include two million cycles of loading, with a stress range of $28 \mathrm{ksi}(159 \mathrm{MPa})$ and a maximum stress equivalent to $45 \%$ of the cable's nominal strength. The number of wire breaks during fatigue tests should not exceed $2 \%$ of the total number of wires in the cable. After fatigue tests, cables are loaded statically to achieve a target load of $95 \%$ of the nominal strength or $92 \%$ of the actual strength of the strands. Some European codes such as the SETRA/CIP require fatigue tests that include a small angle change (rotation) induced at the anchorages. The PTI requirements do not have this provision at this time. The PTI recommendations also specify procedures for axial and flexural tests involving cable saddles. It should be noted however that the PTI qualification tests do not specifically address fatigue issues related to cable vibrations.

In response to the observed rain-wind vibrations on two bridges in Texas, Dowd et al. (2001) began a research project aimed at developing a set of procedures for evaluating fatigue damage in stay cables resulting from large amplitude and rain-wind-induced vibrations. This effort includes testing of cable specimens in the laboratory as they are subjected to axial loads and simultaneous cyclic lateral loads at the mid-point of the cable. The authors reported that similar tests were done in Japan on cables with 163 parallel and galvanized wires with Hi-Am-type sockets and PE pipes (without grout). In the Japanese tests, angle changes of $\pm 1.35^{\circ}$ produced fatigue failures at 0.26 million cycles, whereas no fatigue failures were observed after 10 million cycles for a $\pm 0.9^{\circ}$ angle change.

Frank and Breen (2004) discussed stay cable bending fatigue test results in which performance of grouted and ungrouted stay cable specimens were compared. Bare strands were used and the two cable types were identical except for grouting. The number of wire breaks recorded was much higher in the grouted specimens. The authors suggest that the grout acts as an abrasive that reduces fatigue life resulting from fretting.

Prato and Ceballos (2003) studied dynamic bending stresses near anchorage sockets for grouted cables with HDPE pipes, but with bituminous epoxy replacing grout just before the anchorage (Figure 38). The authors show that the dynamic stresses in wires are higher, and stress concentration occurs, when such a discontinuity is present (i.e., grout is replaced by bituminous epoxy). They noted that shear deformations in such cases would not be negligible, and the dominant discontinuity would be that of shear stiffness and not bending stiffness. Figure 39 shows the results of the survey with respect to fatigue.

\section{Vibrations}

Since the mid-1980s, bridge owners and researchers have reported large-amplitude stay cable vibrations with increasing frequency. This has resulted in increased concern for the fatigue performance of cables. Figure 40 shows vibrations recorded on the Cochrane Bridge in Alabama, and witnessed by this writer.

\section{Categories of Vibration}

The primary types of stay cable vibrations are as follows (Irwin 1997):

- Rain-wind induced vibrations,

- Sympathetic vibration of cables with other bridge components excited by wind (parametric excitation),

- Inclined cable galloping,

- Vortex excitation (single cable or groups of cables),

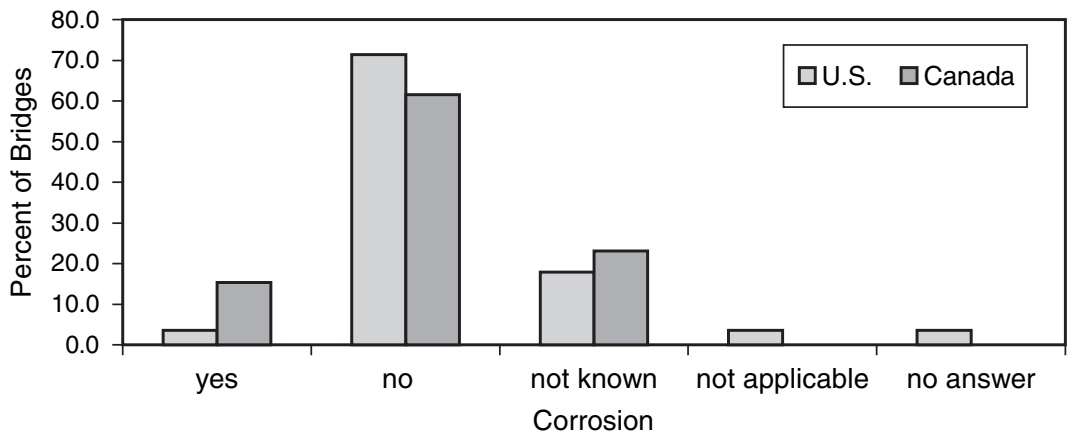

FIGURE 37 Incidence of MTE corrosion. 


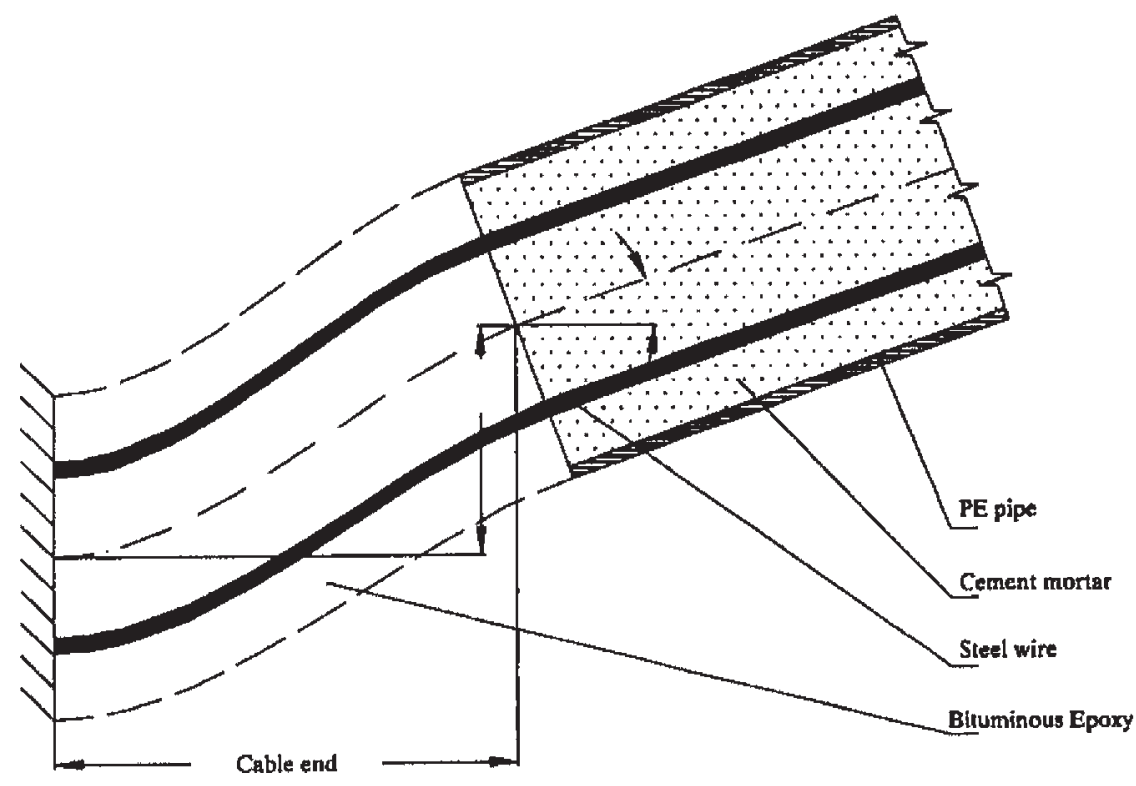

FIGURE 38 Deformations near cable anchorages with discontinuous grout (Prato and Ceballos 2003).

- Wake galloping, and

- Buffeting by wind turbulence.

The rain-wind-induced vibrations are by far the most widely reported, large-amplitude (up to a few feet) vibration phenomenon in stay cables. It was first reported on the MeikoWest Bridge in Japan in 1986 (Matsumoto 2000), and has since been reported on many bridges worldwide. This phenomenon occurs in moderate wind and rain conditions, and is believed to be caused by an aerodynamic instability resulting from the formation of water rivulets on the surface of the cable. However, uncertainties still exist regarding this phenomenon (Matsumoto 2000).

When vibrations are occurring, the speed of the wind is sufficient to maintain the upper rivulet within a critical zone (Irwin 1997). Larose and Wagner Smitt (1999) discussed the results of their wind tunnel studies and reported that rain-wind vibrations were reproduced in the laboratory for a single cable and for cables in tandem configuration. They also reported that the rivulet changes its position with wind speed and also cable motion. Miyazaki (1999) reported that the lower rivulet is formed at lower wind speeds, and both rivulets appear at higher speeds. This is consistent with what this writer observed on the Cochrane Bridge in 1998. In this case it was the lower rivulet that appeared first; however, it was the subsequent formation of the upper rivulet that initiated large amplitude vibrations. Also, the rivulets appeared to oscillate up and down within a "wet" band as they moved down the cable (Figure 41).

Larose and Wagner Smitt suggest that the "wetability" of the cable surface is important in the formation of rivulets. They noted that a slightly eroded surface with dust particles is more "wetable," and thus can form the rivulets more easily. This may be the reason why some bridges do not experience rain-wind vibrations for the first few years of their service. According to Swan (1997), "a very smooth surface may initially avoid the problem, until atmospheric deposits allow just enough roughness to hold the rivulet."

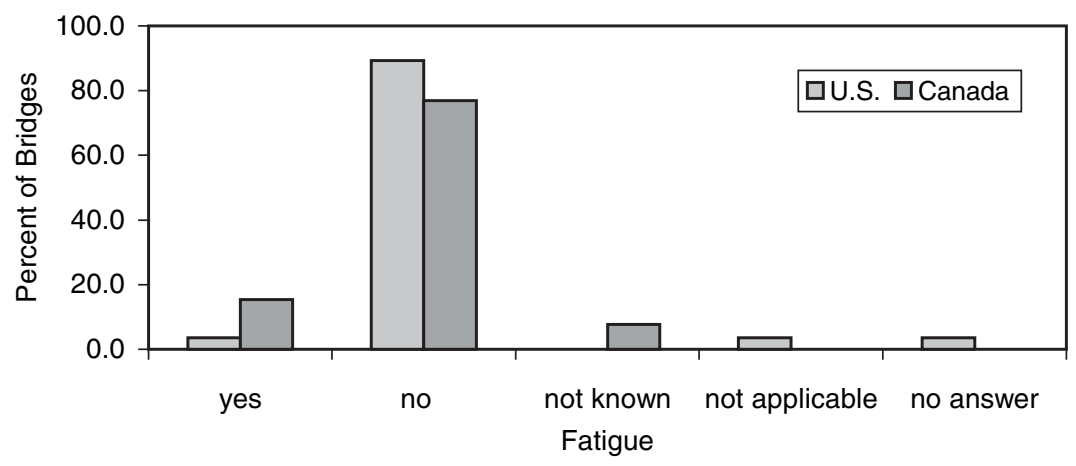

FIGURE 39 Incidence of fatigue of MTEs. 


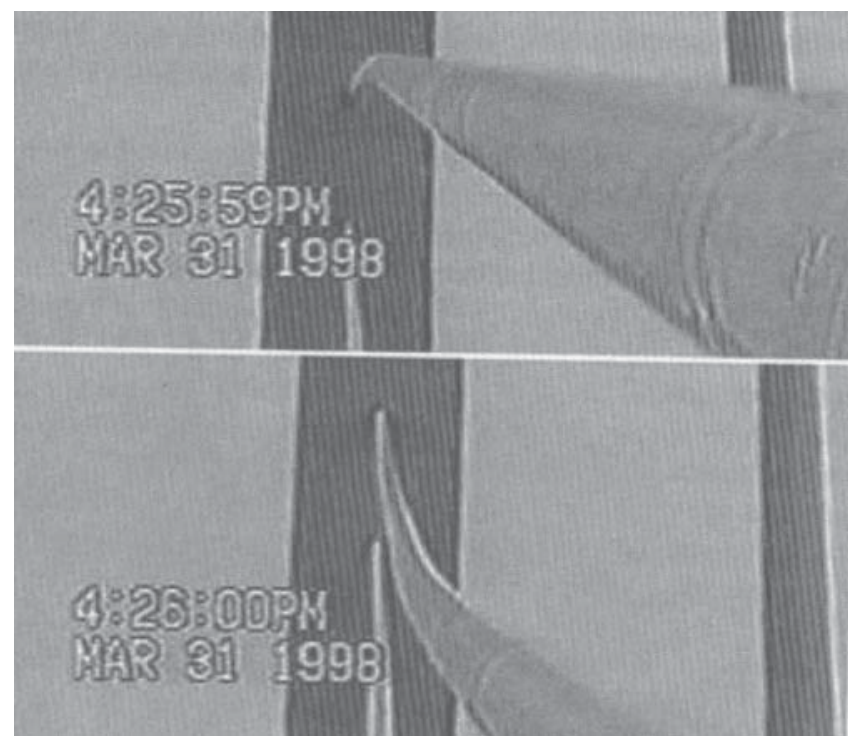

FIGURE 40 Large amplitude vibrations of the Cochrane Bridge (Alabama) (Telang et al. 2000).

Jones and Porterfield (1997) reported on the instrumentation and long-term vibration monitoring of the East Huntington Bridge in West Virginia. They reported random buffeting response, locked-in vortex-induced vibration, and rainwind oscillations. They noted that significant displacement responses are in the lower modes of the structure. High acceleration values at higher modes do not mean high displacements at those frequencies (acceleration amplitudes are equivalent to displacement amplitudes multiplied by frequency squared). Main and Jones (2000) also reported on the instrumentation and long-term vibration monitoring of the Fred Hartman and Veterans Memorial Bridges in Texas. Figure $42 a$ shows a sample histogram of dominant modes for one stay cable, and Figure $42 b$ shows vibration amplitudes versus wind speed for the same cable.

Main and Jones (2000) concluded that the highest amplitude responses (which occurred during rainfall) were in the lower modes and "seemed to 'lock-in' to a specific mode of vibration over a wide range of wind speeds." High-frequency vibrations over narrow wind ranges were also observed, which

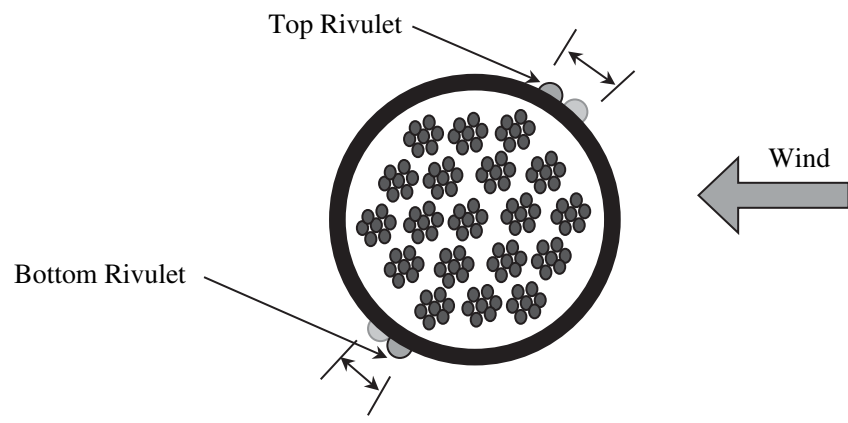

FIGURE 41 Position and movements of water rivulets during rain-wind vibrations. were attributed to vortex-induced vibrations. Tabatabai et al. (1998a) and Lankin et al. (2000) have reported on vibration measurements and mitigation efforts for the Cochrane Bridge in Alabama. In these studies, the level of damping in all cables was measured and studies were performed to determine and optimize mitigation solutions.

Irwin (1997) recommended the following equation for controlling rain-wind vibrations:

$S_{c}=\frac{m \zeta}{\rho D} \geq 10$

Eq. 1

where

$$
\begin{aligned}
& S_{c}=\text { Scruton number } \\
& m=\text { mass per unit length of cable, } \\
& \zeta=\text { damping ratio, } \\
& \rho=\text { density of air }\left(1.225 \mathrm{~kg} / \mathrm{m}^{3}\right), \text { and } \\
& D \text { is the cable diameter. }
\end{aligned}
$$

This equation has been adopted in the PTI Recommendations for Stay Cable Design, Testing, and Installation (2001) for control of rain-wind vibrations.

Tabatabai and Mehrabi (2000) used cable information from 16 cable-stayed bridges to determine the level of damping required based on Eq. 1. Figure 43 shows a histogram of required cable damping for all stay cables in those 16 bridges. These data indicate that $90 \%$ of the cables would meet the requirements of Eq. 1 with a damping ratio of $0.7 \%$. The authors suggested that the typical first mode damping ratios for cables are in the range of $0.05 \%$ to $0.9 \%$. Similar data for control of inclined cable galloping is also provided.

Incidences of large amplitude cable vibrations have also been reported when there is no rain, and typically at higher wind speeds. There is debate and uncertainty regarding the exact nature of all of the events that fall under this category of vibrations. It is known that cable vibrations can occur when deck or tower vibrations are occurring at frequencies close to the cable frequency (Stubler et al. 1999; Wu et al. 2003). This is also called "parametric vibrations" or "local parametric vibrations" by some investigators. Wu et al. (2003) reported that parametric vibration has been confirmed on three bridges in Japan, including the Tatara Bridge. Irwin (1997) discussed the possibility of inclined cable galloping based on the work of Saito et al. (1994) in Japan. Although circular cross sections do not gallop when aligned normal to wind (Starossek 1994), Irwin provides a possible explanation in that the wind would "see" an inclined cable as an elliptical section, and thus be able to gallop. This phenomenon has been investigated in wind tunnel tests and it was determined that separate requirements to address this phenomenon are not necessary.

Until recently, there were no vibrations reported on the Sunshine Skyway Bridge, which joins St. Petersburg and 


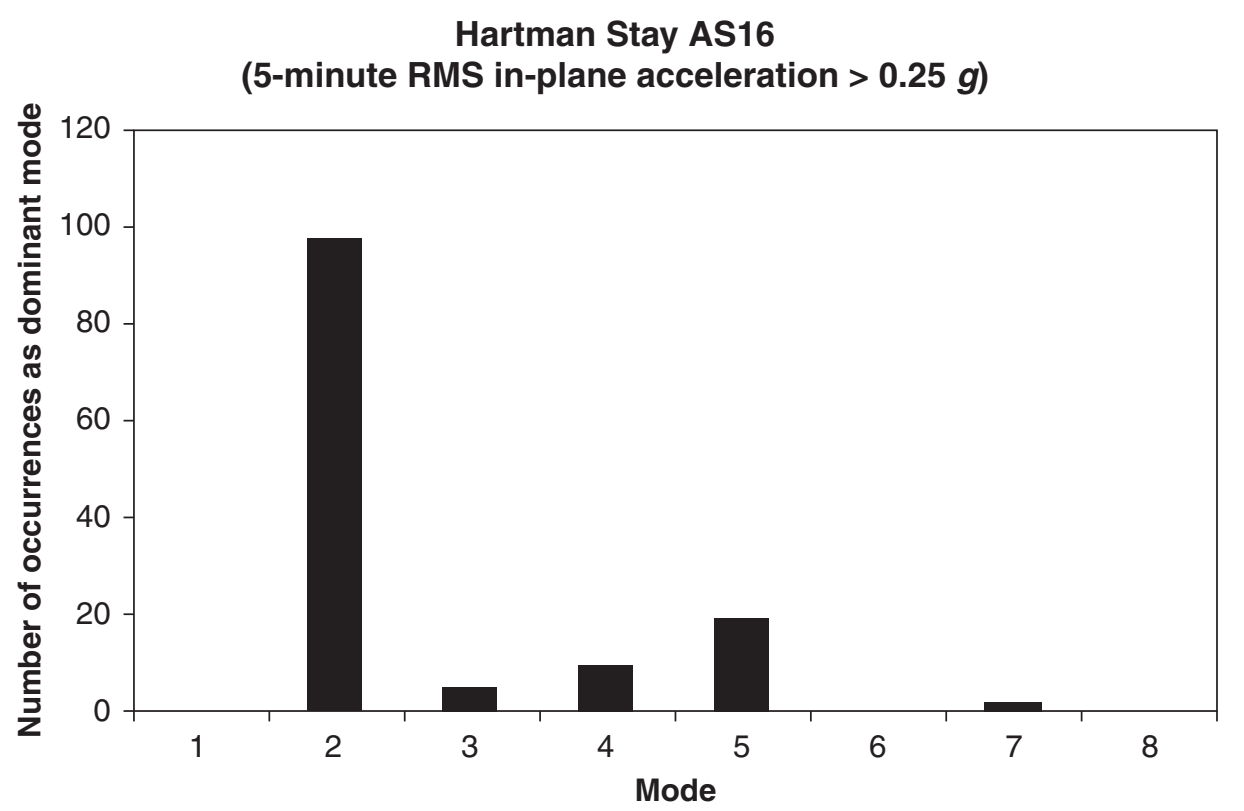

(a)
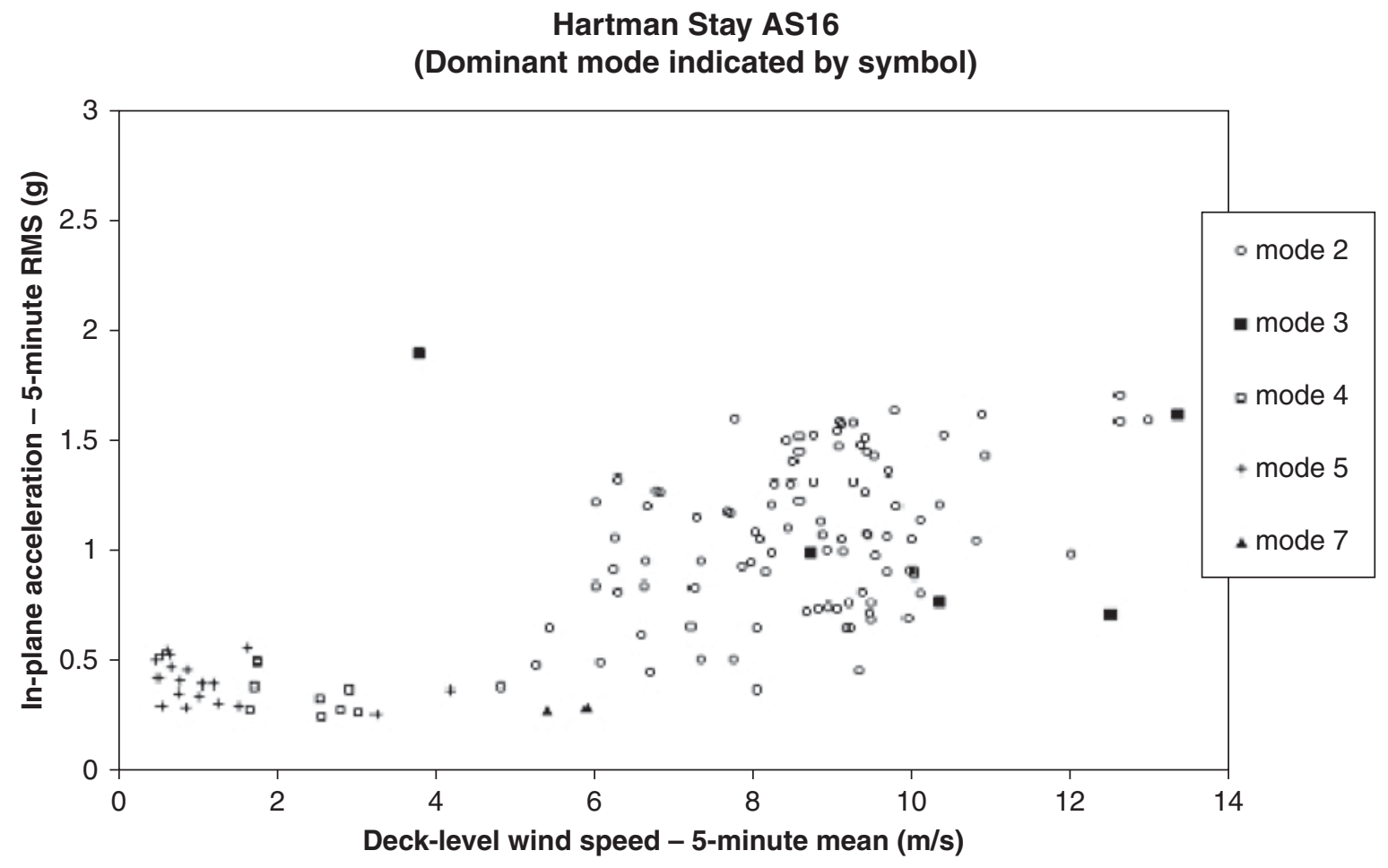

(b)

FIGURE 42 Vibration data from Fred Hartman Bridge: (a) histogram of modes, $(b)$ vibration amplitudes (Main and Jones 2000).

Bradenton in Florida, whether rain-wind or otherwise. This bridge was opened to traffic in 1987 , has grouted parallel strand cables with steel sheathing, and has two-dimensional viscous dampers (shock absorbers) installed on each cable. On April 12, 2004, Florida DOT personnel noted smallamplitude vibrations on one of the longest cables of the bridge (personal communication, S.D. Womble, April 14, 2004). It was reported that, according to National Oceanic and Atmo- spheric Administration records, a sustained wind of $72 \mathrm{kph}$ (45 mph) and gusts of up to $96 \mathrm{kph}(60 \mathrm{mph})$ were present in the area. Wind was blowing at 90 degrees to the structures (perpendicular to cable plane). There was no rain, and estimated vibration amplitudes of up to $75 \mathrm{~mm}$ ( $3 \mathrm{in}$.) were reported. It should be noted that the reported amplitudes in this case are far smaller than amplitudes typically reported for rain-wind vibrations in other bridges. 


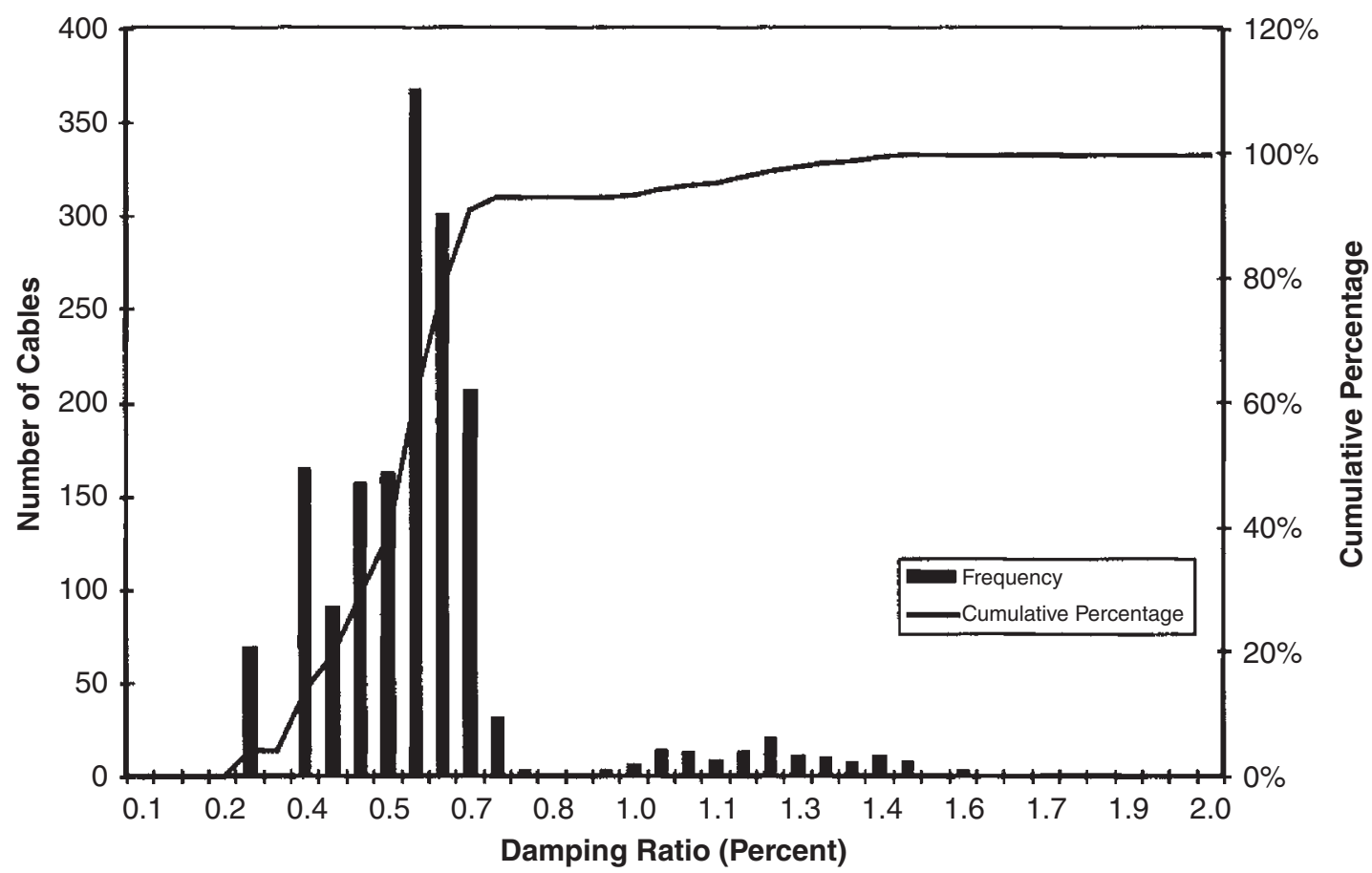

FIGURE 43 Histogram of required damping ratio for controlling rain-wind vibrations (Tabatabai and Mehrabi 2000).

Vortex excitation is likely the most common form of cable vibration, with the cables vibrating at lower displacement amplitudes and higher frequencies (mode 5 and higher) (Main and Jones 2001). Therefore, this mode of vibration is not as significant a risk to stay cables as rain-wind vibrations. Vortex-induced vibrations have been noted on the Tatara Bridge in Japan (Yamaguchi et al. 1999).

When cables are positioned in the wake of towers or other cables, they can have large amplitude wake galloping vibrations. However, the wake galloping that could occur in stay cables is typically characterized by very small cable spacing, on the order of six cable diameters (Miyazaki 1999).

Bruce et al. (1987) reported on the aerodynamic monitoring of the Luling Bridge in Louisiana 3 years after the open- ing of bridge to traffic. They noted vortex shedding and wake-induced effects. However, they also reported a first mode response of stays to "either galloping or bridge deck motion."

The responses to the questionnaire indicated that a sizable number of cable-stayed bridges included in the survey have experienced rain-wind vibrations. These bridges are the Cochrane Bridge in Alabama; Talmadge Memorial over the Savannah River in Georgia; Clark in Alton, Illinois; Burlington in Iowa; Veterans Memorial between Bridge City and Port Arthur in Texas; and Fred Hartman in Houston, Texas. In Canada, the Prince's Island and Fox Hollow bridges (Alberta, Calgary), and the Hawkshaw, Longs Creek \#1, and Nackawic River bridges (New Brunswick) have reportedly been affected. Figure 44 shows the results of the survey as related to rain-wind-induced cable vibrations. It is interesting

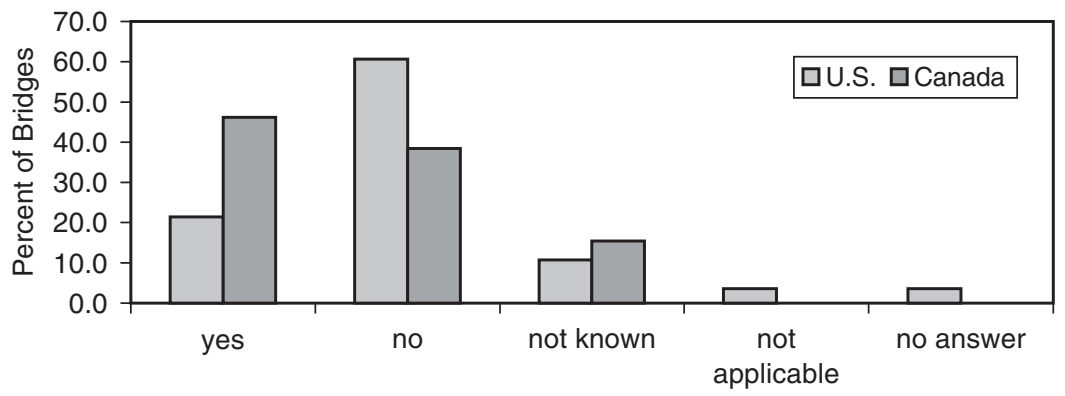

Rain-Wind Vibrations

FIGURE 44 Rain-wind induced cable vibrations. 
to note that the survey response for the Fox Hollow Bridge indicated rain-wind vibrations even though the stay cable is made of exposed threadbars, which would not likely promote the formation of water rivulets. It may be that, in this case, other vibration types have been mischaracterized as rain-wind.

Figures 45 and 46 show survey results with respect to the use of viscous dampers and cross cables. It appears that the most popular method of vibration control is the use of cross cables. Nearly one-third of the bridges in the United States and about one-quarter of the bridges in Canada have cross cables for vibration control, either installed from the beginning or retrofitted later to control vibrations.

Viscous dampers are used in the United States by six bridges $(21.5 \%)$ and in Canada by three bridges $(23.1 \%)$. In some bridges such as the Fred Hartman Bridge in Texas, both viscous dampers and cross cables are added (retrofitted) to control vibrations. In the Cooper River Bridge in South Carolina, viscous dampers will be installed, but provisions for future installation of cross cables are made in case they are needed. Figure 47 shows the survey results with respect to the use of other types of dampers.

\section{Extreme Events}

There are a number of extreme or unusual events that could affect the performance of stay cables including earthquakes, fire, blasts, impacts, and ice build-up. The earthquake design issues are generally handled through a global analysis of the entire cable-stayed bridge. However, during the fall 2004 meeting of the PTI cable-stayed bridge committee, David Goodyear noted that there potentially are cases when during an earthquake the tension force in a cable can rapidly decrease to zero or even compression. This impact loading, in a direction opposite to how the cable anchorage is designed to resist may result in permanent dislocation and damage to some crucial anchorage components, potentially rendering them ineffective and resulting in failures. Specifically, wedge systems could be affected where there is no significant resistance to forces that would push the wedges out of their positions within the anchorage plates. This issue may be considered by the stay cable community and studied further. However, there have not been any reported cases where this scenario has materialized.

During an oral presentation at a stay cable seminar, Zoli and McCabe (2004) reported on issues related to fire, ice, and impact on stay cables. They reported that there have not been major fire incidents involving cable-stayed bridges. However, six major Interstate highway fires have occurred, resulting in significant cost and extended closures of major arteries. Zoli and McCabe suggest that wedge anchorage systems would be more resistant than some other anchorages. Zinc-filled sockets are temperature sensitive and contain materials with low melting points. Possible mitigation measures include utilization of fire-resistant cable sheathing near deck level, intumescent paints, ablative coatings, ceramics and composites. According to Zoli and McCabe, there are currently no code provisions in the United States addressing fires on bridges, although the Eurocode includes some provisions.

Regarding the effects of icing on cables, Zoli and McCabe noted that ice formations on a major suspension bridge have been periodically removed as a safety precaution. They reported on research being done on the issue of icing of cables, including assessments of sheathing performance and icing wind tunnel tests. The effects of icing on galloping vibrations of stay cables need to be studied. They discussed "icephobic" coatings and ultrasonic deicing systems.

Regarding impact, Zoli and McCabe discussed a number of approaches including cable "armoring" involving hybrid ceramic FRP materials.

\section{Inspectability and Maintainability}

Question 11 in the survey questionnaire asked agencies the following: what do you see as the single most important prob-

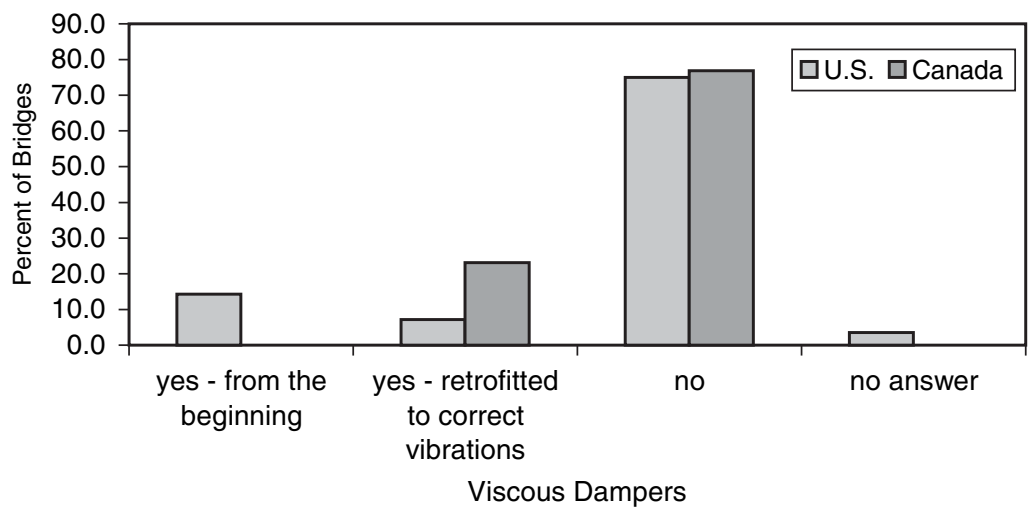

FIGURE 45 Percentage of bridges using viscous dampers. 


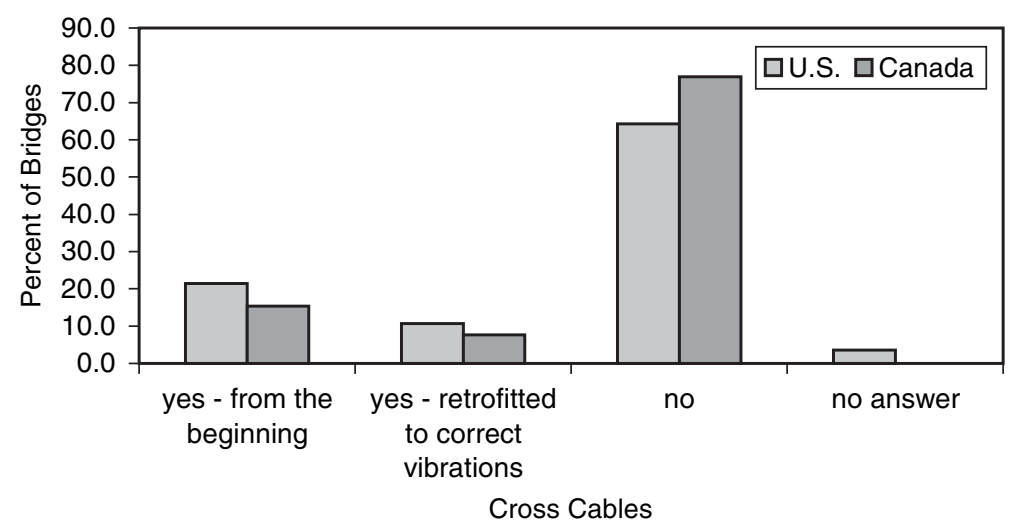

FIGURE 46 Percentage of bridges using cross cables.

lem in stay cable maintenance? The great majority of answers mentioned accessibility and inspection problems, especially in the anchorage areas. The general consensus of the respondents points to a concern by the owners about difficulties in access for inspections and maintenance. It should be noted that although there is general agreement by the stay cable community about the need to address the stay cable maintenance issue and problems, there is no universal consensus on this issue, especially with the characterization of the subject as a "problem" as indicated by one respondent. The following are some of the answers provided by respondents:

- Access and rain-wind induced oscillation.

- Access to upper anchorage.

- Inspection and condition evaluation of anchorages.

- Effective corrosion barriers that do not interfere with the ability to adequately inspect and assess the health of the cable stay system on a regular interval and within practical means.

- Accessibility for inspection and maintenance.

- Access to the cable anchorages.

- Uncertainty of cable condition and anchorages.

- Inspection, access, testing, and cost.

- Inability to inspect the elements inside the cable and anchorage areas.
- Inspecting the cable anchors and grout-filled cables.

- Hidden nature of the system.

- Access for inspection.

- Integrity of the stays. Grouted cables are impossible to inspect with a nondestructive technique (i.e., one that does not require removal of sheathing and grout); therefore, it is impossible to identify corrosion problems early.

- The largest "problem" with stay cables is that they are widely perceived of as "a problem" rather than just another bridge member with specific needs and characteristics. Stay cables have been placed unnecessarily "on a pedestal." Although they are a very important bridge member, in current designs they are highly redundant, overtested, and (relatively) easily replaced. There is no other major bridge member that fits into all three of these categories. Let us not promote the feeling that stays are "a maintenance problem."

- Provide end caps that are easily removed and fully protected against corrosion.

- Ability to determine the effectiveness and remaining life of corrosion protection systems for main tension elements. The configuration and construction techniques make evaluation and inspection using nondestructive techniques almost impossible.

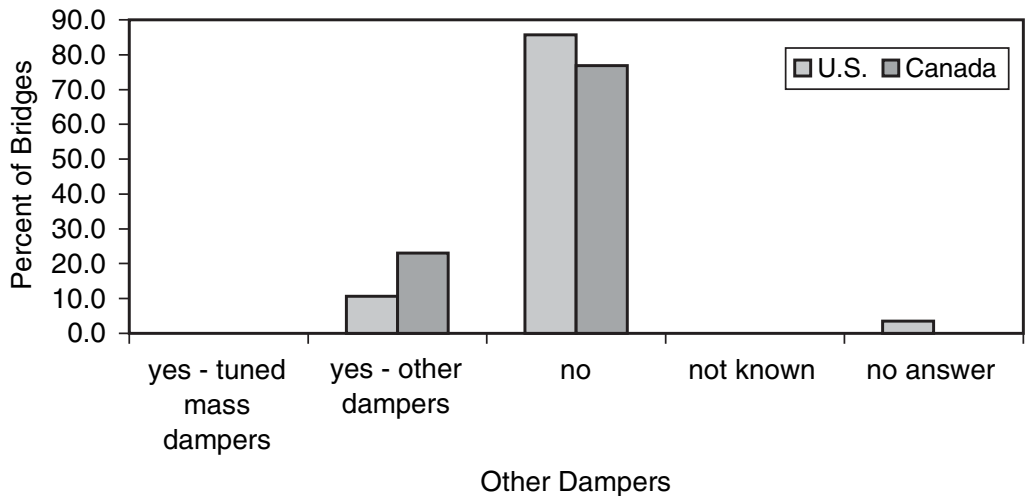

FIGURE 47 Percentage of bridges using other types of dampers. 
- Lack of familiarity with this type of construction by the department's staff, which requires assistance from the consultant community in the inspection of these elements.

- Cannot inspect cables without pulling strand every 10 years.

- Access for inspection and actual testing.

- Detection of corrosion in cables; maintenance of sheaths and boots.

- Corrosion at the anchorages.

- Migration of water into cable strands.

- Fatigue.

- Inspectability in the anchorage area.

The anchorages are typically unreachable except from the deck by special "reach-all" trucks (see Figure 48). Some newer bridges (such as the Cooper River Bridge) incorporate anchorages that are at about deck level. The end caps are generally difficult to remove, especially when filled with grout or epoxy. Even when the end caps are removed, the condition of MTEs within the anchorage area and beyond cannot be examined visually. If moisture were to enter the cable along its length, gravity would likely force it down to the bottom anchorage. There is currently no easy way to check for the presence of moisture or corrosion in the bottom anchorage, except through removal of the cap. Massive reinforced concrete or steel superstructure elements that are designed to resist anchorage forces typically surround the anchorage zones. Therefore, the sides of the anchorage zones are generally neither visible nor accessible all the way up to the top of the neoprene rings and boots.

Some recent anchorage designs (such as the 6th Street bridges in Wisconsin) have incorporated individually coated and sheathed strands that reportedly allow for future replacements of individual strands (one by one). Some recent bridges also include additional strands in the cables that are designed for removal at 10 to 15 year intervals for inspection. In some cases, allowance is made in the cables to add new strands, if needed. Permanent access platforms for use by inspectors are also an important consideration.

Question 5 in the survey asked whether the current inspection, testing, monitoring, and repair methods were effective

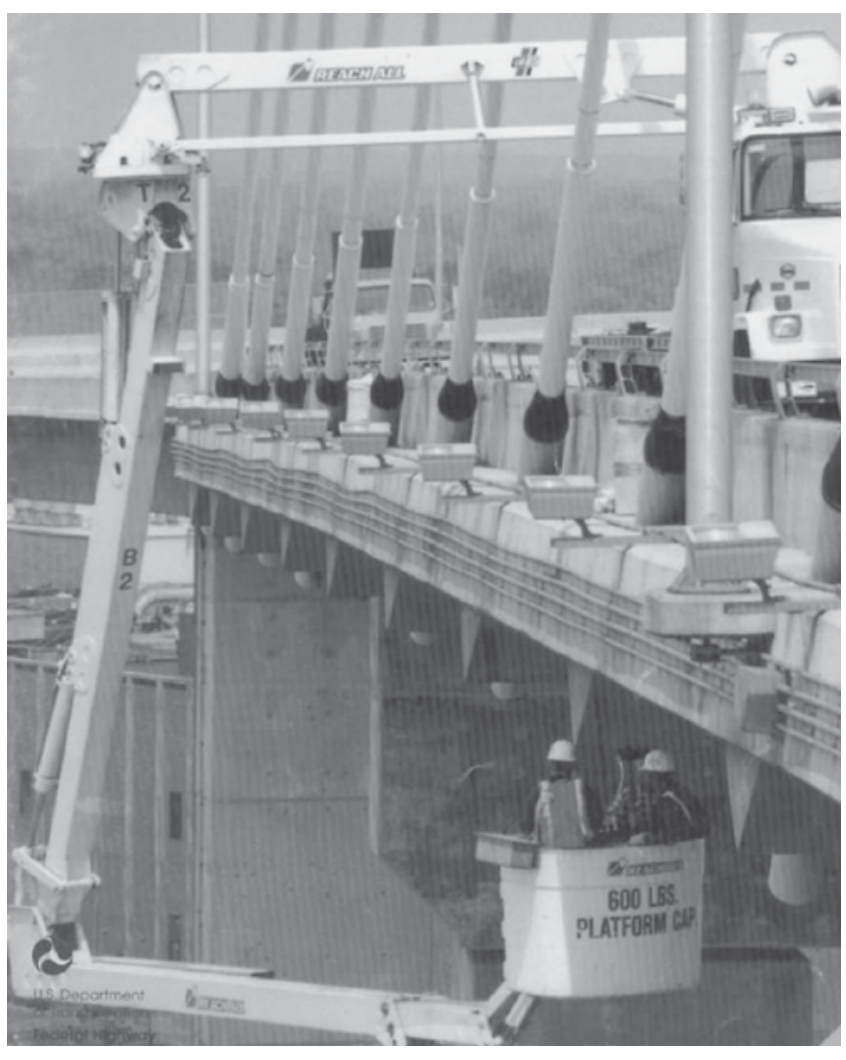

FIGURE 48 Access to cable bottom anchorage for ultrasonic testing.

and adequate. Figure 49 summarizes these responses. The U.S. respondents were far less certain than their Canadian counterparts, with less than $40 \%$ believing that they have effective and adequate methods available. One of the respondents indicated that for cables with steel sheathing the inspection methods available are limited. Another respondent referred to problems in inspection of anchorage areas and expressed the need for a technological breakthrough to address this problem.

One important question in the maintainability of a cablestayed bridge is whether the cable (or individual strands) can

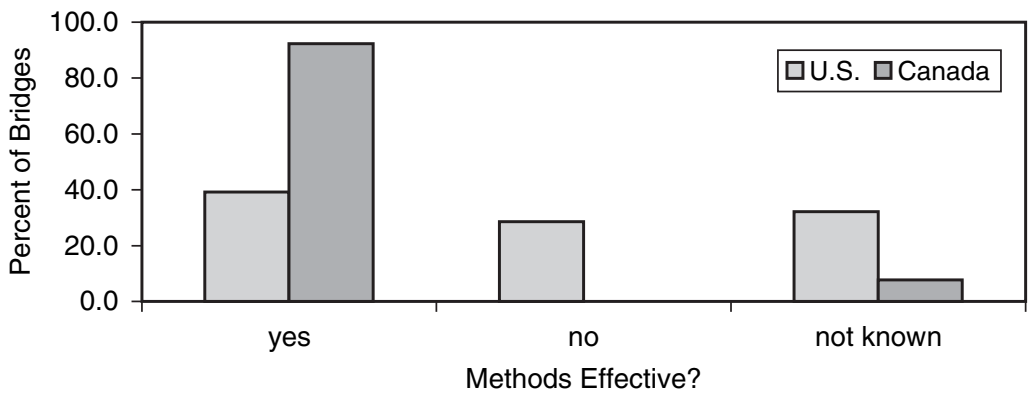

FIGURE 49 Respondents reporting that inspection, testing, monitoring, and repairs are effective and adequate. 


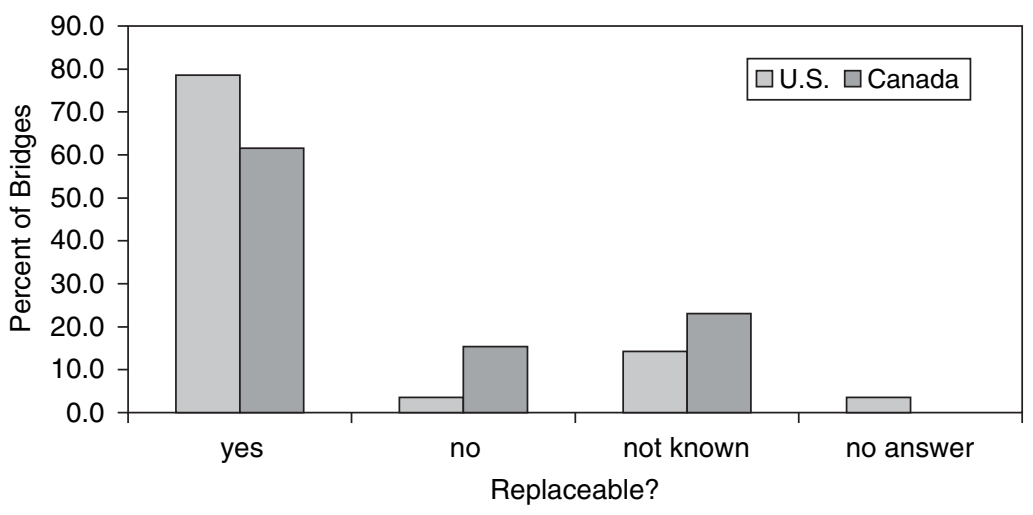

FIGURE 50 Can the cables (or strands) be replaced?

be replaced, if needed. In the opinion of respondents for $79 \%$ of U.S. bridges and $62 \%$ of Canadian bridges, the answer to this question is "yes." Figure 50 summarizes the survey results for this question.

Another question in the survey asked whether there is an inspection and maintenance manual for the bridge. Figure 51 shows the results of the survey for this question. The great majority of U.S. bridges $(71 \%)$ have maintenance manuals; however, more than $92 \%$ of Canadian bridges do not. As will be discussed later, there is a wide variation in topics discussed in individual maintenance manuals.

Survey question 10 asked whether an up-to-date resource such as a national database of information on stay cable inspection, repairs, and testing would be a useful tool. Figure 52 summarizes the responses. An overwhelming majority of responses (approximately 90\%) in both the United States and Canada responded in the affirmative.

There was a wide variety of answers provided to the survey question on what the cable suppliers should incorporate into their systems to make them accessible and inspectable. The following are some of the suggestions:
- Transparent outer pipe, eliminate grout.

- Current grouted and sheathed systems do not allow for visual inspection. New stay systems (perhaps ungrouted, unsheathed systems consisting of bare corrosionresistant tension members) need to be developed that allow for inspection of the entire stay length. Research is also needed to develop rapid, economical nondestructive evaluation (NDE) methods to determine conditions of stay cables.

- Access is a very sharp two-edged sword. If you can more easily access the cable, so can corrosive elements (not to mention potential terrorist/security considerations).

- Include a maintenance manual with clear instructions for both specific wires or full cables.

- Perhaps a permanent load cell that would permit realtime readings of cable forces at any time during the life of the bridge.

- Our cables are reasonably accessible, inspectable. Possibly a closeable drain at the lower end of the cable to allow visual inspection, sample collection, testing for corrosion product of any water in the cable sheaths.

- Different corrosion protection system at the anchorages that permits easier visual inspection. Removable sections of the HDPE and Vandal Tubes would make it easier to inspect strands near the anchorages.

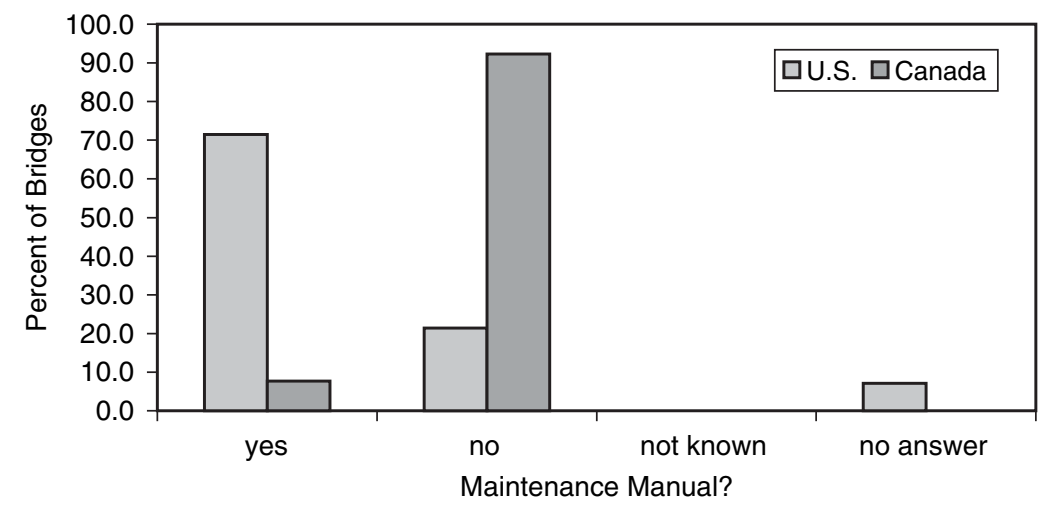

FIGURE 51 Bridges with an inspection and maintenance manual available. 


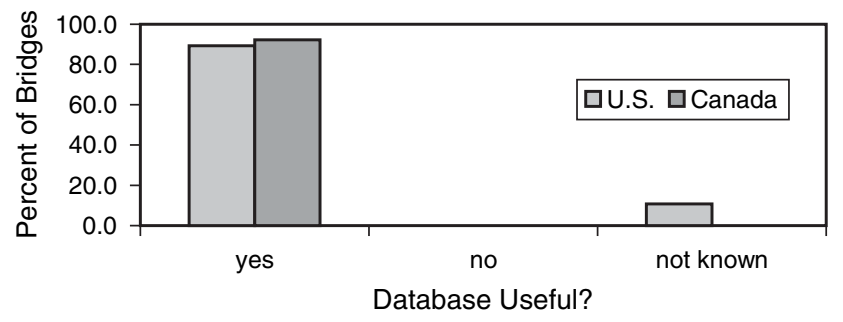

FIGURE 52 Would a national database of stay cable information be useful?

- I like the idea of hermetically sealed, ungrouted cables with fiber optic sensors throughout or exposed wire that can be directly inspected.

- Provide access on inside and outside of tower anchorage.

- Fiber optic strain gauges and redundant systems.

- We would recommend the development of individual strand monitoring capabilities that encompass the strands from anchorage to anchorage.

- For non-box bridges, an inspection traveler should be installed on the cable-stayed bridge. This should be done by the owner.

- Not possible that the cable suppliers can do any more.
- Ability to detension, inspect, and retension individual strands; ability to add strands to each cable or cable group (5\%).

\section{FABRICATION AND ERECTION OF STAY CABLES}

As discussed in the previous section, stay cables can be either shop- or field-fabricated. In United States practice, and especially in recent years, field fabrication has been more common. The shop-fabricated cables come with the entire cable, including anchorages and sheathing pre-assembled and coiled on reels. The cables are then uncoiled and lifted into place. If fillers are required, they are generally placed or injected after stressing of cables. In this arrangement, the entire cable must be stressed with one large hydraulic jack. The fieldfabrication method generally involves inserting strands one by one into the wedge plate in the bottom anchorage and, through various methods developed by cable suppliers, the strands are pulled through the top wedge plate. The strands are typically stressed one at a time using a single-strand jack. If required, the cable fillers (e.g., grout) would then be injected into the anchorage zones (in the case of bond socket) or the entire cable. 


\section{INSPECTION AND MONITORING TECHNIQUES}

In this chapter, various inspection and monitoring techniques for stay cables are discussed, including their advantages and disadvantages. Figure 53 shows survey results with respect to the types of nondestructive tests performed on the cables. The most commonly used method is the vibration-based force measurement. However, the largest group belongs to the "not performed" category.

Figure 54 shows the survey results with respect to the types of sensor-based, long-term monitoring on the cables. Three respondents' bridges in the United States and one in Canada incorporate acoustic wire break detection, whereas two respondents in the United States and one in Canada incorporate long-term vibration monitoring.

Question 6 in the survey asked respondents to comment on the effectiveness of any nondestructive test methods for stay cables of which they are familiar. Some of their comments are given later in this chapter. Others are provided here:

- Several nondestructive tests were run after an extreme oscillation event. Practically all of the methods cited in Question 6 were performed to determine if there was any loss of force in the stays. Geometric, physical, and visual tests were performed. The only discoveries were deficiencies in the original construction, which were corrected.

- The fundamental frequency of the cables was recorded. Alaska DOT\&PF (Department of Transportation and Public Facilities) will monitor the cables and attempt to determine if the fundamental frequency of the cables has changed.

- The presence of the steel protective pipe limits the effectiveness of many available testing methods, particularly magnetic-based methods. Implementation of laser-based cable stay force measurements are being considered by the department to establish baseline force data for the cable stays.

- Nondestructive testing is needed to determine the condition of tension bars inside the steel casing of the cables.

- The only problem is the anchorage area. So far, no method is available for inspection. I see additional problems with inspection of the grout-filled cables.

- Vibration-based cable load determination - effective and inexpensive; X-ray - expensive, slow, very questionable ability to detect wire defects; magnetic inspectionused to rapidly, effectively inspect mine cables_-but the cables move past the inspection unit, which would need to be reversed on a cable bridge; impulse radar-good for detecting grout defects; sonic methods-dampened to the point of being ineffective.

- Four single strands are to be removed (one at each pylon) for inspection for rust every 10 years, starting in year 2014.

\section{SHORT-TERM EVALUATION AND MONITORING}

This section covers methods that can be used during limitedduration inspections of stay cables. The currently available methods, as well as new and promising technologies, are categorized and explained. The techniques that are addressed include conventional visual/manual techniques, and magnetic, ultrasonic, X-ray, laser, acoustic, and remote or contact vibration-based techniques.

As discussed earlier, Mayrbaurl and Camo (2004) reported on a study of structural safety of suspension bridge parallelwire cables. They concluded that there were currently (as of 2004) no effective NDE methods for the condition assessment of parallel wire main cables of suspension bridges. Instead, they focused their efforts on manual unwrapping and opening of cables for their evaluations.

\section{Visual Inspections}

Visual inspections are the most common approach used on stay cables. Surveys completed by a number of respondents indicated a preference for visual inspections (when feasible) and a desire to see stay cable designs that can be visually inspected.

Some bridges have dual inspection schedules, a routine inspection at 2-year (or less) intervals, and more detailed inspections at longer intervals. In the case of the Faroe Bridge between Sealand and Falster in Denmark, a three-step inspection process is used (Bloomstine and Stoltzner 1999). The bridge master performs a drive-through inspection every day. Various bridge components are inspected at yearly intervals, so that the inspection of the entire bridge is completed in a 5 -year cycle. Special inspections are done if damage is noted.

During typical inspections of stay cables, the entire surface of the cable is visually inspected at close range, followed 


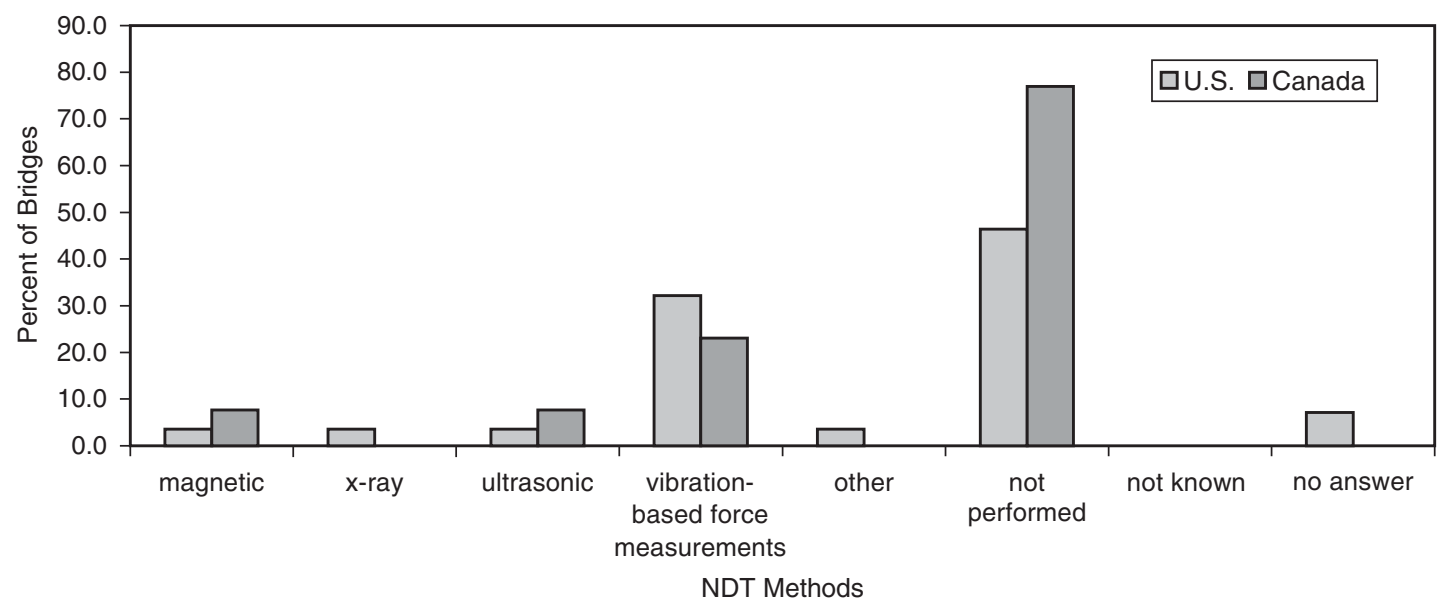

FIGURE 53 Types and levels of nondestructive testing on stay cables.

by an inspection of neoprene boots and neoprene rings (by removing neoprene boots), visible surfaces of guide pipes, and accessible anchorage surfaces. General visual inspections of stay cables typically involve the following:

- Identification of longitudinal or transverse cracking or excessive bulging in the sheathing, as well as damage at connections to dampers or cross cables, if any.

- Inspection for cable alignment irregularities including waviness or excessive sag. Cable sag can be estimated (measured) using optical devices or through video or photo image processing. Cable angle can be measured with an inclinometer at specific points.

- Identification of changes to bridge deck elevations.

- Examine damage to protective tape wrapping (tears, cracks, and delaminations).

- Examine damage to sheathing, especially when PVF tape is not used. Attention should be paid to cracking in the sheathing, especially at high stress areas.

- Identification of damage to connections between anchorage pipes and cable sheathing.

- Inspection for damage, loosening, lack of water tightness, and deterioration of neoprene boots and band clamps.
- Inspection for damage or dislocation of neoprene rings and keeper rings, if applicable.

- Identification of gaps between the neoprene rings and the sheathing.

- Examination of sheathing surface inside the guide pipe through a boroscope or other means, looking for damage or deformation to the sheathing near the anchorage.

- Review of cracking or damage to guide pipes or evidence of the impact of cable components on guide pipes.

- Examination of surface conditions on the visible anchorage components including ring nuts, end caps, and bearing plates.

- Examination of visible parts of saddles for damage, corrosion, and cracking, if applicable.

- Review of evidence of moisture or fillers (such as grease) exiting the anchorage components. If there is an access port at the end cap (ideally at the lowest point), it can be opened and examined for moisture or moisturecontaminated grease.

- Removal, in some cases, of the end caps on the sockets to allow for visual inspection of the anchorage plate and anchorage devices and to see if there is moisture or corrosion inside.

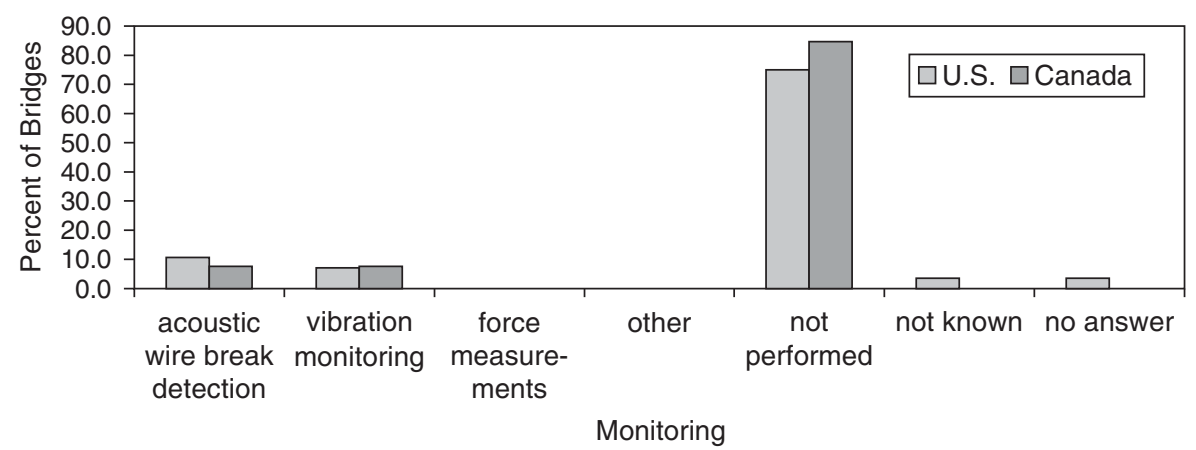

FIGURE 54 Types and levels of sensor-based, long-term monitoring. 
- Inspection of the cross tie cables for sagging (losing their force and need to be retensioned).

- Inspection of damage or cracking on components of cross tie cables. Evidence of fretting and fatigue, especially at connections, are of particular interest.

- Examination of dampers, if any, as per recommendations of manufacturer.

Some maintenance manuals recommend inspection of stay cable surfaces using binoculars during routine inspections and close viewing during detailed inspections. However, it should be noted that the bridge maintenance community in general does not view the use of binoculars for bridge inspections positively, as it may discourage the preferred method of close inspection.

The access to cable components can be gained through "reach-all" trucks, and lifts or cranes with "baskets." In some bridges, special inspection vehicles for stay cables have been designed to allow for easier access to cables. For example, the Luling Bridge in Louisiana has two trolleys designed for inspections of cables (Elliott and Heymsfield 2003). They were reportedly built in 1985 at a cost of $\$ 3,000$. Only the maintenance lane and one traffic lane need to be closed during inspection. The trolley is a steel frame carriage with a detached basket (see Figure 55). Two inspectors and equipment totaling $1780 \mathrm{~N}$ (400 lb) can be used. A wire rope is used to pull the trolley up the cables. However, there are indications that changes to the design of the trolley are recommended by DOT personnel to increase redundancy and provide a braking system. This system is reportedly suitable for larger diameter cables only.
For the inspection of the Dame Point Bridge in Florida ("B\&N Creates Custom Device ..." 2005), the inspection team custom designed a rolling device (Figure 56). The weight of the device was an important factor in the design, because the inspector has to carry several hundred feet of rope and other inspection equipment ("B\&N Creates Custom Device..."2005).

In Denmark, a carrier for inspection of the main cables of a suspension bridge has been developed (Figure 57).

In their written comments, many survey respondents emphasized the desirability of finding effective ways to inspect cables visually.

\section{Vibration-Based Cable Force Measurements}

The vibrating chord theory presents a simple relationship between the tension in a string $(T)$ with its mass per unit length $(m)$, its length $(L)$, and its natural frequency $(f)$ as follows:

$T=4 L^{2} f^{2} m$

Eq. 2

In its simplest form, a stay cable can also be approximated as a vibrating string. If its natural frequency could be determined then, knowing all other parameters, the cable force could be determined. A number of researchers have used accelerometers installed on cables to measure the cable's natural frequency and estimate the cable force (Casas 1994). However, in some cases, measurement of cable frequencies on a large number of stay cables on a major bridge can be time consuming. The assumptions inherent in Eq. 2 are also not strictly valid in stay cables. Stay cables have bending stiffness,
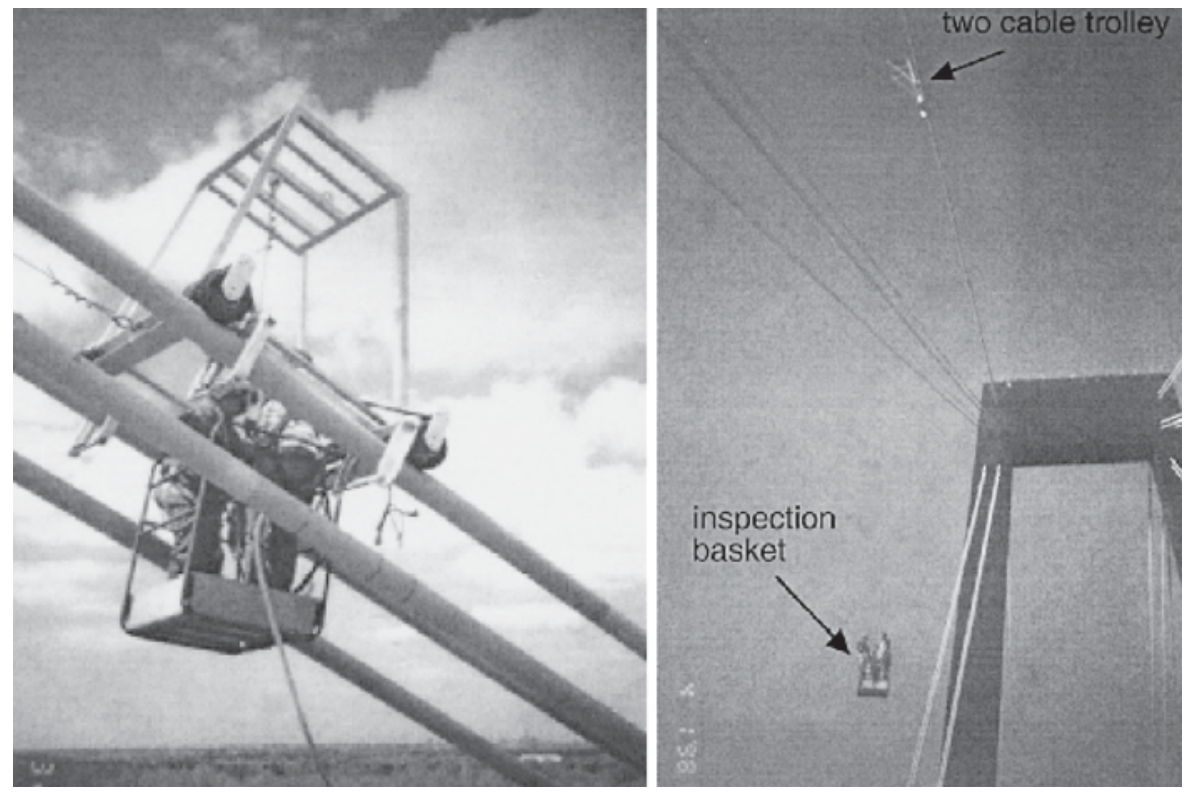

FIGURE 55 Trolley used for inspection of Luling Bridge cables (Elliott and Heymsfield 2003). 


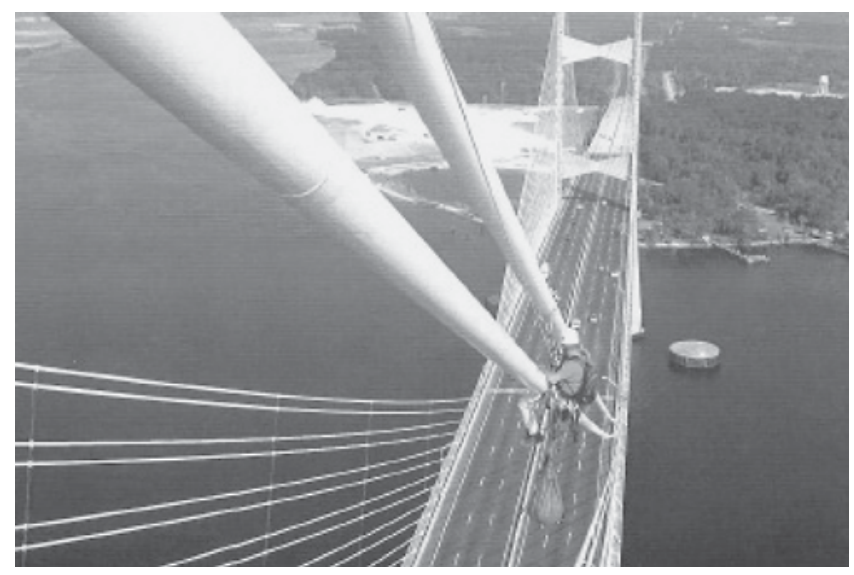

FIGURE 56 Rolling device for inspection of the stay cables on the Dame Point Bridge ("B\&N Creates Custom Device ..." 2005).

whereas Eq. 2 assumes zero bending stiffness. Cables also sag under their own dead weight and have other complicating factors such as neoprene rings, viscous dampers, and variable stiffness along their length (e.g., anchorage sockets), that further complicate the analytical relationship. To address these issues, FHWA funded a research project in the mid-1990s to develop a laser-based noncontact method for cable vibration measurements in the field (Angelo 1997). The effectiveness of using a laser Doppler vibrometer was established for measurements of ambient cable vibrations from distances of up to several hundred feet (Tabatabai et al. 1998b). More importantly, nondimensional relationships that included the effect of cable bending stiffness, cable sag, and so forth, were developed for a more accurate estimation of cable forces (within $1 \%$ to $3 \%$ accuracy) using measured frequencies. This approach has been used on several U.S. cable-stayed bridges including the Weirton-Steubenville Bridge in West Virginia, Varina-Enon Bridge in Virginia, Cochrane Bridge in Alabama, and Sun- shine Skyway Bridge in Florida. Figure 58 shows the laser measurement approach in the field.

Cunha and Caetano (1999) used the developed laser measurement approach to measure cable frequencies on the Vasco de Gama cable-stayed bridge in Lisbon, Portugal. Also, the survey results in this study indicated that the Ministry of Transportation personnel in Quebec, Canada, have themselves measured the cable forces on the Galipeault Bridge using the same laser-based method.

Yamagiwa et al. (1999) presented a method for simultaneous identification of bending stiffness and tension in a cable using vibration measurements. Experiments on a spiral rope for a cable-stayed bridge were performed and the authors reported good agreement between measured and calculated values.

It should be noted that results of similar accuracy could alternatively be obtained by simply attaching an accelerometer on the cables to determine frequencies, and then using the available equations to estimate forces. Whether the accelerometer or laser-based approach is selected, it is important to reemphasize that one could not necessarily conclude that there has not been a section loss because cable forces have not changed. This is especially true in grouted cables where broken wires redevelop over a short distance. Unless and until wire breaks result in global stiffness changes in the cable, section loss could not be inferred from cable force measurements.

The following comments related to vibration-based force measurements were provided by the respondents to the survey:

- "Laser-based force measurements will give results that will indicate if a cable is deviating from the trending val-

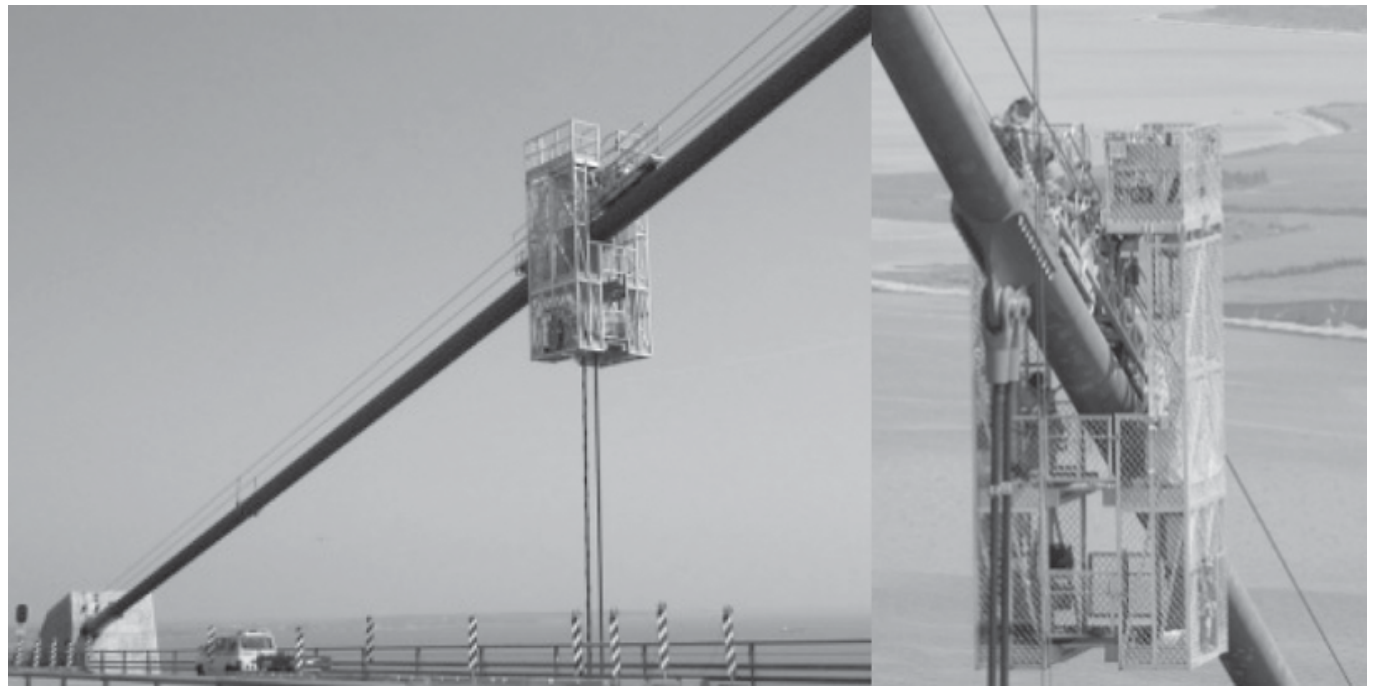

FIGURE 57 Carrier for inspection of main cable of suspension bridge in Denmark. 

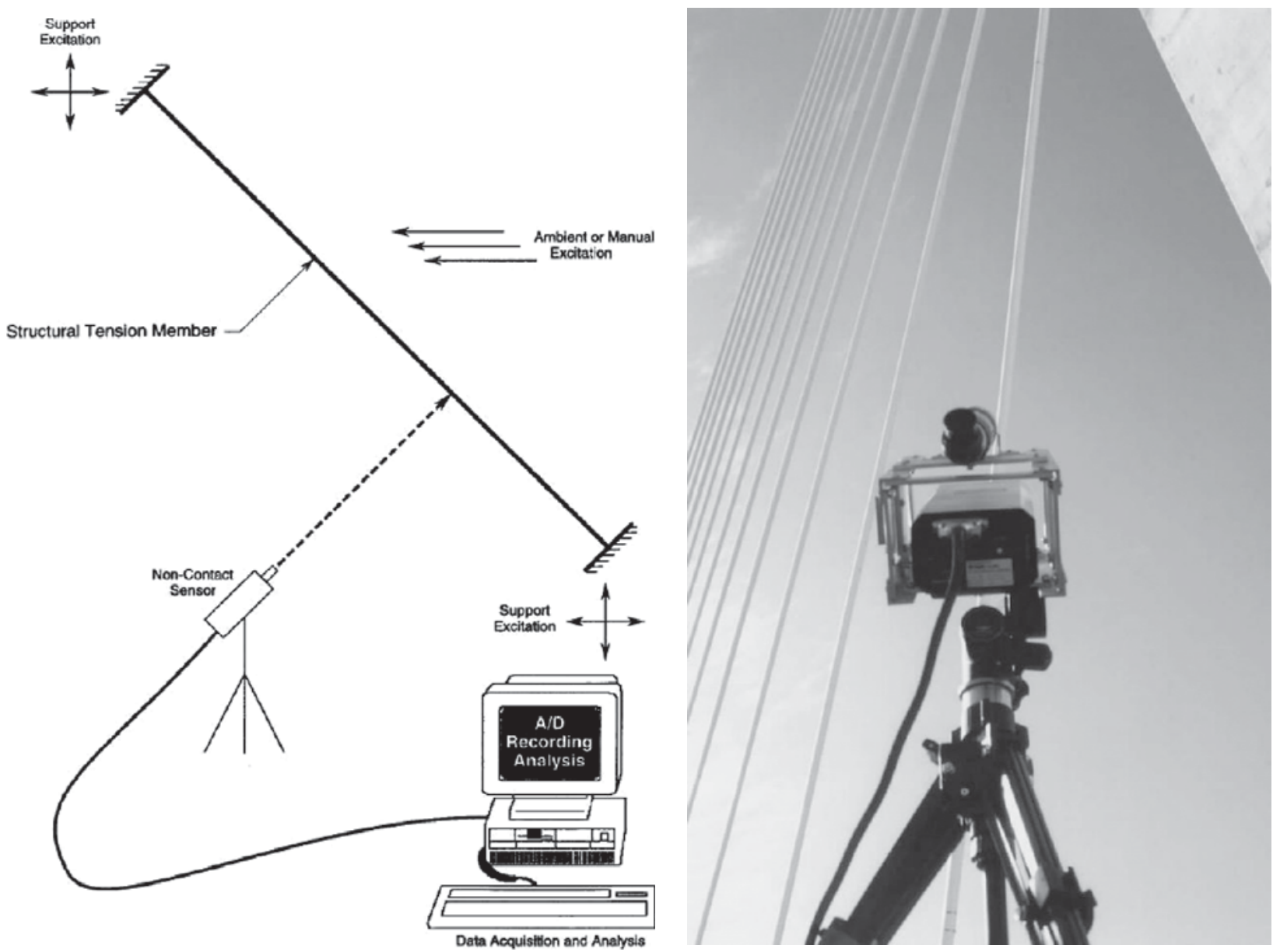

FIGURE 58 Use of laser doppler vibrometer for stay cable vibration and force measurements.

ues of the other cables. It may not give you an accurate value of the force in a cable. It is relatively easy and inexpensive to perform."

- "TxDOT has employed vibration-based force measurements to refine the model used for designing viscous dampers on each of the cable stay bridges. The technique seemed to give good correlation cable dimensions and damping requirements. The technique requires some traffic control and depending upon the number of lanes carried by the structure could produce minor-to-significant traffic disruption. At least one lane and the shoulder will need to be closed; therefore, if the bridge is narrow with a small number of lanes carrying two-way traffic the disruption could be considerable. This could last for several weeks if there are a large number of stays that need to be tested. The cost can run anywhere from $\$ 50,000$ to $\$ 75,000$ per bridge per test event depending upon the size of the structure."

- "Laser-based force measurements were utilized in the initial in-depth inspection of this bridge in 1999. The cost incurred was approximately $\$ 35,000$, with minimum impact on traffic."

- "Force measurements on selected MTEs will be performed as part of the SHM system with the use of uni- axial accelerometers to determine frequency of the cable and relate back to force."

\section{Other Methods of Measuring Cable Forces}

Some stay cable suppliers and contractors have used measurements of cable sag to estimate cable forces. Cable sag is defined as the maximum vertical displacement of the cable with respect to a line connecting its two ends. There is a simple inverse relationship between the sag of a cable and its tension. However, the results of the survey in this study did not reveal any instances where inspectors have measured cable sag as part of their routine inspections of cable-stayed bridges. Photogrammetric or optical methods can be used to allow inspectors to measure cable sag from the deck level without the need for specialized assistance.

Another option for cable force measurements on new cables would be to install low-profile load cells under the anchorage. This could be an effective, although relatively costly option. Contractors have also used a method called "liftoff" to measure forces. In this approach, a large hydraulic jack is used to lift the anchorage off of the anchorage plate. The 
force required for the liftoff is the cable force. This method is cumbersome and costly, especially for inspection purposes.

Force measurement sensors on selected individual strands on a cable are likely to be developed based on magnetoelastic effect or other effect in the near future. Some cable suppliers are working to develop force-measuring systems for their cables. The sensors can be applied to the entire cable or to individual strands. If individual strands are instrumented, the total force is estimated based on an assumption of equal forces in all strands.

\section{Ultrasonic Assessments of MTEs in Anchorage Zones}

Ultrasonic techniques have been used for assessment of MTEs in stay cables. Desimone et al. (2001) studied the pulse wave propagation along a bar (wire), and reported on experiments on wires with and without notches and grooves of various depths. The first known application of ultrasonic testing for assessments of wire conditions in stay cable anchorages was by Suzuki et al. (1988). The cable anchorage in that case was a Hi-Am-type socket (a steel socket filled with an epoxy-steel ball compound) containing steel wires terminating at button heads. In this method, an ultrasonic transducer is coupled to the end of each wire or button head and a high-frequency stress wave is sent into the wire. The reflections are monitored by the same sensor and displayed. A trained technician can view the record and decide if a wire break has occurred. It should be noted that ultrasonic pulses could travel a long distance along a wire if that wire was free in air. However, as the wire is enclosed by grout and/or anchorage epoxy, a significant attenuation of the pulse reduces the effective length over which this method can be used. Suzuki et al. (1988) reported that the depth of wire-break detection for a Hi-Am-type anchorage was a few meters. However, a few meters would theoretically be sufficient for inspection of most anchorages.

Following the failure of a cable on the Zarate-Brazo Largo Bridges in Argentina, a series of ultrasonic tests was performed on the remaining anchorages. The failure was noted in the cable near the entrance to the anchorage socket (HiAm-type). Prato et al. (1997) reported on the ultrasonic tests undertaken in which a large number of wire breaks were detected in various cables. Figure 59 shows an ultrasonic test record indicating a wire break. However, it is not clear if the test record shown in the figure is indicative of the clarity and definiteness of a typical ultrasonic test record or perhaps a representation of one of the better results.

The first application of ultrasonic testing on seven-wire strands was done on 12 anchorages of the Cochrane Bridge in Alabama (Tabatabai et al. 1998a; Ciolko and Yen 1999). Figure 60 shows testing on a tower anchorage.

There are further complications with stress wave transmission through a seven-wire strand. Typical ultrasonic transduc-

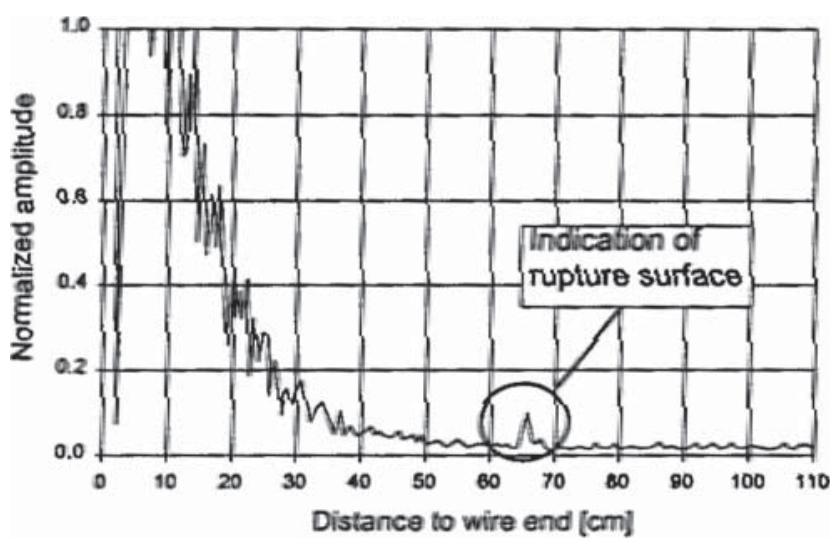

FIGURE 59 Typical ultrasonic test record of broken wire (Prato et al. 1997).

ers must be properly coupled to the cut-and-ground ends of the strands. Because the six perimeter wires wrap around the center wire and are in contact with each other, wave transmission is more complicated than in single straight wires.

It is very important that an existing anchorage of an identical or similar type be made available (or a mock-up made) before field testing to calibrate the results for known defects and their locations. The operator's experience and ability is crucial, as judgment is required when interpreting results. There are however no known systematic and rigorous research programs performed to date that are aimed at quantifying the degree of accuracy of this method for various anchorages, and ways of improving the interpretation of results.

\section{Magnetic Methods}

When a magnetic field moves along the length of a cable containing steel MTEs, presence of corrosion or fracture in the wires changes the magnetic field. Sensors can detect such changes and produce electrical output as a result. Figure 61 shows a magnetic flux leakage signature, with the characteristic shape representing the flaw. The horizontal axis is the posi-

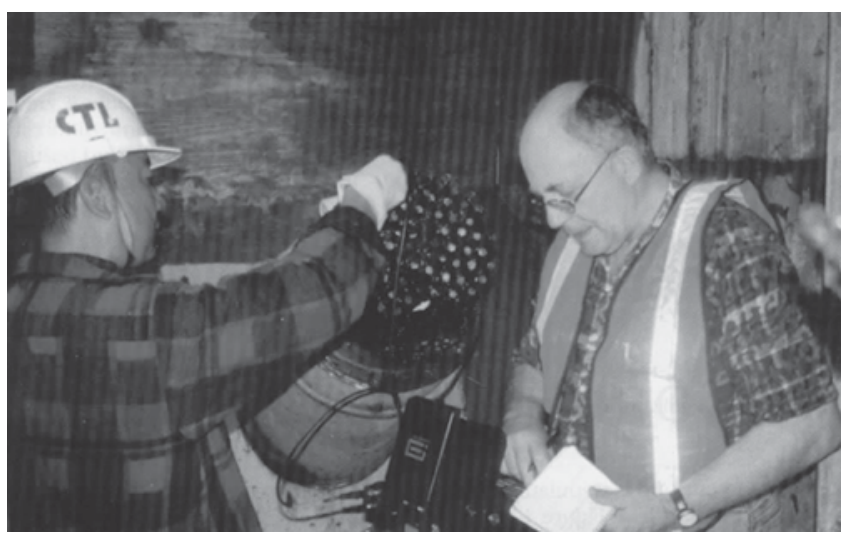

FIGURE 60 Ultrasonic testing of cable anchorage (Ciolko and Yen 1999). 


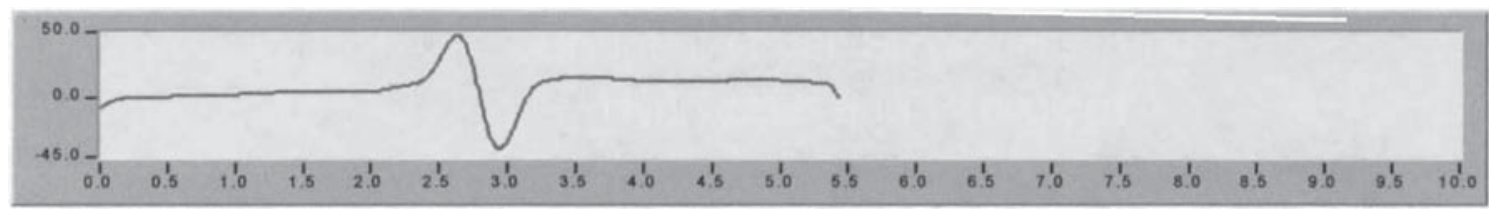

FIGURE 61 Signature from a flaw in a steel cable (courtesy: A. Ghorbanpoor, University of Wisconsin-Milwaukee).

tion along the scanned length of cable. The size of flaw and distance from the sensor determine the signal amplitude and shape. The method to identify location and extent of damage based on the above approach is variably called magnetic perturbation, magnetic flux leakage, or magnetic induction.

Barton et al. (1989) developed the first prototype device for inspection of the free lengths of stay cables based on the magnetic perturbation method. This device would surround the cable and move along its accessible free length. The first application of this device was on the Luling Bridge in Louisiana. Teller et al. (1990) also reported on the use of this device on the Pasco-Kennewick Bridge in Washington State. This system was effective; however, because of its large size and weight, it was difficult and time consuming to position and move the device from one cable to another. It was also limited to the cable free length and could not access the anchorages.

EMPA, a materials science and research institution in Switzerland, has developed a magneto-inductive evaluation system for stay cables (Bergamini et al. 2003). This system was used to evaluate the conditions of 68 cables of the Rama IX Bridge in Thailand in 2001. EMPA's device uses an electromagnet instead of permanent magnets to allow magnetic saturation of large stay cables. The current system can travel along the cable and detect the position of flaws along the length of the cable and provide a "qualitative statement about the position and size of the flaw within the cross section." EMPA is trying to increase the amount of information obtained so that additional information on the size and position of flaws within the cross section can be determined.

Weischedel and Hohle (1995) discussed the use of dualfunction electromagnetic (EM) instruments for evaluation of stay cables. They referred to the following two different and distinct EM inspection methods:

1. Localized flaw inspection (LF inspection).

2. Inspection for loss of metallic cross-sectional area (LMA inspection).

Weischedel and Hohle suggest that the LF inspection (as used in the United States and elsewhere) is based on differential sensors that cannot measure gradual changes in condition such as corrosion, wear, and so forth. They assert that an absolute sensor is required to measure such changes. A dual system would include the two different sensor types and would measure LF and LMA at the same time. They reported that EM methods had been used in Germany for bridge stay cables for 25 years (the publication date of the paper was 1995). In addition, they referred to a device that can travel along the cable and that uses four differential sensors (LF type) to detect wire breaks. They also discussed the effects of trapped magnetic debris on the accuracy of LMA measurements.

In the United States, Ghorbanpoor (1999) developed a MFL robotic device for NDE of strands within prestressed concrete girders. This device would attach itself to the bottom flange of typical I-girders and would automatically travel the length of the beam.

Kitagawa et al. (2001) briefly described using the magnetic flux method to detect corrosion in hangers of a suspension bridge in Japan. Wichmann et al. (2003) described an EM resonance measurement method for identification of localized fractures in tendons. The idea is described as follows: the tendon is considered as an "unshielded resonator located in a material with electromagnetic loss (e.g., concrete). An electromagnetic wave of variable frequency is coupled into the end of the tendon." The reflection coefficient is scanned over a frequency spectrum to measure resonance frequencies. The authors suggest that the method has the advantage that only one end of a tendon has to be accessed.

The MFL methods described previously have not been applied to stay cable anchorages because the magnet and the sensors cannot physically reach around the anchorage within a reasonable distance. However, if future anchorage designs allow such access, then this methodology could potentially be developed for anchorages as well.

\section{Video Monitoring (Photogrammetry)}

Aas-Jakobsen et al. (1995) used a video camera to measure the amplitude of stay cable vibrations on the Helgeland Bridge in Norway. Elgamal et al. (2001) considered the use of video monitoring on an FRP bridge. Video cameras with sensor data activation and target tracking software were also considered.

Dr. Derek Lichti of the Curtin University of Technology (Perth, Western Australia) has used video monitoring of beam deflections in static tests, and reportedly plans to perform dynamic measurements at $50 \mathrm{~Hz}$ frequency or greater. Software has been developed to capture image sequences from two video cameras at $50 \mathrm{~Hz}$. Targets are imaged and, using 
photogrammetric algorithms, "sub-pixel target measurements" are obtained and transformed into three-dimensional coordinates. At least one cable supplier plans to investigate and incorporate some form of video monitoring for stay cables. In addition to dynamic measurement from a distance through a camera, photogrammetric techniques can also be used for static measurements such as cable sag.

This synthesis effort did not identify methods to obtain a three-dimensional image of the entire stay cable for comparisons with future such images. However, some forms of scanning (perhaps laser-based) may eventually become available.

\section{Radiography}

Nondestructive test methods based on radiography have been used in civil structures and, in limited cases, on stay cables. The radiation source in radiography is either X-rays or gamma rays. There are safety hazards associated with both of them. Special high-voltage machines (X-ray tubes) produce X-rays, and gamma rays are produced from radioactive isotopes. PlaRucki and Eberhard (1995) presented a summary of various imaging technologies for reinforced concrete, including radiography. General radiography produces two-dimensional images, whereas computed tomography can produce crosssectional images of the three-dimensional object.

The anchorage sockets of the Sacramento River Bridge (Meridian) cables (wire rope cables) were inspected in 1988 using a $6.0 \mathrm{MeV}$ portable linear accelerator. The inspected sockets were $203 \mathrm{~mm}$ ( 8 in.) in diameter, and a length of $150 \mathrm{~mm}$ (6 in) was inspected. According to California DOT personnel, the testing was successful and clear images were obtained. However, the process was considered lengthy and costly. There were no indications of distress detected.

FHWA has constructed a mock-up of a stay cable component for the C\&D Canal Bridge in Delaware. This mock-up included wire and strand breaks and grout voids. The mock-up was tested by a company that specialized in radiographic testing. Field testing on this bridge saddle has not been done. The Delaware DOT has investigated this method and offered the following observations in response to the survey:

X-ray imaging of the cable stays was considered and dismissed. Several concerns were encountered with this method including protection of public and working personnel during the exposure, access and holding the equipment at the higher elevations of the cable stay, and scheduling of the equipment. Interpretation of the image was also a concern. It is believed that the multiple materials (steel, grout, steel strand) which comprise the cable stays combined with the changing geometry would make interpretation of the image difficult and would not allow for an accurate understanding of the conditions. Our understanding is that the X-ray imaging would only be able to detect gross section loss of the stay and is not precise enough to discern the onset or early stages of corrosion. Finally, when the X-ray imaging method was considered, it only allowed a view of a discrete section of the cable stay as opposed to a global or 'traveling' operation, which would allow an investigation of the entire length of the cable stay.
The following is a survey comment received regarding the Meridian Bridge in California:

Used radiographic testing once on this structure. It was costly and impractical, but did appear to give satisfactory results.

Would not use this method for routine inspections on this bridge.

Telang et al. (2004) performed tests on cable mock-ups to determine whether a low-energy X-ray method could be effective in identifying splits in PE sheathing, previously repaired splits in PE sheathing, damage to external tape, and grout void or damage. They made the following overall assessment:

The low-energy, X-ray radiography was effective for almost all types of flaws in the cable specimen. However, the use of radiography is associated with higher cost and slower process, and the results require expert interpretation.

A number of manufacturers produce portable radiographic systems for field applications, especially for grouted posttensioned tendon applications (Brown and St Leger 2003). Keating et al. (2000) reported on advances in industrial computed tomography applications.

In 2004, Akers and Rideout discussed a new Photon/ Neutron Induced Positron Annihilation method for detecting corrosion and fatigue in bridge structures and cables. This method was developed at the Idaho National Engineering and Environmental Laboratory. According to the authors, positrons, which are anti-particles of electrons, are sensitive to change in a material's atomic structure. The authors stated that the method can detect damage at the atomic level before overt manifestation of damage. In response to an inquiry, one of the authors indicated that they have not yet performed tests on wire bundles, and hope to conduct research on cables in the future.

\section{Magnetostrictive Sensors}

The magnetostrictive sensor (MsS) technology was developed in the early 1990s at the Southwest Research Institute (SwRI) (Bartels et al. 1996). This technology is based on the concept that magnetic fields produce small changes in the physical dimensions of a ferromagnetic material (such as steel), and material strains produce changes in magnetization. Therefore, if the magnetic field around a bar is changed, an elastic wave (guided wave) would be generated, which would travel in both directions along the length of wire. The stress wave would change the magnetic induction of the material, thus generating voltage in the receiving coil, which can be monitored. The transmitting and receiving coils can be identical. This approach is a form of ultrasonic testing. Figure 62 shows the basic MsS concept. This approach was used on the hanger cables of the George Washington Bridge in New York City. Figure 63 shows the trace of the results as well as the attachment of sensors on the hanger. 


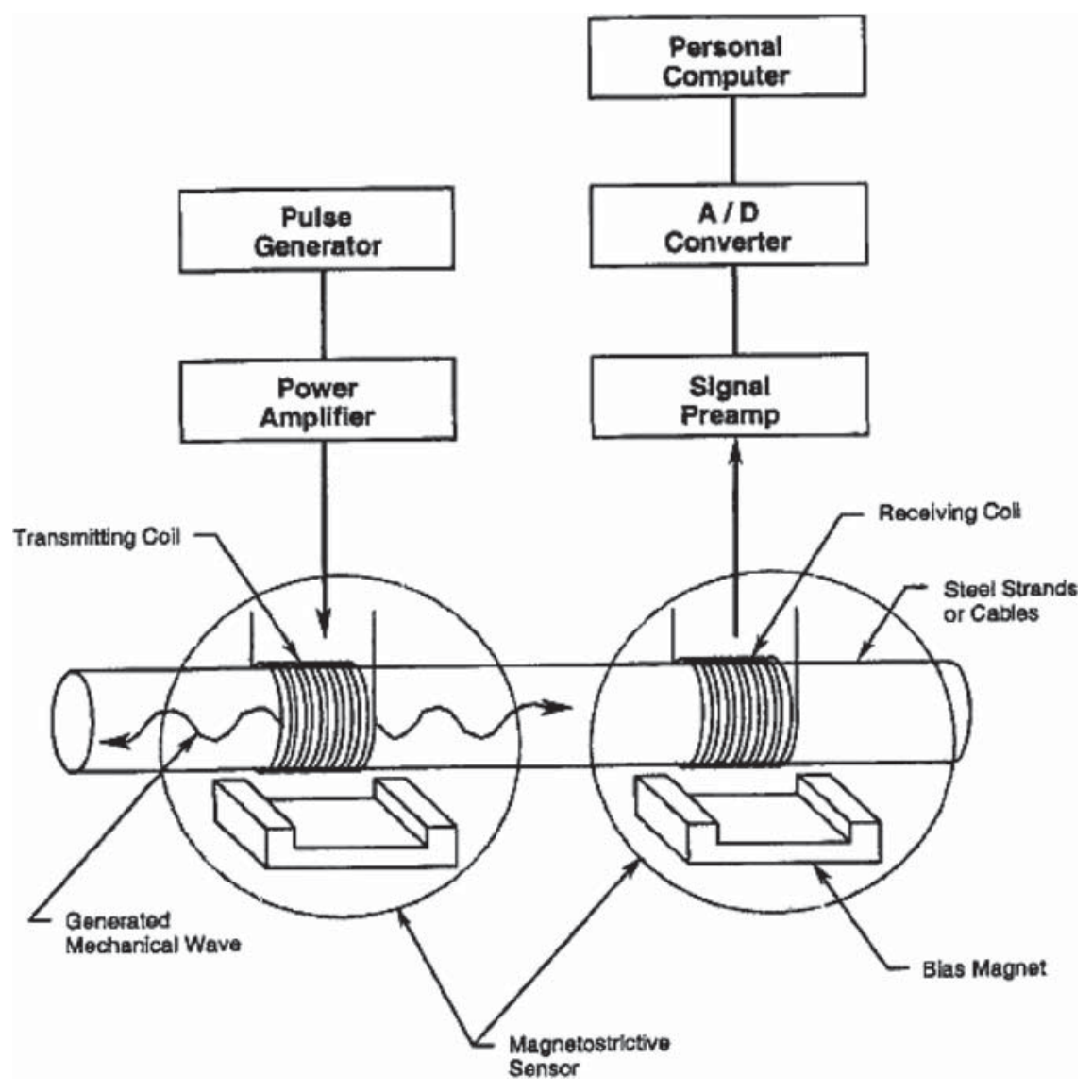

FIGURE 62 Schematic diagram of MsS sensors (Bartels et al. 1996).
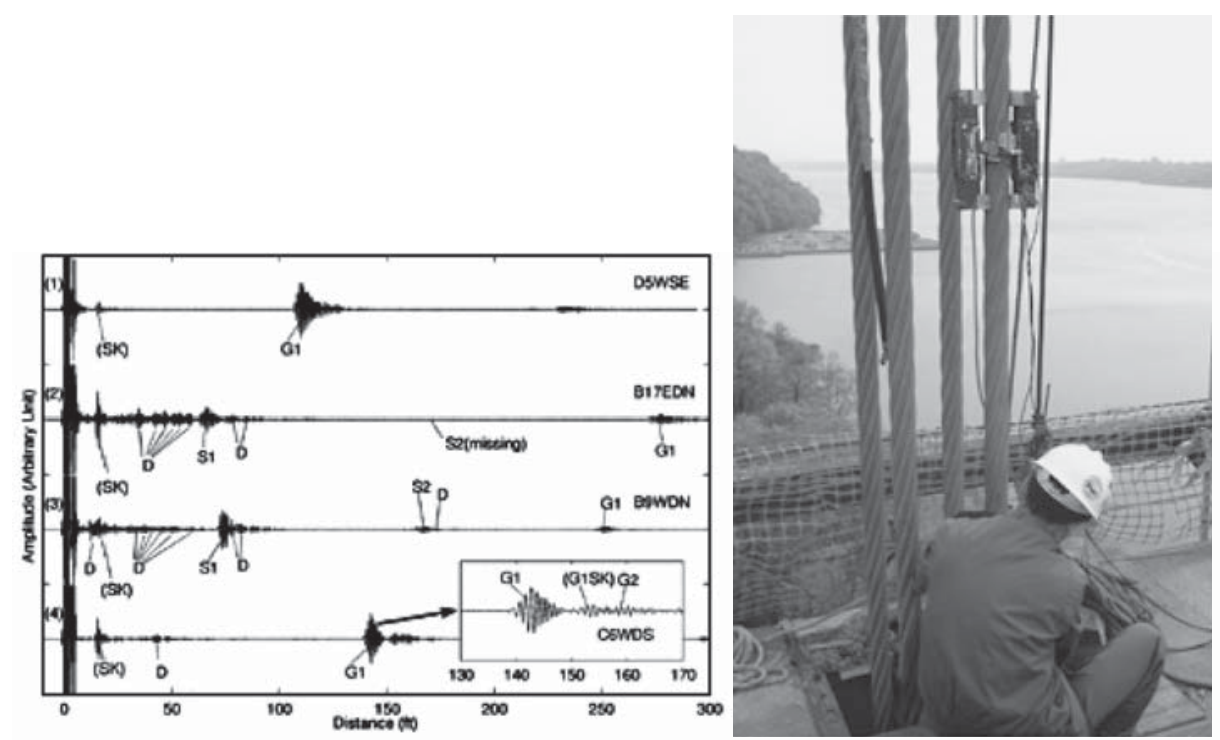

MsS technology can effectively inspect the approximately 3-inch-diameter suspenders of the George Washington Bridge. The image above left compares the data collected from four wires in the suspenders on the bridge. "D" represents a defect. "SK" represents a socket and " $G$ " represents a gatherer, both of which are normal components of the suspender. Suspender 1 had been recently replaced, and thus showed a clean signal with no defect indications.

FIGURE 63 Application of MsS technology to inspection of hanger cables (Kwun 2003). 
Dr. Hegeon Kwun of SwRI indicated that they have tested anchorage areas of main suspension cables where wires are separated. SwRI researchers believe that the MsS technology can be applied to stay cables; however, they as yet have not had an opportunity to test stay cables. Dr. Kwun believes that, in the anchorage zone, small defects (some broken wires) would likely not be detectable using these guided waves.

\section{Laser Ultrasound}

A guided ultrasonic wave for NDT and evaluation can be applied to a test structure (e.g., a strand) in different ways, such as coupled (contact) ultrasonic transducer, MsS, or laser ultrasound. In ultrasonic testing of strands in stay cable anchorages, the ends of seven-wire strands are typically ground smooth to allow perfect coupling with the ultrasonic transducer. However, typically larger transducers that are used cannot be practically coupled to individual wires. The same applies to the MsS technique. However, the laser ultrasound can be applied as a point load anywhere at the end of the strand or wire. It can also be applied eccentrically to generate both longitudinal and flexural modes (Rizzo and Lanza di Scalea 2004). In this article the authors discuss the dispersive and attenuating behavior of guided ultrasonic waves in multiwire strands. The use of laser ultrasound may potentially offer a way to improve the basic ultrasonic technique for inspection of stay cable anchorage, either on its own or in combination with the MsS technique.

\section{Other Methods}

Telang et al. (2004) performed a number of tests on two mockup stay cable specimens to evaluate various NDT techniques including impulse response, impulse radar, infrared thermography, and radiography. These specimens contained parallel steel wires enclosed within PE sheathing and grouted. The objective was to find methods that could be used to identify deficiencies in PE sheathing (cracking and previously epoxyrepaired cracks), damage to ultraviolet (UV)-resistant wrapping over the sheathing, and grout defects. The sheathing defects were hidden under a UV-resistant wrapping tape. The sheathing was cut in different directions to represent cracks before wrapping. Telang et al. (2004) reported that the impulse response method was found not to be effective. The impulse radar method (involving high-frequency EM energy) was reportedly successful in detecting grout voids or damage. Figure 64 shows a radar survey identifying grout voids.

Telang et al. (2004) summarized their results as shown in Table 8. They suggested that splits in PE sheathing (under the tape) can best be identified with infrared thermography or lowenergy X-rays. The authors explained that the thermographic method was not able to discern filled voids or voids in the shade on the bottom of the specimen. In addition, the method was not able to see defects beneath areas with damage to the UV tape. The solar heating of the black pipe in areas where it was exposed masked any potential defects in the PE. It should be noted that the best results occurred immediately after the specimens were moved from the climate-controlled laboratory to the outside in a warm and sunny environment. This thermal gradient may not be representative to normal environmental heating and cooling except in extreme conditions. It is likely that the effectiveness of the thermography would be limited to early morning or late evening. They also noted that:

\begin{abstract}
The infrared thermography was very effective in detecting unfilled splits in the HDPE under certain environmental conditions. This condition requires sudden variation in the ambient temperature to result in temperature gradient in the cable material. It is believed that to keep the effectiveness of thermography for unfilled split detection, perhaps also for filled split detection, thermography should be combined with heat generation source.
\end{abstract}

Figure 65 shows a thermographic image from this test series.

Finally, another method that has been discussed in the literature for detection of corrosion in steel cables is Time Domain Reflectometry (TDR). This method has been referred to as "closed-loop" radar (Ciolko and Tabatabai 1999). It has been widely used in identifying problems in transmission lines. The process involves sending a high-frequency signal through the sensing cable and monitoring the reflections. The reflections come about as a result of impendence changes along the length of the cable. There have been a number of research efforts aimed at using strands as sensing wires in the TDR setup. Ciolko and Tabatabai (1999) reported that the results of laboratory and field studies on this method were not encouraging.

Liu et al. (2002) discussed using TDR in a manner slightly different from the earlier studies. In this research, an external wire is used in conjunction with the strand to form the "transmission line" for TDR tests. This method is sensitive to the presence of or variations in moisture. At the present time, the available data do not indicate a potential for successful field applications to stay cables.

\section{LONG-TERM EVALUATION AND MONITORING}

This section includes methods that could be used for long-term monitoring and inspections of stay cables.

\section{Acoustic Monitoring}

Acoustic monitoring is a passive method for detection of wire breaks in stay cables. It "listens" for shock waves emanating from wire breaks. It is called "passive" because it cannot detect existing wire breaks. It has to be there and be "on" if it is to detect a break.

Acoustic monitoring for stay cables probably began when a method for detecting wire breaks during qualification tests of stay cables was needed. Various test laboratories that performed such tests needed to count the number of wire breaks 


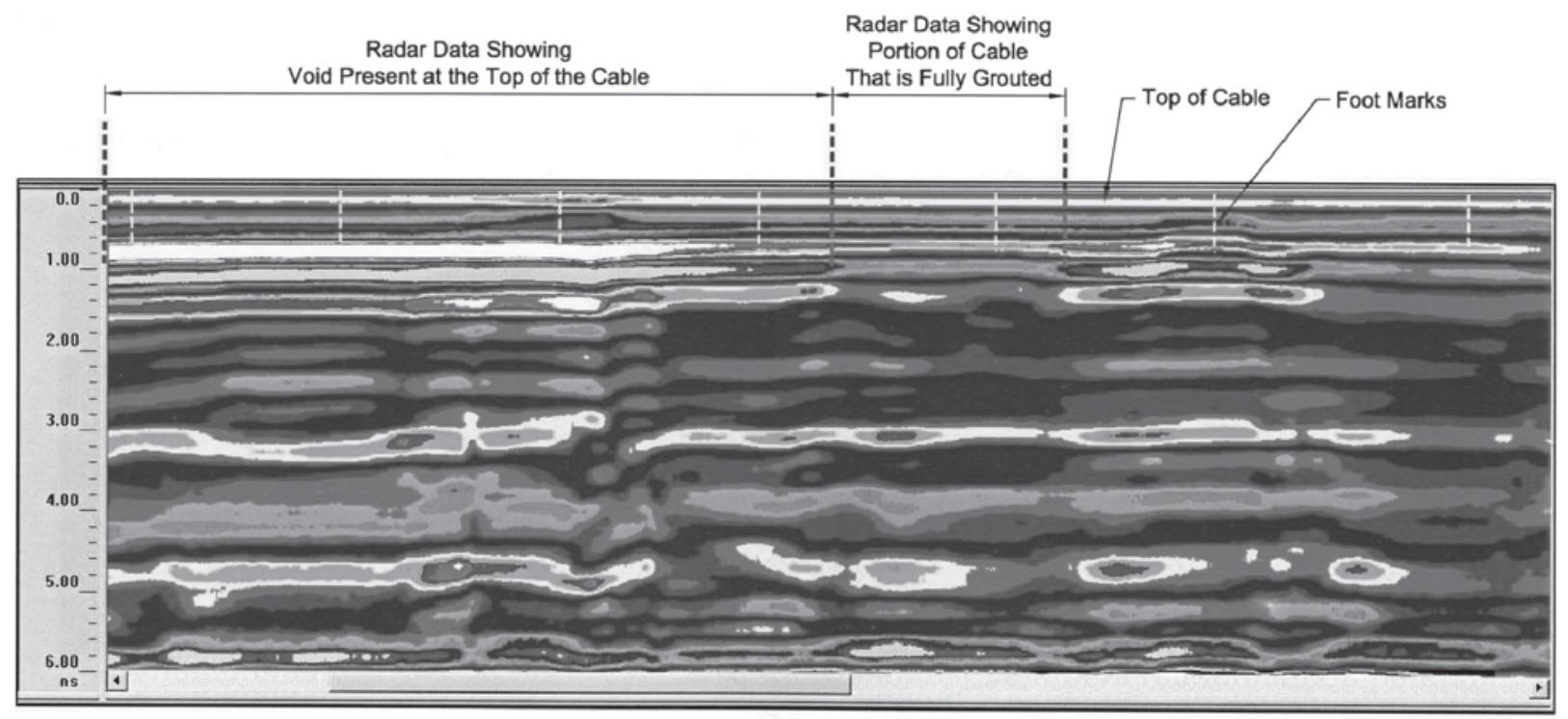

Sample Radar Scan

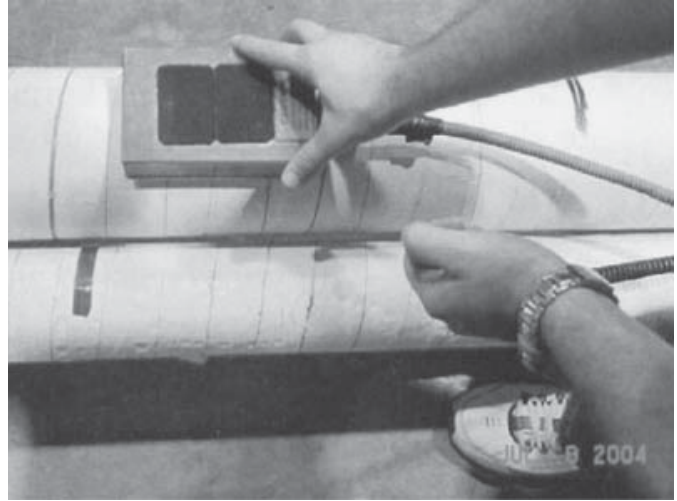

FIGURE 64 Sample impulse radar survey (Telang et al. 2004).

TABLE 8

COMPARISONS OF SOME NDT METHODS FOR DEFECTS IN PE SHEATHING, GROUT, AND TAPE

\begin{tabular}{lccccccc}
\hline & & & & \multicolumn{4}{c}{ Effectiveness } \\
\cline { 5 - 8 } & Relative & $\begin{array}{c}\text { Relative } \\
\text { Inspection } \\
\text { Rate }\end{array}$ & $\begin{array}{c}\text { Adaptability to } \\
\text { Environmental } \\
\text { Conditions }\end{array}$ & $\begin{array}{c}\text { Unfilled } \\
\text { Split in } \\
\text { Sheathing }\end{array}$ & $\begin{array}{c}\text { Epoxy- } \\
\text { Silled } \\
\text { Split in } \\
\text { Sheathing }\end{array}$ & $\begin{array}{c}\text { Damage } \\
\text { to UV } \\
\text { Tape }\end{array}$ & $\begin{array}{c}\text { Grout } \\
\text { Void or } \\
\text { Damage }\end{array}$ \\
\hline $\begin{array}{l}\text { Impulse } \\
\text { response }\end{array}$ & low & high & high & none & none & none & none \\
$\begin{array}{c}\text { Impulse } \\
\text { radar }\end{array}$ & low & medium & high & none & none & none & good \\
$\begin{array}{c}\text { Infrared } \\
\text { thermography }\end{array}$ & low & medium & low & good & none & good & none \\
$\begin{array}{c}\text { Low energy } \\
\text { X-ray }\end{array}$ & high & low & high & good & fair & good & good \\
\hline
\end{tabular}

Source: Telang et al. (2004). 


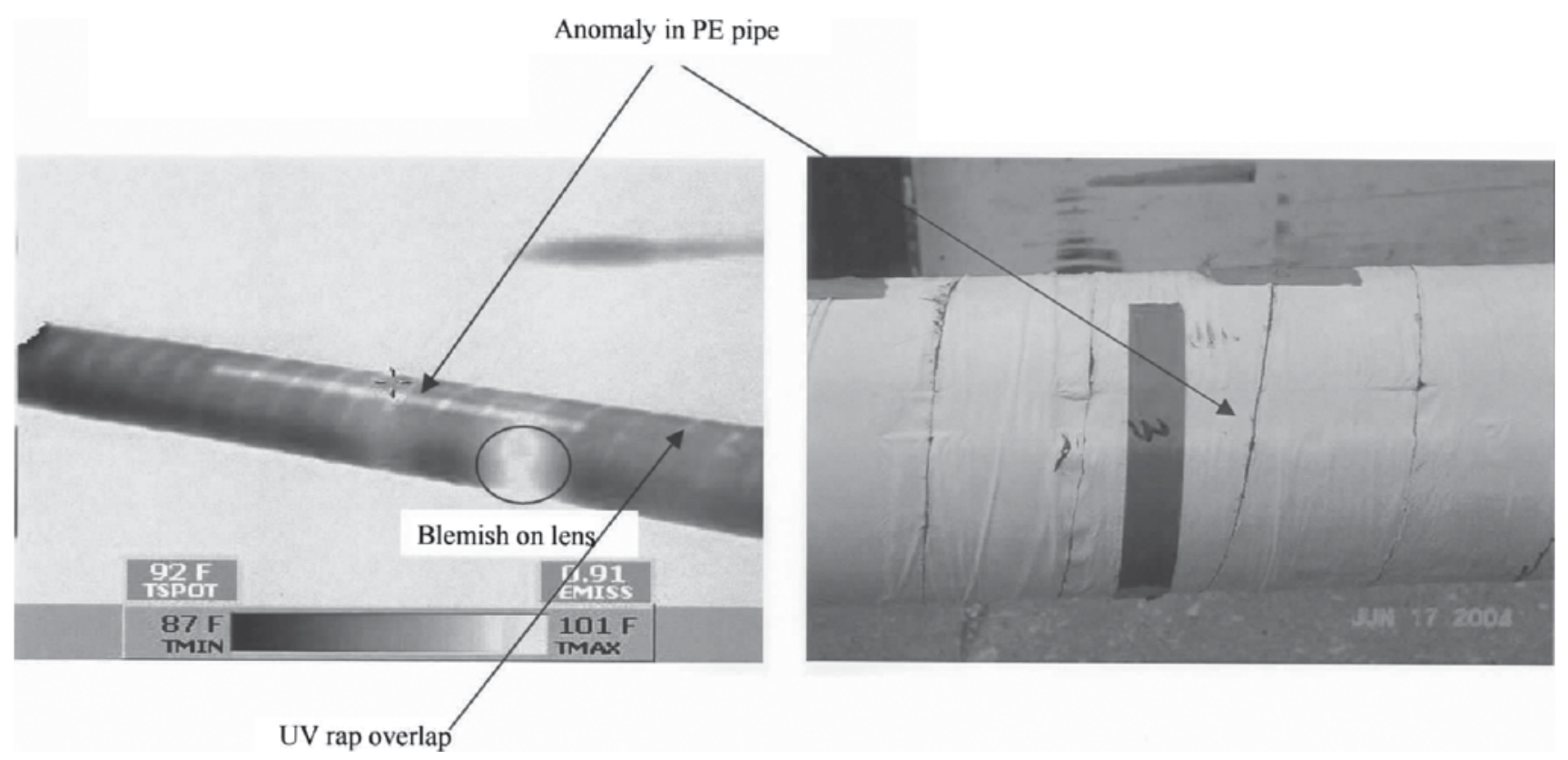

FIGURE 65 Infrared thermography image for detection of HDPE splits under tape (Telang et al. 2004).

during fatigue tests on the cable specimens, and therefore developed their own acoustic monitoring techniques. The basic system essentially consists of accelerometers located at selected points and the anchorages. The location of a break could be determined by comparing the arrival time of the shock wave at different sensors. It should be noted that the attenuation of acoustic waves in grouted cables is much higher than in ungrouted cables.

Tabatabai et al. (1995) performed tests on a one-tenth-scale model of a nuclear containment structure containing unbonded post-tensioning strands. Wires were cut, and the wire breaks were detected by accelerometers.

A commercial acoustic monitoring system based on piezoelectric sensors and proprietary software is available. The system was initially developed for post-tensioned buildings and parking garages, and was then extended to bridges and other structures. According to the company, this system has been installed on the following cable-stayed bridges:

- Fred Hartman Bridge (Texas)_acoustic monitoring system was installed in March 2002 on all 192 cables (grouted seven-wire strands).

- Quincy Bridge (Illinois)—system was installed in June 2002 on 14 of 56 stays (grouted seven-wire strands).

- Seyssel Bridge (France)—-system was installed in May 2003 on 4 of 36 stays (grouted seven-wire strands).

- Penang Bridge (Malaysia)—system was installed in December 2003 on 120 of 148 stay cables (grouted bars).

A research program involving the acoustic monitoring system has been in progress at the University of Texas-Austin. On request, Prof. Sharon L. Wood and the research team at
University of Texas-Austin prepared a write-up of the test plan and a summary of their findings based on two Master's theses. The research team's conclusions for the acoustic monitoring system are given here:

[The system] provides an accurate method for monitoring wire breaks due to fatigue damage in grouted stay cables. The system was able to identify the number of wire breaks accurately. The locations of the estimated wire breaks along the free length of the cable were typically within 6 in. of the actual breaks. The accuracy of the system was less near the anchor heads, but the geometry of the specimen is much more complex in this region. The locations of the estimated wire breaks near the ends of the cable tended to be within 18 in. of the actual breaks.

\section{Long-Term Sensor-Based Monitoring}

A number of parameters can be measured on stay cables using sensors. In previous sections of this report, examples of longterm vibration monitoring were given. Uniaxial or biaxial accelerometers are generally used for vibration monitoring. Uniaxial accelerometers are used to capture in-plane vibrations. Biaxial accelerometers can measure both in-plane and out-of-plane vibrations. The accelerometers are attached to the cable with suitable clamps or other hardware that could withstand long-term exposure. The positions of the sensors are selected to maximize the desired sensor response for the vibration modes of interest, and considering access limitations. In conjunction with acceleration measurements, weather data are also typically collected including wind speed, direction, rain, and so forth. The sensors are connected to a highspeed data acquisition system at a secure location on the bridge. The system is typically powered with AC (alternating current) power (if available) or solar panels. The system should be designed in such a way as to protect against dam- 
age resulting from lightning, vandalism, moisture, extreme heat, and extreme cold. Typically, data transfer to the office can be accomplished through wireless or landline modems. Data can also be stored on-site for manual retrieval.

In addition to vibration measurements, stay cable sensing could also include cable tension measurements through load cells or other force sensors. Bronnimann et al. (1998) reported on the testing of distributed fiber optic strain sensors for stay cables. Continuous (nondiscrete) strain or even acceleration sensing along the length of cable, if practical and reasonable from a cost standpoint, can be important in condition assessments. In such cases, the localized strain changes, or changes in mode shapes indicative of damage, could potentially be determined.

A search of the literature and the survey results did not identify any bridges where moisture or humidity sensing is performed. In the James River Bridge in Richmond, Virginia, drain holes are placed in the bottom of the area between the guide pipe and the transition pipe near the threaded anchor heads to prevent accumulation of water. Considering that penetration of moisture is an important issue, humidity measurements or moisture sensing inside the guide pipe, anchorage caps, or other cable components could be made in the future.

It appears that in at least two cable-stayed bridges that were in the path of hurricanes, the idea of monitoring cable vibrations with security cameras mounted on the tower, the deck, or on the shores was explored, but it is believed not to have been implemented. There is also no indication as to whether any monitoring of rain-wind vibrations using security cameras has occurred.

In large-scale monitoring systems, an appropriate method for analyzing and interpreting the large amounts of data that are collected must be designed. This has been an important issue in all large-scale monitoring systems. 


\section{MAINTENANCE AND REPAIR OF STAY CABLES}

\section{REPAIR AND RETROFIT STRATEGIES AND METHODS}

The maintenance manuals of 11 bridges were reviewed in this study. There were major differences between the approaches and contents of the different manuals. Although a few manuals included procedures for the repair of cable sheathing and replacement of cables, others did not provide such information. There were major differences as to the level of detail between different manuals, even for the coverage of the same topics. The as-designed and as-built cable forces, deck profile elevations, and others, are typically not included in the manuals and are not required to be measured during inspections. Procedures for checking for moisture and evidence of vibration problems are generally lacking in many maintenance manuals.

The following is a list of the items found in the different manuals that are related to stay cables:

- Bridge description;

- Design considerations;

- Loads;

- Stay cable details: identification numbers, number of strands and wires, diameter of cable, mass per unit length, inclination angles, length, estimated cable tension at the end of construction and after creep and shrinkage effects are taken into account;

- Stay cable shop drawings including as-built anchorage design, materials used, any repairs done during construction, and history of problems during construction;

- Inspection and maintenance frequencies, and qualifications of inspection teams;

- Information on access: platforms, ladders, and snooper trucks;

- Cable retensioning procedures;

- Cable replacement procedures including traffic patterns and specific replacement procedures;

- Inspection procedures for anchorages, guide pipes, neoprene boots, neoprene washers, sheathing, cross cables, dampers, and so forth, including identification of critical areas and how and where to look for moisture and corrosion;

- Listing of designers, contractors, and suppliers of stay cables and components;

- Summary of qualification test results for MTEs;

- Summary of qualification test results for the entire stay cable system;
- Deck elevation surveys;

- Repair procedures including sheathing repair, PVF tape repair, repair of damage to guide pipes, and welded connections;

- Safety and traffic control during inspections;

- Description of methods for measuring cable forces;

- Inspection forms; and

- Deck elevation survey forms.

The examination of the maintenance manuals did not identify cases where any of the following methods discussed in the literature were included in the manuals:

- Recommendations for baseline measurements of cable frequency, damping ratio, cable sag, and cable inclination angles (at specific points accessible by inspectors). Such measurements can be taken when the effects of creep and shrinkage have dissipated. Such measurements could also include air and structure temperatures.

- The designer's estimated (calculated) cable frequencies, sag, and inclination angles (at a specific point) with and without the effects of cross cables or dampers (if used). This information could be provided for different ambient temperatures.

- The designer's estimated (calculated) bending stiffness and damping of cable in the free length and in the anchorage zones.

- The designer's estimated (calculated) stiffness of neoprene rings and/or proprietary dampers in contact with the cable.

- Procedures for checking if viscous or other dampers are actually working as intended including maintenance procedures for dampers.

- The designer's estimated (calculated) wind speeds at which vibrations owing to vortex shedding would be expected.

- The designer's calculated values of the "precursor transformation matrix." This matrix would be required if the damage detection methodology, Precursor Transformation Method (Tabatabai et al. 1998b), is employed in the future. This method uses a linearly elastic finite-element model of the bridge. In the computer model, the temperature of the cables are, one by one, raised by say 100 degrees, and the force changes in all other cables are noted. Each column in the transformation matrix would consist of cable force changes associated with tempera- 
ture increase in a particular cable. Temperature increases are meant to represent loss of stiffness of individual cables without the need to modify the cable stiffness. Future measured cable force changes can then be used together with the transformation matrix to identify cables that have suffered stiffness losses. A similar transformation matrix can be formed that is related to deck elevations instead of cable forces. Other sources of damage, such as support settlements, can also be incorporated.

There are very few components of the common stay cables (i.e., those that have been designed over the last 30 years) that could be considered repairable. Practically, the only items that the inspectors and maintenance engineers can realistically repair are the HDPE cable sheathings, neoprene boots, and possibly the elastomeric rings. Retrofitting for vibration control can also be done. However, repair of corrosion or fatigue damage to MTEs in the free length or anchorages of older cables (not the newer designs) is practically impossible, short of removal of the entire cable. The removal process itself is a major challenge and a significant undertaking, especially on older bridges. The main task of the maintenance engineer and inspectors is therefore prevention, especially control of moisture (from internal and external sources) and elimination of excessive vibrations. If preventive measures fail, the maintenance engineer must then have a reliable tool to determine if a cable or cables must be replaced and when they should be replaced.

A number of options are available with regard to repair of damaged or cracked HDPE sheathing. For minor localized damage, conventional wrapping with PVF tape is typically done, although this is believed by some not to be effective. When the HDPE has cracked or has more widespread damage, then a more extensive repair must be considered. The options include an elastomeric wrap system and a two-piece HDPE pipe that snaps together to form a cover for the original pipe. The elastomeric wrap is installed with an automatic wrapping device with $50 \%$ overlap. Within $24 \mathrm{~h}$ after wrapping, the wrap is heated to fuse the seams and shrink the wrap against the cable. The ends of the wrap must be secured firmly to prevent lifting.
The maintenance manual for the James River Bridge in Virginia included procedures for the repair of longitudinal splits in PE sheathing. This involves removal of the existing film tape, cleaning of the damaged area at least $3 \mathrm{ft}$ above and below the split, filling of the crack with a suitable polyurethane grout or other compatible material to obtain a smooth surface, using 8 mil polyester film tape with fiberglass reinforcement to wrap the cable from $2 \mathrm{ft}$ below to $2 \mathrm{ft}$ above the split with minimum of $50 \%$ overlap, and wrapping again with PVF film.

The available choices for the repair of steel sheathings are far more limited, and there is no known track record for the effectiveness of such repairs. A report prepared for the Delaware DOT recommends application of flexible liquid mastic to the cracks on a steel saddle pipe and continual inspections.

Figure 66 shows the results of the survey as related to the repair of stay cables. Approximately $30 \%$ of cables in the United States and Canada have had some form of repair.

\section{MITIGATION OF STAY CABLE VIBRATIONS}

A wide variety of solutions to the problem of stay cable vibrations have been proposed and/or implemented. These mitigation approaches can be categorized as modifications to the surface of HDPE pipe, cross cables, viscous dampers, viscoelastic dampers, friction dampers, tuned mass dampers, semiactive and active dampers, and others. In this section, a brief summary of each approach is given.

\section{Modifications to the Surface of HDPE Pipes}

As discussed earlier, the formation of rivulets on the surface of the cable is believed to be the cause of rain-wind vibrations. Therefore, a very popular and effective approach has been to modify the surface of the cable to break up and disrupt the flow of water, thus not allowing the formation of rivulets. A very common form of this modification is helical or spiral marks, fillets, or ribs on the surface of HDPE pipe as shown in Figure 67. Figure 68 provides wind tunnel results with and

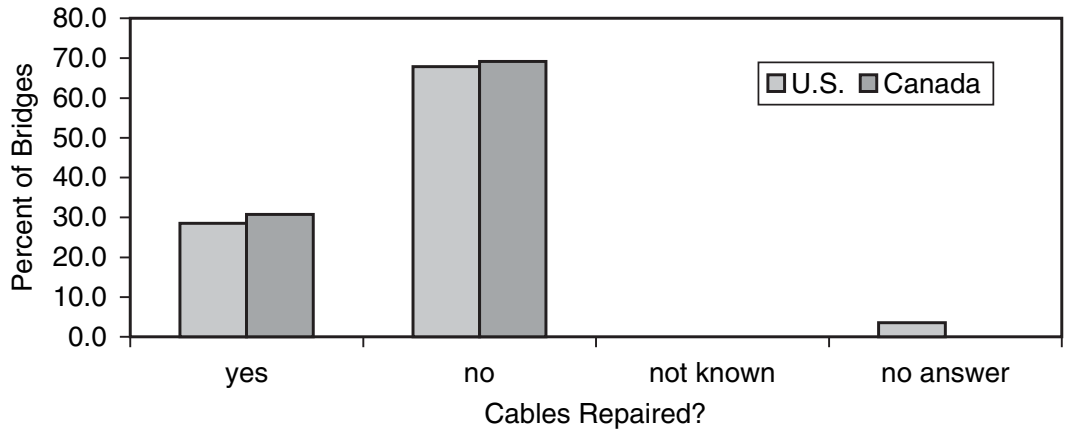

FIGURE 66 Percentage of bridges that have had cables repaired. 


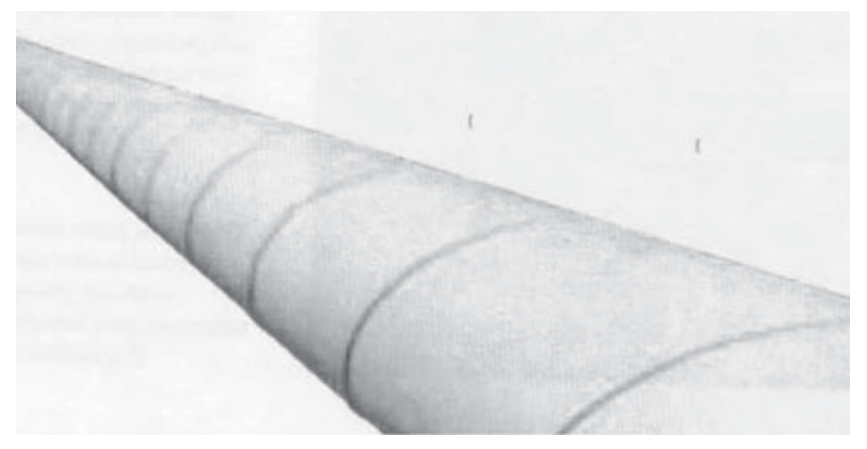

FIGURE 67 Spiral strakes on the surface of HDPE pipe to control rain-wind vibrations.

without surface modifications. According to the wind tunnel tests by Larose and Wagner Smitt (1999), in some cases, the rain-wind vibrations persisted with limited amplitudes even with the helical fillets.

Other, less frequently used options are dimples or longitudinal ribs on the surface (Figure 69). Surface dimples were used on the Tatara Bridge in Japan, and Yamaguchi et al. (1999) reported that they were effective in controlling rainwind vibrations.

\section{Cross Cables}

Cross cables, secondary cables, cable restrainers, or cross ties are used to connect different stay cables within a cable plane. Figure 70 shows a cross cable installed on SR-46 over the East Fork White River in Indiana.

These transverse connections reduce the effective length of the cable and increase cable frequency (Ito 1999). They also somewhat increase cable damping (Lankin et al. 2000). Yamaguchi and Nagahawatta (1995) performed experimental and analytical research on the damping effects of cable cross ties. The experiments consisted of two cables connected with two cross ties. They concluded that "there exists a more or less

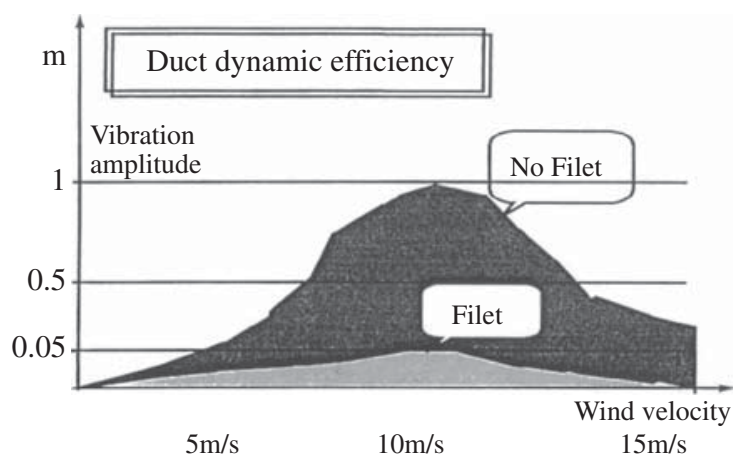

FIGURE 68 Effect of surface modifications on vibration amplitudes (Stubler 1999).
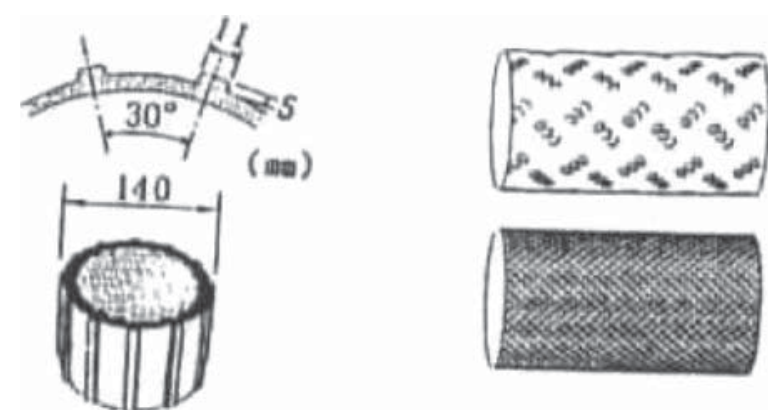

FIGURE 69 Surface modifications on the HDPE (Matsumoto 2000).

damping effect" from cross ties, which can be increased by using more flexible and dissipative ties.

Cable restrainers have also been used as a temporary solution to rain-wind vibrations (Poston 2002). Figure 71 $a$ shows the restrainer system with three lines of cables, and Figures $71 b$ and $c$, respectively, show the measured vibration amplitudes before and after installation of restrainers.

During the construction of the Burlington Bridge over the Mississippi in Iowa, several incidences of rain-wind vibrations were observed with amplitudes of up to $0.6 \mathrm{~m} \mathrm{(2 \textrm {ft } )}$ (Bierwagen no date). Bierwagen reports that temporary ropes in the form of 25-mm or 1-in.-diameter Manila ropes were first used to help tie the cables down. However, the Manila rope broke during a subsequent occurrence of vibrations. There-

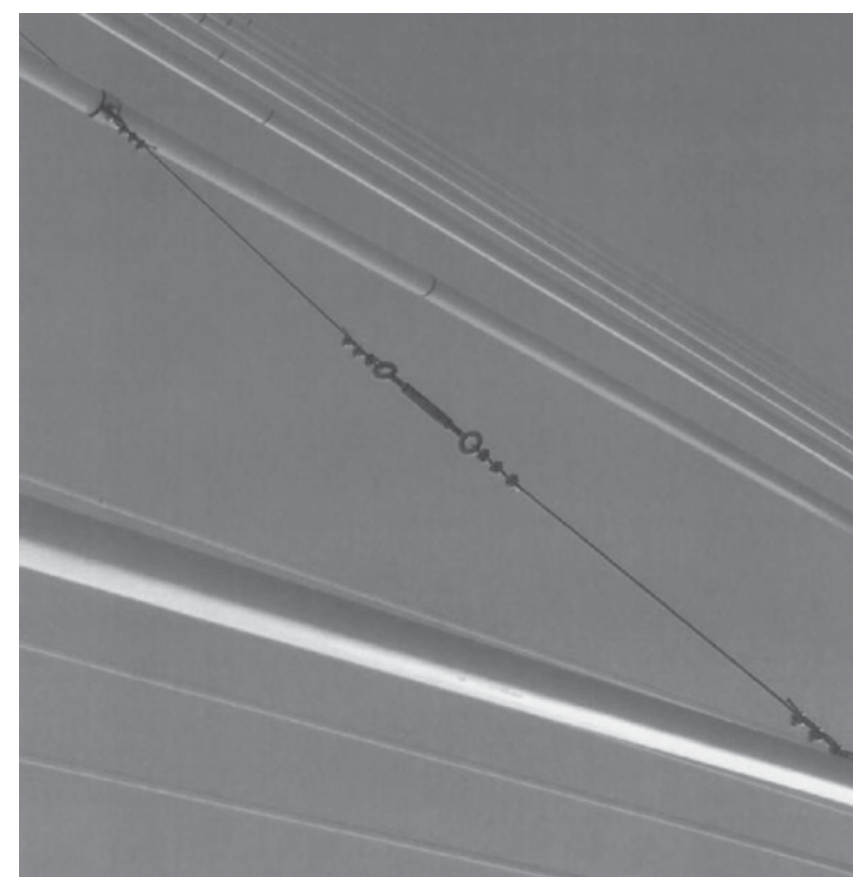

FIGURE 70 Cross cable installed on a bridge in Indiana (courtesy: Indiana DOT). 


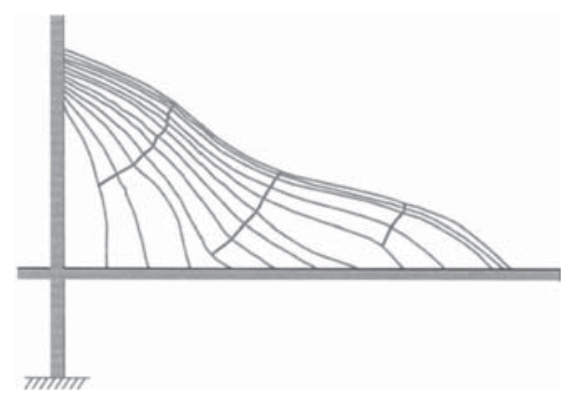

(a)

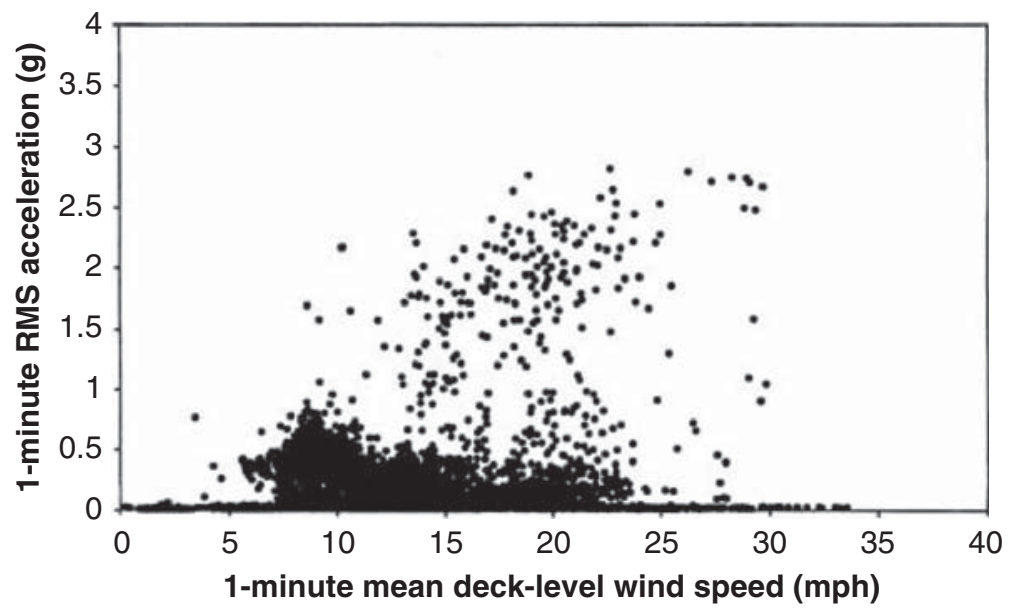

(b)

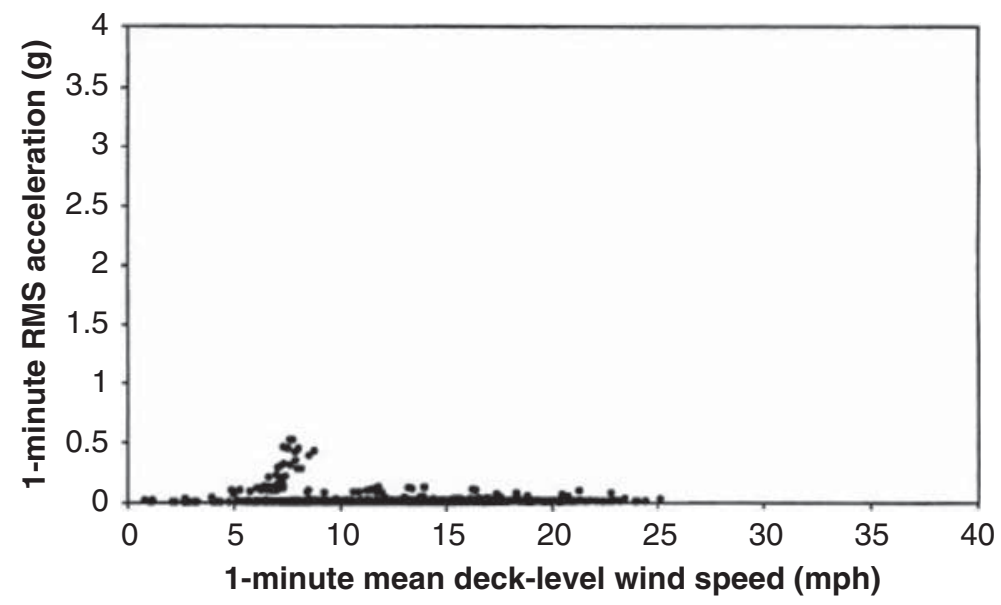

(c)

FIGURE 71 (a) Cable restrainer, (b) vibrations before installation of cross cables, (c) vibrations after installation of restrainers (Poston 2002).

fore, a cross cable system was designed and implemented. Figure 72 shows the layout of cross cables (top) and the method of connection to the cables (bottom). According to Bierwagen, the restraint system included 12.6-mm or 0.5-in.diameter zinc-coated wire ropes that crisscross through the cables and are attached to them using friction clamps. Similar cross cables have also been used on the Clark Bridge in Alton, Illinois.
It is reported that the cross cables should be tensioned properly to prevent slacking of the restrainers (Bournand 1999). Bournand reported that the cross cables on the Fred Hartman Bridge in Texas failed one year after installation as a result of fatigue and fretting. He suggests that "the cables must be designed using a flexible wire rope or similar system (with high internal damping) and with good fatigue and wear resistance." This system was installed on the bridge. Some observers also 

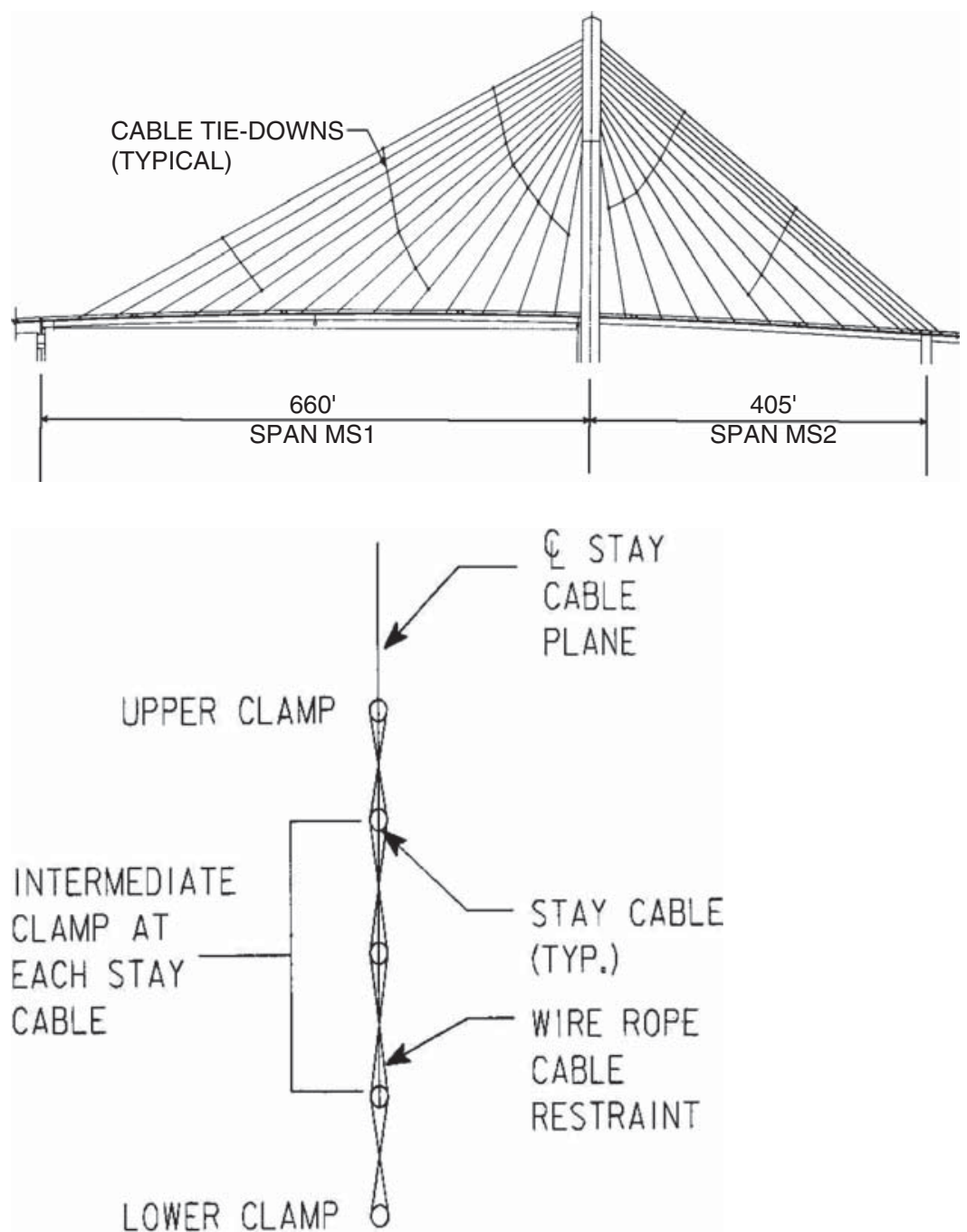

FIGURE 72 Cable restraint system for the Burlington Bridge in lowa (Bierwagen no date).

believe that cross cables reduce the aesthetic quality of cablestayed bridges (Johnson et al. 2002).

Bloomstine and Stoltzner (1999) reported on the failure of a wire cross cable on the Faroe cable-stayed bridge in Denmark. The original system consisted of steel brackets with neoprene linings attached to the cables with stainless steel wire connected in between them. The wires "were wrapped around a thick washer in the bracket and secured by two wire locks." Abrasion between wire and the washer caused the first wire failure after 4 years. A new system using $10-\mathrm{mm}$ marine grade stainless steel wire and turnbuckles was used.

Many respondents to the survey had positive views concerning cross cables, with the ability to inspect them and know whether they are working given as an important factor. Figure 73 shows the results of the survey as related to the use of cross cables.

\section{Viscous Dampers}

In this section, the application of mechanical viscous dampers for suppression of stay cable vibrations is discussed. In general, the term "viscous damper" used here refers to a mechanical damper that generates force proportional to the velocity of piston movements (i.e., it can be idealized as a dashpot). Other investigators sometimes prefer to use the terms "oil damper" or "hydraulic damper," and distinguish them from viscous damper. In this discussion, they are all referred to as viscous damper as long as they meet the definition given.

Viscous dampers for stay cables have been installed on a large number of cable-stayed bridges worldwide, including the Sunshine Skyway Bridge, Cochrane Bridge, and Erasmus Bridge. Figure 74 shows a schematic of a cable of length $L$, with a viscous damper positioned at a distance of $L_{d}$ from one end. 


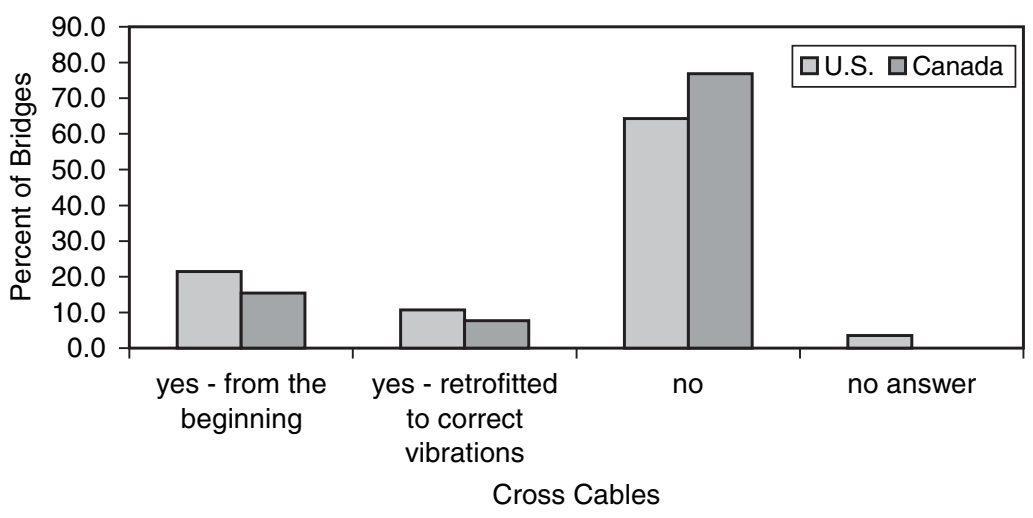

FIGURE 73 Frequency of the use of cross cables.

Several researchers have proposed numerical approaches for determining the contribution of a viscous damper to the overall cable damping. Some of the earlier works were by Kovacs (1982), Yoneda and Maeda (1989), and Pacheco et al. (1993). Each idealized the cable as a taut string when deriving their formulations. In 1999, Xu et al. presented results of their experimental study on control of cable vibrations using viscous dampers.

Tabatabai and Mehrabi (2000) presented a nondimensional formulation that included the effects of cable sag and bending stiffness, and performed parametric studies (using cable parameter ranges from a database of stay cables) to develop an equation for calculating the first mode damping contribution by a viscous damper. This study indicated that the influence of cable sag was insignificant for the range of parameters found in stay cables. However, the influence of cable bending stiffness was found to be important, as dampers are typically located close to the anchorages. Although their formulation was applicable to higher modes as well, their proposed equation was optimized for the first mode only.

Main and Jones (2002) investigated the multi-mode contribution of a linear viscous damper attached to a taut string. They pointed out that damper performance at higher modes is of particular interest, because vibrations occur over a wide range of cable modes. The influences of sag and bending stiffness were ignored.

Main and Jones (2001) discussed the installation of two viscous dampers on the Fred Hartman Bridge in Texas. They analyzed the pre- and post-damper installation response of the cables, and showed that although the dampers were designed for the first mode, they were very effective in controlling all of the high-amplitude vibrations that had been observed before damper installation.

There is a rough "rule-of-thumb" that can be used to estimate the maximum achievable damping (in fraction of critical damping). The maximum damping is approximated as $0.5\left(L_{d} / L\right)$ (Lankin et al. 2000). Therefore, if a damper is located at $2 \%$ of the length of the cable, then the maximum achievable damping is $1 \%$. It is important to realize that the theoretical end of the cable from which $L_{d}$ is calculated is generally different from the actual end. The complicating factors are the varying bending stiffness of the cable at the end, the presence of neoprene dampers, and the presence of steel sockets. Tabatabai et al. (1998b) presented approximate relationships that allow determination of an equivalent effective length for different end conditions.

L

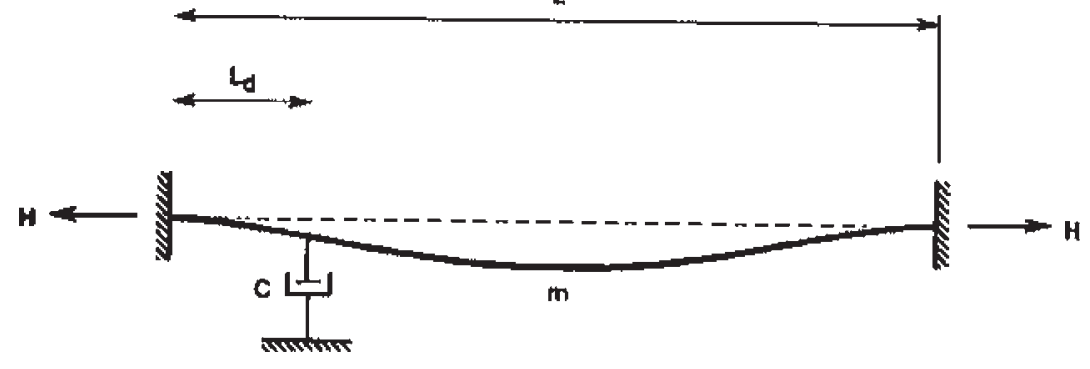

FIGURE 74 Idealized cable with viscous damper (Tabatabai and Mehrabi 2000). 
The respondents to the questionnaire indicated seven bridges with viscous dampers, most of which were installed to correct observed vibrations. There is some concern expected about potential leakage of fluids in such dampers.

\section{Viscoelastic Dampers}

The commonly used neoprene ring can essentially serve as a viscoelastic damper; however, because of difficulty with consistent installation and their variability, their level of damping contribution is difficult to estimate. Tabatabai and Mehrabi (2000) performed tests on a scale stay cable model with and without neoprene rings. The neoprene rings increased damping by more than 10 -fold to $0.6 \%$ of critical damping.

There is at least one cable supplier that is supplying proprietary viscoelastic and hydraulic damping systems. These systems are placed between the HDPE and the guide pipe (or an extension of guide pipe). The viscoelastic damper uses a shaped elastomeric material to damp cable vibrations (Figure 75). It is expected that most suppliers would have their own damping systems in the near future.

Another form of viscoelastic damper is the Super HighDamping Rubber Damper (SDR). Mizoe et al. (1999) presented a damping device that is installed between the cable and the guide pipe (or anchor pipe). When the cable moves, a relative displacement occurs between the cable and the guide pipe causing shear deformations in the damping material. A high-damping material is developed by combining styrene butadiene rubber, high-damping carbon, and some plastics to achieve its properties. Figure 76 shows the SDR damper. These dampers were first installed on two cables of the Meiko East Bridge in Japan for testing. The authors reported that the damping level achieved was confirmed with calculated values. Subsequently, these dampers were installed on most cables of this bridge. They have been in service since 1998, and wind-induced vibrations have reportedly not been observed.

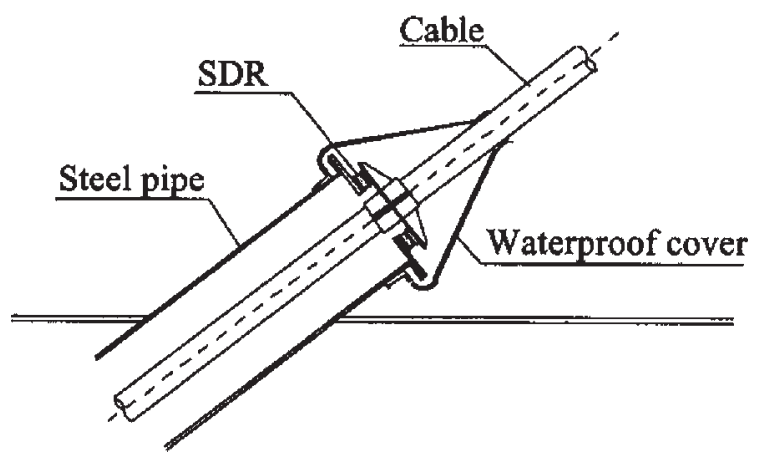

FIGURE 76 SDR damper (Mizoe et al. 1999).

\section{Friction Dampers}

Bournand (1999) reported on the development of a friction damper for stay cables (see Figure 77). This damper system has two parts; a movable part that is attached to the strands by a bolted collar and a fixed part that is bolted to the steel support pipe. The bolted collar has several "friction wings," and the fixed part has several "spring ring blades supporting several friction screws." The ring blades are deflected to have a steady friction contact of the friction screws. This damper type has reportedly been installed on the Uddevalla Bridge in Sweden.

\section{Semi-Active Dampers}

Johnson et al. (2002) presented a theoretical discussion and described the development of semi-active damping for stay cables. A semi-active damper can be a variable-orifice viscous damper, a controllable friction damper, or a controllable fluid damper (Johnson et al. 2000). Computational simulations were used to examine the effectiveness of semi-active damping. The authors reported that the potential for using semi-active dampers to control stay cable vibrations "has been demonstrated" in comparison with passive viscous dampers.

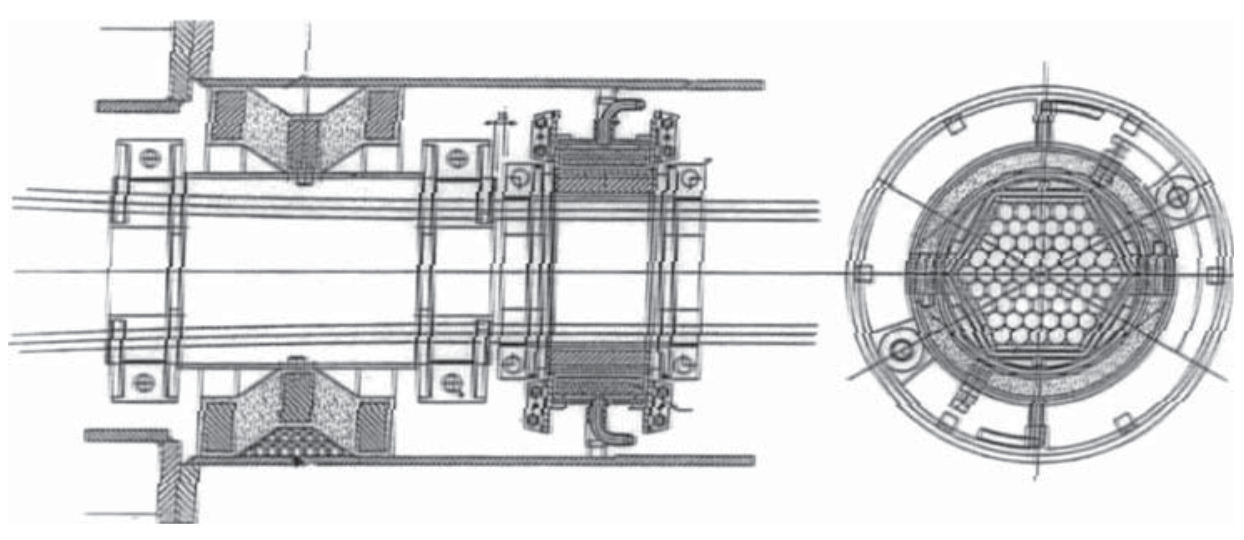

FIGURE 75 Viscoelastic and hydraulic dampers (Stubler et al. 1999). 


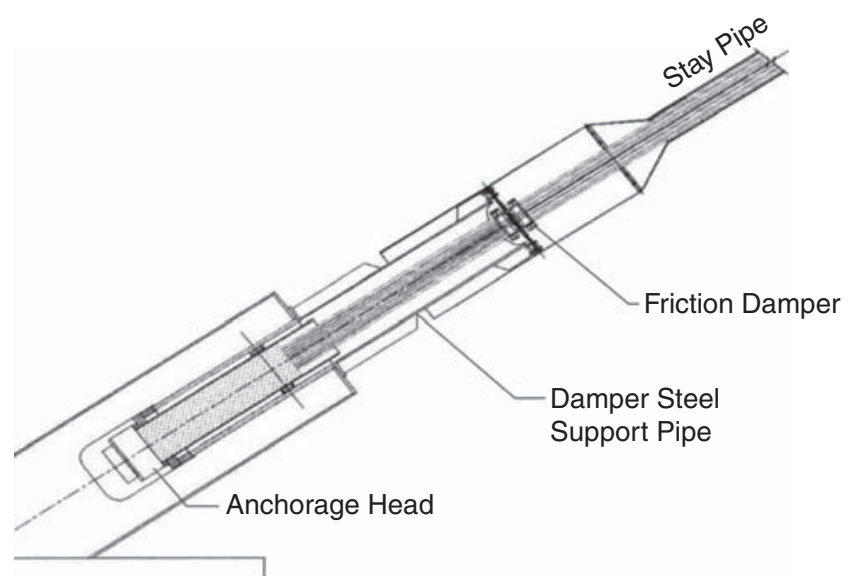

FIGURE 77 Friction damper (Bournand 1999).

Using an optimal control algorithm, the authors stated that a simulated semi-active damper located at $2 \%$ of the distance from the end of cable reduced responses by $71 \%$ compared with an optimal viscous damper and $72 \%$ compared with fully active devices.

Johnson et al. (2000) reported on laboratory experiments on scaled stay cables with a magnetorheological (MR) fluid damper. MR dampers are a type of semi-active damper (controllable fluid) in which the yield stress of the fluid is changeable through variations in magnetic field strength. Laboratory results indicated that the damper was able to achieve "significant" response reductions, but not to the level expected from simulations. Recommendations were made for addressing this problem in future studies.

Ko et al. (2002) reported on field tests of stay cables with MR dampers on the Dongting Lake Bridge in China. Field measurements were taken before and after damper installations. The equivalent damping level was found to be dependent on damper location, voltage applied to damper, and the level of vibration. Under optimum voltage input, the damping ratios for the second and third modes can reportedly be greater than $0.8 \%$ of critical damping. These semi-active dampers are commercially available. Figure 78 shows MR damper installation on a bridge cable in China.

\section{Tuned Mass Dampers}

The tuned mass damper (TMD) is tuned to a particular frequency of interest; for example, the first mode of the cable. The TMD, in its basic mathematical representation, consists of a mass, a spring, and a damping component. By changing the basic properties of the damper, the TMD can be tuned to the right frequency. TMDs have been applied to a variety of structures including power line cables. Tabatabai and Mehrabi (1999) patented a shaped viscoelastic TMD for stay cables.

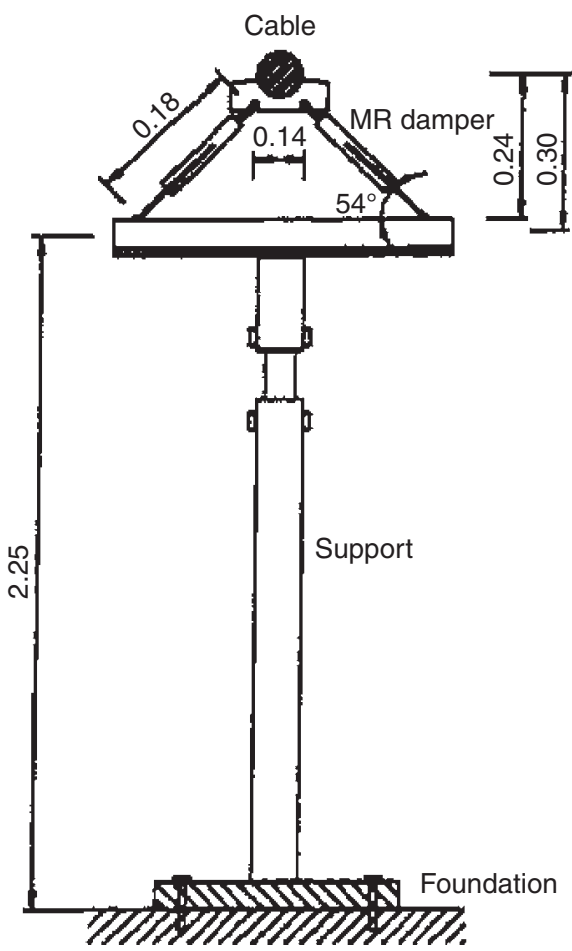

FIGURE 78 MR damper installation on bridge cable in China (Ko et al. 2002).

The main advantage of the TMD is that it is not restricted to the cable ends. The main disadvantage is that it can only be tuned to a particular frequency, and its effectiveness is reduced at other frequencies.

Jensen et al. (2002) proposed using a TMD between two cables at mid-length. In their article, the authors present an analytical formulation for their concept.

\section{Other Damping Systems}

Tabatabai and Mehrabi (2000) reported on damping tests on a scale model of a stay cable. They tested a number of approaches for cable damping including using common neoprene rings, latex grout as filler inside HDPE, a liquid damper, application of spiral adhesive damping tapes around HDPE, and filling of the guide pipes with a low stiffness polyurethane. They concluded that the conventionally used neoprene ring improved cable damping significantly to $0.4 \%$ to $0.6 \%$ of critical damping (compared with a damping of $0.05 \%$ for cable without neoprene ring). They suggested that the effectiveness of neoprene rings is influenced by the degree of precompression in the neoprene ring and any restraint of ring movement in the transverse direction. The use of latex grout increased cable damping by $60 \%$, but not to the level needed for control of rain-wind vibrations. They also concluded that the liquid damper and damping tapes did not significantly improve damping. Filling of guide pipes 
around HDPE with polyurethane improved cable damping somewhat, but not to the level achieved by a properly installed neoprene ring. The authors suggested experimenting with higher stiffness polyurethanes as a possible effective approach. It is interesting to note however that Yamaguchi et al. (1999) reported that filling "rubber seals into the entrance of cable in the girder" in some cables of the Tatara Bridge in Japan reduced incidences of vortex-induced vibrations, and they consider this to be an efficient solution for long cables.

There are a number of other patented concepts for damping stay cable vibrations including flexible damper bands by Sarkar et al. (2002) and two separate patents on active damper bands with shiftable mass by Phelan et al. (2002, 2004).

\section{CHALLENGES IN MAINTENANCE, REPAIR,} AND RETROFIT

The main challenges in maintenance and repair are:

- Determining the condition of the anchorage elements, especially those that include cement grout or epoxy fillers, at reasonable cost and with reasonable confidence.

- Proper and safe access for inspection of cables.

- Methods and procedures to replace existing cables on a number of aging bridges, when needed.

- Control and elimination of moisture and corrosion inside cable components.

- Vibration control and fatigue issues associated with vibrations.

- Insufficient sharing of knowledge and training for those responsible for maintaining cable-stayed bridges. 


\section{FUTURE TRENDS}

It is anticipated that several of the following trends will dominate the design, construction, and maintenance of stay cables in the next 2 to 5 years. Some of these trends have already taken hold.

- Stay cable systems supplied by U.S. manufacturers will finally converge and settle (at least for a time) on a system composed of wedge anchorages, greased-and-sheathed strands (possibly galvanized), and co-extruded HDPE pipe with helical strakes on the surface. Grout will likely not be used in many cases. Strands will be changeable, at least in theory. Issues related to performance of anchorages during earthquakes may force a reconsideration of wedge systems in seismically active areas.

- Stay cable manufacturers will include additional features and options on their stay systems such as strand force measurements, damper systems that are contained within the guide pipe or in the vicinity of guide pipes, removable test strands, and visible or inspectable anchorages and MTEs.
- Video monitoring systems for cable vibrations may become available and widely used.

- More tools and procedures that would allow inspectors to improve the effectiveness of visual surveys will become available.

- Built-in damage monitoring systems may be developed for the anchorage zones (based on magnetic method or guided stress waves), perhaps included as an option on supplier's systems.

- Methods that will likely become common for nondestructive evaluation of existing grouted/ungrouted cables are acoustic monitoring, vibration-based force measurements, ultrasonic testing of anchorages, impulse radar surveys, infrared thermography, and magnetic methods for assessing conditions in the free length of cable. Radiographic methods will also have their place; however, safety and cost issues continue to limit their usage.

- Global sensor-based cable damage detection algorithms will be further developed and begin to be used. 


\section{CONCLUSIONS AND FUTURE RESEARCH NEEDS}

For this synthesis effort, a worldwide search was undertaken for information on the inspection, repair, testing, and design of stay cable. On-line sources of information as well as engineering databases were examined. A number of knowledgeable individuals were contacted for additional information. A questionnaire was distributed among all state departments of transportation in the United States and provincial departments of transportation in Canada. Based on this information, various methods, approaches, and practices have been explained in detail and their strengths and weaknesses identified. Specific inspection and repair approaches are presented and discussed.

The challenges in inspection and maintenance of cablestayed bridges are substantial. Those who are tasked with inspection and maintenance of stay cables confront challenges for which proven and accepted methodologies and tools are limited and, in many cases, very costly. The main tension elements (MTEs) within a cable bundle are, in most cases, hidden from the view of inspectors. Access to cables for visual inspections or nondestructive testing (NDT) is often difficult and, in the case of the anchorage zones, almost impossible.

At the time of this study there were 36 cable-stayed bridges in the United States and 16 in Canada. As of 2005, the average age of such bridges in the United States was 11.4 years. As these bridges become older, the need for effective inspection and maintenance methods and tools becomes more important. Because no one method is sufficient, a combination of methods is necessary.

The following table lists some of the issues involved in the inspection, maintenance, and repair of stay cables. Methods identified in the literature to address those issues and their known advantages and disadvantages, as well as other factors are discussed.

\begin{tabular}{ll}
\hline Issue & Method \\
\hline General inspections & Visual \\
& \\
& \\
& \\
& \\
Assessment of MTE & Magnetic \\
condition in free & flux \\
length & leakage
\end{tabular}

Comments

Visual inspections are, in most cases, the only method used for cable-stayed bridges. These inspections typically include surveys of the exterior surfaces of cables, exposed surfaces of the anchorages, cross cables and their connections (if available), dampers (if available), and conditions of neoprene boots and guide pipes. However, inspections of neoprene rings inside guide pipes are also done in some inspections. Boroscopes or videoscopes can be used to check the exterior condition of the cable and presence of moisture inside the guide pipe. Anchorage caps can sometimes be removed to check the condition of wedges or button heads. Visual inspections could potentially involve measurements of cable sag and the inclination angle by the inspector from the deck level using simple photogrammetric or optical devices.

This system has a long history in the inspection of industrial cables and ropes. Systems that can travel along the stay cable are commercially available. This method does not work well with cables that have steel sheathing. The cable size cannot be too large in diameter. Depending on the size of the magnet or electromagnet used, the range of detection would be limited to a thickness around the perimeter. The system can identify the extent of damage and its location along the length of cable, but cannot identify location of damage within the cross section. In its current state of development, this method cannot be used for inspections in the anchorage zones and in the vicinity of the anchorage zones. Unfortunately, those are the areas where most serious problems have occurred.

Assessment of MTE Cable force condition measurements
Assessment of MTE Ultrasonic condition
This approach is the most widely used, and sometimes misunderstood, nondestructive evaluation (NDE) method. Measurement of cable forces (through the methods described) can help determine if global stiffness changes have occurred in cables. Methods such as the Precursor Transformation Method (discussed in chapter four) can then be used to identify which cables are affected. However, damage in the form of MTE section loss does not necessarily translate into global stiffness change. This is particularly true in grouted cables, where a broken wire can redevelop its stress a short distance away. Therefore, when cable forces in a grouted cable array do not change over time, it cannot necessarily be concluded that there is no loss of MTE.

This method has been used on a few bridges to evaluate the condition of MTEs in Hi-Am-type anchorages. A stress wave is sent into the exposed end of a wire or strand at the anchorage and the results are displayed. There has been no been systematic and controlled evaluation of this method to determine its degree of effectiveness for stay cable anchorages. Therefore, ultrasonic 


\begin{tabular}{|c|c|c|}
\hline Issue & Method & Comments \\
\hline
\end{tabular}
Assessment of MTE Radiography
condition

Detection of wire breaks as they happen

Detection of grout voids inside highdensity polyethylene pipe (HDPE)

sheathing

Repair of large grout voids

Cable force measurements

Cable force measurements

Cable force measurements

Detection of hidden splits in HDPE

Detection of damage to polyvinyl fluoride tape

Assessment of cable vibrations

Acoustic monitoring

Impulse radar

Vacuum grouting using laser vibrometer

using accel-

erometer

Based on of cable sag

Long-term tests on cable anchorages for any bridge should ideally first be calibrated with a mock-up of the same anchorage with known defects. Seven-wire strands pose a larger challenge than individual wires because of the complexities of transmission of stress waves in them. The operator must be highly qualified in such tests, because the judgment of the operator is crucial, and the answers in many cases would not be clearly evident. Problems arise owing to the anchorage materials surrounding the MTEs. The stress wave attenuates significantly in a wire embedded in grout or epoxy compared with a wire in air. This method is not applied to the MTEs in the free length of cable. Unfortunately, this is the only known and practical test that is currently available for the assessment of MTEs in the anchorage zones of typical U.S. stay cables.

Theoretically, this method has the potential to successfully assess conditions of cable anchorages where access to the perimeter can be achieved. This method was used on the anchorages of the Meridian Bridge in California. However, safety issues, cost, and the typically large and heavy equipment have significantly limited their use.

The test laboratories performing qualification fatigue tests of stay cables have long used this method to detect wire breaks in the cable specimens as they happen. As a wire breaks, a stress wave travels along the length of the cable in both directions. Accelerometers attached at the anchorage can detect the event and determine its location along the cable. The recorded response or "signature" can be analyzed to determine if the event is actually a wire break. A commercial system is currently available and has been installed on a number of bridges. This system has proprietary software to identify wire breaks. In grouted cables, the attenuation of the wave is significantly higher than in the ungrouted cables.

Hand-held impulse radar equipment can be placed over the cable and moved longitudinally to identify potential grout voids inside the cable sheathing. This method has been tested on mock-up specimens involving HDPE sheathing. A field application of this method is planned.

Vibration-based

This method has long been used in post-tensioning tendon applications. A vacuum is used to ensure that the grout would fill all the voids in the affected area. Specialty post-tensioning contractors can perform these tasks.

In this method, a laser vibrometer is used to measure small vibrations of the cable from a large distance. No special targets need to be placed on the cable. A low-power laser beam (class 2 laser) is used. The measured response is then used to determine the frequencies of vibration. The measured frequencies are then used to calculate force. One should note that to improve accuracy the effects of bending stiffness, neoprene rings, and socket stiffness changes should be considered. When cross cables or dampers are used, the calculation process becomes more difficult. Using an accelerometer in lieu of a laser vibrometer is expected to provide similarly accurate results. However, in some cases, the laser vibrometer could speed up the measurement process.

Vibration-based Similar to the laser-based method described previously. measurement

Although the tension in a cable is related to the square of the fundamental frequency, it is also inversely proportional to the cable sag. Therefore, measurements of the cable sag can also be used to estimate cable tension. It is expected that the cable sag could be measured by inspectors from the deck level using simple photogrammetric or optical methods. This approach has apparently not yet been used for inspections; however, contractors have reportedly used it during construction.

Infrared Hand-held infrared thermography equipment can be used to detect splits in HDPE pipes that thermography are hidden under the protective tape. This method has been tested on mock-up specimens involving HDPE sheathing. A field application of this method is planned. However, tests indicated potential problems in using ambient temperature changes to monitor such defects. The test report suggested that external thermal applications may be required.

Infrared Similar to the method discussed previously.

thermography

When cable vibration problems are suspected, sensors (accelerometers) can be mounted on select monitoring using cables to monitor vibrations over a period of several weeks, months, or years. Typically, a accelerometers weather station is also installed on the bridge to obtain local wind and rain information. The data are collected through a high-speed data acquisition system, and typically transmitted to the engineer by means of conventional or wireless communications. The vibration amplitudes and associated frequencies are then studied in conjunction with rain and wind data to assess vibration conditions. 


\begin{tabular}{lll}
\hline Issue & Method & Comments \\
\hline $\begin{array}{l}\text { Assessment of } \\
\text { cable vibrations }\end{array}$ & $\begin{array}{l}\text { Video cameras } \\
\text { on bridge }\end{array}$ & $\begin{array}{l}\text { There are no known instances of using video cameras to monitor vibrations on cable-stayed } \\
\text { bridges. However, this option was discussed for two bridges in the path of hurricanes, but was } \\
\text { not implemented. There is research (discussed in chapter three) on using photogrammetric } \\
\text { techniques to measure structural vibrations. }\end{array}$ \\
$\begin{array}{l}\text { Assessment of } \\
\text { cable damping }\end{array}$ & $\begin{array}{l}\text { Vibration } \\
\text { decay method }\end{array}$ & $\begin{array}{l}\text { There are different approaches to measuring cable damping. In one, an accelerometer is first } \\
\text { attached on the cable. Then, a rope is placed around the cable and around an individual standing } \\
\text { on the deck next to the cable. The individual pushes back on the rope in a rhythmic fashion try- } \\
\text { ing to match the frequency of the cable. At the same time, the individual would pull the rope } \\
\text { higher along the cable. When the cable achieves sufficiently high-vibration amplitudes, the } \\
\text { cable is allowed to slow down while the accelerometer is monitored. The time it takes to decay } \\
\text { the signal is used to calculate the damping ratio. }\end{array}$ \\
\hline
\end{tabular}

There is no single method that would answer all of the questions regarding the condition of stay cables. In most cases, it is the combination of NDT techniques together with the experience, knowledge, and judgment of engineers, inspectors, and technicians that can possibly lead to the appropriate answer. The effectiveness and accuracy of many of the methods described here would be significantly enhanced if baseline comparative measurements were available when the bridge is known to be defect free.

Based on the results of this effort, it is recommended that the following research be undertaken:

- Consider the possibility of establishing minimum requirements for the information that must be included in the inspection and maintenance manuals for cable-stayed bridges. A list of possible topics is included in this report.

- Study the strengths and limitations of ultrasonic testing of MTEs in various types of anchorages.

- Study the effectiveness of visual inspection techniques, and the development of visually inspectable stay cable systems.

- Review the feasibility of built-in or remote inspection and imaging systems for the monitoring of MTE condi- tions in the cables (especially anchorages) for incorporation into new cable designs.

- Undertake the identification of the appropriate choice and use of combinations of NDE methods based on the conditions at hand.

- Study the feasibility of global, three-dimensional, physical mapping of stay cables and the entire cable-stayed bridge.

- Study the development of safe and effective cable inspection vehicles that can travel along cable length and carry NDE test hardware. It may be possible that different states with similar cable systems can share the equipment.

- Undertake the development of a national resource for information on stay cables and cable-stayed bridges to assist bridge owners and others with information on inspections, maintenance, and testing of stay cables; new trends and methods; and a statistical database of cable information. Creation of a database of information on stay cables was strongly supported (90\%) by the respondents to the questionnaire.

- Study the development of national or regional periodic training programs for state engineers and inspectors responsible for cable-stayed bridges to learn about new developments and to share their experiences. 


\section{REFERENCES}

Aas-Jakobsen, K., E. Jordet, and S.K. Rambjor, "Full-Scale Measurements of the Behavior of the Helgeland Bridge, A Cable Stayed Bridge Located in a Harsh Environment" [Online]. Available: http://www.aas-jakobsen.no/Bridges/ Publications/Helgeland_Bridge/full_scale_measurements. Akers, D.W. and C.A. Rideout, "Innovative Nondestructive Inspection Technology for Quantifying Deterioration in Bridge Structures and Cables Using Induced Positron Annihilation Technologies," Proceedings of Structural Materials Technology (SMT): NDE/NDT for Highways and Bridges, Buffalo, N.Y., Sep. 2004.

Andersen, E.Y., D.L. Hommel, and E.M. Veje, "Emergency Rehabilitation of the Zarate-Brazo Largo Bridges, Argentina," Proceedings of the IABSE Conference, CableStayed Bridges, Past, Present, and Future, Malmo, Sweden, June 1999, pp. 698-706.

Angelo, W., "Lasers Ensure Stay Cable Safety," Engineering News Record, Vol. 239, No. 4, July 28, 1997, pp. 10-11.

"B\&N Creates Custom Device for Florida Cable-Stay Inspection," brochure, Burgess \& Niple, Columbus, Ohio, 2005.

Bartels, K.A., H. Kwun, and J.J. Hanley, "Magnetostrictive Sensors for the Characterization of Corrosion in Rebars and Prestressing Strands," SPIE Proceedings, Vol. 2946, 1996, pp. 40-50.

Barton, J.R., C.M. Teller, and S.A. Suhler, Design, Develop, and Fabricate a Prototype Nondestructive Inspection and Monitoring System for Structural Cables and Strands of Suspension Bridges, Report FHWA-RD-89-158, Federal Highway Administration, Washington, D.C., 1989, 133 pp.

Barton, S.C., G.W. Vermaas, P.F. Duby, A.C. West, and R. Betti, "Accelerated Corrosion and Embrittlement of HighStrength Bridge Wire," Journal of Materials in Civil Engineering, Vol. 12, No. 1, Feb. 2000, pp. 33-38.

Bergamini, A., R. Christen, and M. Motavalli, "A Simple Approach to the Automatic Recognition of Flaws in Large Diameter Steel Cables," 2003 [Online]. Available: http://www.ndt.net/article/ndtce03/papers/p019/p019.htm.

Bierwagen, D., "Burlington Cable-Stayed Bridge Design and Construction Summary," Iowa Department of Transportation Office of Bridges and Structures, informational report prepared for FHWA and others, 33 pp., nd.

Bloomstine, M.L. and E. Stoltzner, "The Faroe Cable-Stayed Bridge-Maintenance Experience with Major Components," Proceedings of the IABSE Conference, Cable-Stayed Bridges, Past, Present, and Future, Malmo, Sweden, June 1999, pp. 688-697.

Bournand, Y., "Development of New Stay Cable Dampers," Proceedings of the IABSE Conference, Cable-Stayed Bridges, Past, Present, and Future, Malmo, Sweden, June 1999, pp. 559-566.

Bridge Design and Engineering, London, United Kingdom, 2005 [Online]. Available: http://www.bridgeweb.com/ magazine/FeatureDetails.cfm?ArticleID=9.
Brönnimann, R., P.M. Nellen, and U. Sennhauser, “Application and Reliability of a Fiber Optical Surveillance System for a Stay Cable Bridge," Smart Materials and Structures, Vol. 7, 1998, pp. 229-236.

Brown, J.L., "Hong Kong to Boast World's Longest CableStayed Bridge," Civil Engineering, Vol. 71, No. 1, Jan. 2001a, p. 10.

Brown, J.L., "Long Cable-Stayed Span Planned for St. Louis," Civil Engineering, Vol. 71, No. 11, Nov. 2001b, p. 16.

Brown, K. and J. St Leger, "Use of the Megascan"TM Imaging Process Inspection Systems for Post-Tensioned Bridge and Other Major Structures," 2003 [Online]. Available: http://www.ndt.net/article/ndtce03/papers/v021/ v021.htm.

Bruce, R., R. Drake, C. Sperry, and H. Thompson, “Aerodynamic Monitoring of the Cable-Stayed Mississippi River Bridge," IABSE Colloquium: Monitoring of Large Structures and Assessment of Their Safety," Bergamo, Italy, IABSE Reports, Vol. 56, 1987, pp. 191-203.

"Cable Stays of Cable-Stayed Bridges," Technical Advisory T 5140.25, Federal Highway Administration, Washington, D.C., June 17, 1994.

Casas, J.R., "A Combined Method for Measuring Cable Forces: The Cable-Stayed Alamillo Bridge, Spain," Structural Engineering International, No. 4, 1994, pp. 235-240.

Christenson, R.E., B.F. Spencer, and E.A. Johnson, "Experimental Verification of Semiactive Damping of Stay Cables," Proceedings of the 2001 American Control Conference, Arlington, Va., June 25-27, 2001, pp. 5058-5063.

Christoffersen, J., L. Hauge, H. Elgaard Jensen, and J. Bjerrum, "Design and Construction of a CFRP Cable Stayed Footbridge," Proceedings of the IABSE Conference, CableStayed Bridges, Past, Present, and Future, Malmo, Sweden, June 1999, pp. 135-144.

Ciolko, A.T. and H. Tabatabai, "Condition Evaluation of Prestressed Steel Strands in Concrete Bridges," Document 23, Transportation Research Board, National Research Council, Washington, D.C. [Online]. Available: http://www4. nationalacademies.org/trb/CRP.nsf/all+projects/NCHRP+ 10-53 [Sep. 1999].

Ciolko, A.T. and W.P. Yen, "An Immediate Payoff from FHWA's NDE Initiative,” Public Roads, May/June 1999, Vol. 62, No. 6, pp. 10-17.

Cunha, A. and E. Caetano, "Dynamic Measurements on Stay Cables of Cable-Stayed Bridges Using an Interferometry Laser System,” Experimental Techniques, May/June 1999, pp. 38-43.

Desimone, C., P. Katchadjian, M. Tacchia, and R. Giacchetta, "Damage Detection on Wires of Ropes Applying Ultrasonic Waves," 10th Asia-Pacific Conference on NonDestructive Testing, Brisbane, Australia, Sep. 17-21, 2001 [Online]. Available: http://www.ndt.net/article/apcndt01/ papers/1023/1023.htm. 
Dowd, J., M. Poser, K.H. Frank, S.L. Wood, and E.B. Williamson, "Bending Fatigue of Cable Stays," Journal of Bridge Engineering, Vol. 6, No. 6, Nov./Dec. 2001, pp. 639-644.

DSI, "Maumee Stay Cable Bridge Breaks World Record" [Online]. Available: http://www.dywidag-systems.com/ docs/markets.php? market $=$ Bridges $\&$ content $=$ maumee, 2004.

Elgamal, A., F. Seible, F. Vernon, M. Trivedi, and M. Fraser, "On-Line Structural Monitoring and Data Management," Proceedings of the 6th Seismic Research Workshop, California Department of Transportation, Sacramento, June 2001.

Elliott, M.E. and E. Heymsfield, "Inspection of Luling Bridge Cable Stays: Case Study," Journal of Construction Engineering and Management, Vol. 129, No. 2, April 2003, pp. 226-230.

Fisher, K. and S. Bassett, "Cables, Strands, and Rods Keep Tension High," High-Performance Composites, July/Aug. 1997, pp. 23-29.

Frank, K.H. and J.E. Breen, "Durability of Stay Cable," Proceedings of the High Performance Stay Cable Systems Seminar, sponsored by Freyssinet International, Washington, D.C., Oct. 1, 2004.

Funahashi, M., "Reliable Corrosion Protection for Bridge Stay Cables," Concrete International, Vol. 17, No. 2, Feb. 1995, pp. 33-37.

Ghorbanpoor, A., "Evaluation of Prestressed Concrete Girders Using Magnetic Flux Leakage," Proceedings of the 1999 ASCE Structures Congress, Structural Engineering in the 21st Century, New Orleans, La., Apr. 1999, pp. 284-287.

Gimsing, N.J., Cable-Supported Bridges-Concept and Design, 2nd ed., John Wiley, Chichester, West Sussex, England, 1998, 471 pp.

Gimsing, N.J., "History of Cable-Stayed Bridges," Proceedings of the IABSE Conference, Cable-Stayed Bridges, Past, Present, and Future, Malmo, Sweden, June 1999, pp. 8-24.

Grant, A., "Cables Not in Trouble," Civil Engineering, Vol. 61, No. 5, May 1991, pp. 61-63.

Hamilton, H.R. and J.E. Breen, "International Survey of Current Opinion on Bridge Stay Cable Systems," Proceedings of the IABSE Symposium Extending the Lifespan of Structures, San Francisco, Calif., Aug. 23-25, 1995, pp. 843-853.

Hamilton, H.R., J.E. Breen, and K.H. Frank, "Bridge Stay Cable Corrosion Protection. I: Grout Injection and Load Testing," Journal of Bridge Engineering, Vol. 3, No. 2, May 1998a, pp. 64-71.

Hamilton, H.R., J.E. Breen, and K.H. Frank, "Bridge Stay Cable Corrosion Protection. II: Accelerated Corrosion Tests," Journal of Bridge Engineering, Vol. 3, No. 2, May 1998b, pp. 72-81.

Harris, C.A., "Cradle System Anchors Stay Cables to Decks," Civil Engineering, Vol. 72, No. 3, 2002, p. 36.
Hemmert, H.A. and S. Sczyslo, "Corrosion Protection of Locked Coil Ropes at Road Bridges," Proceedings of the IABSE Conference, Cable-Stayed Bridges, Past, Present, and Future, Malmo, Sweden, June 1999, pp. 586-595.

Hooks, J., et al., "FHWA Study Tour for Advanced Composites in Bridges in Europe and Japan," National Transportation Library, Washington, D.C., Oct. 1997 [Online]. Available: http://ntl.bts.gov/DOCS/advcom3a.html.

"Immersion of Stays Protects Bridge Cables," Civil Engineering News, Vol. 5, No. 1, Feb. 1993, p. 9.

Irwin, P., "Wind Vibrations of Cables on Cable-Stayed Bridges," Proceedings of the ASCE Structures Congress XV, Building to Last, Vol. 1, Portland, Ore., April 13-16, 1997, pp. 383-387.

Ito, M., "Stay Cable Technology: Overview," Proceedings of the IABSE Conference, Cable-Stayed Bridges, Past, Present, and Future, Malmo, Sweden, June 1999, pp. 481-490.

Jensen, C.N., S.R.K. Nielsen, and J.D. Sorensen, "Optimal Damping of Stays in Cable-Stayed Bridges for In-Plane Vibrations," Journal of Sound and Vibration, Vol. 256, No. 3, 2002, pp. 499-513.

Johnson, E.A., G.A. Baker, B.F. Spencer, and Y. Fujino, "Semiactive Damping of Stay Cables," 2002 [Online]. Available: http://rcf.usc.edu/ johnsone/papers/smartdamping_tautcable_jem.html.

Johnson, E.A., G.A. Baker, B.F. Spencer, and Y. Fujino, "Mitigating Stay Cable Oscillation Using Semiactive Damping," Proceedings of the Smart Structures and Materials 2000: Smart Systems for Bridges, Structures, and Highways, S.C. Liu, Ed., SPIE, Vol. 3988, pp. 207-216.

Jones, N.P. and M. Porterfield, "Measurement of Stay-Cable Vibration," Proceedings of the ASCE Structures Congress XV-Building to Last, ASCE, Portland, Ore., April 13-16, 1997, pp. 1290-1294.

Keating, S., T.N. Claytor, A. Davis, and M. Sheats, "Technological Advancements for High-Speed Industrial Computed Tomography," Proceedings of the Structures Congress 2000_Advanced Technology in Structural Engineering, Philadelphia, Pa., May 8-10, 2000.

Kitagawa, M., S. Suzuki, and M. Okuda, "Assessment of Cable Maintenance Technologies for Honshu-Shikoku Bridges," Journal of Bridge Engineering, Vol. 6, No. 6, Nov./Dec. 2001, pp. 418-424.

Ko, J.M., G. Zheng, Z.Q. Chen, and Y.Q. Yi, "Field Vibration Tests of Bridge Stay Cables Incorporated with MagnetoRheological (MR) Dampers," Proceedings of SPIE-The International Society for Optical Engineering, Vol. 4696Smart Structures and Materials 2002, Smart Systems for Bridges, Structures, and Highways, pp. 30-40.

Kovacs, I., "Zur frage der seilschwingungen und der seildampfung," Die Bautechnik, 10, pp. 325-332 (in German).

Kumarasena, S., N.P. Jones, P. Irwin, and P. Taylor, Wind Induced Vibration of Stay Cables, Report submitted to the 
Federal Highway Administration, Contract No. DTFH6199-C-00095, 2002.

Kwun, H., "Waves of the Future," SwRI Technology Today Article, 2003 [Online]. Available: http://www.swri.edu/ 3pubs/ttoday/fall03/Future.htm.

Lankin, J., J. Kilpatrick, P.A. Irwin, and N. Alca, "WindInduced Stay Cable Vibrations-Measurement and Mitigation," Proceedings of the ASCE Structures Congress, Philadelphia, Pa., May 8-10, 2000.

Larose, G.L. and L. Wagner Smitt, "Rain/Wind Induced Vibrations of Parallel Stay Cables," Proceedings of the IABSE Conference, Cable-Stayed Bridges, Past, Present, and Future, Malmo, Sweden, June 1999, pp. 310-311.

Little, B., R. Staehle, and R. Davis, "Fungal Influenced Corrosion of Post-Tensioned Cables," International Biodeterioration and Biodegradation, Vol. 47, No. 2, 2001, pp. 71-77.

Liu, W., R. Hunsperger, M. Chajes, K. Folliard, and E. Kunz, "Corrosion Detection of Steel Cables Using Time Domain Reflectometry," Journal of Materials in Civil Engineering, Vol. 14, No. 3, 2002, pp. 217-223.

Main, J.A. and N. P. Jones, "A Comparison of Full-Scale Measurements of Stay Cable Vibration," Proceedings of the ASCE Structures Congress, Philadelphia, Pa., May 8-10, 2000.

Main, J.A. and N.P. Jones, "Evaluation of Viscous Dampers for Stay-Cable Vibration Mitigation," Journal of Bridge Engineering, Vol. 6, No. 6, Nov./Dec. 2001, pp. 385-397.

Main, J.A. and N.P. Jones, "Free Vibrations of Taut Cable with Attached Damper: I. Linear Viscous Damper," Journal of Engineering Mechanics, Vol. 128, No. 10, Oct. 2002, pp. 1062-1071.

Marsh, D., "Cable Ready," Concrete Products, April 2003 [Online]. Available: http://concreteproducts.com/mag/ concrete_cable_ready/.

Matsumoto, M., "Inclined Cable Aerodynamics of CableStayed Bridges," Proceedings of the ASCE Structures Congress, Philadelphia, Pa., May 8-10, 2000.

Mayrbaurl, R.M. and S. Camo, NCHRP Report 534: Guidelines for Inspection and Strength Evaluation of Suspension Bridge Parallel-Wire Cables, Transportation Research Board, National Research Council, Washington, D.C., 2004.

Mehrabi, A.B., H. Tabatabai, and H.R. Lotfi, "Damage Detection in Structures Using Precursor Transformation Method," Journal of Intelligent Material Systems and Structures, Vol. 9, No. 10, Oct. 1999, pp. 808-817.

Miyazaki, M., "Aerodynamic and Structural Dynamic Control System of Cable-Stayed Bridge for Wind Induced Vibration," Proceedings of the IABSE Conference, Cable-Stayed Bridges, Past, Present, and Future, Malmo, Sweden, June 1999, pp. 86-94.

Mizoe, M., S. Muroi, T. Horii, T. Isobe, R. Kiyota, and Y. Imada, "The Super High Damping Rubber Damper on the
Stay Cables of the Meiko East Bridge," Proceedings of the IABSE Conference, Cable-Stayed Bridges, Past, Present, and Future, Malmo, Sweden, June 1999.

Noro, T., S. Konno, and H. Maikuma, "Material Properties of Carbon-Fiber Cables for Suspension Bridges," Proceedings of the IABSE Conference, Cable-Supported Bridges, Challenging Technical Limits, Seoul, Korea, June 12-14, 2001, pp. 126-127.

Pacheco, B.M., Y. Fujino, and A. Sulekh, "Estimation Curve for Modal Damping in Stay Cables with Viscous Damper," Journal of Structural Engineering, Vol. 119, No. 6, June 1993, pp. 1961-1979.

Phelan, R.S., P.P. Sarkar, K.C. Mehta, T.B. Gardner, and Z. Zhan, "Distributed Aerodynamic and Mechanical Damping of Cables with Active Smart Control," USPTO Patent No. 6,435,323 B2, Aug. 20, 2002.

Phelan, R.S., P.P. Sarkar, K.C. Mehta, T. B. Gardner, and Z. Zhan, "Cable Stay Damper Band and Method of Use for Reduction of Fluid Induced Cable Vibrations," USPTO Patent No. 6,705,440 B2, Mar. 16, 2004.

Pla-Rucki, G.F. and M.O. Eberhard, "Imaging of Reinforced Concrete: State-of-the-Art Review," Journal of Infrastructure Systems, Vol. 1, No. 2, June 1995, pp. 134-141.

Podolny, W., "Cable-Stayed Bridges-Future Developments, North American Viewpoint," ASCE Annual Convention, New York, N.Y., Sep. 13-17, 1992.

Poston, R.W., "Evaluation and Mitigation of Rain Vibration of Stay Cables," 2002 [Online]. Available: http://www. asbi-assoc.org/news_research/winter_02/vibration.cfm.

Prato, C.A. and M.A. Ceballos, "Dynamic Bending Stresses Near the Ends of Parallel-Bundle Stay Cables," Structural Engineering International, Vol. 13, No. 1, Feb. 2003, pp. 64-68.

Prato, C.A., M.A. Ceballos, P.J.F. Huerta, C.F. Gerbaudo, C.E. Grunbaum, and D.L. Hommel, "Diagnosis, Construction Procedures, and Design Recommendations for Replacement of Cables in Cable-Stayed Bridges: Experience from Two Current Cases in Argentina," Proceedings of the US-Canada Workshop of Bridge Engineering, July 1997, pp. 303-316.

Prato, C.A., M.A. Ceballos, P.J.F. Huerta, and C.F. Gerbaudo, "Application of Ambient Vibration Measurements for Repair of the Chaco-Corrientes Cable-Stayed Bridge in Argentina," Proceedings of the International Seminar, Workshop and Exhibition/The Repair and Rehabilitation of Reinforced Concrete Structures; The State of the Art, 1998, pp. 177-191.

Recommendations for Stay Cable Design, Testing, and Installation, 4th ed., Post-Tensioning Institute, Pheonix, Ariz., 2001, 101 pp.

Reinholdt, P., E. Veje, and J. Kalvslund, "Rehabilitation of the Luangwa Bridge," Proceedings of the IABSE Conference, Cable-Stayed Bridges, Past, Present, and Future, Malmo, Sweden, June 1999. 
Rizzo, P. and F. Lanza di Scalea, "Wave Propagation in Multiwire Strands by Wavelet-Based Laser Ultrasound," Experimental Mechanics, Vol. 44, No. 3, 2004.

Roos, F. and J.F. Noisternig, "CFRP-Tendons-Development and Testing," Proceedings of the IABSE Conference, Cable-Stayed Bridges, Past, Present, and Future, Malmo, Sweden, June 1999, pp. 623-630.

Saito, T., M. Matsumoto, and M. Kitazawa, "Rain-Wind Excitation of Cables on Cable-Stayed Higashi-Kobe Bridge and Cable Vibration Control," Proceedings of Conference on Cable-Stayed and Suspension Bridges, Deauville, France, Oct. 1994, pp. 507-514.

Sarcos-Portillo, A., A. Navarro-Cerpa, and H. Garcia-Legl, "Inspection and Process of Tension of Cables of General Rafael Urdaneta Bridge," Journal of Bridge Engineering, Vol. 8, No. 4, July 2003, pp. 223-228.

Sarkar, P.P., S. Phelan, K.C. Mehta, T.B. Gardner, and Z. Zhao, "Cable Stay Aerodynamic Damper Band and Method of Use," USPTO Patent No. 6,386,526, May 14, 2002.

Saul, R. and H.S. Svensson, "On the Corrosion Protection of Stay Cables," Wire Rope News and Sling Technology, Aug. 1991, pp. 14-29.

Seible, F. and R. Burgueno, "Advanced Composites in Pedestrian Bridge Design," Proceedings of the ASCE Structures Congress XV, Vol. 1, Portland, Ore., April 13-16, 1997, pp. 378-382.

Stafford, D.G. and S.C. Watson, "A Discussion of Some Critical Corrosion Problems in the Cable Elements of Stayed Girder Structures," Proceedings of the US-European Workshop on Bridge Evaluation, Repair, and Rehabilitation, St. Remy-les-Chevreuse, June 1987, pp. 622-637.

Starossek, U., "Cable-Dynamics, A Review," Structural Engineering International, No. 3, 1994, pp. 171-176.

Stubler, J., P. Ladret, and J.B. Domage, "Vibration Control of Stay Cables," Proceedings of the IABSE Conference, Cable-Stayed Bridges, Past, Present, and Future, Malmo, Sweden, June 1999, pp. 606-612.

Suzuki, N., H. Takamatsu, S. Kawashima, K. Sugii, and M. Iwasaki, "Ultrasonic Detection Method for Wire Breakage," Kobelco Technology Review, No. 4, Aug. 1988, pp. 23-26.

Suzumura, K. and S.-I. Nakamura, "Environmental Factors Affecting Corrosion of Galvanized Steel Wires," Journal of Materials in Civil Engineering, Vol. 16, No. 1, Feb. 2004, pp. 1-7.

Swan, R., "Vibrations Damped," Bridge Design \& Engineering, Nov. 1997, Vol. 3, No. 9.

Tabatabai, H., A.T. Ciolko, and T.J. Dickson, "Implications of Test Results from Full-Scale Fatigue Tests of Stay Cables Composed of Seven-Wire Prestressing Strands," Proceedings of the Fourth International Bridge Engineering Conference, Vol. 1, Aug. 28-30, 1995, pp. 266-277.

Tabatabai, H. and A.B. Mehrabi, "Bridge Stay Cable Condition Assessment Using Vibration Measurement Techniques," Proceedings of SPIE Structural Materials Tech- nology III, an NDT Conference, Vol. 3400, Mar.-Apr. 1998, San Antonio, Tex., pp. 194-204.

Tabatabai, H., A. Mehrabi, and A.G. Davis, "Field Testing of Stay Cables for the Cochrane Bridge in Mobile, Alabama," Report submitted to A.G. Lichtenstein, Inc., Paramus, N.J., Construction Technology Laboratories, Inc., Skokie, Ill., 1998.

Tabatabai, H. and A. Mehrabi, "Vibration Suppression Measures for Stay Cables," Proceedings of the 17th International Modal Analysis Conference, Kissimmee, Fla., Feb. 1999, pp. 1237-1243.

Tabatabai, H. and A. Mehrabi, "Evaluation of Various Damping Treatments for Stay Cables," Proceedings of the 18th International Modal Analysis Conference, San Antonio, Tex., Feb. 2000.

Tabatabai, H. and A.B. Mehrabi, "Design of Mechanical Viscous Dampers for Stay Cables," Journal of Bridge Engineering, Vol. 5, No. 2, May 2000, pp. 114-123.

Tabatabai, H. and A.B. Mehrabi, "TMD-Damped Stay Cable and Method and TMD," USPTO Patent No. 6,292,967 B1, Sep. 25, 2001.

Tarui, T., N. Maruyama, T. Eguchi, and S. Konno, "Development of High Strength Galvanized Steel Wire for Bridge Cable," Proceedings of the IABSE Conference, Cable-Supported Bridges, Challenging Technical Limits, Seoul, Korea, 2001.

Telang, N.M., C.M. Minervino, and P.G. Norton, "Retrofit of Aerodynamic Cable Instability on a Cable-Stayed Bridge: Case Study," Transportation Research Record 1740, Transportation Research Board, National Research Council, Washington, D.C., 2000, pp. 61-67.

Telang, N.M., C.A. Ligozio, and A.B. Mehrabi, "Luling Bridge-Phase II Structural Evaluation of Luling Bridge Stay Cable Array-Tasks 1, 2, and 3," Report to the Louisiana Department of Transportation and Development, State Project No. 700-45-0107, Construction Technology Laboratories, Skokie, Ill., July 2004.

Walther, R., et al. Cable Stayed Bridges, 2nd ed., Thomas Telford, London, 1999, 320 pp.

Walton, J.M., "Developments in Steel Cables," Journal of Constructional Steel Research, Vol. 39, No. 1, 1996, pp. 3-29.

Watson, S.C. and D. Stafford, "Cables in Trouble," Civil Engineering, Vol. 58, No. 4, Apr. 1988, pp. 38-41.

Weischedel, H.R. and H.-W. Hohle, "Quantitative NonDestructive In-Service Evaluation of Stay Cables of CableStayed Bridges: Methods and Practical Experience," SPIE, Vol. 2456, May 1995, pp. 226-236.

Wichmann, H.J., A. Holst, and H. Budelmann, "Detection and Localization of Fractures in Tendons by Means of Electromagnetic Resonance Measurement," 2003 [Online]. Available: http://www.ndt.net/article/ndtce03/papers/ v104/v104.htm.

Wu, Q., K. Takahashi, T. Okabayashi, and S. Nakamura, "Response Characteristics of Local Vibrations in Stay Cables on an Existing Cable-Stayed Bridge," Journal of Sound and Vibration, Vol. 261, No. 3, Mar. 27, 2003, pp. 403-420. 
Yamagiwa, I., H. Utsuno, K. Endo, and K. Sugii, “Application of Simultaneous Identification of Tension and Flexural Rigidity at Once to the Bridge Cables," Proceedings of the IABSE Conference, Cable-Stayed Bridges, Past, Present, and Future, Malmo, Sweden, June 1999.

Yamaguchi, K., Y. Manabe, N. Sasaki, and K. Morishita, "Field Observation and Vibration Test of the Tatara Bridge," Proceedings of the IABSE Conference, CableStayed Bridges, Past, Present, and Future, Malmo, Sweden, June 1999, pp. 707-714.

Yoneda, M. and K. Maeda, “A Study on Practical Estimation Method for Structural Damping of Stay Cable with
Damper," Proceedings of the Canada-Japan Workshop on Bridge Aerodynamics, Ottawa, Canada, Sep. 1989, pp. 119-128.

Xu, Y.L., S. Zhan, and J.M. Ko, "Experimental Study of Vibration Mitigation of Bridge Stay Cables," Journal of Structural Engineering, Vol. 125, No. 9, Sep. 1999, pp. 977-986.

Zoli, T. and R. McCabe, "Cable-Stayed Bridge Design," Presented at the High Performance Stay Cable Systems Seminar, sponsored by Freyssinet International, Washington, D.C., Oct. 1, 2004. 


\title{
APPENDIX A \\ Survey Questionnaire
}

\author{
NATIONAL COOPERATIVE HIGHWAY RESEARCH PROGRAM \\ SYNTHESIS TOPIC 35-07 \\ INSPECTION AND MAINTENANCE OF BRIDGE STAY CABLE SYSTEMS \\ QUESTIONNAIRE
}

With this request for information, we are seeking your help in developing a synthesis report on inspection and maintenance of stay cables in cable-stayed bridges. You and your agency have been selected because of the relevant knowledge and experience that we believe can be shared with us that are important to the success of this effort. We are striving to make the outcome of this effort (i.e., the synthesis report) a valuable and state-of-the-art resource for those such as yourself who are involved in the inspection, design, maintenance, or repair/retrofit of stay cables. The synthesis will focus on the advantages and limitations of various non-destructive test methods, repair procedures, preventive maintenance strategies, vibration control methods, corrosion protection systems, fatigue, etc. Please feel free to contact the consultant for this synthesis project, Dr. Habib Tabatabai, at (414) 229-5166 or ht@uwm.edu should you have any questions. You may also receive a call or e-mail from the consultant for the purpose of clarifying or augmenting your answers to the questions. Please provide any additional information that you feel is relevant to the answers provided in the questionnaire. Thank you in advance for your valued input into this effort.

\section{Respondent Information:}

Please provide the information requested below for the person completing this questionnaire (if you received the questionnaire and someone else is in a better position to respond, please forward the document to that person).

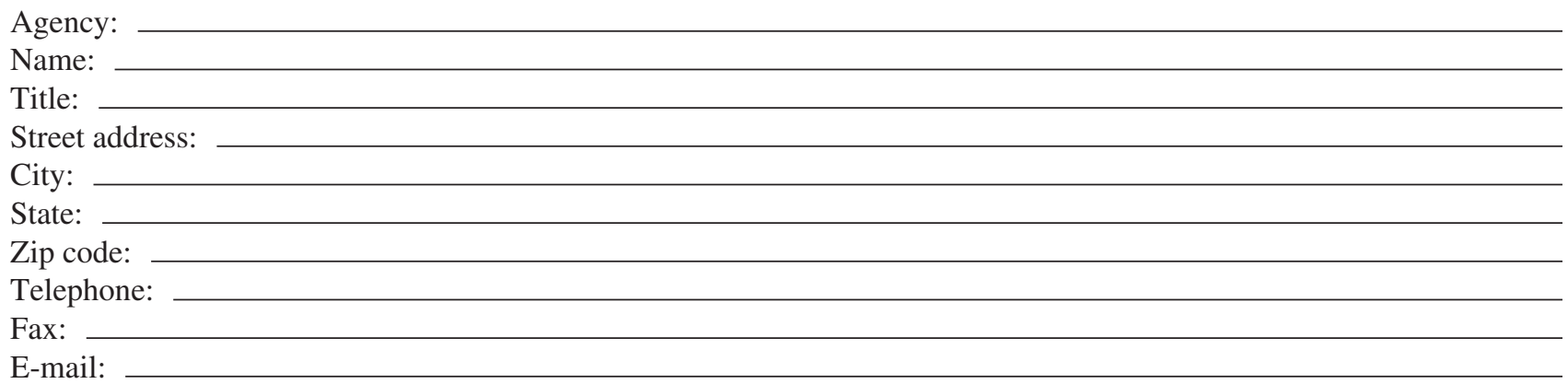

Please return the completed questionnaire and any supporting documents by e-mail, fax, or mail by Friday March 26, 2004 to:

Habib Tabatabai

Department of Civil Engineering \& Mechanics

University of Wisconsin-Milwaukee

3200 N. Cramer Street

Milwaukee, WI 53211

Telephone: (414) 229-5166 Fax: (414) 229-6958

E-mail: ht@uwm.edu 


\section{QUESTIONS}

Please feel free to expand on your answers to the following questions. If you need additional space, you can use the comments section at the end of this questionnaire.

1) Are you or your agency involved in the design, fabrication, inspection, testing, repair, maintenance, or retrofit of stay cables in cable-stayed bridges?

$$
\text { Yes } \square \quad \text { No } \square
$$

If the answer is "Yes," please proceed to the next question. If the answer is "No," please return the questionnaire as directed above and thank you for your time. Please note that submitting a "blank" questionnaire is preferred to not submitting.

2) Is your agency an owner (or responsible for the maintenance) of at least one cable-stayed bridge?

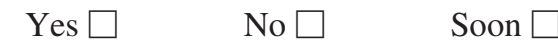

If the answer is "Yes" or "Soon," please proceed to the next question. If the answer is "No," please proceed to question No. 5.

3) How many cable-stayed bridges are under the jurisdiction of your agency or are maintained by your agency?

$1 \square \quad 2 \square \quad 3 \square \quad$ over $3 \square$ (please provide number)

4) Please provide the following information on each of the cable-stayed bridges that are maintained by your agency. (If you have more than two cable-stayed bridges, please provide the requested information on additional sheets. Also, please note that MTE refers to the main tension-resisting elements in the cable, which are typically 7-wire strands, parallel wires, or bars.)

\begin{tabular}{|c|c|c|c|}
\hline No. & Questions & Bridge No. 1 & Bridge No. 2 \\
\hline $4-1$ & Bridge name and location & & \\
\hline $4-2$ & Year built & & \\
\hline $4-3$ & Main span length (ft) & & \\
\hline $4-4$ & $\begin{array}{l}\text { Type of main tension element (MTE)? (7-wire steel strand, steel } \\
\text { wire, steel bar or threadbar, rope, helical lock-coil strand, other) }\end{array}$ & & \\
\hline $4-5$ & $\begin{array}{l}\text { Coating/treatment on main tension element within free length of } \\
\text { cable? (bare, greased-and-sheathed, epoxy-coated on outside only, } \\
\text { epoxy-coated inside and outside, galvanized steel, stainless steel, } \\
\text { other) }\end{array}$ & & \\
\hline $4-6$ & $\begin{array}{l}\text { Are the coatings/treatments on main tension element discontinued } \\
\text { or removed within the anchorage zone? (yes, no, not known, not } \\
\text { applicable) }\end{array}$ & & \\
\hline $4-7$ & $\begin{array}{l}\text { Type of grout used? (grout not used, cement-water, cement-water- } \\
\text { admixtures, commercial pre-packaged grouts, not known) }\end{array}$ & & \\
\hline $4-8$ & $\begin{array}{l}\text { Are filler materials used in the anchorage zone? (yes-grout, yes- } \\
\text { grease, yes-other, no filler, not known) }\end{array}$ & & \\
\hline $4-9$ & $\begin{array}{l}\text { Type of anchorage? (wedges, conical socket with wedges, cylindri- } \\
\text { cal sockets with wedges, "Hi-Am"-type, other) }\end{array}$ & & \\
\hline $4-10$ & Do cables go over "saddles" on the pylons? (yes, no) & & \\
\hline $4-11$ & $\begin{array}{l}\text { Type of cable sheathing used? [HDPE with PVF (Tedlar®) tape, } \\
\text { UV-resistant HDPE, UV-resistant HDPE with spiral on surface, } \\
\text { HDPE with dimples on the surface, steel pipe, no sheathing, other] }\end{array}$ & & \\
\hline
\end{tabular}




\begin{tabular}{|c|c|c|c|}
\hline No. & Questions & Bridge No. 1 & Bridge No. 2 \\
\hline $4-12$ & $\begin{array}{l}\text { Have rain-wind-induced cable vibrations been observed on this } \\
\text { bridge? (yes, no, not known) }\end{array}$ & & \\
\hline $4-13$ & Have MTE corrosion problems been noted? (yes, no, not known) & & \\
\hline $4-14$ & $\begin{array}{l}\text { Do cables have neoprene rings near the top and bottom anchorages? } \\
\text { (yes, no, not known) }\end{array}$ & & \\
\hline $4-15$ & $\begin{array}{l}\text { If there are neoprene rings on the cables, have there been any } \\
\text { reports of movements of the rings out of their positions? (yes-due } \\
\text { to loosening of retainers, yes-due to shearing off of retainers, } \\
\text { yes-due to other reasons, no, not known, not applicable) }\end{array}$ & & \\
\hline $4-16$ & $\begin{array}{l}\text { Has moisture been found in any of the internal components of stay } \\
\text { cables such as the bottom anchorage areas? (yes, no, not tested, not } \\
\text { known) }\end{array}$ & & \\
\hline $4-17$ & $\begin{array}{l}\text { Has fatigue of MTE or other components of stay cables been } \\
\text { observed (yes, no, not known) }\end{array}$ & & \\
\hline $4-18$ & $\begin{array}{l}\text { Do the cables have viscous dampers installed at deck or tower } \\
\text { levels? (yes-from the beginning, yes-retrofitted to correct } \\
\text { vibrations, no) }\end{array}$ & & \\
\hline $4-19$ & $\begin{array}{l}\text { Do the cables have cross cables installed between them? (yes-from } \\
\text { the beginning, yes-retrofitted to correct vibrations, no) }\end{array}$ & & \\
\hline $4-20$ & $\begin{array}{l}\text { Do cables have other dampers (other than viscous or neoprene } \\
\text { rings) to control vibrations? [yes-tuned mass dampers, yes-other } \\
\text { dampers (please specify), no, not known] }\end{array}$ & & \\
\hline $4-21$ & $\begin{array}{l}\text { Has cracking of the cable sheathing or sheathing connections been } \\
\text { noted? (yes-sheathing, yes-connections, yes-both, no, not } \\
\text { known, not applicable) }\end{array}$ & & \\
\hline $4-22$ & $\begin{array}{l}\text { Has cracking or misalignment of the guide pipes been noted? (yes- } \\
\text { cracking, yes-misalignment, yes-both, no, not known, } \\
\text { not applicable) }\end{array}$ & & \\
\hline $4-23$ & $\begin{array}{l}\text { If there is protective tape wrapped around the cable sheathing, have } \\
\text { there been reports of deterioration of the tape? (yes-minor damage, } \\
\text { yes-moderate damage, yes-extensive damage, no, not known, } \\
\text { not applicable) }\end{array}$ & & \\
\hline $4-24$ & $\begin{array}{l}\text { Have any problems associated with neoprene boots been noted? } \\
\text { (yes, no, not known, not applicable) }\end{array}$ & & \\
\hline $4-25$ & $\begin{array}{l}\text { Types of non-destructive tests that any of the cables on this bridge } \\
\text { have been subjected to? [magnetic, X-ray, ultrasonic, vibration- } \\
\text { based force measurements, other (please specify), not performed, } \\
\text { not known] }\end{array}$ & & \\
\hline $4-26$ & $\begin{array}{l}\text { Types of sensor-based long-term monitoring performed on the } \\
\text { cables? [acoustic wire break detection, vibration monitoring, force } \\
\text { measurements, other (please specify), not performed, not known] }\end{array}$ & & \\
\hline $4-27$ & $\begin{array}{l}\text { Have the cables on this bridge (or any of their components) been } \\
\text { repaired? [yes (please explain), no, not known] }\end{array}$ & & \\
\hline $4-28$ & $\begin{array}{l}\text { Has the sheathing been partially removed on any of the cables to } \\
\text { examine condition of grout (if applicable) and/or the MTE? (yes, } \\
\text { no, not known, not applicable) }\end{array}$ & & \\
\hline $4-29$ & $\begin{array}{l}\text { Can the strands or cables be replaced if needed? (yes, no, not } \\
\text { known) }\end{array}$ & & \\
\hline $4-30$ & $\begin{array}{l}\text { Do you have an inspection and maintenance manual for this bridge? } \\
\text { (yes, no, not known) - If yes, we would appreciate receiving a copy } \\
\text { of this manual for the purposes of this synthesis report. }\end{array}$ & & \\
\hline
\end{tabular}


5) Based on your experience and in general, do you believe that the current inspection, testing, monitoring, and repair methods available to you for stay cables are effective and adequate?

- Yes

- No

- Not known

6) Please comment on the effectiveness of any non-destructive test methods for inspections of stay cables that you may be familiar with. These methods include (but are not limited to) ultrasonic testing, magnetic inspections, laser-based force measurements, X-ray imaging, etc. If possible, please comment on issues such as practicality, cost, duration, impact on traffic, and any other factors that you consider important.

7) Please comment on the effectiveness of any cable vibration control measures that you may be familiar with. Examples include installation of cross cables, viscous dampers, neoprene rings, etc.

8) Please comment on the effectiveness of any sensor-based long-term monitoring systems for stay cables that you may be familiar with. Examples include acoustic monitoring, vibration monitoring, force measurements, strain measurements, etc.

9) What would you recommend that the cable suppliers incorporate into their systems to make cables more accessible and inspectable?

10) Do you believe that an up-to-date resource such as a national database of information on stay cable inspection methods, repairs, and testing would be a useful tool?

- Yes

- No

- Not known

11) What do you see as the single most important problem in stay cable maintenance?

12) Please comment on any other methods for inspections, testing, monitoring, and repair of stay cable (including conventional methods) that you have found beneficial and are not listed above.

Additional comments?

We appreciate the time you have taken to provide this information and thank you very much for your help with this important undertaking. 


\section{APPENDIX B}

\section{Statistical Analysis of Survey Results}

QUESTION 4.4

TYPE OF MAIN TENSION ELEMENT (MTE)?

\begin{tabular}{|l|c|c|c|c|c|}
\hline & U.S. & $\begin{array}{c}\% \\
\text { U.S. }\end{array}$ & Canada & $\begin{array}{c}\% \\
\text { Canada }\end{array}$ & $\begin{array}{c}\% \\
\text { Total }\end{array}$ \\
\hline $\begin{array}{l}\text { Seven-wire steel } \\
\text { strand }\end{array}$ & 21 & 75.0 & 1 & 7.7 & 53.7 \\
\hline Steel wire & 3 & 10.7 & 7 & 53.8 & 24.4 \\
\hline Steel bar or threadbar & 1 & 3.6 & 4 & 30.8 & 12.2 \\
\hline Other & 2 & 7.1 & 1 & 7.7 & 7.3 \\
\hline No answer & 1 & 3.6 & 0 & 0.0 & 2.4 \\
\hline \hline
\end{tabular}

QUESTION 4.5

COATING/TREATMENT ON MAIN TENSION ELEMENT WITHIN FREE LENGTH OF CABLE?

\begin{tabular}{|l|c|c|c|c|c|}
\hline \hline & U.S. & $\begin{array}{c}\% \\
\text { U.S. }\end{array}$ & Canada & $\begin{array}{c}\% \\
\text { Canada }\end{array}$ & $\begin{array}{c}\% \\
\text { Total }\end{array}$ \\
\hline Bare & 12 & 42.9 & 0 & 0.0 & 29.3 \\
\hline $\begin{array}{l}\text { Greased-and- } \\
\text { sheathed }\end{array}$ & 6 & 21.4 & 0 & 0.0 & 14.6 \\
\hline $\begin{array}{l}\text { Epoxy-coated outside } \\
\text { only }\end{array}$ & 4 & 14.3 & 0 & 0.0 & 9.8 \\
\hline $\begin{array}{l}\text { Epoxy-coated in and } \\
\text { out }\end{array}$ & 1 & 3.6 & 0 & 0.0 & 2.4 \\
\hline Galvanized & 3 & 10.7 & 8 & 61.5 & 26.8 \\
\hline Stainless steel & 0 & 0.0 & 0 & 0.0 & 0.0 \\
\hline Other & 1 & 3.6 & 5 & 38.5 & 14.6 \\
\hline No answer & 1 & 3.6 & 0 & 0.0 & 2.4 \\
\hline \hline
\end{tabular}

QUESTION 4.6

ARE THE COATINGS/TREATMENTS ON MAIN TENSION ELEMENT DISCONTINUED OR REMOVED WITHIN THE ANCHORAGE ZONE?

\begin{tabular}{|l|c|c|c|c|c|}
\hline \hline & U.S. & $\begin{array}{c}\% \\
\text { U.S. }\end{array}$ & Canada & $\begin{array}{c}\% \\
\text { Canada }\end{array}$ & $\begin{array}{c}\% \\
\text { Total }\end{array}$ \\
\hline Yes & 9 & 32.1 & 2 & 15.4 & 26.8 \\
\hline No & 1 & 3.6 & 9 & 69.2 & 24.4 \\
\hline Not known & 7 & 25.0 & 2 & 15.4 & 22.0 \\
\hline Not applicable & 10 & 35.7 & 0 & 0.0 & 24.4 \\
\hline No answer & 1 & 3.6 & 0 & 0.0 & 2.4 \\
\hline \hline
\end{tabular}

QUESTION 4.7

TYPE OF GROUT USED?

\begin{tabular}{|l|c|c|c|c|c|}
\hline \hline & U.S. & $\begin{array}{c}\% \\
\text { U.S. }\end{array}$ & Canada & $\begin{array}{c}\% \\
\text { Canada }\end{array}$ & $\begin{array}{c}\% \\
\text { Total }\end{array}$ \\
\hline Grout not used & 6 & 21.4 & 12 & 92.3 & 43.9 \\
\hline Cement-water & 5 & 17.9 & 0 & 0.0 & 12.2 \\
\hline $\begin{array}{l}\text { Cement-water- } \\
\text { admixtures }\end{array}$ & 9 & 32.1 & 0 & 0.0 & 22.0 \\
\hline $\begin{array}{l}\text { Commercial } \\
\text { prepackaged grouts }\end{array}$ & 1 & 3.6 & 0 & 0.0 & 2.4 \\
\hline Not known & 6 & 21.4 & 0 & 0.0 & 14.6 \\
\hline Not applicable & 0 & 0.0 & 1 & 7.7 & 2.4 \\
\hline No answer & 1 & 3.6 & 0 & 0.0 & 2.4 \\
\hline \hline
\end{tabular}

QUESTION 4.8

ARE FILLER MATERIALS USED IN THE ANCHORAGE ZONE?

\begin{tabular}{|l|c|c|c|c|c|}
\hline \hline & U.S. & $\begin{array}{c}\% \\
\text { U.S. }\end{array}$ & Canada & $\begin{array}{c}\% \\
\text { Canada }\end{array}$ & $\begin{array}{c}\% \\
\text { Total }\end{array}$ \\
\hline Yes_grout & 6 & 21.4 & 0 & 0.0 & 14.6 \\
\hline Yes_grease & 10 & 35.7 & 0 & 0.0 & 24.4 \\
\hline Yes_other & 7 & 25.0 & 2 & 15.4 & 22.0 \\
\hline No filler & 0 & 0.0 & 11 & 84.6 & 26.8 \\
\hline Not known & 4 & 14.3 & 0 & 0.0 & 9.8 \\
\hline No answer & 1 & 3.6 & 0 & 0.0 & 2.4 \\
\hline \hline
\end{tabular}

QUESTION 4.9

TYPE OF ANCHORAGE?

\begin{tabular}{|l|c|c|c|c|c|}
\hline \hline & U.S. & $\begin{array}{c}\% \\
\text { U.S. }\end{array}$ & Canada & $\begin{array}{c}\% \\
\text { Canada }\end{array}$ & $\begin{array}{c}\% \\
\text { Total }\end{array}$ \\
\hline Wedges & 6 & 21.4 & 0 & 0.0 & 14.6 \\
\hline $\begin{array}{l}\text { Conical socket with } \\
\text { wedges }\end{array}$ & 13 & 46.4 & 2 & 15.4 & 36.6 \\
\hline $\begin{array}{l}\text { Cylindrical sockets } \\
\text { with wedges }\end{array}$ & 0 & 0.0 & 0 & 0.0 & 0.0 \\
\hline "Hi-Am" type & 3 & 10.7 & 0 & 0.0 & 7.3 \\
\hline Other & 3 & 10.7 & 11 & 84.6 & 34.1 \\
\hline Not known & 2 & 7.1 & 0 & 0.0 & 4.9 \\
\hline No answer & 1 & 3.6 & 0 & 0.0 & 2.4 \\
\hline \hline
\end{tabular}


QUESTION 4.10

DO CABLES GO OVER SADDLES " ON THE PYLONS?

\begin{tabular}{|l|c|c|c|c|c|}
\hline \hline & & $\%$ & & $\%$ & $\%$ \\
& U.S. & U.S. & Canada & Canada & $\begin{array}{c}\% \\
\text { Total }\end{array}$ \\
\hline Yes & 6 & 21.4 & 1 & 7.7 & 17.1 \\
\hline No & 21 & 75.0 & 12 & 92.3 & 80.5 \\
\hline No answer & 1 & 3.6 & 0 & 0.0 & 2.4 \\
\hline \hline
\end{tabular}

QUESTION 4.11

TYPE OF CABLE SHEATHING USED?

\begin{tabular}{|l|c|c|c|c|c|}
\hline \hline & U.S. & $\begin{array}{c}\% \\
\text { U.S. }\end{array}$ & Canada & $\begin{array}{c}\% \\
\text { Canada }\end{array}$ & $\begin{array}{c}\% \\
\text { Total }\end{array}$ \\
\hline $\begin{array}{l}\text { HDPE with PVF } \\
\text { (Tedlar@ tape) }\end{array}$ & 10 & 35.7 & 0 & 0.0 & 24.4 \\
\hline UV-resistant HDPE & 0 & 0.0 & 1 & 7.7 & 2.4 \\
\hline $\begin{array}{l}\text { UV-resistant HDPE } \\
\text { with spiral on } \\
\text { surface }\end{array}$ & 7 & 25.0 & 1 & 7.7 & 19.5 \\
\hline $\begin{array}{l}\text { HDPE with dimples } \\
\text { on the surface }\end{array}$ & 0 & 0.0 & 0 & 0.0 & 0.0 \\
\hline Steel pipe & 2 & 7.1 & 0 & 0.0 & 4.9 \\
\hline No sheathing & 3 & 10.7 & 9 & 69.2 & 29.3 \\
\hline Other & 3 & 10.7 & 2 & 15.4 & 12.2 \\
\hline No answer & 3 & 10.7 & 0 & 0.0 & 7.3 \\
\hline \hline
\end{tabular}

QUESTION 4.12

HAVE RAIN-WIND-INDUCED CABLE VIBRATIONS BEEN OBSERVED ON THIS BRIDGE?

\begin{tabular}{|l|c|c|c|c|c|}
\hline \hline & U.S. & $\begin{array}{c}\% \\
\text { U.S. }\end{array}$ & Canada & $\begin{array}{c}\% \\
\text { Canada }\end{array}$ & $\begin{array}{c}\% \\
\text { Total }\end{array}$ \\
\hline Yes & 6 & 21.4 & 6 & 46.2 & 29.3 \\
\hline No & 17 & 60.7 & 5 & 38.5 & 53.7 \\
\hline Not known & 3 & 10.7 & 2 & 15.4 & 12.2 \\
\hline Not applicable & 1 & 3.6 & 0 & 0.0 & 2.4 \\
\hline No answer & 1 & 3.6 & 0 & 0.0 & 2.4 \\
\hline \hline
\end{tabular}

QUESTION 4.13

HAVE MTE CORROSION PROBLEMS BEEN NOTED?

\begin{tabular}{|l|c|c|c|c|c|}
\hline \hline & U.S. & $\begin{array}{c}\% \\
\text { U.S. }\end{array}$ & Canada & $\begin{array}{c}\% \\
\text { Canada }\end{array}$ & $\begin{array}{c}\% \\
\text { Total }\end{array}$ \\
\hline Yes & 1 & 3.6 & 2 & 15.4 & 7.3 \\
\hline No & 20 & 71.4 & 8 & 61.5 & 68.3 \\
\hline Not known & 5 & 17.9 & 3 & 23.1 & 19.5 \\
\hline Not applicable & 1 & 3.6 & 0 & 0.0 & 2.4 \\
\hline No answer & 1 & 3.6 & 0 & 0.0 & 2.4 \\
\hline \hline
\end{tabular}

QUESTION 4.14

DO CABLES HAVE NEOPRENE RINGS NEAR THE TOP AND BOTTOM ANCHORAGES?

\begin{tabular}{|l|c|c|c|c|c|}
\hline \hline & U.S. & $\begin{array}{c}\% \\
\text { U.S. }\end{array}$ & Canada & $\begin{array}{c}\% \\
\text { Canada }\end{array}$ & $\begin{array}{c}\% \\
\text { Total }\end{array}$ \\
\hline Yes & 18 & 64.3 & 4 & 30.8 & 53.7 \\
\hline No & 7 & 25.0 & 9 & 69.2 & 39.0 \\
\hline Not known & 1 & 3.6 & 0 & 0.0 & 2.4 \\
\hline Not applicable & 1 & 3.6 & 0 & 0.0 & 2.4 \\
\hline No answer & 1 & 3.6 & 0 & 0.0 & 2.4 \\
\hline \hline
\end{tabular}

QUESTION 4.15

IF THERE ARE NEOPRENE RINGS ON THE CABLES, HAVE THERE BEEN ANY REPORTS OF MOVEMENTS OF THE RINGS OUT OF THEIR POSITIONS?

\begin{tabular}{|l|c|c|c|c|c|}
\hline \hline & U.S. & $\begin{array}{c}\% \\
\text { U.S. }\end{array}$ & Canada & $\begin{array}{c}\% \\
\text { Canada }\end{array}$ & $\begin{array}{c}\% \\
\text { Total }\end{array}$ \\
\hline $\begin{array}{l}\text { Yes_due to } \\
\text { loosening of } \\
\text { retainers }\end{array}$ & 4 & 14.3 & 0 & 0.0 & 9.8 \\
\hline $\begin{array}{l}\text { Yes-due to shearing } \\
\text { off of retainers }\end{array}$ & 1 & 3.6 & 1 & 7.7 & 4.9 \\
\hline $\begin{array}{l}\text { Yes-due to other } \\
\text { reasons }\end{array}$ & 2 & 7.1 & 1 & 7.7 & 7.3 \\
\hline No, not known & 12 & 42.9 & 2 & 15.4 & 34.1 \\
\hline Not applicable & 8 & 28.6 & 9 & 69.2 & 41.5 \\
\hline No answer & 1 & 3.6 & 0 & 0.0 & 2.4 \\
\hline \hline
\end{tabular}

QUESTION 4.16

HAS MOISTURE BEEN FOUND IN ANY OF THE INTERNAL COMPONENTS OF STAY CABLES SUCH AS THE BOTTOM ANCHORAGE AREAS?

\begin{tabular}{|l|c|c|c|c|c|}
\hline \hline & U.S. & $\begin{array}{c}\% \\
\text { U.S. }\end{array}$ & Canada & $\begin{array}{c}\% \\
\text { Canada }\end{array}$ & $\begin{array}{c}\% \\
\text { Total }\end{array}$ \\
\hline Yes & 7 & 25.0 & 0 & 0.0 & 17.1 \\
\hline No & 13 & 46.4 & 7 & 53.8 & 48.8 \\
\hline Not tested & 3 & 10.7 & 6 & 46.2 & 22.0 \\
\hline Not known & 3 & 10.7 & 0 & 0.0 & 7.3 \\
\hline Not applicable & 1 & 3.6 & 0 & 0.0 & 2.4 \\
\hline No answer & 1 & 3.6 & 0 & 0.0 & 2.4 \\
\hline \hline
\end{tabular}

QUESTION 4.17

HAS FATIGUE OF MTE OR OTHER COMPONENTS OF STAY CABLES BEEN OBSERVED?

\begin{tabular}{|l|c|c|c|c|c|}
\hline \hline & U.S. & $\begin{array}{c}\% \\
\text { U.S. }\end{array}$ & Canada & $\begin{array}{c}\% \\
\text { Canada }\end{array}$ & $\begin{array}{c}\% \\
\text { Total }\end{array}$ \\
\hline Yes & 1 & 3.6 & 2 & 15.4 & 7.3 \\
\hline No & 25 & 89.3 & 10 & 76.9 & 85.4 \\
\hline Not known & 0 & 0.0 & 1 & 7.7 & 2.4 \\
\hline Not applicable & 1 & 3.6 & 0 & 0.0 & 2.4 \\
\hline No answer & 1 & 3.6 & 0 & 0.0 & 2.4 \\
\hline \hline
\end{tabular}


QUESTION 4.18

DO THE CABLES HAVE VISCOUS DAMPERS INSTALLED AT DECK OR TOWER LEVELS?

\begin{tabular}{|l|c|c|c|c|c|}
\hline \hline & U.S. & $\begin{array}{c}\% \\
\text { U.S. }\end{array}$ & Canada & $\begin{array}{c}\% \\
\text { Canada }\end{array}$ & $\begin{array}{c}\% \\
\text { Total }\end{array}$ \\
\hline $\begin{array}{l}\text { Yes_from the } \\
\text { beginning }\end{array}$ & 4 & 14.3 & 0 & 0.0 & 9.8 \\
\hline $\begin{array}{l}\text { Yes_retrofitted to } \\
\text { correct vibrations }\end{array}$ & 2 & 7.1 & 3 & 23.1 & 12.2 \\
\hline No & 21 & 75.0 & 10 & 76.9 & 75.6 \\
\hline No answer & 1 & 3.6 & 0 & 0.0 & 2.4 \\
\hline \hline
\end{tabular}

QUESTION 4.19

DO THE CABLES HAVE CROSS CABLES INSTALLED BETWEEN THEM?

\begin{tabular}{|l|c|c|c|c|c|}
\hline \hline & U.S. & $\begin{array}{c}\% \\
\text { U.S. }\end{array}$ & Canada & $\begin{array}{c}\% \\
\text { Canada }\end{array}$ & $\begin{array}{c}\% \\
\text { Total }\end{array}$ \\
\hline $\begin{array}{l}\text { Yes—from the } \\
\text { beginning }\end{array}$ & 6 & 21.4 & 2 & 15.4 & 19.5 \\
\hline $\begin{array}{l}\text { Yes—retrofitted to } \\
\text { correct vibrations }\end{array}$ & 3 & 10.7 & 1 & 7.7 & 9.8 \\
\hline No & 18 & 64.3 & 10 & 76.9 & 68.3 \\
\hline No answer & 1 & 3.6 & 0 & 0.0 & 2.4 \\
\hline \hline
\end{tabular}

QUESTION 4.20

DO CABLES HAVE OTHER DAMPERS (OTHER THAN VISCOUS OR NEOPRENE RINGS) TO CONTROL VIBRATIONS?

\begin{tabular}{|l|c|c|c|c|c|}
\hline \hline & U.S. & $\begin{array}{c}\% \\
\text { U.S. }\end{array}$ & Canada & $\begin{array}{c}\% \\
\text { Canada }\end{array}$ & $\begin{array}{c}\% \\
\text { Total }\end{array}$ \\
\hline $\begin{array}{l}\text { Yes_tuned mass } \\
\text { dampers }\end{array}$ & 0 & 0.0 & 0 & 0.0 & 0.0 \\
\hline Yes-other dampers & 3 & 10.7 & 3 & 23.1 & 14.6 \\
\hline No & 24 & 85.7 & 10 & 76.9 & 82.9 \\
\hline Not known & 0 & 0.0 & 0 & 0.0 & 0.0 \\
\hline No answer & 1 & 3.6 & 0 & 0.0 & 2.4 \\
\hline \hline
\end{tabular}

QUESTION 4.21

HAS CRACKING OF THE CABLE SHEATHING OR SHEATHING CONNECTIONS BEEN NOTED?

\begin{tabular}{|l|c|c|c|c|c|}
\hline \hline & U.S. & $\begin{array}{c}\% \\
\text { U.S. }\end{array}$ & Canada & $\begin{array}{c}\% \\
\text { Canada }\end{array}$ & $\begin{array}{c}\% \\
\text { Total }\end{array}$ \\
\hline Yes_-sheathing & 3 & 10.7 & 0 & 0.0 & 7.3 \\
\hline Yes_connections & 1 & 3.6 & 0 & 0.0 & 2.4 \\
\hline Yes_both & 0 & 0.0 & 0 & 0.0 & 0.0 \\
\hline No & 17 & 60.7 & 5 & 38.5 & 53.7 \\
\hline Not known & 1 & 3.6 & 0 & 0.0 & 2.4 \\
\hline Not applicable & 4 & 14.3 & 8 & 61.5 & 29.3 \\
\hline No answer & 2 & 7.1 & 0 & 0.0 & 4.9 \\
\hline \hline
\end{tabular}

QUESTION 4.22

HAS CRACKING OR MISALIGNMENT OF THE GUIDE PIPES BEEN NOTED?

\begin{tabular}{|l|c|c|c|c|c|}
\hline \hline & U.S. & $\begin{array}{c}\% \\
\text { U.S. }\end{array}$ & Canada & $\begin{array}{c}\% \\
\text { Canada }\end{array}$ & $\begin{array}{c}\% \\
\text { Total }\end{array}$ \\
\hline Yes_cracking & 1 & 3.6 & 0 & 0.0 & 2.4 \\
\hline Yes_misalignment & 4 & 14.3 & 0 & 0.0 & 9.8 \\
\hline Yes_both & 0 & 0.0 & 0 & 0.0 & 0.0 \\
\hline No & 17 & 60.7 & 2 & 15.4 & 46.3 \\
\hline Not known & 3 & 10.7 & 0 & 0.0 & 7.3 \\
\hline Not applicable & 2 & 7.1 & 11 & 84.6 & 31.7 \\
\hline No answer & 1 & 3.6 & 0 & 0.0 & 2.4 \\
\hline \hline
\end{tabular}

QUESTION 4.23

IF THERE IS PROTECTIVE TAPE WRAPPED AROUND THE CABLE SHEATHING, HAVE THERE BEEN REPORTS OF DETERIORATION OF THE TAPE?

\begin{tabular}{|l|c|c|c|c|c|}
\hline \hline & U.S. & $\begin{array}{c}\% \\
\text { U.S. }\end{array}$ & Canada & $\begin{array}{c}\% \\
\text { Canada }\end{array}$ & $\begin{array}{c}\% \\
\text { Total }\end{array}$ \\
\hline Yes-minor damage & 5 & 17.9 & 1 & 7.7 & 14.6 \\
\hline $\begin{array}{l}\text { Yes-moderate } \\
\text { damage }\end{array}$ & 1 & 3.6 & 0 & 0.0 & 2.4 \\
\hline $\begin{array}{l}\text { Yes-extensive } \\
\text { damage }\end{array}$ & 1 & 3.6 & 0 & 0.0 & 2.4 \\
\hline No & 9 & 32.1 & 2 & 15.4 & 26.8 \\
\hline Not known & 0 & 0.0 & 1 & 7.7 & 2.4 \\
\hline Not applicable & 11 & 39.3 & 9 & 69.2 & 48.8 \\
\hline No answer & 1 & 3.6 & 0 & 0.0 & 2.4 \\
\hline \hline
\end{tabular}

QUESTION 4.24

HAVE ANY PROBLEMS ASSOCIATED WITH NEOPRENE BOOTS BEEN NOTED?

\begin{tabular}{|l|c|c|c|c|c|}
\hline \hline & U.S. & $\begin{array}{c}\% \\
\text { U.S. }\end{array}$ & Canada & $\begin{array}{c}\% \\
\text { Canada }\end{array}$ & $\begin{array}{c}\% \\
\text { Total }\end{array}$ \\
\hline Yes & 4 & 14.3 & 1 & 7.7 & 12.2 \\
\hline No & 19 & 67.9 & 6 & 46.2 & 61.0 \\
\hline Not known & 1 & 3.6 & 0 & 0.0 & 2.4 \\
\hline Not applicable & 1 & 3.6 & 3 & 23.1 & 9.8 \\
\hline Other & 2 & 7.1 & 0 & 0.0 & 4.9 \\
\hline No answer & 1 & 3.6 & 3 & 23.1 & 9.8 \\
\hline \hline
\end{tabular}


QUESTION 4.25

TYPES OF NON-DESTRUCTIVE TESTS THAT ANY OF THE CABLES ON THIS BRIDGE HAVE BEEN SUBJECTED TO?

\begin{tabular}{|l|c|c|c|c|c|}
\hline \hline & U.S. & $\begin{array}{c}\% \\
\text { U.S. }\end{array}$ & Canada & $\begin{array}{c}\% \\
\text { Canada }\end{array}$ & $\begin{array}{c}\% \\
\text { Total }\end{array}$ \\
\hline Magnetic & 1 & 3.6 & 1 & 7.7 & 4.9 \\
\hline X-ray & 1 & 3.6 & 0 & 0.0 & 2.4 \\
\hline Ultrasonic & 1 & 3.6 & 1 & 7.7 & 4.9 \\
\hline $\begin{array}{l}\text { Vibration-based } \\
\text { force } \\
\text { measurements }\end{array}$ & 9 & 32.1 & 3 & 23.1 & 29.3 \\
\hline Other & 1 & 3.6 & 0 & 0.0 & 2.4 \\
\hline Not performed & 13 & 46.4 & 10 & 76.9 & 56.1 \\
\hline Not known & 0 & 0.0 & 0 & 0.0 & 0.0 \\
\hline No answer & 2 & 7.1 & 0 & 0.0 & 4.9 \\
\hline \hline
\end{tabular}

QUESTION 4.26

TYPES OF SENSOR-BASED LONG-TERM MONITORING PERFORMED ON THE CABLES?

\begin{tabular}{|l|c|c|c|c|c|}
\hline \hline & U.S. & $\begin{array}{c}\% \\
\text { U.S. }\end{array}$ & Canada & $\begin{array}{c}\% \\
\text { Canada }\end{array}$ & $\begin{array}{c}\% \\
\text { Total }\end{array}$ \\
\hline $\begin{array}{l}\text { Acoustic wire break } \\
\text { detection }\end{array}$ & 3 & 10.7 & 1 & 7.7 & 9.8 \\
\hline Vibration monitoring & 2 & 7.1 & 1 & 7.7 & 7.3 \\
\hline Force measurements & 0 & 0.0 & 0 & 0.0 & 0.0 \\
\hline Other & 0 & 0.0 & 0 & 0.0 & 0.0 \\
\hline Not performed & 21 & 75.0 & 11 & 84.6 & 78.0 \\
\hline Not known & 1 & 3.6 & 0 & 0.0 & 2.4 \\
\hline No answer & 1 & 3.6 & 0 & 0.0 & 2.4 \\
\hline \hline
\end{tabular}

QUESTION 4.27

HAVE THE CABLES ON THIS BRIDGE (OR ANY OF THEIR COMPONENTS) BEEN REPAIRED?

\begin{tabular}{|l|c|c|c|c|c|}
\hline \hline & U.S. & $\begin{array}{c}\% \\
\text { U.S. }\end{array}$ & Canada & $\begin{array}{c}\% \\
\text { Canada }\end{array}$ & $\begin{array}{c}\% \\
\text { Total }\end{array}$ \\
\hline Yes & 8 & 28.6 & 4 & 30.8 & 29.3 \\
\hline No & 19 & 67.9 & 9 & 69.2 & 68.3 \\
\hline Not known & 0 & 0.0 & 0 & 0.0 & 0.0 \\
\hline No answer & 1 & 3.6 & 0 & 0.0 & 2.4 \\
\hline \hline
\end{tabular}

QUESTION 4.28

HAS THE SHEATHING BEEN PARTIALLY REMOVED ON ANY OF THE CABLES TO EXAMINE CONDITION OF GROUT (IF APPLICABLE) AND/OR THE MTE?

\begin{tabular}{|l|c|c|c|c|c|}
\hline \hline & U.S. & $\begin{array}{c}\% \\
\text { U.S. }\end{array}$ & Canada & $\begin{array}{c}\% \\
\text { Canada }\end{array}$ & $\begin{array}{c}\% \\
\text { Total }\end{array}$ \\
\hline Yes & 3 & 10.7 & 0 & 0.0 & 7.3 \\
\hline No & 20 & 71.4 & 5 & 38.5 & 61.0 \\
\hline Not known & 1 & 3.6 & 0 & 0.0 & 2.4 \\
\hline Not applicable & 3 & 10.7 & 8 & 61.5 & 26.8 \\
\hline No answer & 1 & 3.6 & 0 & 0.0 & 2.4 \\
\hline \hline
\end{tabular}

QUESTION 4.29

CAN THE STRANDS OR CABLES BE REPLACED IF NEEDED?

\begin{tabular}{|l|c|c|c|c|c|}
\hline \hline & U.S. & $\begin{array}{c}\% \\
\text { U.S. }\end{array}$ & Canada & $\begin{array}{c}\% \\
\text { Canada }\end{array}$ & $\begin{array}{c}\% \\
\text { Total }\end{array}$ \\
\hline Yes & 22 & 78.6 & 8 & 61.5 & 73.2 \\
\hline No & 1 & 3.6 & 2 & 15.4 & 7.3 \\
\hline Not known & 4 & 14.3 & 3 & 23.1 & 17.1 \\
\hline No answer & 1 & 3.6 & 0 & 0.0 & 2.4 \\
\hline \hline
\end{tabular}

QUESTION 4.30

DO YOU HAVE AN INSPECTION AND MAINTENANCE MANUAL FOR THIS BRIDGE?

\begin{tabular}{|l|c|c|c|c|c|}
\hline \hline & U.S. & $\begin{array}{c}\% \\
\text { U.S. }\end{array}$ & Canada & $\begin{array}{c}\% \\
\text { Canada }\end{array}$ & $\begin{array}{c}\% \\
\text { Total }\end{array}$ \\
\hline Yes & 20 & 71.4 & 1 & 7.7 & 51.2 \\
\hline No & 6 & 21.4 & 12 & 92.3 & 43.9 \\
\hline Not known & 0 & 0.0 & 0 & 0.0 & 0.0 \\
\hline No answer & 2 & 7.1 & 0 & 0.0 & 4.9 \\
\hline \hline
\end{tabular}

\section{QUESTION 5}

BASED ON YOUR EXPERIENCE AND IN GENERAL, DO YOU BELIEVE THAT THE CURRENT INSPECTION, TESTING, MONITORING, AND REPAIR METHODS AVAILABLE TO YOU FOR STAY CABLES ARE EFFECTIVE AND ADEQUATE?

\begin{tabular}{|l|c|c|c|c|c|}
\hline \hline & & $\%$ & & $\%$ & $\%$ \\
& U.S. & U.S. & Canada & Canada & Total \\
\hline Yes & 11 & 39.3 & 12 & 92.3 & 56.1 \\
\hline No & 8 & 28.6 & 0 & 0.0 & 19.5 \\
\hline Not known & 9 & 32.1 & 1 & 7.7 & 24.4 \\
\hline \hline
\end{tabular}

QUESTION 10

DO YOU BELIEVE THAT AN UP-TO-DATE RESOURCE SUCH AS A NATIONAL DATABASE OF INFORMATION ON STAY CABLE INSPECTION METHODS, REPAIRS, AND TESTING WOULD BE A USEFUL TOOL?

\begin{tabular}{|l|c|c|c|c|c|}
\hline \hline & U.S. & $\begin{array}{c}\% \\
\text { U.S. }\end{array}$ & Canada & $\begin{array}{c}\% \\
\text { Canada }\end{array}$ & $\begin{array}{c}\% \\
\text { Total }\end{array}$ \\
\hline Yes & 25 & 89.3 & 12 & 92.3 & 90.2 \\
\hline No & 0 & 0.0 & 0 & 0.0 & 0.0 \\
\hline Not known & 3 & 10.7 & 0 & 0.0 & 7.3 \\
\hline
\end{tabular}




\section{APPENDIX C}

Responses to Questionnaire 


\section{NCHRP SYNTHESIS TOPIC 35-07-INSPECTION AND MAINTENANCE OF BRIDGE STAY CABLE SYSTEMS}

Cochrane Africatown

Alabama

Questionnaire Results

Survey performed in 2004

\section{Cochrane Africatown}

State/Province: Alabama

$\begin{array}{ll}\text { Agency: } & \text { Alabama DOT } \\ \text { Respondent: } & \text { Fred Conway } \\ \text { Span Length: } & \mathbf{7 8 0 ~ f t} \\ \text { Year Built: } & \mathbf{1 9 9 1}\end{array}$

Q4-4: Type of main tension element (MTE)?

seven-wire steel strand

Q4-5: Coating/treatment on main tension element within free length of cable?

bare

Q4-6: Are the coatings/treatments on main tension element discontinued or removed within the anchorage zone?

N/A

Q4-7: Type of grout used?

cement-water admixtures

Q4-8: Are filler materials used in the anchorage zone?

yes, other

Q4-9: Type of anchorage?

conical socket with wedges

Q4-10: Do cables go over "saddles" on the pylons?

no
Q4-11: Type of cable sheathing used?

\section{HDPE with PVF Tedlar tape}

Q4-12: Have rain-wind-induced cable vibrations been observed on this bridge? yes

Q4-13: Have MTE corrosion problems been noted?

no

Q4-14: Do cables have neoprene rings near the top and bottom anchorages? yes

Q4-15: If there are neoprene rings on the cables; have there been any reports of movements of the rings out of their positions?

yes-due to loosening of retainers, and yesdue to shearing off of retainers

Q4-16: Has moisture been found in any of the internal components of stay cables such as the bottom anchorage areas?

yes

Q4-17: Has fatigue of MTE or other components of stay cables been observed?

no

Q4-18: Do the cables have viscous dampers installed at deck or tower levels?

yes-retrofitted to correct vibrations

Q4-19: Do the cables have cross cables installed between them?
Q4-20: Do cables have other dampers (other than viscous or neoprene rings) to control vibrations?

no

Q4-21: Has cracking of the cable sheathing or sheathing connections been noted?

no

Q4-22: Has cracking or misalignment of the guide pipes been noted?

\section{yes-misalignment}

Q4-23: If there is protective tape wrapped around the cable sheathing; have there been reports of deterioration of the tape?

\section{yes-minor damage}

Q4-24: Have any problems associated with neoprene boots been noted?

yes

Q4-25: Types of non-destructive tests that any of the cables on this bridge have been subjected to?

ultrasonic and vibration-based force measurements

Q4-26: Types of sensor-based, long-term monitoring performed on the cables?

\section{vibration monitoring}

Q4-27: Have the cables on this bridge (or any of their components) been repaired? 


\section{NCHRP SYNTHESIS TOPIC 35-07-INSPECTION AND MAINTENANCE OF BRIDGE STAY CABLE SYSTEMS}

Cochrane Africatown

Alabama
Questionnaire Results

Survey performed in 2004 yes-some neoprene boots were replaced

Q4-28: Has the sheathing been partially removed on any of the cables to examine condition of grout (if applicable) and/or the MTE?

yes-thorough inspection performed. Selected cables were opened up where voids in grout were detected

Q4-29: Can the strands or cables be replaced if needed?

yes-individual strands cannot be replaced but an entire stay can be replaced

Q4-30: Do you have an inspection and yes

Q5: Based on your experience and in general, do you believe that the current inspection, testing, monitoring, and repair methods available to you for stay cables are effective and adequate?

yes

Q6: Please comment on the effectiveness of any non-destructive test methods for inspections of stay cables that you may be familiar with. These methods include (but are not limited to) ultrasonic testing, magnetic inspections, laser-based force measurements, $\mathrm{X}$-ray imaging, etc. If possible, please comment on issues such as practicality, cost, duration, impact on traffic, and any other factors that you consider important
Several non-destructive tests were run after an extreme oscillation event. Practically all the above were performed to determine if there was any loss of force in the stays. Geometric, physical and visual tests were performed. The only discoveries were deficiencies in the original construction which were corrected

Q7: Please comment on the effectiveness of any cable vibration control measures that you may be familiar with. Examples include installation of cross cables, viscous dampers, neoprene rings, etc.

We realigned stay pipes and replaced neoprene rings and keeper rings. Also external hydraulic dampers were installed on the longer stays

Q8: Please comment on the effectiveness of any sensor-based, long-term monitoring systems for stay cables that you may be familiar with. Examples include acoustic monitoring, vibration monitoring, force measurements, strain measurements, etc.

\section{Check with A.G. Lichtenstein}

Q9: What would you recommend that the cable suppliers incorporate into their systems to make cables more accessible and inspectable?

Provide access on inside and outside of tower anchorage.

Q10: Do you believe that an up-to-date resource such as a national database of information on stay cable inspection methods, repairs, and testing would be a useful tool?

not known
Q11: What do you see as the single most important problem in stay cable maintenance?

Stay anchors. (Access and rain-wind-induced oscillation.)

Q12: Please comment on any other methods for inspections, testing, monitoring, and repair of stay cable (including conventional methods) that you have found beneficial and are not listed above.

no answer

Additional comments? 


\section{NCHRP SYNTHESIS TOPIC 35-07-INSPECTION AND MAINTENANCE OF BRIDGE STAY CABLE SYSTEMS}

Sitka Harbor Bridge Sitka, Alaska

Questionnaire Results

Alaska

Survey performed in 2004

\section{Sitka Harbor Bridge, Sitka,}

\section{Alaska}

State/Province: Alaska

Agency:

\section{Alaska DOT}

Respondent:

Gary Scarbrough

Span Length: $\quad \mathbf{4 5 0} \mathrm{ft}$

Year Built: 1970

Q4-4: Type of main tension element (MTE)?

other-galvanized bridge strand

Q4-5: Coating/treatment on main tension element within free length of cable?

galvanized steel

Q4-6: Are the coatings/treatments on main tension element discontinued or removed within the anchorage zone?

\section{not known}

Q4-7: Type of grout used?

\section{not known}

Q4-8: Are filler materials used in the anchorage zone?

\section{yes-other, liquid polymer sealer}

Q4-9: Type of anchorage?

conical socket with wedges

Q4-10: Do cables go over "saddles" on the pylons?
Q4-11: Type of cable sheathing used? no sheathing

Q4-12: Have rain-wind-induced cable vibrations been observed on this bridge? not known

Q4-13: Have MTE corrosion problems been noted?

no

Q4-14: Do cables have neoprene rings near the top and bottom anchorages?

no

Q4-15: If there are neoprene rings on the cables; have there been any reports of movements of the rings out of their positions?

\section{not applicable}

Q4-16: Has moisture been found in any of the internal components of stay cables such as the bottom anchorage areas?

yes-area around each cable was filled with grease

Q4-17: Has fatigue of MTE or other components of stay cables been observed? no

Q4-18: Do the cables have viscous dampers installed at deck or tower levels?

no

Q4-19: Do the cables have cross cables installed between them?
Q4-20: Do cables have other dampers (other than viscous or neoprene rings) to control vibrations?

no

Q4-21: Has cracking of the cable sheathing or sheathing connections been noted?

\section{not applicable}

Q4-22: Has cracking or misalignment of the guide pipes been noted?

\section{not known}

Q4-23: If there is protective tape wrapped around the cable sheathing; have there been reports of deterioration of the tape?

\section{not applicable}

Q4-24: Have any problems associated with neoprene boots been noted?

no

Q4-25: Types of non-destructive tests that any of the cables on this bridge have been subjected to?

\section{vibration-based force measurements}

Q4-26: Types of sensor-based, long-term monitoring performed on the cables?

\section{not performed}

Q4-27: Have the cables on this bridge (or any of their components) been repaired? 
no-during mid-1990s cables were removed inspected, and replaced after no defects observed.

Q4-28: Has the sheathing been partially removed on any of the cables to examine condition of grout (if applicable) and/or the MTE?

\section{not applicable}

Q4-29: Can the strands or cables be replaced if needed?

yes

Q4-30: Do you have an inspection and maintenance manual for this bridge?

Q5: Based on your experience and in general, do you believe that the current inspection, testing, monitoring, and repair methods available to you for stay cables are effective and adequate?

not known-cables on both bridges were inspected during the mid-1990s. Cables on Captain William Moore were replaced due to an upgrade of the structure. Cables on the Sitka Harbor Bridge were removed, inspected, and reinstalled. No problems were reported with any of the cables during the mid-1990 inspection.

Q6: Please comment on the effectiveness of any non-destructive test methods for inspections of stay cables that you may be familiar with. These methods include (but are not limited to) ultrasonic testing, magnetic

inspections, laser-based force measurements, $\mathrm{X}$-ray imaging, etc. If possible, please comment on issues such as practicality, cost duration, impact on traffic, and any other factors that you consider important.

The fundamental frequency of the cables was recorded. Alaska DOT\&PF will monitor the cables and attempt to determine if the fundamental frequency of the cables has changed.

Q7: Please comment on the effectiveness of any cable vibration control measures that you may be familiar with. Examples include installation of cross cables, viscous dampers, neoprene rings, etc.

\section{N/A}

Q8: Please comment on the effectiveness of any sensor-based, long-term monitoring systems for stay cables that you may be familiar with. Examples include acoustic monitoring, vibration monitoring, force measurements, strain measurements, etc.

Q9: What would you recommend that the cable suppliers incorporate into their systems to make cables more accessible and inspectable?

N/A

Q10: Do you believe that an up-to-date resource such as a national database of information on stay cable inspection methods, repairs, and testing would be a useful tool?
Q11: What do you see as the single most important problem in stay cable maintenance? Access to upper cable anchorage

Q12: Please comment on any other methods for inspections, testing, monitoring, and repair of stay cable (including conventional methods) that you have found beneficial and are not listed above.

$N / A$

Additional comments?

no answer 


\section{NCHRP SYNTHESIS TOPIC 35-07-INSPECTION AND MAINTENANCE OF BRIDGE STAY CABLE SYSTEMS}

Captain William Moore Bridge, Skagway

Questionnaire Results

Alaska

Survey performed in 2004

\section{Captain William Moore Bridge,}

\section{Skagway}

State/Province: Alaska

Agency:

\section{Alaska DOT}

Respondent:

\section{Gary Scarbrough}

Span Length: $\quad \mathbf{3 0 0} \mathrm{ft}$

Year Built: 1975

Q4-4: Type of main tension element (MTE)?

other-ASTM Desig A586-86

Q4-5: Coating/treatment on main tension element within free length of cable?

galvanized steel

Q4-6: Are the coatings/treatments on main tension element discontinued or removed within the anchorage zone?

\section{not known}

Q4-7: Type of grout used?

\section{not known}

Q4-8: Are filler materials used in the anchorage zone?

yes, grease

Q4-9: Type of anchorage?

conical socket with wedges

Q4-10: Do cables go over "saddles" on the pylons?
Q4-11: Type of cable sheathing used? no sheathing

Q4-12: Have rain-wind-induced cable vibrations been observed on this bridge? not known

Q4-13: Have MTE corrosion problems been noted?

no

Q4-14: Do cables have neoprene rings near the top and bottom anchorages?

no

Q4-15: If there are neoprene rings on the cables; have there been any reports of movements of the rings out of their positions?

\section{not applicable}

Q4-16: Has moisture been found in any of the internal components of stay cables such as the bottom anchorage areas?

yes-area around each cable was filled with grease.

Q4-17: Has fatigue of MTE or other components of stay cables been observed? no

Q4-18: Do the cables have viscous dampers installed at deck or tower levels?

no

Q4-19: Do the cables have cross cables installed between them?
Q4-20: Do cables have other dampers (other than viscous or neoprene rings) to control vibrations?

no

Q4-21: Has cracking of the cable sheathing or sheathing connections been noted?

\section{not applicable}

Q4-22: Has cracking or misalignment of the guide pipes been noted?

\section{not known}

Q4-23: If there is protective tape wrapped around the cable sheathing; have there been reports of deterioration of the tape?

\section{not applicable}

Q4-24: Have any problems associated with neoprene boots been noted?

no

Q4-25: Types of non-destructive tests that any of the cables on this bridge have been subjected to?

\section{vibration-based force measurements}

Q4-26: Types of sensor-based, long-term monitoring performed on the cables?

\section{not performed}

Q4-27: Have the cables on this bridge (or any of their components) been repaired? 


\section{NCHRP SYNTHESIS TOPIC 35-07-INSPECTION AND MAINTENANCE OF BRIDGE STAY CABLE SYSTEMS}

\section{Captain William Moore Bridge, Skagway}

Alaska

Bridge redesigned for higher load capacity. New cables were installed during mid-1990s.

Q4-28: Has the sheathing been partially removed on any of the cables to examine condition of grout (if applicable) and/or the MTE?

\section{not applicable}

Q4-29: Can the strands or cables be replaced if needed?

yes

Q4-30: Do you have an inspection and maintenance manual for this bridge?
X-ray imaging, etc. If possible, please comment on issues such as practicality, cost, duration, impact on traffic, and any other factors that you consider important.

The fundamental frequency of the cables was recorded. Alaska DOT\&PF will monitor the cables and attempt to determine if the fundamental frequency of the cables has changed.

Q7: Please comment on the effectiveness of any cable vibration control measures that you may be familiar with. Examples include installation of cross cables, viscous dampers, neoprene rings, etc.

N/A

Q5: Based on your experience and in general, do you believe that the current inspection, testing, monitoring, and repair methods available to you for stay cables are effective and adequate?

not known-cables on both bridges were inspected during the mid-1990s. Cables on Captain William Moore were replaced due to an upgrade of the structure. Cables on the Sitka Harbor Bridge were removed, inspected, and reinstalled. No problems were reported with any of the cables during the mid-1990 inspection.

Q6: Please comment on the effectiveness of any non-destructive test methods for inspections of stay cables that you may be familiar with. These methods include (but are not limited to) ultrasonic testing, magnetic inspections, laser-based force measurements,
Q8: Please comment on the effectiveness of any sensor-based, long-term monitoring systems for stay cables that you may be familiar with. Examples include acoustic monitoring, vibration monitoring, force measurements, strain measurements, etc.

\section{N/A}

Q9: What would you recommend that the cable suppliers incorporate into their systems to make cables more accessible and inspectable?

\section{N/A}

Q10: Do you believe that an up-to-date resource such as a national database of information on stay cable inspection methods, repairs, and testing would be a useful tool? yes
Questionnaire Results

Survey performed in 2004

Q11: What do you see as the single most important problem in stay cable maintenance? Access to upper cable anchorage

Q12: Please comment on any other methods for inspections, testing, monitoring, and repair of stay cable (including conventional methods) that you have found beneficial and are not listed above.

N/A

Additional comments?

no answer 


\section{NCHRP SYNTHESIS TOPIC 35-07-INSPECTION AND MAINTENANCE OF BRIDGE STAY CABLE SYSTEMS}

Sacramento River (Meridian)

California

Questionnaire Results

Survey performed in 2004

\section{Sacramento River (Meridian)}

State/Province: California

Agency: Caltrans

Respondent: $\quad$ Erol C. Kaslan

Span Length: $\quad \mathbf{1 8 0} \mathrm{ft}$

Year Built: $\quad 1977$

Q4-4: Type of main tension element (MTE)? steel wire

Q4-5: Coating/treatment on main tension element within free length of cable?

\section{galvanized steel}

Q4-6: Are the coatings/treatments on main tension element discontinued or removed within the anchorage zone?

no

Q4-7: Type of grout used?

grout not used

Q4-8: Are filler materials used in the anchorage zone?

yes, grease

Q4-9: Type of anchorage?

other-main cables are swedged onto a steel conical threaded coupler that is attached to a threaded HS steel rod, which uses a spherical anchor socket and anchor nut to provide anchorage connection. This system appears to be uniquely designed.
Q4-10: Do cables go over "saddles" on the pylons?

yes

Q4-11: Type of cable sheathing used? no sheathing

Q4-12: Have rain-wind-induced cable vibrations been observed on this bridge? no

Q4-13: Have MTE corrosion problems been noted?

no

Q4-14: Do cables have neoprene rings near the top and bottom anchorages?

no

Q4-15: If there are neoprene rings on the cables; have there been any reports of movements of the rings out of their positions?

$N / A$

Q4-16: Has moisture been found in any of the internal components of stay cables such as the bottom anchorage areas?

\section{not tested, not known}

Q4-17: Has fatigue of MTE or other components of stay cables been observed? no

Q4-18: Do the cables have viscous dampers installed at deck or tower levels?

no
Q4-19: Do the cables have cross cables installed between them?

no

Q4-20: Do cables have other dampers (other than viscous or neoprene rings) to control vibrations?

Cables utilize clamps near the saddles to retain separation of the cable groups-these may provide some unintentional damping.

Q4-21: Has cracking of the cable sheathing or sheathing connections been noted?

$N / A$

Q4-22: Has cracking or misalignment of the guide pipes been noted?

$N / A$

Q4-23: If there is protective tape wrapped around the cable sheathing; have there been reports of deterioration of the tape?

$N / A$

Q4-24: Have any problems associated with neoprene boots been noted?

The neoprene seals noted above that retain grease in the anchorage areas leak.

Q4-25: Types of non-destructive tests that any of the cables on this bridge have been subjected to?

$X$-ray; primary inspection method is VT.

"MINAC" radiographic inspection was used once in 1989 to inspect the swedged 
NCHRP SYNTHESIS TOPIC 35-07-INSPECTION AND MAINTENANCE OF BRIDGE STAY CABLE SYSTEMS

Sacramento River (Meridian)

California

Questionnaire Results

Survey performed in 2004

anchorage components as a demonstration of the technology.

Q4-26: Types of sensor-based, long-term monitoring performed on the cables?

\section{not performed}

Q4-27: Have the cables on this bridge (or any of their components) been repaired?

no

Q4-28: Has the sheathing been partially removed on any of the cables to examine condition of grout (if applicable) and/or the MTE?

Q4-29: Can the strands or cables be replaced if needed?

yes-as this swing bridge only fully utilizes the cables to support the spans in the open condition, cable replacement would be relatively straightforward.

Q4-30: Do you have an inspection and maintenance manual for this bridge?

no

Q5: Based on your experience and in general, do you believe that the current inspection, testing, monitoring, and repair methods available to you for stay cables are effective and adequate?

\section{not known}

Q6: Please comment on the effectiveness of any non-destructive test methods for

inspections of stay cables that you may be familiar with. These methods include (but are not limited to) ultrasonic testing, magnetic inspections, laser-based force measurements, $\mathrm{X}$-ray imaging, etc. If possible, please comment on issues such as practicality, cost, duration, impact on traffic, and any other factors that you consider important.

Used radiographic testing once on this structure. It was costly and impractical, but did appear to give satisfactory results. Would not use this method for routine inspections on this bridge.

Q7: Please comment on the effectiveness of any cable vibration control measures that you may be familiar with. Examples include installation of cross cables, viscous dampers, neoprene rings, etc.

\section{no answer}

Q8: Please comment on the effectiveness of any sensor-based, long-term monitoring systems for stay cables that you may be familiar with. Examples include acoustic monitoring, vibration monitoring, force measurements, strain measurements, etc.

Acoustic monitoring appears to have great value and promise. Would recommend that this technology be fully developed.

Q9: What would you recommend that the cable suppliers incorporate into their systems to make cables more accessible and inspectable?

Fiber optic strain gauges and redundant systems
Q10: Do you believe that an up-to-date resource such as a national database of information on stay cable inspection methods, repairs, and testing would be a useful tool?

yes

Q11: What do you see as the single most important problem in stay cable maintenance?

\section{Inspection and condition evaluation of} anchorages

Q12: Please comment on any other methods for inspections, testing, monitoring, and repair of stay cable (including conventional methods) that you have found beneficial and are not listed above.

Engineering judgment and experience seem to prevail in determining appropriate inspection and maintenance strategies.

Additional comments? 


\section{NCHRP SYNTHESIS TOPIC 35-07-INSPECTION AND MAINTENANCE OF BRIDGE STAY CABLE SYSTEMS}

Br. 1-902, SR1 over the Chesapeake and Delaware Canal, St. Georges, New Castle County, Delaware

Questionnaire Results

Delaware

Survey performed in 2004

\section{Br. 1-902, SR-1 over the \\ Chesapeake and Delaware \\ Canal, St. Georges, New Castle \\ County, Delaware}

State/Province: Delaware

Agency: $\quad$ Delaware DOT

Respondent: Douglas Finney

Span Length: $\quad \mathbf{7 5 0} \mathrm{ft}$

Year Built: 1995

Q4-4: Type of main tension element (MTE)?

seven-wire steel strand

Q4-5: Coating/treatment on main tension element within free length of cable?

bare

Q4-6: Are the coatings/treatments on main tension element discontinued or removed

within the anchorage zone?

not applicable

Q4-7: Type of grout used?

cement-water admixtures

Q4-8: Are filler materials used in the anchorage zone?

yes, grout

Q4-9: Type of anchorage?

conical socket with wedges
Q4-10: Do cables go over "saddles" on the pylons?

yes

Q4-11: Type of cable sheathing used?

steel pipe

Q4-12: Have rain-wind-induced cable vibrations been observed on this bridge? no

Q4-13: Have MTE corrosion problems been noted?

not known-moisture infiltration is suspected however, due to the limitations of available inspection methods; definitive evidence of corrosion is not available.

Q4-14: Do cables have neoprene rings near the top and bottom anchorages? yes

Q4-15: If there are neoprene rings on the cables; have there been any reports of movements of the rings out of their positions?

yes-due to loosening of retainers; movement observed in outer neoprene ring of anchorage set. No retaining devices were present.

Q4-16: Has moisture been found in any of the internal components of stay cables such as the bottom anchorage areas?

not known-effloresence from anchorages as well as protective pipe splice sleeves leads inspectors to believe moisture is infiltrating the cable stay system.

Q4-17: Has fatigue of MTE or other components of stay cables been observed? no

Q4-18: Do the cables have viscous dampers installed at deck or tower levels?

no

Q4-19: Do the cables have cross cables installed between them?

no

Q4-20: Do cables have other dampers (other than viscous or neoprene rings) to control vibrations?

no

Q4-21: Has cracking of the cable sheathing or sheathing connections been noted?

yes, sheathing-cracking of the steel protective pipe has been noted on the uppermost stay cable of the north pylon. Cracking has been attributed to the position of a construction grout vent hole at a high stress location.

Q4-22: Has cracking or misalignment of the guide pipes been noted?

no

Q4-23: If there is protective tape wrapped around the cable sheathing; have there been reports of deterioration of the tape? 


\section{NCHRP SYNTHESIS TOPIC 35-07-INSPECTION AND MAINTENANCE OF BRIDGE STAY CABLE SYSTEMS}

Br. 1-902, SR1 over the Chesapeake and Delaware Canal, St. Georges, New Castle County, Delaware

Questionnaire Results

Delaware

not applicable-protective steel pipe is painted.

Q4-24: Have any problems associated with neoprene boots been noted?

yes-minor tearing of one neoprene boot has been observed.

Q4-25: Types of non-destructive tests that any of the cables on this bridge have been subjected to?

other-borescope has been utilized to view the guidepipe area of select cable stays for moisture, fatigue, deterioration, and corrosion. An attempt was made to remove the anchorage caps made removal difficult.

High-powered X-ray inspection of the cable stays was considered. This method has not been employed due to concerns for protection of the public and personnel during testing, access limitations, uncertainty of the results of such investigations due to the complicated geometry of the subject area.

Q4-26: Types of sensor-based, long-term monitoring performed on the cables?

not performed. Vibration monitoring equipment has been installed on the cable stays by the FHWA. However, this equipment is currently not operating and data are not available.

Q4-27: Have the cables on this bridge (or any of their components) been repaired?

yes-out of position neoprene dampers have been repositioned and set screws have been installed to secure the position of the outer neoprene damper rings on all cable stays.

Q4-28: Has the sheathing been partially removed on any of the cables to examine condition of grout (if applicable) and/or the MTE?

no-limited investigation of the cable stay grout has been performed via the open construction grout vents in the saddle pipe area of the cable stay.

Q4-29: Can the strands or cables be replaced if needed?

yes-The original design accounted for the replacement of the stay cables (one at a time).

Q4-30: Do you have an inspection and maintenance manual for this bridge?

yes

Q5: Based on your experience and in general, do you believe that the current inspection, testing, monitoring, and repair methods available to you for stay cables are effective and adequate?

no-use of the steel protective pipe limits the inspection methods available to investigate the condition of the stay cables.

Q6: Please comment on the effectiveness of any non-destructive test methods for inspections of stay cables that you may be familiar with. These methods include (but are not limited to) ultrasonic testing, magnetic inspections, laser-based force measurements, $\mathrm{X}$-ray imaging, etc. If possible, please comment on issues such as practicality, cost, duration, impact on traffic, and any other factors that you consider important.

The presence of the steel protective pipe limits the effectiveness of many available testing methods, particularly magnetic based methods. As noted above, X-ray imaging of the cable stays was considered and dismissed. Several concerns were encountered with this method including protection of public and working personnel during the exposure, access and holding the equipment at the higher elevations of the cable stay, and scheduling of the equipment. Interpretation of the image was also a concern. It is believed that the multiple materials (steel, grout, steel strand) that comprise the cable stays combined with the changing geometry would make interpretation of the image difficult and would not allow for an accurate understanding of the conditions. Our understanding is that the X-ray imaging would only be able to detect gross section loss of the stay and is not precise enough to discern the onset or early stages of corrosion. Finally, when the X-ray imaging method was considered, it only allowed a view of a discrete section of the cable stay as opposed to a global or "traveling" operation which would allow an investigation of the entire length of the cable stay. Implementation of laser-based cable stay force measurements are being 
NCHRP SYNTHESIS TOPIC 35-07-INSPECTION AND MAINTENANCE OF BRIDGE STAY CABLE SYSTEMS

Delaware

considered by the department to establish baseline force data for the cable stays.

Q7: Please comment on the effectiveness of any cable vibration control measures that you may be familiar with. Examples include installation of cross cables, viscous dampers, neoprene rings, etc.

The neoprene dampers of the C\&D Canal Bridge appear to operating adequately, particularly since the repositioning and installation of set screws into the outer neoprene rings. Excessive vibrations of the stay cables have not been noted. No other cable stay damping systems are present on the bridge. Grout spalls have been observed in the grout bedding (cable stays saddle area) where the upper stays (13 thru 16) enter the pylon. This spalling has been attributed to minor vibrations of the stays.

Q8: Please comment on the effectiveness of any sensor-based, long-term monitoring systems for stay cables that you may be familiar with. Examples include acoustic monitoring, vibration monitoring, force measurements, strain measurements, etc.

\section{The current sensor-based, long-term} monitoring system installed on the bridge is not operable and therefore comment cannot be made. The department is considering the addition of force measurement (deck-based laser method) to the list of inspections items required for the bridge.
Q9: What would you recommend that the cable suppliers incorporate into their systems to make cables more accessible and inspectable?

We would recommend the development of individual strand monitoring capabilities, which encompass the strands from anchorage to anchorage.

Q10: Do you believe that an up-to-date resource such as a national database of information on stay cable inspection methods, repairs, and testing would be a useful tool?

\section{yes}

Q11: What do you see as the single most important problem in stay cable maintenance?

Effective corrosion barriers that do not interfere with the ability to adequately inspect and assess the health of the cable stay system on a regular interval and within practical means.

Q12: Please comment on any other methods for inspections, testing, monitoring, and repair of stay cable (including conventional methods) that you have found beneficial and are not listed above.

\section{No answer}

Additional comments? 
NCHRP SYNTHESIS TOPIC 35-07-INSPECTION AND MAINTENANCE OF BRIDGE STAY CABLE SYSTEMS

Dame Point Bridge

Florida

\section{Dame Point Bridge}

State/Province: Florida

Agency: $\quad$ Florida DOT

Respondent: Rick Vallier

Span Length: $\quad \mathbf{1 , 3 0 0 ~ f t}$

Year Built: 1989

Q4-4: Type of main tension element (MTE)? steel bar or threadbar

Q4-5: Coating/treatment on main tension element within free length of cable?

Q4-6: Are the coatings/treatments on main tension element discontinued or removed within the anchorage zone?

\section{not known}

Q4-7: Type of grout used?

not known-a cement grout was used

Q4-8: Are filler materials used in the anchorage zone?

yes, grout

Q4-9: Type of anchorage?

wedges

Q4-10: Do cables go over "saddles" on the pylons?

no

Q4-11: Type of cable sheathing used? steel pipe

Q4-12: Have rain-wind-induced cable vibrations been observed on this bridge?

no

Q4-13: Have MTE corrosion problems been noted?

no

Q4-14: Do cables have neoprene rings near the top and bottom anchorages?

no

Q4-15: If there are neoprene rings on the cables; have there been any reports of movements of the rings out of their positions?

N/A

Q4-16: Has moisture been found in any of the internal components of stay cables such as the bottom anchorage areas?

yes

Q4-17: Has fatigue of MTE or other components of stay cables been observed? no

Q4-18: Do the cables have viscous dampers installed at deck or tower levels?

no

Q4-19: Do the cables have cross cables installed between them?

yes-from the beginning
Questionnaire Results

Survey performed in 2004

Q4-20: Do cables have other dampers (other than viscous or neoprene rings) to control vibrations?

no

Q4-21: Has cracking of the cable sheathing or sheathing connections been noted?

yes-connections

Q4-22: Has cracking or misalignment of the guide pipes been noted?

no

Q4-23: If there is protective tape wrapped around the cable sheathing; have there been reports of deterioration of the tape?

N/A

Q4-24: Have any problems associated with neoprene boots been noted?

no

Q4-25: Types of non-destructive tests that any of the cables on this bridge have been subjected to?

\section{not performed}

Q4-26: Types of sensor-based, long-term monitoring performed on the cables?

\section{not performed}

Q4-27: Have the cables on this bridge (or any of their components) been repaired?

no 


\section{NCHRP SYNTHESIS TOPIC 35-07-INSPECTION AND MAINTENANCE OF BRIDGE STAY CABLE SYSTEMS}

\section{Dame Point Bridge}

Florida

Q4-28: Has the sheathing been partially removed on any of the cables to examine condition of grout (if applicable) and/or the MTE?

no

Q4-29: Can the strands or cables be replaced if needed?

no

Q4-30: Do you have an inspection and maintenance manual for this bridge?

yes

Q5: Based on your experience and in general, do you believe that the current inspection, testing, monitoring, and repair methods available to you for stay cables are effective and adequate?

\section{not known}

Q6: Please comment on the effectiveness of any non-destructive test methods for inspections of stay cables that you may be familiar with. These methods include (but are not limited to) ultrasonic testing, magnetic inspections, laser-based force measurements, $\mathrm{X}$-ray imaging, etc. If possible, please comment on issues such as practicality, cost, duration, impact on traffic, and any other factors that you consider important.

Non-destructive testing is needed to determine the condition of tension bars inside the steel casing of the cables.

Q7: Please comment on the effectiveness of any cable vibration control measures that you may be familiar with. Examples include installation of cross cables, viscous dampers, neoprene rings, etc.

Cross cables are installed on the bridge and from time to time they sag and need to be retightened.

Q8: Please comment on the effectiveness of any sensor-based, long-term monitoring systems for stay cables that you may be familiar with. Examples include acoustic monitoring, vibration monitoring, force measurements, strain measurements, etc.

none

Q9: What would you recommend that the cable suppliers incorporate into their systems to make cables more accessible and inspectable?

\section{Not familiar with this}

Q10: Do you believe that an up-to-date resource such as a national database of information on stay cable inspection methods, repairs, and testing would be a useful tool?

yes

Q11: What do you see as the single most important problem in stay cable maintenance?

Accessibility for inspection and maintenance

Q12: Please comment on any other methods for inspections, testing, monitoring, and repair of stay cable (including conventional methods) that you have found beneficial and are not listed above.

Man-lift truck
Questionnaire Results

Survey performed in 2004
Additional comments? 
NCHRP SYNTHESIS TOPIC 35-07_INSPECTION AND MAINTENANCE OF BRIDGE STAY CABLE SYSTEMS

Talmadge Memorial Bridge, Savannah Georgia

\section{Talmadge Memorial Bridge,}

\section{Savannah}

State/Province: Georgia

Agency: $\quad$ Georgia DOT

Respondent: $\quad$ Paul V.Liles, Jr.

Span Length: $\quad \mathbf{1 , 1 0 0 ~ f t}$

Year Built: 1991

Q4-4: Type of main tension element (MTE)? seven-wire steel strand

Q4-5: Coating/treatment on main tension

\section{bare}

Q4-6: Are the coatings/treatments on main tension element discontinued or removed within the anchorage zone?

\section{N/A}

Q4-7: Type of grout used?

\section{cement-water}

Q4-8: Are filler materials used in the anchorage zone?

yes, other-steel shot and epoxy

Q4-9: Type of anchorage?

other-American Stronghold system

Q4-10: Do cables go over "saddles" on the pylons?

no

Q4-11: Type of cable sheathing used? HDPE with PVF Tedlar tape

Q4-12: Have rain-wind-induced cable vibrations been observed on this bridge?

yes

Q4-13: Have MTE corrosion problems been noted?

no

Q4-14: Do cables have neoprene rings near the top and bottom anchorages?

yes

Q4-15: If there are neoprene rings on the cables; have there been any reports of movements of the rings out of their positions?

yes-due to loosening of retainers, and yesdue to shearing off of retainers

Q4-16: Has moisture been found in any of the internal components of stay cables such as the bottom anchorage areas?

no

Q4-17: Has fatigue of MTE or other components of stay cables been observed? no

Q4-18: Do the cables have viscous dampers installed at deck or tower levels?

no

Q4-19: Do the cables have cross cables installed between them? no

Q4-20: Do cables have other dampers (other than viscous or neoprene rings) to control vibrations?

no

Q4-21: Has cracking of the cable sheathing or sheathing connections been noted?

no

Q4-22: Has cracking or misalignment of the guide pipes been noted?

yes-cracking

Q4-23: If there is protective tape wrapped around the cable sheathing; have there been reports of deterioration of the tape?

no

Q4-24: Have any problems associated with neoprene boots been noted?

no

Q4-25: Types of non-destructive tests that any of the cables on this bridge have been subjected to?

vibration-based force measurements

Q4-26: Types of sensor-based, long-term monitoring performed on the cables?

not performed

Q4-27: Have the cables on this bridge (or any of their components) been repaired?

no 


\section{NCHRP SYNTHESIS TOPIC 35-07-INSPECTION AND MAINTENANCE OF BRIDGE STAY CABLE SYSTEMS}

Q4-28: Has the sheathing been partially removed on any of the cables to examine condition of grout (if applicable) and/or the MTE?

yes-some removal and inspection was done in 2002. Grout was found to be satisfactory.

Q4-29: Can the strands or cables be replaced if needed?

yes

Q4-30: Do you have an inspection and maintenance manual for this bridge?

yes

Q5: Based on your experience and in general, do you believe that the current inspection, testing, monitoring, and repair methods available to you for stay cables are effective and adequate?

yes

Q6: Please comment on the effectiveness of any non-destructive test methods for inspections of stay cables that you may be familiar with. These methods include (but are not limited to) ultrasonic testing, magnetic inspections, laser-based force measurements, $\mathrm{X}$-ray imaging, etc. If possible, please comment on issues such as practicality, cost, duration, impact on traffic, and any other factors that you consider important.

Laser-based force measurements will give results that will indicate if a cable is deviating from the trending values of the other cables. It may not give you an accurate value of the force in a cable. It is relatively easy and inexpensive to perform.

Q7: Please comment on the effectiveness of any cable vibration control measures that you may be familiar with. Examples include installation of cross cables, viscous dampers, neoprene rings, etc.

These methods are all effective in controlling free vibrations of the cables. Helical strakes formed in the cable neoprene sheathing are also effective.

Q8: Please comment on the effectiveness of any sensor-based, long-term monitoring systems for stay cables that you may be familiar with. Examples include acoustic monitoring, vibration monitoring, force measurements, strain measurements, etc.

\section{These are all effective but they are generally} expensive and have not been used on Georgia's bridges.

Q9: What would you recommend that the cable suppliers incorporate into their systems to make cables more accessible and inspectable?

For non-box bridges, an inspection traveller should be installed on the cable-stayed bridge. This should be done by the owner.

Q10: Do you believe that an up-to-date resource such as a national database of information on stay cable inspection methods, repairs, and testing would be a useful tool?
Q11: What do you see as the single most important problem in stay cable maintenance?

\section{Access to the cable anchorages}

Q12: Please comment on any other methods for inspections, testing, monitoring, and repair of stay cable (including conventional methods) that you have found beneficial and are not listed above.

Television endoscope type cameras for access to guide pipes at bridge deck level are helpful.

Additional comments? 


\section{NCHRP SYNTHESIS TOPIC 35-07-INSPECTION AND MAINTENANCE OF BRIDGE STAY CABLE SYSTEMS}

Sidney Lanier Bridge, Brunswick Georgia

\section{Sidney Lanier Bridge, \\ Brunswick}

$\begin{array}{ll}\text { State/Province: } & \text { Georgia } \\ \text { Agency: } & \text { Georgia DOT } \\ \text { Respondent: } & \text { Paul V. Liles, Jr. } \\ \text { Span Length: } & \mathbf{1 , 2 5 0} \mathrm{ft} \\ \text { Year Built: } & \mathbf{2 0 0 3}\end{array}$

Q4-4: Type of main tension element (MTE)? seven-wire steel strand

Q4-5: Coating/treatment on main tension

\section{bare}

Q4-6: Are the coatings/treatments on main tension element discontinued or removed within the anchorage zone?

\section{$N / A$}

Q4-7: Type of grout used?

\section{cement-water}

Q4-8: Are filler materials used in the anchorage zone?

yes, grout

Q4-9: Type of anchorage?

conical socket with wedges

Q4-10: Do cables go over "saddles" on the pylons?

no

Q4-11: Type of cable sheathing used? HDPE with PVF Tedlar tape

Q4-12: Have rain-wind-induced cable vibrations been observed on this bridge?

no

Q4-13: Have MTE corrosion problems been noted?

no

Q4-14: Do cables have neoprene rings near the top and bottom anchorages?

yes

Q4-15: If there are neoprene rings on the cables; have there been any reports of movements of the rings out of their positions?

\section{no, not known}

Q4-16: Has moisture been found in any of the internal components of stay cables such as the bottom anchorage areas?

no

Q4-17: Has fatigue of MTE or other components of stay cables been observed?

no

Q4-18: Do the cables have viscous dampers installed at deck or tower levels?

no

Q4-19: Do the cables have cross cables installed between them?
Q4-20: Do cables have other dampers (other than viscous or neoprene rings) to control vibrations?

no

Q4-21: Has cracking of the cable sheathing or sheathing connections been noted?

no

Q4-22: Has cracking or misalignment of the guide pipes been noted?

no

Q4-23: If there is protective tape wrapped around the cable sheathing; have there been reports of deterioration of the tape?

no

Q4-24: Have any problems associated with neoprene boots been noted?

no

Q4-25: Types of non-destructive tests that any of the cables on this bridge have been subjected to?

\section{not performed}

Q4-26: Types of sensor-based, long-term monitoring performed on the cables?

\section{not performed}

Q4-27: Have the cables on this bridge (or any of their components) been repaired?

no 
Q4-28: Has the sheathing been partially removed on any of the cables to examine condition of grout (if applicable) and/or the MTE?

\section{no answer}

Q4-29: Can the strands or cables be replaced if needed?

yes

Q4-30: Do you have an inspection and maintenance manual for this bridge?

yes

Q5: Based on your experience and in general, do you believe that the current inspection, testing, monitoring, and repair methods available to you for stay cables are effective and adequate?

yes

Q6: Please comment on the effectiveness of any non-destructive test methods for inspections of stay cables that you may be familiar with. These methods include (but are not limited to) ultrasonic testing, magnetic inspections, laser-based force measurements, $\mathrm{X}$-ray imaging, etc. If possible, please comment on issues such as practicality, cost, duration, impact on traffic, and any other factors that you consider important.

Laser-based force measurements will give results that will indicate if a cable is deviating from the trending values of the other cables. It may not give you an accurate value of the force in a cable. It is relatively easy and inexpensive to perform.

Q7: Please comment on the effectiveness of any cable vibration control measures that you may be familiar with. Examples include installation of cross cables, viscous dampers, neoprene rings, etc.

These methods are all effective in controlling free vibrations of the cables. Helical strakes formed in the cable neoprene sheathing are also effective

Q8: Please comment on the effectiveness of any sensor-based, long-term monitoring systems for stay cables that you may be familiar with. Examples include acoustic monitoring, vibration monitoring, force measurements, strain measurements, etc.

\section{These are all effective but they are generally} expensive and have not been used on Georgia's bridges

Q9: What would you recommend that the cable suppliers incorporate into their systems to make cables more accessible and inspectable?

For non-box bridges, an inspection traveller should be installed on the cable-stayed bridge. The should be done by the owner.

Q10: Do you believe that an up-to-date resource such as a national database of information on stay cable inspection methods, repairs, and testing would be a useful tool?
Q11: What do you see as the single most important problem in stay cable maintenance? Access to the cable anchorages

Q12: Please comment on any other methods for inspections, testing, monitoring, and repair of stay cable (including conventional methods) that you have found beneficial and are not listed above.

Television endoscope type cameras for access to guide pipes at bridge deck levelares helpful.

Additional comments? 
NCHRP SYNTHESIS TOPIC 35-07-INSPECTION AND MAINTENANCE OF BRIDGE STAY CABLE SYSTEMS

Quincy Bayview Bridge at Quincy, IL

Illinois

\section{Quincy Bayview Bridge at Quincy, IL}

State/Province: Illinois

Agency: $\quad$ Illinois DOT

Respondent: Carl Puzey

Span Length: $\quad \mathbf{9 0 0} \mathrm{ft}$

Year Built: 1986

Q4-4: Type of main tension element (MTE)? seven-wire steel strand

Q4-5: Coating/treatment on main tension

\section{epoxy-coated on outside only}

Q4-6: Are the coatings/treatments on main tension element discontinued or removed within the anchorage zone?

\section{not known}

Q4-7: Type of grout used?

\section{not known}

Q4-8: Are filler materials used in the anchorage zone?

\section{not known}

Q4-9: Type of anchorage?

not known

Q4-10: Do cables go over "saddles" on the pylons?

no

Q4-11: Type of cable sheathing used?

$U V$-resistant HDPE contract in 2003 to wrap cables with elastomeric wrap

Q4-12: Have rain-wind-induced cable vibrations been observed on this bridge? no

Q4-13: Have MTE corrosion problems been noted?

\section{not known}

Q4-14: Do cables have neoprene rings near the top and bottom anchorages?

yes

Q4-15: If there are neoprene rings on the cables; have there been any reports of movements of the rings out of their positions?

\section{no, not known}

Q4-16: Has moisture been found in any of the internal components of stay cables such as the bottom anchorage areas? yes

Q4-17: Has fatigue of MTE or other components of stay cables been observed? no

Q4-18: Do the cables have viscous dampers installed at deck or tower levels?

no

Q4-19: Do the cables have cross cables installed between them? no

Q4-20: Do cables have other dampers (other than viscous or neoprene rings) to control vibrations?

\section{no}

Q4-21: Has cracking of the cable sheathing or sheathing connections been noted?

\section{yes, sheathing}

Q4-22: Has cracking or misalignment of the guide pipes been noted?

no

Q4-23: If there is protective tape wrapped around the cable sheathing; have there been reports of deterioration of the tape?

N/A-see comment above about wrapping in 2003

Q4-24: Have any problems associated with neoprene boots been noted?

no

Q4-25: Types of non-destructive tests that any of the cables on this bridge have been subjected to?

\section{not performed}

Q4-26: Types of sensor-based, long-term monitoring performed on the cables?

\section{acoustic wire break detection}

Q4-27: Have the cables on this bridge (or any of their components) been repaired? 
NCHRP SYNTHESIS TOPIC 35-07_INSPECTION AND MAINTENANCE OF BRIDGE STAY CABLE SYSTEMS

Quincy Bayview Bridge at Quincy, IL

Illinois

yes-previous intermittent wrapping. See comment above about complete wrapping in 2003.

Q4-28: Has the sheathing been partially removed on any of the cables to examine condition of grout (if applicable) and/or the MTE?

no

Q4-29: Can the strands or cables be replaced if needed?

yes

Q4-30: Do you have an inspection and maintenance manual for this bridge?

no

Q5: Based on your experience and in general do you believe that the current inspection, testing, monitoring, and repair methods available to you for stay cables are effective and adequate?

no

Q6: Please comment on the effectiveness of any non-destructive test methods for inspections of stay cables that you may be familiar with. These methods include (but are not limited to) ultrasonic testing, magnetic inspections, laser-based force measurements, $\mathrm{X}$-ray imaging, etc. If possible, please comment on issues such as practicality, cost, duration, impact on traffic, and any other factors that you consider important.

no answer
Q7: Please comment on the effectiveness of any cable vibration control measures that you may be familiar with. Examples include installation of cross cables, viscous dampers, neoprene rings, etc.

Cross cables on the Clark Bridge have been effective.

Q8: Please comment on the effectiveness of any sensor-based, long-term monitoring systems for stay cables that you may be familiar with. Examples include acoustic monitoring, vibration monitoring, force measurements, strain measurements, etc.

An acoustic monitoring system was installed (approximately a year and a half ago) on onefourth of the stays of the Quincy Bayview Bridge. This was done due to concern over water in the cable anchorages and to evaluate the technology. The system appears to be functioning properly and so far has provided information on one "event" that has been classified as a wire break.

Q9: What would you recommend that the cable suppliers incorporate into their systems to make cables more accessible and inspectable?

\section{no answer}

Q10: Do you believe that an up-to-date resource such as a national database of information on stay cable inspection methods, repairs, and testing would be a useful tool?

yes

Q11: What do you see as the single most important problem in stay cable maintenance?
Questionnaire Results

Survey performed in 2004

\section{Uncertainty of cable condition and anchorages}

Q12: Please comment on any other methods for inspections, testing, monitoring, and repair of stay cable (including conventional methods) that you have found beneficial and are not listed above.

\section{no answer}

Additional comments? 


\section{NCHRP SYNTHESIS TOPIC 35-07-INSPECTION AND MAINTENANCE OF BRIDGE STAY CABLE SYSTEMS}

Clark Bridge at Alton, IL

Illinois

\section{Clark Bridge at Alton, IL}

$\begin{array}{ll}\text { State/Province: } & \text { Illinois } \\ \text { Agency: } & \text { Illinois DOT } \\ \text { Respondent: } & \text { Carl Puzey } \\ \text { Span Length: } & \mathbf{7 5 6 f t} \\ \text { Year Built: } & \mathbf{1 9 9 4}\end{array}$

Q4-4: Type of main tension element (MTE)? seven-wire steel strand

Q4-5: Coating/treatment on main tension element within free length of cable?

Q4-6: Are the coatings/treatments on main tension element discontinued or removed within the anchorage zone?

No, the ends of strands were sealed with flexible sealer and a flexible rubber cap.*

Q4-7: Type of grout used?

Bulk non-shrink grout mixed on site*

Q4-8: Are filler materials used in the anchorage zone?

yes-grout with sand*

Q4-9: Type of anchorage?

conical socket with wedges*

Q4-10: Do cables go over "saddles" on the pylons?

yes

Q4-11: Type of cable sheathing used? HDPE*

Q4-12: Have rain-wind-induced cable vibrations been observed on this bridge? yes-prior to installation of cross cables

Q4-13: Have MTE corrosion problems been noted?

no

Q4-14: Do cables have neoprene rings near the top and bottom anchorages?

yes

Q4-15: If there are neoprene rings on the cables; have there been any reports of movements of the rings out of their positions?

\section{no, not known}

Q4-16: Has moisture been found in any of the internal components of stay cables such as the bottom anchorage areas?

not known, some rust visible at a few anchorages

Q4-17: Has fatigue of MTE or other components of stay cables been observed? no

Q4-18: Do the cables have viscous dampers installed at deck or tower levels?

no

Q4-19: Do the cables have cross cables installed between them?
Questionnaire Results

Survey performed in 2004

\section{yes-retrofitted to correct vibrations}

Q4-20: Do cables have other dampers (other than viscous or neoprene rings) to control vibrations?

no

Q4-21: Has cracking of the cable sheathing or sheathing connections been noted?

\section{not known}

Q4-22: Has cracking or misalignment of the guide pipes been noted?

no

Q4-23: If there is protective tape wrapped around the cable sheathing; have there been reports of deterioration of the tape?

\section{yes-minor damage*}

Q4-24: Have any problems associated with neoprene boots been noted?

no

Q4-25: Types of non-destructive tests that any of the cables on this bridge have been subjected to?

\section{not performed}

Q4-26: Types of sensor-based, long-term monitoring performed on the cables?

\section{not performed}

Q4-27: Have the cables on this bridge (or any of their components) been repaired?

no 


\section{Clark Bridge at Alton, IL}

Illinois

Q4-28: Has the sheathing been partially removed on any of the cables to examine condition of grout (if applicable) and/or the MTE?

no

Q4-29: Can the strands or cables be replaced if needed?

yes

Q4-30: Do you have an inspection and maintenance manual for this bridge?

\section{yes, not included for security reasons}

Q5: Based on your experience and in general, do you believe that the current inspection, testing, monitoring, and repair methods available to you for stay cables are effective and adequate?

no

Q6: Please comment on the effectiveness of any non-destructive test methods for inspections of stay cables that you may be familiar with. These methods include (but are not limited to) ultrasonic testing, magnetic inspections, laser-based force measurements, $\mathrm{X}$-ray imaging, etc. If possible, please comment on issues such as practicality, cost, duration, impact on traffic, and any other factors that you consider important.

\section{no answer}

Q7: Please comment on the effectiveness of any cable vibration control measures that you may be familiar with. Examples include installation of cross cables, viscous dampers, neoprene rings, etc.

Cross cables on the Clark Bridge have been effective.

Q8: Please comment on the effectiveness of any sensor-based, long-term monitoring systems for stay cables that you may be familiar with. Examples include acoustic monitoring, vibration monitoring, force measurements, strain measurements, etc.

An acoustic monitoring system was installed (approximately a year and a half ago) on onefourth of the stays of the Quincy Bayview Bridge. This was done due to concern over water in the cable anchorages and to evaluate the technology. The system appears to be functioning properly and so far has provided information on one "event" that has been classified as a wire break.

Q9: What would you recommend that the cable suppliers incorporate into their systems to make cables more accessible and inspectable?

\section{no answer}

Q10: Do you believe that an up-to-date resource such as a national database of information on stay cable inspection methods, repairs, and testing would be a useful tool? yes

Q11: What do you see as the single most important problem in stay cable maintenance?

Uncertainty of cable condition and anchorages
Q12: Please comment on any other methods for inspections, testing, monitoring, and repair of stay cable (including conventional methods) that you have found beneficial and are not listed above.

no answer

Additional comments?

*Answers provided subsequent to the initial submittal by Mr. Steve Putz, Illinois DOT. 


\section{NCHRP SYNTHESIS TOPIC 35-07-INSPECTION AND MAINTENANCE OF BRIDGE STAY CABLE SYSTEMS}

46-03-7495 EBL

Indiana

\section{6-03-7495 EBL}

State/Province: Indiana

Agency: $\quad$ Indiana DOT

Respondent: $\quad$ Bill Dittrich

Span Length: $\quad \mathbf{4 6 6} \mathrm{ft}$

Year Built: 1999

Q4-4: Type of main tension element (MTE)? seven-wire steel strand

Q4-5: Coating/treatment on main tension element within free length of cable?

\section{I think they are bare??}

Q4-6: Are the coatings/treatments on main tension element discontinued or removed within the anchorage zone?

\section{not known}

Q4-7: Type of grout used? cement-water admixtures

Q4-8: Are filler materials used in the anchorage zone?

\section{not known}

Q4-9: Type of anchorage?

conical socket with wedges

Q4-10: Do cables go over "saddles" on the pylons?

no
Q4-11: Type of cable sheathing used? polyethylene stay pipes

Q4-12: Have rain-wind-induced cable vibrations been observed on this bridge?

no

Q4-13: Have MTE corrosion problems been noted?

no

Q4-14: Do cables have neoprene rings near the top and bottom anchorages?

yes

Q4-15: If there are neoprene rings on the cables; have there been any reports of movements of the rings out of their positions?

\section{no, not known}

Q4-16: Has moisture been found in any of the internal components of stay cables such as the bottom anchorage areas?

\section{not tested}

Q4-17: Has fatigue of MTE or other components of stay cables been observed? no

Q4-18: Do the cables have viscous dampers installed at deck or tower levels?

no

Q4-19: Do the cables have cross cables installed between them?

yes, from the beginning
Questionnaire Results

Survey performed in 2004
Q4-20: Do cables have other dampers (other than viscous or neoprene rings) to control vibrations?

no

Q4-21: Has cracking of the cable sheathing or sheathing connections been noted?

no

Q4-22: Has cracking or misalignment of the guide pipes been noted?

no

Q4-23: If there is protective tape wrapped around the cable sheathing; have there been reports of deterioration of the tape?

N/A

Q4-24: Have any problems associated with neoprene boots been noted?

\section{no}

Q4-25: Types of non-destructive tests that any of the cables on this bridge have been subjected to?

\section{not performed}

Q4-26: Types of sensor-based, long-term monitoring performed on the cables?

\section{not performed}

Q4-27: Have the cables on this bridge (or any of their components) been repaired?

no 


\section{NCHRP SYNTHESIS TOPIC 35-07-INSPECTION AND MAINTENANCE OF BRIDGE STAY CABLE SYSTEMS}

46-03-7495 EBL

Indiana
Questionnaire Results

Survey performed in 2004
Q4-28: Has the sheathing been partially removed on any of the cables to examine condition of grout (if applicable) and/or the MTE?

no

Q4-29: Can the strands or cables be replaced if needed?

not known-I would hope that they could be if needed.

Q4-30: Do you have an inspection and maintenance manual for this bridge?

yes

Q5: Based on your experience and in general, do you believe that the current inspection, testing, monitoring, and repair methods available to you for stay cables are effective and adequate?

no-We will be having these two bridges inspected and tested by a consultant in the next 1-2-year time frame. We are just beginning to get a good understanding of the possible problems that we may encounter on these bridges over the coming years.

Q6: Please comment on the effectiveness of any non-destructive test methods for inspections of stay cables that you may be familiar with. These methods include (but are not limited to) ultrasonic testing, magnetic inspections, laser-based force measurements, $\mathrm{X}$-ray imaging, etc. If possible, please comment on issues such as practicality, cost, duration, impact on traffic, and any other factors that you consider important.
We have not yet done any testing on these two cable-stayed bridges, but probably will be doing so in the next 1-2 years.

Q7: Please comment on the effectiveness of any cable vibration control measures that you may be familiar with. Examples include installation of cross cables, viscous dampers, neoprene rings, etc.

The ones on the SR-46 bridge seem to be $O K$. There are also some on the new US-231 bridge over the Ohio River that we share with Kentucky (Kentucky is the lead state for this bridge). They seem to be OK also. However, I have not been at either of these bridges during bad weather.

Q8: Please comment on the effectiveness of any sensor-based, long-term monitoring systems for stay cables that you may be familiar with. Examples include acoustic monitoring, vibration monitoring, force measurements, strain measurements, etc

Have not used any yet.

Q9: What would you recommend that the cable suppliers incorporate into their systems to make cables more accessible and inspectable?

??

Q10: Do you believe that an up-to-date resource such as a national database of information on stay cable inspection methods, repairs, and testing would be a useful tool?
Q11: What do you see as the single most important problem in stay cable maintenance?

Inspection, access, testing, cost.

Q12: Please comment on any other methods for inspections, testing, monitoring, and repair of stay cable (including conventional methods) that you have found beneficial and are not listed above.

\section{no answer}

Additional comments? 


\section{NCHRP SYNTHESIS TOPIC 35-07-INSPECTION AND MAINTENANCE OF BRIDGE STAY CABLE SYSTEMS}

I65-68-7910

Indiana

\section{I65-68-7910}

State/Province:

Agency:

\section{Indiana}

Respondent:

Indiana DOT

Span Length:

Bill Dittrich

Year Built:

$197.5 \mathrm{ft}$

1996

Q4-4: Type of main tension element (MTE)? seven-wire steel strand

Q4-5: Coating/treatment on main tension element within free length of cable?

\section{I think they are bare??}

Q4-6: Are the coatings/treatments on main tension element discontinued or removed within the anchorage zone?

\section{not known}

Q4-7: Type of grout used?

\section{cement-water admixtures}

Q4-8: Are filler materials used in the anchorage zone?

\section{not known}

Q4-9: Type of anchorage?

conical socket with wedges

Q4-10: Do cables go over "saddles" on the pylons?

\section{no}

Q4-11: Type of cable sheathing used? polyethylene stay pipes with pressure-sensitive PVF tape

Q4-12: Have rain-wind-induced cable vibrations been observed on this bridge? no

Q4-13: Have MTE corrosion problems been noted?

no

Q4-14: Do cables have neoprene rings near the top and bottom anchorages?

yes

Q4-15: If there are neoprene rings on the cables; have there been any reports of movements of the rings out of their positions?

\section{no, not known}

Q4-16: Has moisture been found in any of the internal components of stay cables such as the bottom anchorage areas?

\section{not tested}

Q4-17: Has fatigue of MTE or other components of stay cables been observed? no

Q4-18: Do the cables have viscous dampers installed at deck or tower levels?

no

Q4-19: Do the cables have cross cables installed between them?
Questionnaire Results

Survey performed in 2004

no

Q4-20: Do cables have other dampers (other than viscous or neoprene rings) to control vibrations?

no

Q4-21: Has cracking of the cable sheathing or sheathing connections been noted?

no

Q4-22: Has cracking or misalignment of the guide pipes been noted?

\section{not applicable}

Q4-23: If there is protective tape wrapped around the cable sheathing; have there been reports of deterioration of the tape?

no

Q4-24: Have any problems associated with neoprene boots been noted?

no

Q4-25: Types of non-destructive tests that any of the cables on this bridge have been subjected to?

\section{not performed}

Q4-26: Types of sensor-based, long-term monitoring performed on the cables?

\section{not performed}

Q4-27: Have the cables on this bridge (or any of their components) been repaired?

no 
Q4-28: Has the sheathing been partially removed on any of the cables to examine condition of grout (if applicable) and/or the MTE?

no

Q4-29: Can the strands or cables be replaced if needed?

not known-I would hope that they could be if needed.

Q4-30: Do you have an inspection and maintenance manual for this bridge?

yes

Q5: Based on your experience and in general, do you believe that the current inspection, testing, monitoring, and repair methods available to you for stay cables are effective and adequate?

no-We will be having these two bridges inspected and tested by a consultant in the next 1-2 year time frame. We are just beginning to get a good understanding of the possible problems that we may encounter on these bridges over the coming years.

Q6: Please comment on the effectiveness of any non-destructive test methods for inspections of stay cables that you may be familiar with. These methods include (but are not limited to) ultrasonic testing, magnetic inspections, laser-based force measurements, $\mathrm{X}$-ray imaging, etc. If possible, please comment on issues such as practicality, cost, duration, impact on traffic, and any other factors that you consider important.
We have not yet done any testing on these two cable-stayed bridges, but probably will be doing so in the next 1-2 years.

Q7: Please comment on the effectiveness of any cable vibration control measures that you may be familiar with. Examples include installation of cross cables, viscous dampers, neoprene rings, etc.

The ones on the SR-46 bridge seem to be OK. There are also some on the new US-231 bridge over the Ohio River that we share with Kentucky (Kentucky is the lead state for this bridge). They seem to be OK also. However, I have not been at either of these bridges during bad weather.

Q8: Please comment on the effectiveness of any sensor-based, long-term monitoring systems for stay cables that you may be familiar with. Examples include acoustic monitoring, vibration monitoring, force measurements, strain measurements, etc.

Have not used any yet.

Q9: What would you recommend that the cable suppliers incorporate into their systems to make cables more accessible and inspectable? ??

Q10: Do you believe that an up-to-date resource such as a national database of information on stay cable inspection methods, repairs, and testing would be a useful tool?

yes
Q11: What do you see as the single most important problem in stay cable maintenance?

Inspection, access, testing, cost.

Q12: Please comment on any other methods for inspections, testing, monitoring, and repair of stay cable (including conventional methods) that you have found beneficial and are not listed above.

\section{no answer}

Additional comments? 


\section{NCHRP SYNTHESIS TOPIC 35-07-INSPECTION AND MAINTENANCE OF BRIDGE STAY CABLE SYSTEMS}

Burlington, IA

Iowa

\section{Burlington, IA}

State/Province: Iowa

Agency: $\quad$ Iowa DOT

Respondent: Dean Bierwagen

Span Length: $\quad \mathbf{6 6 0} \mathrm{ft}$

Year Built: 1995

Q4-4: Type of main tension element (MTE)?

seven-wire steel strand-epoxy-coated, 0.6-in. strand, in grouted polyethylene pipe

Q4-5: Coating/treatment on main tension epoxy-coated on outside only-epoxy-coated seven-wire strand

Q4-6: Are the coatings/treatments on main tension element discontinued or removed within the anchorage zone?

yes

Q4-7: Type of grout used?

not known-grout was used but not sure of content

Q4-8: Are filler materials used in the anchorage zone?

yes, other. Epoxy compound with zinc dust and steel ball

Q4-9: Type of anchorage?

“Hi-Am”-type-VSL Stay Cable System 250
Q4-10: Do cables go over "saddles" on the pylons?

no

Q4-11: Type of cable sheathing used?

HDPE with PVF Tedlar tape

Q4-12: Have rain-wind-induced cable vibrations been observed on this bridge?

yes

Q4-13: Have MTE corrosion problems been noted?

\section{not known}

Q4-14: Do cables have neoprene rings near the top and bottom anchorages? yes

Q4-15: If there are neoprene rings on the cables; have there been any reports of movements of the rings out of their positions? no, not known

Q4-16: Has moisture been found in any of the internal components of stay cables such as the bottom anchorage areas?

\section{not known}

Q4-17: Has fatigue of MTE or other components of stay cables been observed? no

Q4-18: Do the cables have viscous dampers installed at deck or tower levels?
Q4-19: Do the cables have cross cables installed between them?

\section{yes-retrofitted to correct vibrations}

Q4-20: Do cables have other dampers (other than viscous or neoprene rings) to control vibrations?

yes, other-tie cables

Q4-21: Has cracking of the cable sheathing or sheathing connections been noted?

no

Q4-22: Has cracking or misalignment of the guide pipes been noted?

\section{no}

Q4-23: If there is protective tape wrapped around the cable sheathing; have there been reports of deterioration of the tape?

yes, minor damage

Q4-24: Have any problems associated with neoprene boots been noted?

no

Q4-25: Types of non-destructive tests that any of the cables on this bridge have been subjected to?

vibration-based force measurementsvibration measurements were done during construction to determine amount of force in cables.

Q4-26: Types of sensor-based, long-term monitoring performed on the cables? 
Burlington, IA

Iowa

\section{not performed}

Q4-27: Have the cables on this bridge (or any of their components) been repaired?

\section{no}

Q4-28: Has the sheathing been partially removed on any of the cables to examine condition of grout (if applicable) and/or the MTE?

no

Q4-29: Can the strands or cables be replaced if needed?

yes

Q4-30: Do you have an inspection and maintenance manual for this bridge?

yes

Q5: Based on your experience and in general, do you believe that the current inspection, testing, monitoring, and repair methods available to you for stay cables are effective and adequate?

\section{no-need way to inspect cable}

Q6: Please comment on the effectiveness of any non-destructive test methods for inspections of stay cables that you may be familiar with. These methods include (but are not limited to) ultrasonic testing, magnetic inspections, laser-based force measurements, $\mathrm{X}$-ray imaging, etc. If possible, please comment on issues such as practicality, cost, duration, impact on traffic, and any other factors that you consider important.
Have not had experience with non-destructive test methods.

Q7: Please comment on the effectiveness of any cable vibration control measures that you may be familiar with. Examples include installation of cross cables, viscous dampers, neoprene rings, etc.

Have not had vibration problems since cross cables were installed.

Q8: Please comment on the effectiveness of any sensor-based, long-term monitoring systems for stay cables that you may be familiar with. Examples include acoustic monitoring, vibration monitoring, force measurements, strain measurements, etc.

\section{Have not had experience with long-term} monitoring.

Q9: What would you recommend that the cable suppliers incorporate into their systems to make cables more accessible and inspectable?

\section{no answer}

Q10: Do you believe that an up-to-date resource such as a national database of information on stay cable inspection methods, repairs, and testing would be a useful tool?

\section{yes}

Q11: What do you see as the single most important problem in stay cable maintenance?

The inability to inspect the elements inside the cable and the anchorage areas.
Q12: Please comment on any other methods for inspections, testing, monitoring, and repair of stay cable (including conventional methods) that you have found beneficial and are not listed above.

no answer

Additional comments?
Questionnaire Results

Survey performed in 2004 
NCHRP SYNTHESIS TOPIC 35-07-INSPECTION AND MAINTENANCE OF BRIDGE STAY CABLE SYSTEMS

William Natcher Bridge, Owensboro, KY

Kentucky

Questionnaire Results

Survey performed in 2004

\section{William Natcher Bridge, Owensboro, $K Y$ \\ State/Province: Kentucky \\ Agency: Kentucky Transportation Cabinet \\ Respondent: $\quad$ Darrell K. Dudgeon \\ Span Length: $\quad 1,200 \mathrm{ft}$ \\ Year Built: 2002}

Q4-4: Type of main tension element (MTE)?

seven-wire steel strand

Q4-5: Coating/treatment on main tension element within free length of cable?

\section{greased-and-sheathed}

Q4-6: Are the coatings/treatments on main tension element discontinued or removed within the anchorage zone?

yes-tubes attached to the anchor block provide corrosion protection.

Q4-7: Type of grout used?

commercial prepackaged grouts

Q4-8: Are filler materials used in the anchorage zone?

\section{yes-grease}

Q4-9: Type of anchorage?

wedges
Q4-10: Do cables go over "saddles" on the pylons?

no

Q4-11: Type of cable sheathing used?

$U V$-resistant HDPE with spiral on surface

Q4-12: Have rain-wind-induced cable vibrations been observed on this bridge?

no

Q4-13: Have MTE corrosion problems been noted?

\section{not known}

Q4-14: Do cables have neoprene rings near the top and bottom anchorages? yes

Q4-15: If there are neoprene rings on the cables; have there been any reports of movements of the rings out of their positions?

\section{no, not known}

Q4-16: Has moisture been found in any of the internal components of stay cables such as the bottom anchorage areas?

\section{yes-moisture was detected during}

construction when a cable slipped the wedge and had to be replaced, but not since.

Q4-17: Has fatigue of MTE or other components of stay cables been observed? no
Q4-18: Do the cables have viscous dampers installed at deck or tower levels?

no

Q4-19: Do the cables have cross cables installed between them?

\section{yes-from the beginning}

Q4-20: Do cables have other dampers (other than viscous or neoprene rings) to control vibrations?

no

Q4-21: Has cracking of the cable sheathing or sheathing connections been noted?

no

Q4-22: Has cracking or misalignment of the guide pipes been noted?

no

Q4-23: If there is protective tape wrapped around the cable sheathing; have there been reports of deterioration of the tape?

no

Q4-24: Have any problems associated with neoprene boots been noted?

no

Q4-25: Types of non-destructive tests that any of the cables on this bridge have been subjected to?

not performed 
Q4-26: Types of sensor-based, long-term monitoring performed on the cables?

\section{not performed}

Q4-27: Have the cables on this bridge (or any of their components) been repaired?

no

Q4-28: Has the sheathing been partially removed on any of the cables to examine condition of grout (if applicable) and/or the MTE?

no

Q4-29: Can the strands or cables be replaced if needed? inspections, laser-based force measurements, $\mathrm{X}$-ray imaging, etc. If possible, please comment on issues such as practicality, cost, duration, impact on traffic, and any other factors that you consider important.

The only problem is the anchorage area. So far no method is available for inspection. (PB) I see additional problems with inspection of the grout-filled cables. (DKD)

Q7: Please comment on the effectiveness of any cable vibration control measures that you may be familiar with. Examples include installation of cross cables, viscous dampers, neoprene rings, etc.

Wind damper is a high tech method that is very effective in most cases. However, the dampers are a delicate mechanism that need constant maintenance like any machine. Only the exterior dampers allow inspection and maintenance. Internal dampers are difficult to access for inspection. Any inspection and maintenanace and/or replacement will be a major project. Another major concern is that the method to determine the damper's condition is still not available. Therefore, after only a few years, no one will know whether the installed dampers are still working. On the other hand, the cross cables will work as long as they are in place. The condition of the cross cables can be easily observed from the deck. Replacement of the cross ties is not a major operation. Therefore, before the damper is improved, the cross cable is the better and sure solution. (PB)
Q8: Please comment on the effectiveness of any sensor-based, long-term monitoring systems for stay cables that you may be familiar with. Examples include acoustic monitoring, vibration monitoring, force measurements, strain measurements, etc.

There are two problems on the monitoring systems. First, who will analyze the large amount of data collected. Second, how long will the sensors and the computer system last? We are talking about 100-year life span. The reality is that the monitoring system will fail or become obsolete within approximately 10 years when the bridge is not expected to have any problems. $(\mathrm{PB})$

Q9: What would you recommend that the cable suppliers incorporate into their systems to make cables more accessible and inspectable?

It seems not possible that the cable suppliers can do any more. $(P B)$

Q10: Do you believe that an up-to-date resource such as a national database of information on stay cable inspection methods, repairs, and testing would be a useful tool?

yes-resource does not exist so far. We (Parsons Brinkerhoff) are developing them right now. (PB)

Q11: What do you see as the single most important problem in stay cable maintenance?

Inspecting the cable anchors. $(P B)$ Inspecting grout-filled cables. (DKD)

Q12: Please comment on any other methods for inspections, testing, monitoring, and repair of inspections of stay cables that you may be
familiar with. These methods include (but are not limited to) ultrasonic testing, magnetic 
NCHRP SYNTHESIS TOPIC 35-07-INSPECTION AND MAINTENANCE OF BRIDGE STAY CABLE SYSTEMS

William Natcher Bridge, Owensboro, KY

Kentucky

Questionnaire Results

Survey performed in 2004

stay cable (including conventional methods)

that you have found beneficial and are not

listed above.

None

Additional comments?

Comments followed by (DKD) were made by Darrell Dudgeon of KYTC. Comments

followed by (PB) were made by Ruchu Hsu,

P.E. of Parsons Brinkerhoff Quade and

Douglas, Inc. Consulting Engineers who was

the lead design engineer for the Owensboro

Bridge. 


\section{William H. Harsha Bridge, Maysville, $\mathrm{KY}$}

State/Province: Kentucky

Agency: $\quad$ Kentucky Transportation Cabinet

Respondent: $\quad$ Darrell K. Dudgeon

Span Length: $\quad \mathbf{1 , 0 5 0} f t$

Year Built: 2000

Q4-4: Type of main tension element (MTE)? seven-wire steel strand

Q4-5: Coating/treatment on main tension element within free length of cable?

\section{greased-and-sheathed}

Q4-6: Are the coatings/treatments on main tension element discontinued or removed within the anchorage zone?

yes

Q4-7: Type of grout used?

cement-water admixtures

Q4-8: Are filler materials used in the anchorage zone?

yes, grease

Q4-9: Type of anchorage?

conical socket with wedges

Q4-10: Do cables go over "saddles" on the pylons? no

Q4-11: Type of cable sheathing used?

$U V$-resistant HDPE with spiral on surface

Q4-12: Have rain-wind-induced cable vibrations been observed on this bridge?

no

Q4-13: Have MTE corrosion problems been noted?

no

Q4-14: Do cables have neoprene rings near the top and bottom anchorages?

no

Q4-15: If there are neoprene rings on the cables; have there been any reports of movements of the rings out of their positions? not applicable

Q4-16: Has moisture been found in any of the internal components of stay cables such as the bottom anchorage areas?

no

Q4-17: Has fatigue of MTE or other components of stay cables been observed? no

Q4-18: Do the cables have viscous dampers installed at deck or tower levels? no

Q4-19: Do the cables have cross cables installed between them?

\section{yes-from the beginning}

Q4-20: Do cables have other dampers (other than viscous or neoprene rings) to control vibrations?

no

Q4-21: Has cracking of the cable sheathing or sheathing connections been noted?

no answer

Q4-22: Has cracking or misalignment of the guide pipes been noted?

no

Q4-23: If there is protective tape wrapped around the cable sheathing; have there been reports of deterioration of the tape?

not applicable

Q4-24: Have any problems associated with neoprene boots been noted?

no

Q4-25: Types of non-destructive tests that any of the cables on this bridge have been subjected to?

\section{not performed}

Q4-26: Types of sensor-based, long-term monitoring performed on the cables?

not performed

Q4-27: Have the cables on this bridge (or any of their components) been repaired? 
Q4-28: Has the sheathing been partially removed on any of the cables to examine condition of grout (if applicable) and/or the MTE?

\section{no}

Q4-29: Can the strands or cables be replaced if needed?

yes

Q4-30: Do you have an inspection and maintenance manual for this bridge?

yes

Q5: Based on your experience and in general, do you believe that the current inspection, testing, monitoring, and repair methods available to you for stay cables are effective and adequate?

no-there are technical limitations that prevent inspection of the stay cables, especially the anchorage area. Technical breakthrough is required.

Q6: Please comment on the effectiveness of any non-destructive test methods for inspections of stay cables that you may be familiar with. These methods include (but are not limited to) ultrasonic testing, magnetic inspections, laser-based force measurements, $\mathrm{X}$-ray imaging, etc. If possible, please comment on issues such as practicality, cost, duration, impact on traffic, and any other factors that you consider important.

The only problem is the anchorage area. So far no method is available for inspection. (PB)
I see additional problems with inspection of the grout-filled cables. (DKD)

Q7: Please comment on the effectiveness of any cable vibration control measures that you may be familiar with. Examples include installation of cross cables, viscous dampers, neoprene rings, etc.

Wind damper is a high tech method that is very effective in most cases. However, the dampers are delicate mechanisms that need constant maintenance like any machine. Only the exterior dampers allow inspection and maintenance. Internal dampers are difficult to access for inspection. Any inspection and maintenanace and/or replacement will be a major project. Another major concern is that the method to determine the damper's condition is still not avilable. Therefore, after only a few years, no one will know whether the installed dampers are still working. On the other hand, the cross cables will work as long as they are in place. The condition of the cross cables can be easily observed from the deck. Replacement of the cross ties is not a major operation. Therefore, before the damper is improved, the cross cable is the better and sure solution. (PB)

Q8: Please comment on the effectiveness of any sensor-based, long-term monitoring systems for stay cables that you may be familiar with. Examples include acoustic monitoring, vibration monitoring, force measurements, strain measurements, etc.

There are two problems on the monitoring systems. First, who will analyze the large amount of data collected. Second, how long will the sensors and the computer system last? We are talking about 100-year life span. The reality is that the monitoring system will fail or become obsolete within approximately 10 years when the bridge is not expected to have any problems. $(\mathrm{PB})$

Q9: What would you recommend that the cable suppliers incorporate into their systems to make cables more accessible and inspectable?

It seems not possible that the cable suppliers can do any more. $(\mathrm{PB})$

Q10: Do you believe that an up-to-date resource such as a national database of information on stay cable inspection methods, repairs, and testing would be a useful tool?

yes-resource does not exist so far. We (Parsons Brinkerhoff) are developing them right now. (PB)

Q11: What do you see as the single most important problem in stay cable maintenance?

Inspecting the cable anchors. $(P B)$ Inspecting grout-filled cables. (DKD)

Q12: Please comment on any other methods for inspections, testing, monitoring, and repair of stay cable (including conventional methods) that you have found beneficial and are not listed above.

none

Additional comments?

Comments followed by (DKD) were made by Darrell Dudgeon of KYTC. Comments 
NCHRP SYNTHESIS TOPIC 35-07-INSPECTION AND MAINTENANCE OF BRIDGE STAY CABLE SYSTEMS

William H. Harsha Bridge, Maysville, KY

Kentucky

Questionnaire Results

Survey performed in 2004

followed by (PB) were made by Ruchu Hsu,

P.E. of Parsons Brinkerhoff Quade and

Douglas, Inc. Consulting Engineers who was

the lead design engineer for the Owensboro

Bridge. 
NCHRP SYNTHESIS TOPIC 35-07-INSPECTION AND MAINTENANCE OF BRIDGE STAY CABLE SYSTEMS

Mississippi River Bridge at Luling, LA

Louisiana

\section{Mississippi River Bridge at}

\section{Luling, LA}

State/Province: Louisiana

Agency: $\quad$ Louisiana DOTD

Respondent: Gill Gautreau

Span Length: $\quad \mathbf{1 , 2 2 2} f t$

Year Built: 1984

Q4-4: Type of main tension element (MTE)? steel wire

Q4-5: Coating/treatment on main tension

\section{bare}

Q4-6: Are the coatings/treatments on main tension element discontinued or removed within the anchorage zone?

\section{not applicable}

Q4-7: Type of grout used?

\section{cement-water}

Q4-8: Are filler materials used in the anchorage zone?

yes, other

Q4-9: Type of anchorage?

"Hi-Am"- type-Each wire also passes through a plate and has a button head anchor

Q4-10: Do cables go over "saddles" on the pylons?

no

Q4-11: Type of cable sheathing used? HDPE with PVF (Tedlar) tape

Q4-12: Have rain-wind-induced cable vibrations been observed on this bridge?

no*-very infrequent, large amplitude motion observed, but not detected.

Q4-13: Have MTE corrosion problems been noted?

\section{yes-see CTL report of July 2004}

Q4-14: Do cables have neoprene rings near the top and bottom anchorages?

yes

Q4-15: If there are neoprene rings on the cables; have there been any reports of movements of the rings out of their positions?

\section{yes-due to other reasons}

Q4-16: Has moisture been found in any of the internal components of stay cables such as the bottom anchorage areas?

yes-see July 2004 CTL report

Q4-17: Has fatigue of MTE or other components of stay cables been observed? no

Q4-18: Do the cables have viscous dampers installed at deck or tower levels?
Q4-19: Do the cables have cross cables installed between them?

no

Q4-20: Do cables have other dampers (other than viscous or neoprene rings) to control vibrations?

no

Q4-21: Has cracking of the cable sheathing or sheathing connections been noted?

\section{yes, sheathing}

Q4-22: Has cracking or misalignment of the guide pipes been noted?

\section{no}

Q4-23: If there is protective tape wrapped around the cable sheathing; have there been reports of deterioration of the tape?

yes-moderate damage-damaged areas of undetermined cause. Look to be impact, but very high off deck.

Q4-24: Have any problems associated with neoprene boots been noted?

yes-not boots, washers-split neoprene washers are held in place by bolts and caulked.

Q4-25: Types of non-destructive tests that any of the cables on this bridge have been subjected to?

vibration-based force measurements 


\section{NCHRP SYNTHESIS TOPIC 35-07-INSPECTION AND MAINTENANCE OF BRIDGE STAY CABLE SYSTEMS}

Mississippi River Bridge at Luling, LA

Questionnaire Results

Louisiana

Survey performed in 2004

Q4-26: Types of sensor-based, long-term monitoring performed on the cables?

\section{vibration monitoring}

Q4-27: Have the cables on this bridge (or any of their components) been repaired?

yes-splits in early years repaired by heat welding, wrapped with Tedlar tape.

Q4-28: Has the sheathing been partially removed on any of the cables to examine condition of grout (if applicable) and/or the MTE?

no-planned for next inspection contract phase with CTL

Q4-29: Can the strands or cables be replaced if needed?

yes, not easily

Q4-30: Do you have an inspection and maintenance manual for this bridge?

no

Q5: Based on your experience and in general, do you believe that the current inspection, testing, monitoring, and repair methods available to you for stay cables are effective and adequate?

not known-our vibration tests over time have indicated consistent cable loads; we are still unable to call the wires pristine.

Q6: Please comment on the effectiveness of any non-destructive test methods for inspections of stay cables that you may be familiar with. These methods include (but are not limited to) ultrasonic testing, magnetic inspections, laser-based force measurements, $\mathrm{X}$-ray imaging, etc. If possible, please comment on issues such as practicality, cost, duration, impact on traffic, and any other factors that you consider important.

Vibration-based cable load determinationeffective and inexpensive; $X$-ray-expensive, slow, very questionable ability to detect wire defects; Magnetic inspection-used to rapidly, effectively inspect mine cables, but the cables move past the inspection unit, which would need to be reversed on a cable bridge; Impulse radar-good for detecting grout defects; Sonic methods-dampened to the point of being ineffective.

Q7: Please comment on the effectiveness of any cable vibration control measures that you may be familiar with. Examples include installation of cross cables, viscous dampers, neoprene rings, etc.

Luling has neoprene rings, but these are relatively very small considering the large diameter of the Luling cables and are there mainly to seal the anchors, but perhaps they also dampen the cables. CTL will check into this.

Q8: Please comment on the effectiveness of any sensor-based, long-term monitoring systems for stay cables that you may be familiar with. Examples include acoustic monitoring, vibration monitoring, force measurements, strain measurements, etc.
Vibration monitoring has been ongoing at Luling for 20 years in anticipation of a hurricane striking the bridge-no significant long duration winds have occurred.

Q9: What would you recommend that the cable suppliers incorporate into their systems to make cables more accessible and inspectable?

I like the idea of hermetically sealed, ungrouted cables with fiber optic sensors throughout or exposed wire that can be directly inspected.

Q10: Do you believe that an up-to-date resource such as a national database of information on stay cable inspection methods, repairs, and testing would be a useful tool? yes

Q11: What do you see as the single most important problem in stay cable maintenance?

The hidden nature of the system.

Q12: Please comment on any other methods for inspections, testing, monitoring, and repair of stay cable (including conventional methods) that you have found beneficial and are not listed above.

no answer

Additional comments?

no answer 


\section{NCHRP SYNTHESIS TOPIC 35-07-INSPECTION AND MAINTENANCE OF BRIDGE STAY CABLE SYSTEMS}

Arkansas (Mississippi)

State/Province: Arkansas (Mississippi)

Agency: $\quad$ Arkansas/Mississippi DOT

Respondent: $\quad$ Phil Brand/Mitchell Carr

Span Length: $\quad f t$

Year Built:

Q4-4: Type of main tension element (MTE)?

Q4-5: Coating/treatment on main tension element within free length of cable?

Q4-6: Are the coatings/treatments on main tension element discontinued or removed within the anchorage zone?

Q4-8: Are filler materials used in the anchorage zone?

Q4-9: Type of anchorage?

Q4-10: Do cables go over "saddles" on the pylons?

Q4-11: Type of cable sheathing used?

Q4-12: Have rain-wind-induced cable vibrations been observed on this bridge?

Q4-13: Have MTE corrosion problems been noted?

Q4-14: Do cables have neoprene rings near the top and bottom anchorages?

Q4-15: If there are neoprene rings on the cables; have there been any reports of movements of the rings out of their positions?

Q4-16: Has moisture been found in any of the internal components of stay cables such as the bottom anchorage areas?

Q4-17: Has fatigue of MTE or other components of stay cables been observed?

Q4-18: Do the cables have viscous dampers installed at deck or tower levels?

Q4-19: Do the cables have cross cables installed between them?

Q4-20: Do cables have other dampers (other than viscous or neoprene rings) to control vibrations?

Q4-21: Has cracking of the cable sheathing or sheathing connections been noted?

Q4-22: Has cracking or misalignment of the guide pipes been noted?

Q4-23: If there is protective tape wrapped around the cable sheathing; have there been reports of deterioration of the tape?

Q4-24: Have any problems associated with neoprene boots been noted?

Q4-25: Types of non-destructive tests that any of the cables on this bridge have been subjected to?

Q4-26: Types of sensor-based, long-term monitoring performed on the cables?

Q4-27: Have the cables on this bridge (or any of their components) been repaired?

Q4-28: Has the sheathing been partially removed on any of the cables to examine condition of grout (if applicable) and/or the MTE?

Q4-29: Can the strands or cables be replaced if needed?

Q4-30: Do you have an inspection and maintenance manual for this bridge?

Q5: Based on your experience and in general, do you believe that the current inspection, testing, monitoring, and repair methods available to you for stay cables are effective and adequate?

Not known-we are several years away from completion of the first cable-stayed bridge for which Arkansas will have responsibility for inspection/maintenance/not known

Q6: Please comment on the effectiveness of any non-destructive test methods for inspections of stay cables that you may be familiar with. These methods include (but are not limited to) ultrasonic testing, magnetic inspections, laser-based force measurements, $\mathrm{X}$-ray imaging, etc. If possible, please comment on issues such as practicality, cost, duration, impact on traffic, and any other factors that you consider important.

\section{No comment/not known}

Q7: Please comment on the effectiveness of any cable vibration control measures that you may be familiar with. Examples include installation of cross cables, viscous dampers, neoprene rings, etc.

No comment/we are currently constructing a cable-stayed bridge on US-82 over the 


\section{NCHRP SYNTHESIS TOPIC 35-07-INSPECTION AND MAINTENANCE OF BRIDGE STAY CABLE SYSTEMS}

Arkansas (Mississippi)

Questionnaire Results

Survey performed in 2004

Mississippi River near Greenville, MS.

Mississippi is responsible for overseeing the construction and Arkansas will be responsible for the maintenance. We are sharing the costs associated with both construction and maintenance. We are using cable ties and cable stay sheathing with a helical drip bead to control the cable vibration. We considered using dampners and a combination of dampners and cable ties. However, we were not comfortable with the reliability of

dampners and felt the cable ties have a longstanding proven record. A visual inspection would show problems with the ties, whereas with the dampners it is not so easy to determine if they are working properly.

Q8: Please comment on the effectiveness of any sensor-based, long-term monitoring systems for stay cables that you may be familiar with. Examples include acoustic monitoring, vibration monitoring, force measurements, strain measurements, etc.

\section{No comment/not known}

Q9: What would you recommend that the cable suppliers incorporate into their systems to make cables more accessible and inspectable?

\section{No comment/no comment}

Q10: Do you believe that an up-to-date resource such as a national database of information on stay cable inspection methods, repairs, and testing would be a useful tool?

Not known/yes
Q11: What do you see as the single most

important problem in stay cable maintenance?

No comment/we do not have enough experience in this area to comment.

Q12: Please comment on any other methods for inspections, testing, monitoring, and repair of stay cable (including conventional methods)

that you have found beneficial and are not listed above.

\section{N/A-N/A}

Additional comments? 
NCHRP SYNTHESIS TOPIC 35-07-INSPECTION AND MAINTENANCE OF BRIDGE STAY CABLE SYSTEMS

Leonard P. Zakim Bunker Hill Bridge, Boston, MA

Massachusetts

\section{Leonard P. Zakim Bunker Hill \\ Bridge, Boston, MA}

State/Province: Massachusetts

Agency: $\quad$ Massachusetts Turnpike Authority

Respondent: Anthony Ricci

Span Length: $\quad \mathbf{7 4 5} \mathrm{ft}$

Year Built: 2002

Q4-4: Type of main tension element (MTE)? seven-wire steel strand

Q4-5: Coating/treatment on main tension element within free length of cable?

\section{greased-and-sheathed}

Q4-6: Are the coatings/treatments on main tension element discontinued or removed within the anchorage zone?

yes-sheathing removed in the anchorage zone

Q4-7: Type of grout used?

grout not used

Q4-8: Are filler materials used in the anchorage zone?

yes, other-wax

Q4-9: Type of anchorage?

wedges
Q4-10: Do cables go over "saddles" on the pylons?

no

Q4-11: Type of cable sheathing used?

$U V$-resistant HDPE with spiral on surface

Q4-12: Have rain-wind-induced cable vibrations been observed on this bridge?

no

Q4-13: Have MTE corrosion problems been noted?

no

Q4-14: Do cables have neoprene rings near the top and bottom anchorages?

no-internal dampers at deck level, stuffing box with HDPE drilled plate and compressive material at pylon

Q4-15: If there are neoprene rings on the cables; have there been any reports of movements of the rings out of their positions?

\section{not applicable}

Q4-16: Has moisture been found in any of the internal components of stay cables such as the bottom anchorage areas?

no

Q4-17: Has fatigue of MTE or other components of stay cables been observed? no
Questionnaire Results

Survey performed in 2004
Q4-18: Do the cables have viscous dampers installed at deck or tower levels?

yes, from the beginning-internal dampers at deck level

Q4-19: Do the cables have cross cables installed between them?

\section{yes-from the beginning}

Q4-20: Do cables have other dampers (other than viscous or neoprene rings) to control vibrations?

no

Q4-21: Has cracking of the cable sheathing or sheathing connections been noted?

no

Q4-22: Has cracking or misalignment of the guide pipes been noted?

no

Q4-23: If there is protective tape wrapped around the cable sheathing; have there been reports of deterioration of the tape?

\section{not applicable}

Q4-24: Have any problems associated with neoprene boots been noted?

\section{no-not applicable}

Q4-25: Types of non-destructive tests that any of the cables on this bridge have been subjected to?

not performed 


\section{NCHRP SYNTHESIS TOPIC 35-07_INSPECTION AND MAINTENANCE OF BRIDGE STAY CABLE SYSTEMS}

\section{Leonard P. Zakim Bunker Hill Bridge, Boston, MA}

Massachusetts

Questionnaire Results

Survey performed in 2004

Q4-26: Types of sensor-based, long-term monitoring performed on the cables?

\section{not performed}

Q4-27: Have the cables on this bridge (or any of their components) been repaired?

no

Q4-28: Has the sheathing been partially removed on any of the cables to examine condition of grout (if applicable) and/or the MTE?

no

Q4-29: Can the strands or cables be replaced if needed?

yes

Q4-30: Do you have an inspection and maintenance manual for this bridge?

yes

Q5: Based on your experience and in general, do you believe that the current inspection, testing, monitoring, and repair methods available to you for stay cables are effective and adequate?

yes

Q6: Please comment on the effectiveness of any non-destructive test methods for inspections of stay cables that you may be familiar with. These methods include (but are not limited to) ultrasonic testing, magnetic inspections, laser-based force measurements, $\mathrm{X}$-ray imaging, etc. If possible, please comment on issues such as practicality, cost, duration, impact on traffic, and any other factors that you consider important.

Have not yet used any NDT methods for stay cable inspection.

Q7: Please comment on the effectiveness of any cable vibration control measures that you may be familiar with. Examples include installation of cross cables, viscous dampers, neoprene rings, etc.

It is our opinion that neoprene rings will not work as intended. Either internal or external viscous dampers are needed. Cross cables are not needed in shorter spans.

Q8: Please comment on the effectiveness of any sensor-based, long-term monitoring systems for stay cables that you may be familiar with. Examples include acoustic monitoring, vibration monitoring, force measurements, strain measurements, etc.

none

Q9: What would you recommend that the cable suppliers incorporate into their systems to make cables more accessible and inspectable?

\section{transparent outer pipe, eliminate grout}

Q10: Do you believe that an up-to-date resource such as a national database of information on stay cable inspection methods, repairs, and testing would be a useful tool?

yes

Q11: What do you see as the single most important problem in stay cable maintenance?

\section{Access for inspection}

Q12: Please comment on any other methods for inspections, testing, monitoring, and repair of stay cable (including conventional methods) that you have found beneficial and are not listed above.

Stay cable anchorage design should allow for accessibility for inspection. Inspection, maintenance, and replacement should be addressed during design.

Additional comments?

no answer 
NCHRP SYNTHESIS TOPIC 35-07-INSPECTION AND MAINTENANCE OF BRIDGE STAY CABLE SYSTEMS

Bill Emerson Memorial Bridge, Cape Girardeau Missouri

\section{Bill Emerson Memorial Bridge, Cape Girardeau}

$\begin{array}{ll}\text { State/Province: } & \text { Missouri } \\ \text { Agency: } & \text { MoDOT } \\ \text { Respondent: } & \text { Greg Sunde } \\ \text { Span Length: } & \mathbf{1 , 1 5 0 ~ f t} \\ \text { Year Built: } & \mathbf{2 0 0 3}\end{array}$

Q4-4: Type of main tension element (MTE)? seven-wire steel strand

Q4-5: Coating/treatment on main tension

\section{greased-and-sheathed}

Q4-6: Are the coatings/treatments on main tension element discontinued or removed within the anchorage zone?

yes

Q4-7: Type of grout used?

cement-water admixtures

Q4-8: Are filler materials used in the anchorage zone?

yes, grease

Q4-9: Type of anchorage?

wedges

Q4-10: Do cables go over "saddles" on the pylons?

no

Q4-11: Type of cable sheathing used? $U V$-resistant HDPE with spiral on surface

Q4-12: Have rain-wind-induced cable vibrations been observed on this bridge?

no

Q4-13: Have MTE corrosion problems been noted?

no

Q4-14: Do cables have neoprene rings near the top and bottom anchorages?

yes

Q4-15: If there are neoprene rings on the cables; have there been any reports of movements of the rings out of their positions?

no, not known

Q4-16: Has moisture been found in any of the internal components of stay cables such as the bottom anchorage areas?

no

Q4-17: Has fatigue of MTE or other components of stay cables been observed? no

Q4-18: Do the cables have viscous dampers installed at deck or tower levels? no

Q4-19: Do the cables have cross cables installed between them?

yes, from the beginning
Q4-20: Do cables have other dampers (other than viscous or neoprene rings) to control vibrations?

no

Q4-21: Has cracking of the cable sheathing or sheathing connections been noted?

no

Q4-22: Has cracking or misalignment of the guide pipes been noted?

no

Q4-23: If there is protective tape wrapped around the cable sheathing; have there been reports of deterioration of the tape?

no

Q4-24: Have any problems associated with neoprene boots been noted?

no

Q4-25: Types of non-destructive tests that any of the cables on this bridge have been subjected to?

not performed

Q4-26: Types of sensor-based, long-term monitoring performed on the cables?

not performed

Q4-27: Have the cables on this bridge (or any of their components) been repaired?

yes-splices were added to HDPE sheathing during construction of a couple of cables 


\section{NCHRP SYNTHESIS TOPIC 35-07-INSPECTION AND MAINTENANCE OF BRIDGE STAY CABLE SYSTEMS}

\section{Bill Emerson Memorial Bridge, Cape Girardeau}

Missouri
Questionnaire Results

Survey performed in 2004
Q4-28: Has the sheathing been partially removed on any of the cables to examine condition of grout (if applicable) and/or the MTE?

no

Q4-29: Can the strands or cables be replaced if needed?

yes

Q4-30: Do you have an inspection and maintenance manual for this bridge?

no

Q5: Based on your experience and in general do you believe that the current inspection, testing, monitoring, and repair methods available to you for stay cables are effective and adequate?

\section{not known-MoDOT has no related} experience

Q6: Please comment on the effectiveness of any non-destructive test methods for inspections of stay cables that you may be familiar with. These methods include (but are not limited to) ultrasonic testing, magnetic inspections, laser-based force measurements, X-ray imaging, etc. If possible, please comment on issues such as practicality, cost, duration, impact on traffic, and any other factors that you consider important.

\section{MoDOT has no related experience}

Q7: Please comment on the effectiveness of any cable vibration control measures that you may be familiar with. Examples include installation of cross cables, viscous dampers, neoprene rings, etc.

Cross cables have been installed on this bridge as the most effective, positive method to eliminate cable vibrations. We understand that worldwide research is being conducted to maximize the efficiency of dampers and to determine, mathematically when they are and are not required

Q8: Please comment on the effectiveness of any sensor-based, long-term monitoring systems for stay cables that you may be familiar with. Examples include acoustic monitoring, vibration monitoring, force measurements, strain measurements, etc.

\section{MoDOT has no related experience}

Q9: What would you recommend that the cable suppliers incorporate into their systems to make cables more accessible and inspectable?

Perhaps a permanent load cell that would premit real-time readings of cable forces at any time during the life of the bridge

Q10: Do you believe that an up-to-date resource such as a national database of information on stay cable inspection methods, repairs, and testing would be a useful tool? yes

Q11: What do you see as the single most important problem in stay cable maintenance?

The integrity of the stays. Grouted cables are impossible to inspect with a non-destructive technique (i.e., one that does not require removal of sheathing and grout); thus, it is impossible to identify corrosion problems early.

Q12: Please comment on any other methods for inspections, testing, monitoring, and repair of stay cable (including conventional methods) that you have found beneficial and are not listed above.

\section{MoDOT has no related experience}

Additional comments? 


\section{NCHRP SYNTHESIS TOPIC 35-07-INSPECTION AND MAINTENANCE OF BRIDGE STAY CABLE SYSTEMS}

Maumee River Bridge

Ohio

\section{Maumee River Bridge, Toledo,}

\section{Ohio}

State/Province: Ohio

Agency: $\quad$ Figg Bridge Engineers

Respondent: $\quad$ W. Denny Pate

Span Length: $\quad 2$ stayed spans of 612.5'

(single tower) $f t$

Year Built:

Currently under

construction (2004)

Q4-4: Type of main tension element (MTE)? seven-wire steel strand

Q4-5: Coating/treatment on main tension element within free length of cable?

\section{epoxy-coated inside and outside}

Q4-6: Are the coatings/treatments on main tension element discontinued or removed within the anchorage zone?

yes

Q4-7: Type of grout used?

grout not used

Q4-8: Are filler materials used in the anchorage zone?

yes, grease

Q4-9: Type of anchorage?

wedges

Q4-10: Do cables go over "saddles" on the pylons?
yes-This project actually uses a "cradle" that separates individual strands within the curved area, avoiding contact stress between them. In that respect, it is different than conventional "saddles."

Q4-11: Type of cable sheathing used?

other, stainless steel

Q4-12: Have rain-wind-induced cable vibrations been observed on this bridge?

no

Q4-13: Have MTE corrosion problems been noted?

no

Q4-14: Do cables have neoprene rings near the top and bottom anchorages?

no

Q4-15: If there are neoprene rings on the cables; have there been any reports of movements of the rings out of their positions?

\section{not applicable}

Q4-16: Has moisture been found in any of the internal components of stay cables such as the bottom anchorage areas?

no

Q4-17: Has fatigue of MTE or other components of stay cables been observed? no

Q4-18: Do the cables have viscous dampers installed at deck or tower levels?
Questionnaire Results

Survey performed in 2004

\section{yes-from the beginning}

Q4-19: Do the cables have cross cables installed between them?

no

Q4-20: Do cables have other dampers (other than viscous or neoprene rings) to control vibrations?

no

Q4-21: Has cracking of the cable sheathing or sheathing connections been noted?

no

Q4-22: Has cracking or misalignment of the guide pipes been noted?

no

Q4-23: If there is protective tape wrapped around the cable sheathing; have there been reports of deterioration of the tape?

\section{not applicable}

Q4-24: Have any problems associated with neoprene boots been noted?

no

Q4-25: Types of non-destructive tests that any of the cables on this bridge have been subjected to?

\section{not performed}

Q4-26: Types of sensor-based, long-term monitoring performed on the cables?

not performed 
Q4-27: Have the cables on this bridge (or any of their components) been repaired?

no

Q4-28: Has the sheathing been partially removed on any of the cables to examine condition of grout (if applicable) and/or the MTE?

no

Q4-29: Can the strands or cables be replaced if needed?

yes

Q4-30: Do you have an inspection and maintenance manual for this bridge?

Q5: Based on your experience and in general, do you believe that the current inspection, testing, monitoring, and repair methods available to you for stay cables are effective and adequate?

yes-while better methods may be developed in the future, the current methods are both effective and adequate. The most likely location of cable issues on all such bridges is at the anchor areas. By the nature of the anchor being embedded in massive concrete or steel areas, direct access to inspect the MTE is generally impractical.

Q6: Please comment on the effectiveness of any non-destructive test methods for inspections of stay cables that you may be familiar with. These methods include (but are not limited to) ultrasonic testing, magnetic

inspections, laser-based force measurements, $\mathrm{X}$-ray imaging, etc. If possible, please comment on issues such as practicality, cost, duration, impact on traffic, and any other factors that you consider important.

no answer

Q7: Please comment on the effectiveness of any cable vibration control measures that you may be familiar with. Examples include installation of cross cables, viscous dampers, neoprene rings, etc.

Volumes can be written on this topic. The short version is that any actual "damping" added to the cable is highly effective since by its nature the cable has very little. Other control measures have had various degrees of success. In most cases, the success or lack of success has been related to the actual details, not so much in the selected approach to the issue.

Q8: Please comment on the effectiveness of any sensor-based, long-term monitoring systems for stay cables that you may be familiar with. Examples include acoustic monitoring, vibration monitoring, force measurements, strain measurements, etc.

no answer

Q9: What would you recommend that the cable suppliers incorporate into their systems to make cables more accessible and inspectable?

Access is a very sharp two-edged sword. If you can more easily access the cable, so can corrosive elements (not to mention potential terrorist/security considerations).
Q10: Do you believe that an up-to-date resource such as a national database of information on stay cable inspection methods, repairs, and testing would be a useful tool?

not known-while information can be useful, it can also be misinterpreted. The best resource is direct contact with those who have hands-on knowledge related to the specific area that an individual may be making inquiries.

Q11: What do you see as the single most important problem in stay cable maintenance?

The largest "problem" with stay cables is that they are widely perceived as "a problem" rather than just another bridge member with specific needs and characteristics. Stay cables have been placed unnecessarily "on a pedestal." While they are a very important bridge member, in current designs they are highly redundant, overtested, and (relatively) easily replaced. There is no other major bridge member that fits into all three of these categories. Let's not promote the feeling that stays are " a maintenance problem."

Q12: Please comment on any other methods for inspections, testing, monitoring, and repair of stay cable (including conventional methods) that you have found beneficial and are not listed above.

no answer

Additional comments?

no answer 
NCHRP SYNTHESIS TOPIC 35-07-INSPECTION AND MAINTENANCE OF BRIDGE STAY CABLE SYSTEMS

Cooper River Bridge

South Carolina

\section{Cooper River Bridge}

State/Province: South Carolina

Agency: $\quad$ South Carolina DOT

Respondent: Charles T. Dwyer

Span Length: $\quad 1546 f t$

Year Built: $\quad 2005$

Q4-4: Type of main tension element (MTE)? seven-wire steel strand

Q4-5: Coating/treatment on main tension element within free length of cable?

Q4-6: Are the coatings/treatments on main tension element discontinued or removed within the anchorage zone?

yes

Q4-7: Type of grout used?

grout not used

Q4-8: Are filler materials used in the anchorage zone?

yes, other

Q4-9: Type of anchorage?

wedges

Q4-10: Do cables go over "saddles" on the pylons?

no

Q4-11: Type of cable sheathing used? UV-resistant HDPE with spiral on surface

Q4-12: Have rain-wind-induced cable vibrations been observed on this bridge?

N/A

Q4-13: Have MTE corrosion problems been noted?

N/A

Q4-14: Do cables have neoprene rings near the top and bottom anchorages?

N/A

Q4-15: If there are neoprene rings on the cables; have there been any reports of movements of the rings out of their positions?

N/A

Q4-16: Has moisture been found in any of the internal components of stay cables such as the bottom anchorage areas?

N/A

Q4-17: Has fatigue of MTE or other components of stay cables been observed?

N/A

Q4-18: Do the cables have viscous dampers installed at deck or tower levels?

\section{yes-from the beginning}

Q4-19: Do the cables have cross cables installed between them?
Questionnaire Results

Survey performed in 2004

no-bridge not finished. A provisional feature if needed.

Q4-20: Do cables have other dampers (other than viscous or neoprene rings) to control vibrations?

yes-external hydraulic dampers

Q4-21: Has cracking of the cable sheathing or sheathing connections been noted?

\section{N/A}

Q4-22: Has cracking or misalignment of the guide pipes been noted?

\section{not known}

Q4-23: If there is protective tape wrapped around the cable sheathing; have there been reports of deterioration of the tape?

N/A

Q4-24: Have any problems associated with neoprene boots been noted?

\section{not known}

Q4-25: Types of non-destructive tests that any of the cables on this bridge have been subjected to?

\section{not performed}

Q4-26: Types of sensor-based, long-term monitoring performed on the cables?

\section{not performed}

Q4-27: Have the cables on this bridge (or any of their components) been repaired? 


\section{NCHRP SYNTHESIS TOPIC 35-07-INSPECTION AND MAINTENANCE OF BRIDGE STAY CABLE SYSTEMS}

\section{Cooper River Bridge}

South Carolina

no

Q4-28: Has the sheathing been partially removed on any of the cables to examine condition of grout (if applicable) and/or the MTE?

\section{not known}

Q4-29: Can the strands or cables be replaced if needed?

yes

Q4-30: Do you have an inspection and maintenance manual for this bridge?

\section{yes-required submittal upon completion in}

\section{5}

Q5: Based on your experience and in general, do you believe that the current inspection, testing, monitoring, and repair methods available to you for stay cables are effective and adequate?

yes

Q6: Please comment on the effectiveness of any non-destructive test methods for inspections of stay cables that you may be familiar with. These methods include (but are not limited to) ultrasonic testing, magnetic inspections, laser-based force measurements, $\mathrm{X}$-ray imaging, etc. If possible, please comment on issues such as practicality, cost, duration, impact on traffic, and any other factors that you consider important.

\section{no comment}

Q7: Please comment on the effectiveness of any cable vibration control measures that you may be familiar with. Examples include installation of cross cables, viscous dampers, neoprene rings, etc.

Viscous dampers for all cables and additional external dampers for the longest cables are in plans and will be installed. Cross cable dampers are a future consideration.

Provisions for future installation of cross cables will be installed. If the system of viscous and external dampers is inadequate, the cross cables can be installed.

Q8: Please comment on the effectiveness of any sensor-based, long-term monitoring systems for stay cables that you may be familiar with. Examples include acoustic monitoring, vibration monitoring, force measurements, strain measurements, etc.

none

Q9: What would you recommend that the cable suppliers incorporate into their systems to make cables more accessible and inspectable?

Include a maintenance manual with clear instructions for both specific wires or full cables.

Q10: Do you believe that an up-to-date resource such as a national database of information on stay cable inspection methods, repairs, and testing would be a useful tool?

yes

Q11: What do you see as the single most important problem in stay cable maintenance?
Questionnaire Results

Survey performed in 2004

\section{Provide end caps that are easily removed and} fully protected against corrosion.

Q12: Please comment on any other methods for inspections, testing, monitoring, and repair of stay cable (including conventional methods) that you have found beneficial and are not listed above.

\section{no answer}

Additional comments? 
NCHRP SYNTHESIS TOPIC 35-07-INSPECTION AND MAINTENANCE OF BRIDGE STAY CABLE SYSTEMS

Veterans Memorial Bridge

Texas

Questionnaire Results

Survey performed in 2004

\section{Veterans Memorial Bridge}

$\begin{array}{ll}\text { State/Province: } & \text { Texas } \\ \text { Agency: } & \text { Texas DOT } \\ \text { Respondent: } & \text { Keith Ramsey } \\ \text { Span Length: } & \mathbf{6 4 0 ~ f t} \\ \text { Year Built: } & \mathbf{1 9 9 1}\end{array}$

Q4-4: Type of main tension element (MTE)? seven-wire steel strand

Q4-5: Coating/treatment on main tension element within free length of cable?

\section{bare}

Q4-6: Are the coatings/treatments on main tension element discontinued or removed within the anchorage zone?

\section{N/A-grouted though entire length and} anchorage

Q4-7: Type of grout used?

\section{cement-water admixtures}

Q4-8: Are filler materials used in the anchorage zone?

\section{yes, other-grout}

Q4-9: Type of anchorage?

conical socket with wedges

Q4-10: Do cables go over "saddles" on the pylons?

yes
Q4-11: Type of cable sheathing used? HDPE with PVF Tedlar tape

Q4-12: Have rain-wind-induced cable vibrations been observed on this bridge?

yes

Q4-13: Have MTE corrosion problems been noted?

no

Q4-14: Do cables have neoprene rings near the top and bottom anchorages?

yes

Q4-15: If there are neoprene rings on the cables; have there been any reports of movements of the rings out of their positions?

yes-due to loosening of retainers

Q4-16: Has moisture been found in any of the internal components of stay cables such as the bottom anchorage areas?

no

Q4-17: Has fatigue of MTE or other components of stay cables been observed? no

Q4-18: Do the cables have viscous dampers installed at deck or tower levels?

yes-retrofitted to correct vibrations; presently being installed

Q4-19: Do the cables have cross cables installed between them? no

Q4-20: Do cables have other dampers (other than viscous or neoprene rings) to control vibrations?

no

Q4-21: Has cracking of the cable sheathing or sheathing connections been noted?

no

Q4-22: Has cracking or misalignment of the guide pipes been noted?

no

Q4-23: If there is protective tape wrapped around the cable sheathing; have there been reports of deterioration of the tape?

yes, minor damage

Q4-24: Have any problems associated with neoprene boots been noted?

no

Q4-25: Types of non-destructive tests that any of the cables on this bridge have been subjected to?

Vibration-based force measurements, used to aid in the design of viscous dampers for the bridge. Performed periodically to compare predampened response to post-dampened response.

Q4-26: Types of sensor-based, long-term monitoring performed on the cables? 


\section{NCHRP SYNTHESIS TOPIC 35-07-INSPECTION AND MAINTENANCE OF BRIDGE STAY CABLE SYSTEMS}

Veterans Memorial Bridge

Texas
Questionnaire Results

Survey performed in 2004 acoustic wire break detection, vibration monitoring, other-Have long-term weather monitoring to associate with oscillation events.

Q4-27: Have the cables on this bridge (or any of their components) been repaired?

yes-retightened the retainers for the neoprene rings

Q4-28: Has the sheathing been partially removed on any of the cables to examine condition of grout (if applicable) and/or the MTE?

no

Q4-29: Can the strands or cables be replaced if needed?

yes

Q4-30: Do you have an inspection and maintenance manual for this bridge?

yes

Q5: Based on your experience and in general, do you believe that the current inspection, testing, monitoring, and repair methods available to you for stay cables are effective and adequate?

yes-owners are unable to non-destructively evaluate the condition of stay cables and anchorages.

Q6: Please comment on the effectiveness of any non-destructive test methods for inspections of stay cables that you may be familiar with. These methods include (but are not limited to) ultrasonic testing, magnetic inspections, laser-based force measurements, $\mathrm{X}$-ray imaging, etc. If possible, please comment on issues such as practicality, cost, duration, impact on traffic, and any other factors that you consider important.

TxDOT has employed vibration-based force measurements to refine the model used for designing viscous dampers on each of the cable stay bridges. The technique seemed to give good correlation cable dimensions and damping requirements. The technique requires some traffic control and depending on the number of lanes carried by the structure could produce minor to significant traffic disruption. At least one lane and the shoulder will need to be closed, therefore if the bridge is narrow with a small number of lanes carrying two-way traffic the disruption could be considerable. This could last for several weeks if there are a large number of stays that need to be tested. The cost can run anywhere from $\$ 50,000$ to $\$ 75,000$ per bridge per test event depending on the size of the structure.

Q7: Please comment on the effectiveness of any cable vibration control measures that you may be familiar with. Examples include installation of cross cables, viscous dampers, neoprene rings, etc.

The only cable vibration control measures that Texas has experience with at this time are cross tie cables and neoprene rings. The neoprene rings do not appear to offer a measurable amount of dampening, and based on the department's experience should not be considered as a primary damping mechanism. The cross tie system that the department has employed has been effective in reducing the extreme vibration events, but vibrations of an amplitude that cause concern still occur. Texas is presently installing viscous damping systems of each of the cable stay bridges in the state. On the Fred Hartman Bridge these will be installed in conjunction with cross tie cables. It is hoped that this combination will effectively eliminate the occurrence and amplitude of any vibrations.

Q8: Please comment on the effectiveness of any sensor-based, long-term monitoring systems for stay cables that you may be familiar with. Examples include acoustic monitoring, vibration monitoring, force measurements, strain measurements, etc.

The department has installed an acoustic monitoring system to identify possible wire breaks at the Fred Hartman Bridge. The system seems to work well and has identified several possible wire breaks. Prior to its installation, the system was tested on a cable mock-up at the Ferguson Structural Lab of the University of Texas at Austin, where research is underway to determine the effects of stay cable vibrations on the fatigue life of the cables. This allowed the department to test the monitoring system to see how accurately it could identify occurrence and location of wire breaks since numerous wire breaks were generated. The correlation between the 
NCHRP SYNTHESIS TOPIC 35-07-INSPECTION AND MAINTENANCE OF BRIDGE STAY CABLE SYSTEMS

Veterans Memorial Bridge

Texas

Questionnaire Results

Survey performed in 2004

monitoring system results and the autopsied cables was very good.

Q9: What would you recommend that the cable suppliers incorporate into their systems to make cables more accessible and inspectable?

Current grouted and sheathed systems do not allow for visual inspection. New stay systems (perhaps ungrouted, unsheathed systems consisting of bare corrosion resistant tension members) need to be developed that allow for inspection of the entire stay length. Research is also needed to develop rapid, economical evaluation (NDE) methods to determine conditions of stay cables.

Q10: Do you believe that an up-to-date resource such as a national database of information on stay cable inspection methods, repairs, and testing would be a useful tool?

yes

Q11: What do you see as the single most important problem in stay cable maintenance?

Ability to determine the effectiveness and remaining life of corrosion protection systems for main tension elements. The configuration and construction techniques make evaluation and inspection using non-destructive tehniques almost impossible.

Q12: Please comment on any other methods for inspections, testing, monitoring, and repair of stay cable (including conventional methods) that you have found beneficial and are not listed above.

no answer
Additional comments? 


\section{NCHRP SYNTHESIS TOPIC 35-07-INSPECTION AND MAINTENANCE OF BRIDGE STAY CABLE SYSTEMS}

\section{Fred Hartman Bridge}

Texas

\section{Fred Hartman Bridge}

State/Province: Texas

Agency:

\section{Texas DOT}

Respondent:

\section{Keith Ramsey}

Span Length: $\quad \mathbf{1 , 2 5 0} \mathrm{ft}$

Year Built:

1995

Q4-4: Type of main tension element (MTE)?

seven-wire steel strand

Q4-5: Coating/treatment on main tension element within free length of cable?

\section{bare}

Q4-6: Are the coatings/treatments on main tension element discontinued or removed within the anchorage zone?

N/A-grouted through entire length and anchorage

Q4-7: Type of grout used?

cement-water admixtures

Q4-8: Are filler materials used in the anchorage zone?

yes, other-grout

Q4-9: Type of anchorage?

conical socket with wedges

Q4-10: Do cables go over "saddles" on the pylons?

no
Q4-11: Type of cable sheathing used?

HDPE with PVF Tedlar tape

Q4-12: Have rain-wind-induced cable vibrations been observed on this bridge?

yes

Q4-13: Have MTE corrosion problems been noted?

no

Q4-14: Do cables have neoprene rings near the top and bottom anchorages? yes

Q4-15: If there are neoprene rings on the cables; have there been any reports of movements of the rings out of their positions? yes-due to shearing off of retainers

Q4-16: Has moisture been found in any of the internal components of stay cables such as the bottom anchorage areas?

no

Q4-17: Has fatigue of MTE or other components of stay cables been observed?

yes-possible wire breaks have been detected by acoustic monitoring system

Q4-18: Do the cables have viscous dampers installed at deck or tower levels?

yes-retrofitted to correct vibrations; presently being installed
Questionnaire Results

Survey performed in 2004
Q4-19: Do the cables have cross cables installed between them?

yes-retrofitted to correct vibrations; presently being installed

Q4-20: Do cables have other dampers (other than viscous or neoprene rings) to control vibrations?

no

Q4-21: Has cracking of the cable sheathing or sheathing connections been noted?

no

Q4-22: Has cracking or misalignment of the guide pipes been noted?

no

Q4-23: If there is protective tape wrapped around the cable sheathing; have there been reports of deterioration of the tape?

yes, minor damage

Q4-24: Have any problems associated with neoprene boots been noted?

\section{no}

Q4-25: Types of non-destructive tests that any of the cables on this bridge have been subjected to?

Vibration-based force measurements, used to aid in the design of viscous dampers for the bridge. Performed periodically to compare predampened response to post-dampened response. 


\section{NCHRP SYNTHESIS TOPIC 35-07-INSPECTION AND MAINTENANCE OF BRIDGE STAY CABLE SYSTEMS}

Fred Hartman Bridge

Texas
Questionnaire Results

Survey performed in 2004
Q4-26: Types of sensor-based, long-term monitoring performed on the cables?

acoustic wire break detection, vibration monitoring, other-have long-term weather monitoring to associate with oscillation events.

Q4-27: Have the cables on this bridge (or any of their components) been repaired?

yes-rewelded and stiffened guide pipe. Replaced initial restrainer system after fatigue and failure of original restrainer cables.

Q4-28: Has the sheathing been partially removed on any of the cables to examine condition of grout (if applicable) and/or the MTE?

yes-sheathing was removed to observe the condition of grout. Grout appeared to be in good/sound condition.

Q4-29: Can the strands or cables be replaced if needed?

yes

Q4-30: Do you have an inspection and maintenance manual for this bridge?

yes

Q5: Based on your experience and in general, do you believe that the current inspection, testing, monitoring, and repair methods available to you for stay cables are effective and adequate? yes-owners are unable to non-destructively evaluate the condition of stay cables and anchorages.

Q6: Please comment on the effectiveness of any non-destructive test methods for inspections of stay cables that you may be familiar with. These methods include (but are not limited to) ultrasonic testing, magnetic inspections, laser-based force measurements, $\mathrm{X}$-ray imaging, etc. If possible, please comment on issues such as practicality, cost, duration, impact on traffic, and any other factors that you consider important.

TxDOT has employed vibration-based force measurements to refine the model used for designing viscous dampers on each of the cable stay bridges. The technique seemed to give good correlation cable dimensions and damping requirements. The technique requires some traffic control and depending on the number of lanes carried by the structure could produce minor to significant traffic disruption. At least one lane and the shoulder will need to be closed, therefore if the bridge is narrow with a small number of lanes carrying two-way traffic the disruption could be considerable. This could last for several weeks if there are a large number of stays that need to be tested. The cost can run anywhere from $\$ 50,000$ to $\$ 75,000$ per bridge per test event depending on the size of the structure.

Q7: Please comment on the effectiveness of any cable vibration control measures that you may be familiar with. Examples include installation of cross cables, viscous dampers, neoprene rings, etc.

The only cable vibration control measures that Texas has experience with at this time are cross tie cables and neoprene rings. The neoprene rings do not appear to offer a measurable amount of dampening, and based on the department's experience should not be considered as a primary damping mechanism. The cross tie system that the department has employed has been effective in reducing the extreme vibration events, but vibrations of an amplitude that cause concern still occur. Texas is presently installing viscous damping systems of each of the cable stay bridges in the state. On the Fred Hartman Bridge these will be installed in conjunction with cross tie cables. It is hoped that this combination will effectively eliminate the occurrence and amplitude of any vibrations.

Q8: Please comment on the effectiveness of any sensor-based, long-term monitoring systems for stay cables that you may be familiar with. Examples include acoustic monitoring, vibration monitoring, force measurements, strain measurements, etc.

The department has installed an acoustic monitoring system to identify possible wire breaks at the Fred Hartman Bridge. The system seems to work well and has identified several possible wire breaks. Prior to its installation, the system was tested on a cable mock-up at the Ferguson Structural Lab of the University of Texas at Austin, where research is underway to determine the effects 


\section{NCHRP SYNTHESIS TOPIC 35-07-INSPECTION AND MAINTENANCE OF BRIDGE STAY CABLE SYSTEMS}

Fred Hartman Bridge

Texas

of stay cable vibrations on the fatigue life of the cables. This allowed the department to test the monitoring system to see how accurately it could identify occurrence and location of wire breaks, since numerous wire breaks were generated. The correlation between the monitoring system results and the autopsied cables was very good.

Q9: What would you recommend that the cable suppliers incorporate into their systems to make cables more accessible and inspectable?

Current grouted and sheathed systems do not allow for visual inspection. New stay systems (perhaps ungrouted, unsheathed systems consisting of bare corrosion resistant tension members) need to be developed that allow for inspection of the entire stay length. Research is also needed to develop rapid, economical evaluation (NDE) methods to determine conditions of stay cables.

Q10: Do you believe that an up-to-date resource such as a national database of information on stay cable inspection methods, repairs, and testing would be a useful tool?

yes

Q11: What do you see as the single most important problem in stay cable maintenance?

Ability to determine the effectiveness and remaining life of corrosion protection systems for main tension elements. The configuration and construction techniques make evaluation and inspection using non-destructive techniques almost impossible.
Q12: Please comment on any other methods for inspections, testing, monitoring, and repair of stay cable (including conventional methods) that you have found beneficial and are not listed above.

no answer

Additional comments?
Questionnaire Results

Survey performed in 2004 


\section{NCHRP SYNTHESIS TOPIC 35-07-INSPECTION AND MAINTENANCE OF BRIDGE STAY CABLE SYSTEMS}

I-295 over James River (Varina-Enon Bridge) Virginia

\section{I-295 over James River (Varina-Enon Bridge)}

$\begin{array}{ll}\text { State/Province: } & \text { Virginia } \\ \text { Agency: } & \text { VDOT } \\ \text { Respondent: } & \text { James M. Fariss } \\ \text { Span Length: } & \mathbf{6 3 0 ~ f t} \\ \text { Year Built: } & \mathbf{1 9 9 0}\end{array}$

Q4-4: Type of main tension element (MTE)? seven-wire steel strand

Q4-5: Coating/treatment on main tension

bare

Q4-6: Are the coatings/treatments on main tension element discontinued or removed within the anchorage zone?

N/A

Q4-7: Type of grout used? cement-water admixtures

Q4-8: Are filler materials used in the anchorage zone?

yes, grout

Q4-9: Type of anchorage?

conical socket with wedges

Q4-10: Do cables go over "saddles" on the pylons?

yes

Q4-11: Type of cable sheathing used? HDPE with PVF Tedlar tape

Q4-12: Have rain-wind-induced cable vibrations been observed on this bridge?

Not known-no such vibrations have been observed on the Varina-Enon Bridge.

Q4-13: Have MTE corrosion problems been noted?

not known

Q4-14: Do cables have neoprene rings near the top and bottom anchorages?

yes-only at the bottom anchorages since the stays are continuous over the pylons

Q4-15: If there are neoprene rings on the cables; have there been any reports of movements of the rings out of their positions?

yes-due to other reasons. Due to the misalignment of stay and guide pipes and no positive restraint was provided to keep neoprene ring from moving outward.

Q4-16: Has moisture been found in any of the internal components of stay cables such as the bottom anchorage areas? no

Q4-17: Has fatigue of MTE or other components of stay cables been observed? no-forces obtained in the initial in-depth inspection indicated a good correlation with the designer's predicted forces.

Q4-18: Do the cables have viscous dampers installed at deck or tower levels?

no-details are included in the maintenance manual (Appendix F) as an alternate stay damper system.

Q4-19: Do the cables have cross cables installed between them?

no

Q4-20: Do cables have other dampers (other than viscous or neoprene rings) to control vibrations?

no

Q4-21: Has cracking of the cable sheathing or sheathing connections been noted? no

Q4-22: Has cracking or misalignment of the guide pipes been noted?

yes, misalignment

Q4-23: If there is protective tape wrapped around the cable sheathing; have there been reports of deterioration of the tape?

no

Q4-24: Have any problems associated with neoprene boots been noted?

yes-minor cracks and tears have been noted in 6 of the 52 neoprene boots. 
Q4-25: Types of non-destructive tests that any of the cables on this bridge have been subjected to?

Vibration-based force measurements. Tension force measurement tests were performed by Construction Technology Laboratory, Inc. (CTL) in April 1999.

Q4-26: Types of sensor-based, long-term monitoring performed on the cables?

\section{not known}

Q4-27: Have the cables on this bridge (or any of their components) been repaired?

\section{no}

Q4-28: Has the sheathing been partially removed on any of the cables to examine condition of grout (if applicable) and/or the MTE?

no

Q4-29: Can the strands or cables be replaced if needed?

yes

Q4-30: Do you have an inspection and maintenance manual for this bridge?

yes

Q5: Based on your experience and in general, do you believe that the current inspection, testing, monitoring, and repair methods available to you for stay cables are effective and adequate?

yes
Q6: Please comment on the effectiveness of any non-destructive test methods for inspections of stay cables that you may be familiar with. These methods include (but are not limited to) ultrasonic testing, magnetic inspections, laser-based force measurements, $\mathrm{X}$-ray imaging, etc. If possible, please comment on issues such as practicality, cost, duration, impact on traffic, and any other factors that you consider important.

Laser-based force measurements were utilized in the initial in-depth inspection of this bridge in 1999. The cost incurred was approximately $\$ 35,000$, with minimum impact on traffic.

Q7: Please comment on the effectiveness of any cable vibration control measures that you may be familiar with. Examples include installation of cross cables, viscous dampers, neoprene rings, etc.

Neoprene rings were installed on the VarinaEnon Bridge as the primary stay damping system. This is a relatively cost-effective system, and appears to be performing satisfactorily on this bridge. We have experienced some difficulty in the installation and removal of these rings. Details of an alternate stay damping system utilizing shock absorbers have been included in the Manual for Inspection and Maintenance of the Varina-Enon Bridge.

Q8: Please comment on the effectiveness of any sensor-based, long-term monitoring systems for stay cables that you may be familiar with. Examples include acoustic monitoring, vibration monitoring, force measurements, strain measurements, etc. no comments

Q9: What would you recommend that the cable suppliers incorporate into their systems to make cables more accessible and inspectable?

no comments

Q10: Do you believe that an up-to-date resource such as a national database of information on stay cable inspection methods, repairs, and testing would be a useful tool? yes

Q11: What do you see as the single most important problem in stay cable maintenance?

\section{Lack of familiarity with this type of} construction by the department's staff, which requires assistance from the consultant community in the inspection of these elements.

Q12: Please comment on any other methods for inspections, testing, monitoring, and repair of stay cable (including conventional methods) that you have found beneficial and are not listed above.

no answer

Additional comments? 
NCHRP SYNTHESIS TOPIC 35-07-INSPECTION AND MAINTENANCE OF BRIDGE STAY CABLE SYSTEMS

Gum Street-Kennewick, WA

Washington

\section{Gum Street-Kennewick, WA \\ State/Province: Washington \\ Agency: $\quad$ Washington State DOT \\ Respondent: David Bruce \\ Span Length: $\quad 981 \mathrm{ft}$ \\ Year Built: $\quad \mathbf{1 9 7 8}$}

Q4-4: Type of main tension element (MTE)? steel wire

Q4-5: Coating/treatment on main tension element within free length of cable?

\section{bare}

Q4-6: Are the coatings/treatments on main tension element discontinued or removed within the anchorage zone?

\section{N/A}

Q4-7: Type of grout used?

\section{cement-water}

Q4-8: Are filler materials used in the anchorage zone?

yes, grease

Q4-9: Type of anchorage?

“Hi-Am" type

Q4-10: Do cables go over "saddles" on the pylons?

\section{no}

Q4-11: Type of cable sheathing used?

\section{HDPE with PVF Tedlar tape}

Q4-12: Have rain-wind-induced cable vibrations been observed on this bridge?

no

Q4-13: Have MTE corrosion problems been noted?

no

Q4-14: Do cables have neoprene rings near the top and bottom anchorages?

\section{not known}

Q4-15: If there are neoprene rings on the cables; have there been any reports of movements of the rings out of their positions?

\section{no, not known}

Q4-16: Has moisture been found in any of the internal components of stay cables such as the bottom anchorage areas?

no

Q4-17: Has fatigue of MTE or other components of stay cables been observed? no

Q4-18: Do the cables have viscous dampers installed at deck or tower levels?

no

Q4-19: Do the cables have cross cables installed between them?
Questionnaire Results

Survey performed in 2004

Q4-20: Do cables have other dampers (other than viscous or neoprene rings) to control vibrations?

no

Q4-21: Has cracking of the cable sheathing or sheathing connections been noted?

no

Q4-22: Has cracking or misalignment of the guide pipes been noted?

no

Q4-23: If there is protective tape wrapped around the cable sheathing; have there been reports of deterioration of the tape?

\section{yes, extensive damage}

Q4-24: Have any problems associated with neoprene boots been noted?

yes

Q4-25: Types of non-destructive tests that any of the cables on this bridge have been subjected to?

\section{magnetic}

Q4-26: Types of sensor-based, long-term monitoring performed on the cables?

\section{not performed}

Q4-27: Have the cables on this bridge (or any of their components) been repaired?

no 
Q4-28: Has the sheathing been partially removed on any of the cables to examine condition of grout (if applicable) and/or the MTE?

no

Q4-29: Can the strands or cables be replaced if needed?

\section{not known}

Q4-30: Do you have an inspection and maintenance manual for this bridge?

yes

Q5: Based on your experience and in general, do you believe that the current inspection, testing, monitoring, and repair methods available to you for stay cables are effective and adequate?

yes

Q6: Please comment on the effectiveness of any non-destructive test methods for inspections of stay cables that you may be familiar with. These methods include (but are not limited to) ultrasonic testing, magnetic inspections, laser-based force measurements, $\mathrm{X}$-ray imaging, etc. If possible, please comment on issues such as practicality, cost, duration, impact on traffic, and any other factors that you consider important.

\section{N/A}

Q7: Please comment on the effectiveness of any cable vibration control measures that you may be familiar with. Examples include installation of cross cables, viscous dampers, neoprene rings, etc.

\section{N/A}

Q8: Please comment on the effectiveness of any sensor-based, long-term monitoring systems for stay cables that you may be familiar with. Examples include acoustic monitoring, vibration monitoring, force measurements, strain measurements, etc.

\section{N/A}

Q9: What would you recommend that the cable suppliers incorporate into their systems to make cables more accessible and inspectable?

\section{unknown}

Q10: Do you believe that an up-to-date resource such as a national database of information on stay cable inspection methods, repairs, and testing would be a useful tool? yes

Q11: What do you see as the single most important problem in stay cable maintenance?

\section{none yet}

Q12: Please comment on any other methods for inspections, testing, monitoring, and repair of stay cable (including conventional methods) that you have found beneficial and are not listed above.

\section{N/A}

Additional comments? 
NCHRP SYNTHESIS TOPIC 35-07-INSPECTION AND MAINTENANCE OF BRIDGE STAY CABLE SYSTEMS

Thea-Foss Tacoma, WA Washington

\section{Thea-Foss Tacoma, WA}

State/Province: Washington

Agency: $\quad$ Washington State DOT

Respondent: David Bruce

Span Length: $\quad 375 \mathrm{ft}$

Year Built: 1996

Q4-4: Type of main tension element (MTE)? seven-wire steel strand

Q4-5: Coating/treatment on main tension element within free length of cable?

\section{bare}

Q4-6: Are the coatings/treatments on main tension element discontinued or removed within the anchorage zone?

\section{N/A}

Q4-7: Type of grout used?

\section{cement-water}

Q4-8: Are filler materials used in the anchorage zone?

yes, grease

Q4-9: Type of anchorage?

wedges

Q4-10: Do cables go over "saddles" on the pylons?

no
Q4-11: Type of cable sheathing used? no answer

Q4-12: Have rain-wind-induced cable vibrations been observed on this bridge?

no

Q4-13: Have MTE corrosion problems been noted?

no

Q4-14: Do cables have neoprene rings near the top and bottom anchorages?

yes

Q4-15: If there are neoprene rings on the cables; have there been any reports of movements of the rings out of their positions?

\section{no, not known}

Q4-16: Has moisture been found in any of the internal components of stay cables such as the bottom anchorage areas?

no

Q4-17: Has fatigue of MTE or other components of stay cables been observed? no

Q4-18: Do the cables have viscous dampers installed at deck or tower levels?

no

Q4-19: Do the cables have cross cables installed between them?
Q4-20: Do cables have other dampers (other than viscous or neoprene rings) to control vibrations?

no

Q4-21: Has cracking of the cable sheathing or sheathing connections been noted?

no

Q4-22: Has cracking or misalignment of the guide pipes been noted?

no

Q4-23: If there is protective tape wrapped around the cable sheathing; have there been reports of deterioration of the tape?

\section{yes, minor damage}

Q4-24: Have any problems associated with neoprene boots been noted?

no

Q4-25: Types of non-destructive tests that any of the cables on this bridge have been subjected to?

\section{not performed}

Q4-26: Types of sensor-based, long-term monitoring performed on the cables?

not performed

Q4-27: Have the cables on this bridge (or any of their components) been repaired?

no 
Q4-28: Has the sheathing been partially removed on any of the cables to examine condition of grout (if applicable) and/or the MTE?

no

Q4-29: Can the strands or cables be replaced if needed?

\section{not known}

Q4-30: Do you have an inspection and maintenance manual for this bridge?

yes

Q5: Based on your experience and in general, do you believe that the current inspection, testing, monitoring, and repair methods available to you for stay cables are effective and adequate?

yes

Q6: Please comment on the effectiveness of any non-destructive test methods for inspections of stay cables that you may be familiar with. These methods include (but are not limited to) ultrasonic testing, magnetic inspections, laser-based force measurements, $\mathrm{X}$-ray imaging, etc. If possible, please comment on issues such as practicality, cost, duration, impact on traffic, and any other factors that you consider important.

\section{N/A}

Q7: Please comment on the effectiveness of any cable vibration control measures that you may be familiar with. Examples include installation of cross cables, viscous dampers, neoprene rings, etc.

\section{N/A}

Q8: Please comment on the effectiveness of any sensor-based, long-term monitoring systems for stay cables that you may be familiar with. Examples include acoustic monitoring, vibration monitoring, force measurements, strain measurements, etc.

Q9: What would you recommend that the cable suppliers incorporate into their systems to make cables more accessible and inspectable?

\section{unknown}

Q10: Do you believe that an up-to-date resource such as a national database of information on stay cable inspection methods, repairs, and testing would be a useful tool?

yes

Q11: What do you see as the single most important problem in stay cable maintenance?

\section{none yet}

Q12: Please comment on any other methods for inspections, testing, monitoring, and repair of stay cable (including conventional methods) that you have found beneficial and are not listed above.

\section{N/A}

Additional comments? 


\section{NCHRP SYNTHESIS TOPIC 35-07-INSPECTION AND MAINTENANCE OF BRIDGE STAY CABLE SYSTEMS}

Sixth Street Viaduct, North Cable Stay

\section{Sixth Street Viaduct, North Cable Stay}

State/Province: Wisconsin/Milwaukee

Agency: City of Milwaukee

Respondent: $\quad$ Craig Liberto

Span Length: $195 \mathrm{ft}$

Year Built: $\quad 2003$

Q4-4: Type of main tension element (MTE)?

seven-wire steel strand

Q4-5: Coating/treatment on main tension

\section{greased-and-sheathed}

Q4-6: Are the coatings/treatments on main tension element discontinued or removed within the anchorage zone?

\section{yes-removed within anchor zone}

Q4-7: Type of grout used?

grout not used

Q4-8: Are filler materials used in the anchorage zone?

yes-grease; greased at butt end and top end Q4-9: Type of anchorage?

conical socket with wedges

Q4-10: Do cables go over "saddles" on the pylons?

Q4-11: Type of cable sheathing used?

$U V$-resistant HDPE with spiral on surface, white co-extruded HDPE

Q4-12: Have rain-wind-induced cable vibrations been observed on this bridge? no-vibration not expected for this small cable-stayed bridge.

Q4-13: Have MTE corrosion problems been noted?

no

Q4-14: Do cables have neoprene rings near the top and bottom anchorages?

\section{no at top, yes at bottom}

Q4-15: If there are neoprene rings on the cables; have there been any reports of movements of the rings out of their positions? no, not known

Q4-16: Has moisture been found in any of the internal components of stay cables such as the bottom anchorage areas?

no

Q4-17: Has fatigue of MTE or other components of stay cables been observed? no

Q4-18: Do the cables have viscous dampers installed at deck or tower levels?
Q4-19: Do the cables have cross cables installed between them?

no

Q4-20: Do cables have other dampers (other than viscous or neoprene rings) to control vibrations?

no

Q4-21: Has cracking of the cable sheathing or sheathing connections been noted?

no

Q4-22: Has cracking or misalignment of the guide pipes been noted?

yes-misalignment; top guide pipes not concentric w/PE is the only misalignment

Q4-23: If there is protective tape wrapped around the cable sheathing; have there been reports of deterioration of the tape?

no

Q4-24: Have any problems associated with neoprene boots been noted?

no

Q4-25: Types of non-destructive tests that any of the cables on this bridge have been subjected to?

Not performed. By requirements of supplier, full-scale stay cable fatigue tests by Construction Technology Laboratories in Skokie, Illinois and Technical University of Munich; no wire breaks during 2 million cycle fatigue tests. During reload and static tests, 
Sixth Street Viaduct, North Cable Stay

Wisconsin/Milwaukee

NCHRP SYNTHESIS TOPIC 35-07-INSPECTION AND MAINTENANCE OF BRIDGE STAY CABLE SYSTEMS

failed to meet minimum tensile force of $95 \%$ GUTS (only 90\%). Therefore, added strands at all locations.

Q4-26: Types of sensor-based, long-term monitoring performed on the cables?

\section{not performed}

Q4-27: Have the cables on this bridge (or any of their components) been repaired?

no

Q4-28: Has the sheathing been partially removed on any of the cables to examine condition of grout (if applicable) and/or the MTE?

no

Q4-29: Can the strands or cables be replaced if needed?

yes

Q4-30: Do you have an inspection and maintenance manual for this bridge?

yes

Q5: Based on your experience and in general, do you believe that the current inspection, testing, monitoring, and repair methods available to you for stay cables are effective and adequate?

not known, no previous experience with cablestayed structure

Q6: Please comment on the effectiveness of any non-destructive test methods for inspections of stay cables that you may be familiar with. These methods include (but are not limited to) ultrasonic testing, magnetic inspections, laser-based force measurements, $\mathrm{X}$-ray imaging, etc. If possible, please comment on issues such as practicality, cost, duration, impact on traffic, and any other factors that you consider important.

City inspection forces are neither qualified nor equipped for non-destructive testing. Four single strands are to be removed (one at each pylon) for inspection for rust every 10 years starting in year 2014.

Q7: Please comment on the effectiveness of any cable vibration control measures that you may be familiar with. Examples include installation of cross cables, viscous dampers, neoprene rings, etc.

\section{no vibrations noted}

Q8: Please comment on the effectiveness of any sensor-based, long-term monitoring systems for stay cables that you may be familiar with. Examples include acoustic monitoring, vibration monitoring, force measurements, strain measurements, etc.

\section{not applicable}

Q9: What would you recommend that the cable suppliers incorporate into their systems to make cables more accessible and inspectable?

\section{no answer}

Q10: Do you believe that an up-to-date resource such as a national database of information on stay cable inspection methods, repairs, and testing would be a useful tool?
Questionnaire Results

Survey performed in 2004

yes

Q11: What do you see as the single most

important problem in stay cable maintenance?

Cannot inspect cables without pulling strand every 10 years.

Q12: Please comment on any other methods for inspections, testing, monitoring, and repair of stay cable (including conventional methods) that you have found beneficial and are not listed above.

Four strands (one at each pylon) will be removed every 10 years starting in 2014 to check for corrosion/rusting.

Additional comments? 


\section{NCHRP SYNTHESIS TOPIC 35-07-INSPECTION AND MAINTENANCE OF BRIDGE STAY CABLE SYSTEMS}

Sixth Street Viaduct, South Cable Stay

\section{Sixth Street Viaduct, South Cable Stay}

State/Province: Wisconsin/Milwaukee

Agency: City of Milwaukee

Respondent: $\quad$ Craig Liberto

Span Length: $195 \mathrm{ft}$

Year Built: $\quad 2003$

Q4-4: Type of main tension element (MTE)? seven-wire steel strand

Q4-5: Coating/treatment on main tension

\section{greased-and-sheathed}

Q4-6: Are the coatings/treatments on main tension element discontinued or removed within the anchorage zone?

\section{yes-removed within anchor zone}

Q4-7: Type of grout used?

grout not used

Q4-8: Are filler materials used in the anchorage zone?

yes-grease; greased at butt end and top end Q4-9: Type of anchorage?

conical socket with wedges

Q4-10: Do cables go over "saddles" on the pylons?

Q4-11: Type of cable sheathing used?

$U V$-resistant HDPE with spiral on surface, white co-extruded HDPE.

Q4-12: Have rain-wind-induced cable vibrations been observed on this bridge?

no-vibration not expected for this small cable-stayed bridge.

Q4-13: Have MTE corrosion problems been noted?

no

Q4-14: Do cables have neoprene rings near the top and bottom anchorages?

\section{no at top, yes at bottom}

Q4-15: If there are neoprene rings on the cables; have there been any reports of movements of the rings out of their positions? no, not known

Q4-16: Has moisture been found in any of the internal components of stay cables such as the bottom anchorage areas?

no

Q4-17: Has fatigue of MTE or other components of stay cables been observed? no

Q4-18: Do the cables have viscous dampers installed at deck or tower levels?

no
Q4-19: Do the cables have cross cables installed between them?

no

Q4-20: Do cables have other dampers (other than viscous or neoprene rings) to control vibrations?

no

Q4-21: Has cracking of the cable sheathing or sheathing connections been noted?

no

Q4-22: Has cracking or misalignment of the guide pipes been noted?

yes-misalignment, top guide pipes not concentric with $P E$ is the only misalignment

Q4-23: If there is protective tape wrapped around the cable sheathing; have there been reports of deterioration of the tape?

no

Q4-24: Have any problems associated with neoprene boots been noted?

no

Q4-25: Types of non-destructive tests that any of the cables on this bridge have been subjected to?

Not performed. By requirements of supplier, full-scale stay cable fatigue tests by Construction Technology Laboratories in Skokie, Illinois and Technical University of Munich; no wire breaks during 2 million cycle fatigue tests. During reload and static tests, 
Sixth Street Viaduct, South Cable Stay

Wisconsin/Milwaukee

NCHRP SYNTHESIS TOPIC 35-07-INSPECTION AND MAINTENANCE OF BRIDGE STAY CABLE SYSTEMS

failed to meet minimum tensile force of $95 \%$ GUTS (only 90\%). Therefore, added strands at all locations.

Q4-26: Types of sensor-based, long-term monitoring performed on the cables?

\section{not performed}

Q4-27: Have the cables on this bridge (or any of their components) been repaired?

no

Q4-28: Has the sheathing been partially removed on any of the cables to examine condition of grout (if applicable) and/or the MTE?

no

Q4-29: Can the strands or cables be replaced if needed?

yes

Q4-30: Do you have an inspection and maintenance manual for this bridge?

yes

Q5: Based on your experience and in general, do you believe that the current inspection, testing, monitoring, and repair methods available to you for stay cables are effective and adequate?

not known, no previous experience with cablestayed structure

Q6: Please comment on the effectiveness of any non-destructive test methods for inspections of stay cables that you may be familiar with. These methods include (but are not limited to) ultrasonic testing, magnetic inspections, laser-based force measurements, $\mathrm{X}$-ray imaging, etc. If possible, please comment on issues such as practicality, cost, duration, impact on traffic, and any other factors that you consider important.

City inspection forces are neither qualified or equipped for non-destructive testing. Four single strands are to be removed (one at each pylon) for inspection for rust every 10 years starting in year 2014.

Q7: Please comment on the effectiveness of any cable vibration control measures that you may be familiar with. Examples include installation of cross cables, viscous dampers, neoprene rings, etc.

\section{no vibrations noted}

Q8: Please comment on the effectiveness of any sensor-based, long-term monitoring systems for stay cables that you may be familiar with. Examples include acoustic monitoring, vibration monitoring, force measurements, strain measurements, etc.

\section{not applicable}

Q9: What would you recommend that the cable suppliers incorporate into their systems to make cables more accessible and inspectable?

\section{no answer}

Q10: Do you believe that an up-to-date resource such as a national database of information on stay cable inspection methods, repairs, and testing would be a useful tool?
Questionnaire Results

Survey performed in 2004

yes

Q11: What do you see as the single most

important problem in stay cable maintenance?

Cannot inspect cables without pulling strand every 10 years.

Q12: Please comment on any other methods for inspections, testing, monitoring, and repair of stay cable (including conventional methods) that you have found beneficial and are not listed above.

Four strands (one at each pylon) will be removed every 10 years starting in 2014 to check for corrosion/rusting.

Additional comments? 


\section{NCHRP SYNTHESIS TOPIC 35-07-INSPECTION AND MAINTENANCE OF BRIDGE STAY CABLE SYSTEMS}

Prince's Island (Pedestrian)

Alberta/Calgary, Canada

\section{Prince's Island (Pedestrian)}

State/Province: Alberta/Calgary, Canada

Agency: $\quad$ City of Calgary

Respondent: Peter Wilson

Span Length: $\quad 220 \mathrm{ft}$

Year Built: $\quad 1972$

Q4-4: Type of main tension element (MTE)? steel wire

Q4-5: Coating/treatment on main tension element within free length of cable?

\section{galvanized steel}

Q4-6: Are the coatings/treatments on main tension element discontinued or removed within the anchorage zone?

\section{not known}

Q4-7: Type of grout used?

\section{grout not used}

Q4-8: Are filler materials used in the anchorage zone?

\section{no filler}

Q4-9: Type of anchorage?

conical socket with wedges

Q4-10: Do cables go over "saddles" on the pylons?

no
Q4-11: Type of cable sheathing used? no sheathing

Q4-12: Have rain-wind-induced cable vibrations been observed on this bridge?

yes

Q4-13: Have MTE corrosion problems been noted?

\section{not known}

Q4-14: Do cables have neoprene rings near the top and bottom anchorages?

no

Q4-15: If there are neoprene rings on the cables; have there been any reports of movements of the rings out of their positions?

\section{not applicable}

Q4-16: Has moisture been found in any of the internal components of stay cables such as the bottom anchorage areas?

\section{not tested}

Q4-17: Has fatigue of MTE or other components of stay cables been observed?

\section{not known}

Q4-18: Do the cables have viscous dampers installed at deck or tower levels?

no

Q4-19: Do the cables have cross cables installed between them?
Q4-20: Do cables have other dampers (other than viscous or neoprene rings) to control vibrations?

no

Q4-21: Has cracking of the cable sheathing or sheathing connections been noted?

\section{not applicable}

Q4-22: Has cracking or misalignment of the guide pipes been noted?

\section{not applicable}

Q4-23: If there is protective tape wrapped around the cable sheathing; have there been reports of deterioration of the tape?

\section{not applicable}

Q4-24: Have any problems associated with neoprene boots been noted?

\section{not known}

Q4-25: Types of non-destructive tests that any of the cables on this bridge have been subjected to?

\section{not performed}

Q4-26: Types of sensor-based, long-term monitoring performed on the cables?

\section{not performed}

Q4-27: Have the cables on this bridge (or any of their components) been repaired? 


\section{NCHRP SYNTHESIS TOPIC 35-07-INSPECTION AND MAINTENANCE OF BRIDGE STAY CABLE SYSTEMS}

Prince's Island (Pedestrian)

Alberta/Calgary, Canada

Q4-28: Has the sheathing been partially removed on any of the cables to examine condition of grout (if applicable) and/or the MTE?

\section{not applicable}

Q4-29: Can the strands or cables be replaced if needed?

no

Q4-30: Do you have an inspection and maintenance manual for this bridge?

no

Q5: Based on your experience and in general, do you believe that the current inspection, testing, monitoring, and repair methods available to you for stay cables are effective and adequate?

yes

Q6: Please comment on the effectiveness of any non-destructive test methods for inspections of stay cables that you may be familiar with. These methods include (but are not limited to) ultrasonic testing, magnetic inspections, laser-based force measurements, $\mathrm{X}$-ray imaging, etc. If possible, please comment on issues such as practicality, cost, duration, impact on traffic, and any other factors that you consider important.

\section{no answer}

Q7: Please comment on the effectiveness of any cable vibration control measures that you may be familiar with. Examples include installation of cross cables, viscous dampers, neoprene rings, etc.

The installation of cross cables has greatly reduced the cable vibration.

Q8: Please comment on the effectiveness of any sensor-based, long-term monitoring systems for stay cables that you may be familiar with. Examples include acoustic monitoring, vibration monitoring, force measurements, strain measurements, etc.

Have not used vibration monitoring on a longterm basis. Has only been used for short durations to determine frequency and magnitude, etc.

Q9: What would you recommend that the cable suppliers incorporate into their systems to make cables more accessible and inspectable?

\section{no answer}

Q10: Do you believe that an up-to-date resource such as a national database of information on stay cable inspection methods, repairs, and testing would be a useful tool?

yes

Q11: What do you see as the single most important problem in stay cable maintenance?

\section{Access for inspection and actual testing}

Q12: Please comment on any other methods for inspections, testing, monitoring, and repair of stay cable (including conventional methods) that you have found beneficial and are not listed above.
Questionnaire Results

Survey performed in 2004

\section{no answer}

Additional comments?

The five bridges identified are all pedestrian structures; three over water and two over roadways. 


\section{NCHRP SYNTHESIS TOPIC 35-07-INSPECTION AND MAINTENANCE OF BRIDGE STAY CABLE SYSTEMS}

Carburn Park (Pedestrian)

Alberta/Calgary, Canada

\section{Carburn Park (Pedestrian)}

State/Province: Alberta/Calgary, Canada

Agency: $\quad$ City of Calgary

Respondent: Peter Wilson

Span Length: $\quad 262 \mathrm{ft}$

Year Built: 1982

Q4-4: Type of main tension element (MTE)? steel bar or threadbar

Q4-5: Coating/treatment on main tension element within free length of cable?

Q4-6: Are the coatings/treatments on main tension element discontinued or removed within the anchorage zone?

\section{not known}

Q4-7: Type of grout used?

\section{grout not used}

Q4-8: Are filler materials used in the anchorage zone?

\section{no filler}

Q4-9: Type of anchorage?

other-threaded couplers

Q4-10: Do cables go over "saddles" on the pylons?

no

Q4-11: Type of cable sheathing used? no sheathing

Q4-12: Have rain-wind-induced cable vibrations been observed on this bridge?

\section{not known}

Q4-13: Have MTE corrosion problems been noted?

\section{not known}

Q4-14: Do cables have neoprene rings near the top and bottom anchorages?

no

Q4-15: If there are neoprene rings on the cables; have there been any reports of movements of the rings out of their positions?

\section{not applicable}

Q4-16: Has moisture been found in any of the internal components of stay cables such as the bottom anchorage areas?

\section{not tested}

Q4-17: Has fatigue of MTE or other components of stay cables been observed? no

Q4-18: Do the cables have viscous dampers installed at deck or tower levels?

no

Q4-19: Do the cables have cross cables installed between them?
Q4-20: Do cables have other dampers (other than viscous or neoprene rings) to control vibrations?

no

Q4-21: Has cracking of the cable sheathing or sheathing connections been noted?

\section{not applicable}

Q4-22: Has cracking or misalignment of the guide pipes been noted?

\section{not applicable}

Q4-23: If there is protective tape wrapped around the cable sheathing; have there been reports of deterioration of the tape?

\section{not applicable}

Q4-24: Have any problems associated with neoprene boots been noted?

\section{not known}

Q4-25: Types of non-destructive tests that any of the cables on this bridge have been subjected to?

\section{not performed}

Q4-26: Types of sensor-based, long-term monitoring performed on the cables?

\section{not performed}

Q4-27: Have the cables on this bridge (or any of their components) been repaired? 
Q4-28: Has the sheathing been partially removed on any of the cables to examine condition of grout (if applicable) and/or the MTE?

\section{not applicable}

Q4-29: Can the strands or cables be replaced if needed?

yes

Q4-30: Do you have an inspection and maintenance manual for this bridge?

\section{no}

Q5: Based on your experience and in general, do you believe that the current inspection, testing, monitoring, and repair methods available to you for stay cables are effective and adequate?

yes

Q6: Please comment on the effectiveness of any non-destructive test methods for inspections of stay cables that you may be familiar with. These methods include (but are not limited to) ultrasonic testing, magnetic inspections, laser-based force measurements, $\mathrm{X}$-ray imaging, etc. If possible, please comment on issues such as practicality, cost, duration, impact on traffic, and any other factors that you consider important.

\section{no answer}

Q7: Please comment on the effectiveness of any cable vibration control measures that you may be familiar with. Examples include installation of cross cables, viscous dampers, neoprene rings, etc.

The installation of cross cables has greatly reduced the cable vibration.

Q8: Please comment on the effectiveness of any sensor-based, long-term monitoring systems for stay cables that you may be familiar with. Examples include acoustic monitoring, vibration monitoring, force measurements, strain measurements, etc.

Have not used vibration monitoring on a longterm basis. Has only been used for short durations to determine frequency and magnitude, etc.

Q9: What would you recommend that the cable suppliers incorporate into their systems to make cables more accessible and inspectable?

\section{no answer}

Q10: Do you believe that an up-to-date resource such as a national database of information on stay cable inspection methods, repairs, and testing would be a useful tool?

yes

Q11: What do you see as the single most important problem in stay cable maintenance?

\section{Access for inspection and actual testing}

Q12: Please comment on any other methods for inspections, testing, monitoring, and repair of stay cable (including conventional methods) that you have found beneficial and are not listed above.

\section{no answer}

Additional comments?

The five bridges identified are all pedestrian structures; three over water and two over roadways. 


\section{NCHRP SYNTHESIS TOPIC 35-07-INSPECTION AND MAINTENANCE OF BRIDGE STAY CABLE SYSTEMS}

McMahon (Pedestrian) Alberta/Calgary, Canada

\section{McMahon (Pedestrian)}

$\begin{array}{ll}\text { State/Province: } & \text { Alberta/Calgary, Canada } \\ \text { Agency: } & \text { City of Calgary } \\ \text { Respondent: } & \text { Peter Wilson } \\ \text { Span Length: } & \mathbf{1 5 4} \mathrm{ft} \\ \text { Year Built: } & \mathbf{1 9 8 7}\end{array}$

Q4-4: Type of main tension element (MTE)? steel bar or threadbar

Q4-5: Coating/treatment on main tension element within free length of cable?

\section{galvanized steel}

Q4-6: Are the coatings/treatments on main tension element discontinued or removed within the anchorage zone?

\section{no}

Q4-7: Type of grout used?

\section{grout not used}

Q4-8: Are filler materials used in the anchorage zone?

\section{no filler}

Q4-9: Type of anchorage?

other, threaded coupler

Q4-10: Do cables go over "saddles" on the pylons?

no
Q4-11: Type of cable sheathing used? no sheathing

Q4-12: Have rain-wind-induced cable vibrations been observed on this bridge?

no

Q4-13: Have MTE corrosion problems been noted?

\section{not known}

Q4-14: Do cables have neoprene rings near the top and bottom anchorages?

no

Q4-15: If there are neoprene rings on the cables; have there been any reports of movements of the rings out of their positions?

\section{not applicable}

Q4-16: Has moisture been found in any of the internal components of stay cables such as the bottom anchorage areas?

\section{not tested}

Q4-17: Has fatigue of MTE or other components of stay cables been observed? no

Q4-18: Do the cables have viscous dampers installed at deck or tower levels?

no

Q4-19: Do the cables have cross cables installed between them?

yes, from the beginning
Q4-20: Do cables have other dampers (other than viscous or neoprene rings) to control vibrations?

no

Q4-21: Has cracking of the cable sheathing or sheathing connections been noted?

\section{not applicable}

Q4-22: Has cracking or misalignment of the guide pipes been noted?

\section{not applicable}

Q4-23: If there is protective tape wrapped around the cable sheathing; have there been reports of deterioration of the tape?

\section{not applicable}

Q4-24: Have any problems associated with neoprene boots been noted?

\section{not known}

Q4-25: Types of non-destructive tests that any of the cables on this bridge have been subjected to?

\section{not performed}

Q4-26: Types of sensor-based, long-term monitoring performed on the cables?

\section{not performed}

Q4-27: Have the cables on this bridge (or any of their components) been repaired? 
Q4-28: Has the sheathing been partially removed on any of the cables to examine condition of grout (if applicable) and/or the MTE?

\section{not applicable}

Q4-29: Can the strands or cables be replaced if needed?

yes

Q4-30: Do you have an inspection and maintenance manual for this bridge?

no

Q5: Based on your experience and in general, do you believe that the current inspection, testing, monitoring, and repair methods available to you for stay cables are effective and adequate?

yes

Q6: Please comment on the effectiveness of any non-destructive test methods for inspections of stay cables that you may be familiar with. These methods include (but are not limited to) ultrasonic testing, magnetic inspections, laser-based force measurements, $\mathrm{X}$-ray imaging, etc. If possible, please comment on issues such as practicality, cost, duration, impact on traffic, and any other factors that you consider important.

\section{no answer}

Q7: Please comment on the effectiveness of any cable vibration control measures that you may be familiar with. Examples include installation of cross cables, viscous dampers, neoprene rings, etc.

The installation of cross cables has greatly reduced the cable vibration.

Q8: Please comment on the effectiveness of any sensor-based, long-term monitoring systems for stay cables that you may be familiar with. Examples include acoustic monitoring, vibration monitoring, force measurements, strain measurements, etc.

Have not used vibration monitoring on a longterm basis. Has only been used for short

durations to determine frequency and magnitude, etc.

Q9: What would you recommend that the cable suppliers incorporate into their systems to make cables more accessible and inspectable?

\section{no answer}

Q10: Do you believe that an up-to-date resource such as a national database of information on stay cable inspection methods, repairs, and testing would be a useful tool?

yes

Q11: What do you see as the single most important problem in stay cable maintenance?

\section{Access for inspection and actual testing}

Q12: Please comment on any other methods for inspections, testing, monitoring, and repair of stay cable (including conventional methods) that you have found beneficial and are not listed above.

\section{no answer}

Additional comments?

The five bridges identified are all pedestrian structures; three over water and two over roadways. 


\section{NCHRP SYNTHESIS TOPIC 35-07-INSPECTION AND MAINTENANCE OF BRIDGE STAY CABLE SYSTEMS}

Fox Hollow (Pedestrian)

Alberta/Calgary, Canada

\section{Fox Hollow (Pedestrian)}

State/Province: Alberta/Calgary, Canada

Agency: $\quad$ City of Calgary

Respondent: Peter Wilson

Span Length: $\quad \mathbf{1 4 8} \mathrm{ft}$

Year Built: 1996

Q4-4: Type of main tension element (MTE)? steel bar or threadbar

Q4-5: Coating/treatment on main tension element within free length of cable?

\section{galvanized steel}

Q4-6: Are the coatings/treatments on main tension element discontinued or removed within the anchorage zone?

\section{no}

Q4-7: Type of grout used?

grout not used

Q4-8: Are filler materials used in the anchorage zone?

\section{no filler}

Q4-9: Type of anchorage?

other, threaded coupler

Q4-10: Do cables go over "saddles" on the pylons?

no
Q4-11: Type of cable sheathing used? no sheathing

Q4-12: Have rain-wind-induced cable vibrations been observed on this bridge?

yes

Q4-13: Have MTE corrosion problems been noted?

yes

Q4-14: Do cables have neoprene rings near the top and bottom anchorages?

no

Q4-15: If there are neoprene rings on the cables; have there been any reports of movements of the rings out of their positions?

\section{not applicable}

Q4-16: Has moisture been found in any of the internal components of stay cables such as the bottom anchorage areas?

no

Q4-17: Has fatigue of MTE or other components of stay cables been observed?

yes

Q4-18: Do the cables have viscous dampers installed at deck or tower levels?

no

Q4-19: Do the cables have cross cables installed between them?

yes, retrofitted to correct vibrations
Q4-20: Do cables have other dampers (other than viscous or neoprene rings) to control vibrations?

no

Q4-21: Has cracking of the cable sheathing or sheathing connections been noted?

\section{not applicable}

Q4-22: Has cracking or misalignment of the guide pipes been noted?

\section{not applicable}

Q4-23: If there is protective tape wrapped around the cable sheathing; have there been reports of deterioration of the tape?

\section{not applicable}

Q4-24: Have any problems associated with neoprene boots been noted?

\section{no}

Q4-25: Types of non-destructive tests that any of the cables on this bridge have been subjected to?

magnetic, ultrasonic, and vibration-based force measurements

Q4-26: Types of sensor-based, long-term monitoring performed on the cables?

\section{not performed}

Q4-27: Have the cables on this bridge (or any of their components) been repaired?

yes-Two bars failed and were replaced. One additional bar replaced due to corrosion. 
Q4-28: Has the sheathing been partially removed on any of the cables to examine condition of grout (if applicable) and/or the MTE?

\section{not applicable}

Q4-29: Can the strands or cables be replaced if needed?

yes

Q4-30: Do you have an inspection and maintenance manual for this bridge?

no

Q5: Based on your experience and in general, do you believe that the current inspection, testing, monitoring, and repair methods available to you for stay cables are effective and adequate?

yes

Q6: Please comment on the effectiveness of any non-destructive test methods for inspections of stay cables that you may be familiar with. These methods include (but are not limited to) ultrasonic testing, magnetic inspections, laser-based force measurements, $\mathrm{X}$-ray imaging, etc. If possible, please comment on issues such as practicality, cost, duration, impact on traffic, and any other factors that you consider important.

\section{no answer}

Q7: Please comment on the effectiveness of any cable vibration control measures that you may be familiar with. Examples include installation of cross cables, viscous dampers, neoprene rings, etc.

The installation of cross cables has greatly reduced the cable vibration.

Q8: Please comment on the effectiveness of any sensor-based, long-term monitoring systems for stay cables that you may be familiar with. Examples include acoustic monitoring, vibration monitoring, force measurements, strain measurements, etc.

Have not used vibration monitoring on a longterm basis. Has only been used for short

durations to determine frequency and magnitude, etc.

Q9: What would you recommend that the cable suppliers incorporate into their systems to make cables more accessible and inspectable?

\section{no answer}

Q10: Do you believe that an up-to-date resource such as a national database of information on stay cable inspection methods, repairs, and testing would be a useful tool?

yes

Q11: What do you see as the single most important problem in stay cable maintenance?

\section{Access for inspection and actual testing}

Q12: Please comment on any other methods for inspections, testing, monitoring, and repair of stay cable (including conventional methods) that you have found beneficial and are not listed above.

\section{no answer}

Additional comments?

The five bridges identified are all pedestrian structures; three over water and two over roadways. 


\section{NCHRP SYNTHESIS TOPIC 35-07-INSPECTION AND MAINTENANCE OF BRIDGE STAY CABLE SYSTEMS}

Stoney Trail (Pedestrian)

Alberta/Calgary, Canada

\section{Stoney Trail (Pedestrian)}

State/Province: Alberta/Calgary, Canada

Agency: $\quad$ City of Calgary

Respondent: Peter Wilson

Span Length: $\quad 335 \mathrm{ft}$

Year Built: 1998

Q4-4: Type of main tension element (MTE)? steel bar or threadbar

Q4-5: Coating/treatment on main tension element within free length of cable?

\section{galvanized steel}

Q4-6: Are the coatings/treatments on main tension element discontinued or removed within the anchorage zone?

\section{no}

Q4-7: Type of grout used?

grout not used

Q4-8: Are filler materials used in the anchorage zone?

\section{no filler}

Q4-9: Type of anchorage?

other, threaded couplers/nuts

Q4-10: Do cables go over "saddles" on the pylons?

no
Q4-11: Type of cable sheathing used? no sheathing

Q4-12: Have rain-wind-induced cable vibrations been observed on this bridge?

\section{not known}

Q4-13: Have MTE corrosion problems been noted?

no

Q4-14: Do cables have neoprene rings near the top and bottom anchorages?

no

Q4-15: If there are neoprene rings on the cables; have there been any reports of movements of the rings out of their positions?

\section{not applicable}

Q4-16: Has moisture been found in any of the internal components of stay cables such as the bottom anchorage areas?

no

Q4-17: Has fatigue of MTE or other components of stay cables been observed? no

Q4-18: Do the cables have viscous dampers installed at deck or tower levels?

no

Q4-19: Do the cables have cross cables installed between them?

yes, from the beginning
Q4-20: Do cables have other dampers (other than viscous or neoprene rings) to control vibrations?

no

Q4-21: Has cracking of the cable sheathing or sheathing connections been noted?

no

Q4-22: Has cracking or misalignment of the guide pipes been noted?

no

Q4-23: If there is protective tape wrapped around the cable sheathing; have there been reports of deterioration of the tape?

\section{not known}

Q4-24: Have any problems associated with neoprene boots been noted?

\section{no}

Q4-25: Types of non-destructive tests that any of the cables on this bridge have been subjected to?

\section{not performed}

Q4-26: Types of sensor-based, long-term monitoring performed on the cables?

\section{not performed}

Q4-27: Have the cables on this bridge (or any of their components) been repaired?

no 
Q4-28: Has the sheathing been partially removed on any of the cables to examine condition of grout (if applicable) and/or the MTE?

no

Q4-29: Can the strands or cables be replaced if needed?

yes

Q4-30: Do you have an inspection and maintenance manual for this bridge?

no

Q5: Based on your experience and in general, do you believe that the current inspection, testing, monitoring, and repair methods available to you for stay cables are effective and adequate?

yes

Q6: Please comment on the effectiveness of any non-destructive test methods for inspections of stay cables that you may be familiar with. These methods include (but are not limited to) ultrasonic testing, magnetic inspections, laser-based force measurements, $\mathrm{X}$-ray imaging, etc. If possible, please comment on issues such as practicality, cost, duration, impact on traffic, and any other factors that you consider important.

\section{no answer}

Q7: Please comment on the effectiveness of any cable vibration control measures that you may be familiar with. Examples include installation of cross cables, viscous dampers, neoprene rings, etc.

The installation of cross cables has greatly reduced the cable vibration.

Q8: Please comment on the effectiveness of any sensor-based, long-term monitoring systems for stay cables that you may be familiar with. Examples include acoustic monitoring, vibration monitoring, force measurements, strain measurements, etc.

Have not used vibration monitoring on a longterm basis. Has only been used for short

durations to determine frequency and magnitude, etc.

Q9: What would you recommend that the cable suppliers incorporate into their systems to make cables more accessible and inspectable?

\section{no answer}

Q10: Do you believe that an up-to-date resource such as a national database of information on stay cable inspection methods, repairs, and testing would be a useful tool?

yes

Q11: What do you see as the single most important problem in stay cable maintenance?

\section{Access for inspection and actual testing}

Q12: Please comment on any other methods for inspections, testing, monitoring, and repair of stay cable (including conventional methods) that you have found beneficial and are not listed above.

\section{no answer}

Additional comments?

The five bridges identified are all pedestrian structures; three over water and two over roadways. 


\section{NCHRP SYNTHESIS TOPIC 35-07-INSPECTION AND MAINTENANCE OF BRIDGE STAY CABLE SYSTEMS}

Alex Fraser Bridge

British Columbia

Questionnaire Results

Survey performed in 2004

\section{Alex Fraser Bridge}

State/Province: British Columbia

Agency: $\quad$ Ministry of Transportation

Respondent: Kevin Baskin

Span Length: $\quad \mathbf{1 , 5 2 6} f t$

Year Built: $\quad 1986$

Q4-4: Type of main tension element (MTE)?

other-7.1 $\mathrm{mm}$ diameter galvanized wire to ASTM A586; ultimate strength $=1520 \mathrm{MPa}$; long lay strand assemblies with 109 to 283 wires per assembly.

Q4-5: Coating/treatment on main tension element within free length of cable?

greased-and-sheathed-galvanized; galvanized wire cable jacketed in polyethylene tube and filled with petroleum wax blocking compound.

Q4-6: Are the coatings/treatments on main tension element discontinued or removed within the anchorage zone?

yes-zinc-filled cast steel socket at end, grease discontinued in anchorages

Q4-7: Type of grout used?

grout not used

Q4-8: Are filler materials used in the anchorage zone?

yes, other-cast steel socket anchorage is filled with zinc.

\section{Q4-9: Type of anchorage?}

zinc-filled cast steel socket

Q4-10: Do cables go over "saddles" on the pylons?

no

Q4-11: Type of cable sheathing used?

\section{$U V$-resistant HDPE}

Q4-12: Have rain-wind-induced cable vibrations been observed on this bridge?

yes

Q4-13: Have MTE corrosion problems been noted?

no

Q4-14: Do cables have neoprene rings near the top and bottom anchorages?

yes

Q4-15: If there are neoprene rings on the cables; have there been any reports of movements of the rings out of their positions?

\section{yes-due to other reasons}

Q4-16: Has moisture been found in any of the internal components of stay cables such as the bottom anchorage areas?

no

Q4-17: Has fatigue of MTE or other components of stay cables been observed?
Q4-18: Do the cables have viscous dampers installed at deck or tower levels?

no

Q4-19: Do the cables have cross cables installed between them?

\section{no}

Q4-20: Do cables have other dampers (other than viscous or neoprene rings) to control vibrations?

no

Q4-21: Has cracking of the cable sheathing or sheathing connections been noted?

\section{no}

Q4-22: Has cracking or misalignment of the guide pipes been noted?

\section{not applicable}

Q4-23: If there is protective tape wrapped around the cable sheathing; have there been reports of deterioration of the tape?

not applicable-repairs used protective tape, no deterioration observed

Q4-24: Have any problems associated with neoprene boots been noted?

yes, shifting and splitting

Q4-25: Types of non-destructive tests that any of the cables on this bridge have been subjected to?

not performed 


\section{NCHRP SYNTHESIS TOPIC 35-07-INSPECTION AND MAINTENANCE OF BRIDGE STAY CABLE SYSTEMS}

Alex Fraser Bridge

British Columbia

Q4-26: Types of sensor-based, long-term monitoring performed on the cables?

Acoustic wire break detection-performed short term, now discontinued.

Q4-27: Have the cables on this bridge (or any of their components) been repaired?

\section{yes-boots replaced or repaired, sheaths} repaired.

Q4-28: Has the sheathing been partially removed on any of the cables to examine condition of grout (if applicable) and/or the MTE?

no

Q4-29: Can the strands or cables be replaced if needed?

yes

Q4-30: Do you have an inspection and maintenance manual for this bridge?

yes

Q5: Based on your experience and in general, do you believe that the current inspection,

testing, monitoring, and repair methods available to you for stay cables are effective and adequate?

yes

Q6: Please comment on the effectiveness of any non-destructive test methods for inspections of stay cables that you may be familiar with. These methods include (but are not limited to) ultrasonic testing, magnetic inspections, laser-based force measurements,
X-ray imaging, etc. If possible, please comment on issues such as practicality, cost, duration, impact on traffic, and any other

factors that you consider important.

\section{not used}

Q7: Please comment on the effectiveness of any cable vibration control measures that you may be familiar with. Examples include installation of cross cables, viscous dampers, neoprene rings, etc.

Neoprene ring dampers alone do not prevent cable vibration.

Q8: Please comment on the effectiveness of any sensor-based, long-term monitoring systems for stay cables that you may be familiar with. Examples include acoustic monitoring, vibration monitoring, force measurements, strain measurements, etc.

Acoustic monitoring may be cost-effective for older structures. For new structures, cost of monitoring outweighs benefits, and may be compromised by other noise (rehab, banging etc.) on the structure.

Q9: What would you recommend that the cable suppliers incorporate into their systems to make cables more accessible and inspectable?

Our cables are reasonably accessible, inspectable. Possibly a closeable drain at the lower end of the cable to allow visual inspection, sample collection, testing for corrosion product of any water in the cable sheaths.
Questionnaire Results

Survey performed in 2004
Q10: Do you believe that an up-to-date resource such as a national database of information on stay cable inspection methods, repairs, and testing would be a useful tool? yes

Q11: What do you see as the single most important problem in stay cable maintenance?

detecting corrosion in cables, maintenance of sheaths and boots

Q12: Please comment on any other methods for inspections, testing, monitoring, and repair of stay cable (including conventional methods) that you have found beneficial and are not listed above.

no comment.

Additional comments?

Have had leakage of wax blocking compound at bottom anchorages during hot weather. 


\section{NCHRP SYNTHESIS TOPIC 35-07-INSPECTION AND MAINTENANCE OF BRIDGE STAY CABLE SYSTEMS}

Esplanade Riel

Manitoba/Winnipeg, Canada

Questionnaire Results

Survey performed in 2004

\section{Esplanade Riel}

State/Province: Manitoba/Winnipeg,

\section{Canada}

Agency: City of Winnipeg Public Works Department

Respondent: $\quad$ Brad Neirinck

Span Length: $\quad 348 f t$

Year Built: 2003

Q4-4: Type of main tension element (MTE)? seven-wire steel strand

Q4-5: Coating/treatment on main tension element within free length of cable?

galvanized steel, further coated with highdensity polyethylene

Q4-6: Are the coatings/treatments on main tension element discontinued or removed within the anchorage zone?

\section{yes, HDPE coating is removed}

Q4-7: Type of grout used?

grout not used

Q4-8: Are filler materials used in the anchorage zone?

yes, other-epoxy filler

Q4-9: Type of anchorage?

conical socket with wedges

Q4-10: Do cables go over "saddles" on the pylons? no

Q4-11: Type of cable sheathing used? $U V$-resistant HDPE with spiral on surface

Q4-12: Have rain-wind-induced cable vibrations been observed on this bridge? no

Q4-13: Have MTE corrosion problems been noted?

no

Q4-14: Do cables have neoprene rings near the top and bottom anchorages?

yes, these provide damping

Q4-15: If there are neoprene rings on the cables; have there been any reports of movements of the rings out of their positions?

no, not known

Q4-16: Has moisture been found in any of the internal components of stay cables such as the bottom anchorage areas?

no

Q4-17: Has fatigue of MTE or other components of stay cables been observed?

no

Q4-18: Do the cables have viscous dampers installed at deck or tower levels?

\section{no-damping via neoprene rings}

Q4-19: Do the cables have cross cables installed between them? no

Q4-20: Do cables have other dampers (other than viscous or neoprene rings) to control vibrations?

no

Q4-21: Has cracking of the cable sheathing or sheathing connections been noted?

no

Q4-22: Has cracking or misalignment of the guide pipes been noted?

no

Q4-23: If there is protective tape wrapped around the cable sheathing; have there been reports of deterioration of the tape?

not applicable

Q4-24: Have any problems associated with neoprene boots been noted?

no

Q4-25: Types of non-destructive tests that any of the cables on this bridge have been subjected to?

Not performed. Vibration-based force measurements on selected MTE will be performed and continuously monitored using a permanent $\mathrm{SHM}$ system.

Q4-26: Types of sensor-based, long-term monitoring performed on the cables?

vibration monitoring 


\section{NCHRP SYNTHESIS TOPIC 35-07-INSPECTION AND MAINTENANCE OF BRIDGE STAY CABLE SYSTEMS}

Esplanade Riel

Questionnaire Results

Manitoba/Winnipeg, Canada

Survey performed in 2004

Q4-27: Have the cables on this bridge (or any of their components) been repaired?

yes-extensions to permit additional thermal contraction capability of the HDPE sheathing installed. Warranty covered this.

Q4-28: Has the sheathing been partially removed on any of the cables to examine condition of grout (if applicable) and/or the MTE?

no

Q4-29: Can the strands or cables be replaced if needed?

yes

Q4-30: Do you have an inspection and maintenance manual for this bridge?

no-since this is a new bridge this should be an upcoming deliverable from our consultant.

Q5: Based on your experience and in general, do you believe that the current inspection, testing, monitoring, and repair methods available to you for stay cables are effective and adequate?

Not known. We require training and awareness in the near future to properly maintain the one new bridge we have.

Q6: Please comment on the effectiveness of any non-destructive test methods for inspections of stay cables that you may be familiar with. These methods include (but are not limited to) ultrasonic testing, magnetic inspections, laser-based force measurements, $\mathrm{X}$-ray imaging, etc. If possible, please comment on issues such as practicality, cost, duration, impact on traffic, and any other factors that you consider important.

\section{We do not yet have enough experience to} respond to this question at this time. We are aware of all the techniques you mention above. Force measurements on selected MTE will be performed as part of the SHM system with the use of uniaxial accelerometers to determine frequency of the cable and relate back to force.

Q7: Please comment on the effectiveness of any cable vibration control measures that you may be familiar with. Examples include installation of cross cables, viscous dampers, neoprene rings, etc.

\section{We have yet to pass judgment on the} effectiveness of the control measures. We specified the requirement for damping at the anchorages. The supplier choose to do this via neoprene rings.

Q8: Please comment on the effectiveness of any sensor-based, long-term monitoring systems for stay cables that you may be familiar with. Examples include acoustic monitoring, vibration monitoring, force measurements, strain measurements, etc.

Not enough experience to comment at this time.

Q9: What would you recommend that the cable suppliers incorporate into their systems to make cables more accessible and inspectable?
Different corrosion protection system at the anchorages that permits easier visual inspection. Removable sections of the HDPE and Vandal Tubes would make it easier to inspect strands near the anchorages.

Q10: Do you believe that an up-to-date resource such as a national database of information on stay cable inspection methods, repairs, and testing would be a useful tool? yes

Q11: What do you see as the single most important problem in stay cable maintenance? corrosion at the anchorages

Q12: Please comment on any other methods for inspections, testing, monitoring, and repair of stay cable (including conventional methods) that you have found beneficial and are not listed above.

no answer

Additional comments? 


\section{NCHRP SYNTHESIS TOPIC 35-07-INSPECTION AND MAINTENANCE OF BRIDGE STAY CABLE SYSTEMS}

Hawkshaw

New Brunswick, Canada

Questionnaire Results

Survey performed in 2004

\section{Hawkshaw}

State/Province: New Brunswick, Canada

Agency: $\quad$ New Brunswick Department of Transportation

Respondent: $\quad$ Ronald H. Joyce

Span Length: $\quad \mathbf{7 1 3 . 3 2} \mathrm{ft}$

Year Built: $\quad 1967$

Q4-4: Type of main tension element (MTE)?

steel wire-2-3/8-in. diameter galvanized steel cables. Located near Nackawic NB over the Saint John River between Rte 2 and Rte 105

Q4-5: Coating/treatment on main tension element within free length of cable?

galvanized steel-cables are wrapped $5 \mathrm{ft}$ above deck with galvanized wire; also in this area they are coated with Denso Paste and tape

Q4-6: Are the coatings/treatments on main tension element discontinued or removed within the anchorage zone?

\section{no}

Q4-7: Type of grout used?

grout not used

Q4-8: Are filler materials used in the anchorage zone?

no filler
Q4-9: Type of anchorage?

other-2-3/8-in. forged open strand socket

Q4-10: Do cables go over "saddles" on the pylons?

\section{no-pin connections at top of pylon}

Q4-11: Type of cable sheathing used? no sheathing

Q4-12: Have rain-wind-induced cable vibrations been observed on this bridge?

yes

Q4-13: Have MTE corrosion problems been noted?

no

Q4-14: Do cables have neoprene rings near the top and bottom anchorages?

no

Q4-15: If there are neoprene rings on the cables; have there been any reports of movements of the rings out of their positions?

\section{not applicable}

Q4-16: Has moisture been found in any of the internal components of stay cables such as the bottom anchorage areas?

\section{not tested}

Q4-17: Has fatigue of MTE or other components of stay cables been observed?
Q4-18: Do the cables have viscous dampers installed at deck or tower levels?

yes-retrofitted to correct vibrations; wood clamps placed at 1/3 points of the six cables

Q4-19: Do the cables have cross cables installed between them?

no

Q4-20: Do cables have other dampers (other than viscous or neoprene rings) to control vibrations?

\section{yes-other dampers, wood clamps}

Q4-21: Has cracking of the cable sheathing or sheathing connections been noted?

\section{not applicable}

Q4-22: Has cracking or misalignment of the guide pipes been noted?

\section{not applicable}

Q4-23: If there is protective tape wrapped around the cable sheathing; have there been reports of deterioration of the tape?

no

Q4-24: Have any problems associated with neoprene boots been noted?

\section{no answer}

Q4-25: Types of non-destructive tests that any of the cables on this bridge have been subjected to?

not performed 
Q4-26: Types of sensor-based, long-term monitoring performed on the cables?

\section{not performed}

Q4-27: Have the cables on this bridge (or any of their components) been repaired?

no

Q4-28: Has the sheathing been partially removed on any of the cables to examine condition of grout (if applicable) and/or the MTE?

\section{not applicable}

Q4-29: Can the strands or cables be replaced if needed?

\section{not known}

Q4-30: Do you have an inspection and maintenance manual for this bridge?

\section{no}

Q5: Based on your experience and in general, do you believe that the current inspection, testing, monitoring, and repair methods available to you for stay cables are effective and adequate?

yes

Q6: Please comment on the effectiveness of any non-destructive test methods for inspections of stay cables that you may be familiar with. These methods include (but are not limited to) ultrasonic testing, magnetic inspections, laser-based force measurements, $\mathrm{X}$-ray imaging, etc. If possible, please comment on issues such as practicality, cost, duration, impact on traffic, and any other factors that you consider important.

None of this testing done on any of the three structures; probably there would be a significant cost to do these tests.

Q7: Please comment on the effectiveness of any cable vibration control measures that you may be familiar with. Examples include installation of cross cables, viscous dampers, neoprene rings, etc.

\section{See comments for Question 4-12.}

Q8: Please comment on the effectiveness of any sensor-based, long-term monitoring systems for stay cables that you may be familiar with. Examples include acoustic monitoring, vibration monitoring, force measurements, strain measurements, etc.

\section{Monitoring of deflection of bridge by student} at Nackawic.

Q9: What would you recommend that the cable suppliers incorporate into their systems to make cables more accessible and inspectable?

\section{no answer}

Q10: Do you believe that an up-to-date resource such as a national database of information on stay cable inspection methods, repairs, and testing would be a useful tool?

yes

Q11: What do you see as the single most important problem in stay cable maintenance?

Migration of water into cable strands.
Q12: Please comment on any other methods for inspections, testing, monitoring, and repair of stay cable (including conventional methods) that you have found beneficial and are not listed above.

\section{no answer}

Additional comments? 


\section{NCHRP SYNTHESIS TOPIC 35-07-INSPECTION AND MAINTENANCE OF BRIDGE STAY CABLE SYSTEMS}

Longs Creek \#1

New Brunswick, Canada

\section{Longs Creek \#1}

State/Province: New Brunswick, Canada

Agency: $\quad$ New Brunswick Department of Transportation

Respondent: $\quad$ Ronald H. Joyce

Span Length: $\quad 713.32 \mathrm{ft}$

Year Built: 1966

Q4-4: Type of main tension element (MTE)?

No answer-located on Rte 102 west of Fredricton, $N B$

Q4-5: Coating/treatment on main tension element within free length of cable?

\section{galvanized steel}

Q4-6: Are the coatings/treatments on main tension element discontinued or removed within the anchorage zone?

\section{no}

Q4-7: Type of grout used?

grout not used

Q4-8: Are filler materials used in the anchorage zone?

\section{no filler}

Q4-9: Type of anchorage?

\section{other}

Q4-10: Do cables go over "saddles" on the pylons? no

Q4-11: Type of cable sheathing used? no sheathing

Q4-12: Have rain-wind-induced cable vibrations been observed on this bridge? yes

Q4-13: Have MTE corrosion problems been noted?

no

Q4-14: Do cables have neoprene rings near the top and bottom anchorages?

no

Q4-15: If there are neoprene rings on the cables; have there been any reports of movements of the rings out of their positions?

\section{not applicable}

Q4-16: Has moisture been found in any of the internal components of stay cables such as the bottom anchorage areas?

\section{not tested}

Q4-17: Has fatigue of MTE or other components of stay cables been observed?

no

Q4-18: Do the cables have viscous dampers installed at deck or tower levels?

\section{yes, retrofitted to correct vibrations}

Q4-19: Do the cables have cross cables installed between them?
Questionnaire Results

Survey performed in 2004

no

Q4-20: Do cables have other dampers (other than viscous or neoprene rings) to control vibrations?

yes, other dampers

Q4-21: Has cracking of the cable sheathing or sheathing connections been noted?

\section{not applicable}

Q4-22: Has cracking or misalignment of the guide pipes been noted?

\section{not applicable}

Q4-23: If there is protective tape wrapped around the cable sheathing; have there been reports of deterioration of the tape?

\section{yes, minor damage}

Q4-24: Have any problems associated with neoprene boots been noted?

Q4-25: Types of non-destructive tests that any of the cables on this bridge have been subjected to?

\section{not performed}

Q4-26: Types of sensor-based, long-term monitoring performed on the cables?

\section{not performed}

Q4-27: Have the cables on this bridge (or any of their components) been repaired? 


\section{NCHRP SYNTHESIS TOPIC 35-07-INSPECTION AND MAINTENANCE OF BRIDGE STAY CABLE SYSTEMS}

Longs Creek \#1

New Brunswick, Canada

Questionnaire Results

Survey performed in 2004

Q4-28: Has the sheathing been partially removed on any of the cables to examine condition of grout (if applicable) and/or the MTE?

\section{not applicable}

Q4-29: Can the strands or cables be replaced if needed?

\section{not known}

Q4-30: Do you have an inspection and maintenance manual for this bridge?

no

Q5: Based on your experience and in general, do you believe that the current inspection, testing, monitoring, and repair methods available to you for stay cables are effective and adequate?

yes

Q6: Please comment on the effectiveness of any non-destructive test methods for inspections of stay cables that you may be familiar with. These methods include (but are not limited to) ultrasonic testing, magnetic inspections, laser-based force measurements, $\mathrm{X}$-ray imaging, etc. If possible, please comment on issues such as practicality, cost, duration, impact on traffic, and any other factors that you consider important.

None of this testing done on any of the three structures; probably there would be a significant cost to do these tests.

Q7: Please comment on the effectiveness of any cable vibration control measures that you

may be familiar with. Examples include installation of cross cables, viscous dampers, neoprene rings, etc.

\section{See comments for Question 4-12.}

Q8: Please comment on the effectiveness of any sensor-based, long-term monitoring systems for stay cables that you may be familiar with. Examples include acoustic monitoring, vibration monitoring, force measurements, strain measurements, etc.

Monitoring of deflection of bridge by student at Nackawic.

Q9: What would you recommend that the cable suppliers incorporate into their systems to make cables more accessible and inspectable?

\section{no answer}

Q10: Do you believe that an up-to-date resource such as a national database of information on stay cable inspection methods, repairs, and testing would be a useful tool? yes

Q11: What do you see as the single most important problem in stay cable maintenance?

\section{Migration of water into cable strands.}

Q12: Please comment on any other methods for inspections, testing, monitoring, and repair of stay cable (including conventional methods) that you have found beneficial and are not listed above.

\section{no answer}

Additional comments?
Paper to be given in Japan I believe in 2004 by an engineer who worked for the National Research Council on the deflections of the Longs Creek Bridge caused by wind and the methods used to greatly reduce this problem. 


\section{NCHRP SYNTHESIS TOPIC 35-07-INSPECTION AND MAINTENANCE OF BRIDGE STAY CABLE SYSTEMS}

Nackawic River

New Brunswick, Canada

\section{Nackawic River}

State/Province: New Brunswick, Canada

Agency: $\quad$ New Brunswick Department of Transportation

Respondent: $\quad$ Ronald H. Joyce

Span Length: $\quad 216.01 \mathrm{ft}$

Year Built: $\quad 1967$

Q4-4: Type of main tension element (MTE)?

Located on Rte. 105 in the town of Nackawic

Q4-5: Coating/treatment on main tension

\section{galvanized steel}

Q4-6: Are the coatings/treatments on main tension element discontinued or removed within the anchorage zone?

no

Q4-7: Type of grout used?

grout not used

Q4-8: Are filler materials used in the anchorage zone?

\section{no filler}

Q4-9: Type of anchorage?

\section{other}

Q4-10: Do cables go over "saddles" on the pylons?

Q4-11: Type of cable sheathing used? no sheathing

Q4-12: Have rain-wind-induced cable vibrations been observed on this bridge? yes

Q4-13: Have MTE corrosion problems been noted?

no

Q4-14: Do cables have neoprene rings near the top and bottom anchorages?

no

Q4-15: If there are neoprene rings on the cables; have there been any reports of movements of the rings out of their positions?

\section{not applicable}

Q4-16: Has moisture been found in any of the internal components of stay cables such as the bottom anchorage areas?

not tested

Q4-17: Has fatigue of MTE or other components of stay cables been observed? no

Q4-18: Do the cables have viscous dampers installed at deck or tower levels?

yes, retrofitted to correct vibrations

Q4-19: Do the cables have cross cables installed between them?

no
Q4-20: Do cables have other dampers (other than viscous or neoprene rings) to control vibrations?

\section{yes, other dampers}

Q4-21: Has cracking of the cable sheathing or sheathing connections been noted?

\section{not applicable}

Q4-22: Has cracking or misalignment of the guide pipes been noted?

\section{not applicable}

Q4-23: If there is protective tape wrapped around the cable sheathing; have there been reports of deterioration of the tape?

no

Q4-24: Have any problems associated with neoprene boots been noted?

Q4-25: Types of non-destructive tests that any of the cables on this bridge have been subjected to?

\section{not performed}

Q4-26: Types of sensor-based, long-term monitoring performed on the cables?

\section{not performed}

Q4-27: Have the cables on this bridge (or any of their components) been repaired?

no

Q4-28: Has the sheathing been partially removed on any of the cables to examine 


\section{NCHRP SYNTHESIS TOPIC 35-07-INSPECTION AND MAINTENANCE OF BRIDGE STAY CABLE SYSTEMS}

Nackawic River

New Brunswick, Canada

Questionnaire Results

Survey performed in 2004

condition of grout (if applicable) and/or the MTE?

not applicable

Q4-29: Can the strands or cables be replaced if needed?

\section{not known}

Q4-30: Do you have an inspection and maintenance manual for this bridge?

no

Q5: Based on your experience and in general, do you believe that the current inspection, testing, monitoring, and repair methods and adequate?

yes

Q6: Please comment on the effectiveness of any non-destructive test methods for inspections of stay cables that you may be familiar with. These methods include (but are not limited to) ultrasonic testing, magnetic inspections, laser-based force measurements, $\mathrm{X}$-ray imaging, etc. If possible, please comment on issues such as practicality, cost, duration, impact on traffic, and any other factors that you consider important.

None of this testing was done on any of the three structures; probably there would be a significant cost to do these tests.

Q7: Please comment on the effectiveness of any cable vibration control measures that you may be familiar with. Examples include

installation of cross cables, viscous dampers, neoprene rings, etc.

See comments for Question 4-12.

Q8: Please comment on the effectiveness of any sensor-based, long-term monitoring systems for stay cables that you may be familiar with. Examples include acoustic monitoring, vibration monitoring, force measurements, strain measurements, etc.

\section{Monitoring of deflection of bridge by student} at Nackawic.

Q9: What would you recommend that the cable suppliers incorporate into their systems to make cables more accessible and inspectable?

\section{no answer}

Q10: Do you believe that an up-to-date resource such as a national database of information on stay cable inspection methods, repairs, and testing would be a useful tool?

yes

Q11: What do you see as the single most important problem in stay cable maintenance?

\section{Migration of water into cable strands.}

Q12: Please comment on any other methods for inspections, testing, monitoring, and repair of stay cable (including conventional methods)

that you have found beneficial and are not listed above.

\section{no answer}

Additional comments? 


\section{Galipeault}

State/Province:

Agency:

Quebec, Canada

Respondent:

Ministry of Transportation

Span Length:

Martin, Talbot

Year Built:

$308 \mathrm{ft}$

1963

Q4-4: Type of main tension element (MTE)?

steel wire-2 9/16-in. diameter bridge strand cable type $=1 \times 140$ wires

Q4-5: Coating/treatment on main tension

\section{galvanized steel}

Q4-6: Are the coatings/treatments on main tension element discontinued or removed within the anchorage zone?

no

Q4-7: Type of grout used?

grout not used

Q4-8: Are filler materials used in the anchorage zone?

\section{no filler}

Q4-9: Type of anchorage?

other-closed and open socket

Q4-10: Do cables go over "saddles" on the pylons?

\section{Q4-11: Type of cable sheathing used?}

\section{no sheathing}

Q4-12: Have rain-wind-induced cable vibrations been observed on this bridge?

no

Q4-13: Have MTE corrosion problems been noted?

no

Q4-14: Do cables have neoprene rings near the top and bottom anchorages?

no

Q4-15: If there are neoprene rings on the cables; have there been any reports of movements of the rings out of their positions?

\section{not applicable}

Q4-16: Has moisture been found in any of the internal components of stay cables such as the bottom anchorage areas?

no

Q4-17: Has fatigue of MTE or other components of stay cables been observed? no

Q4-18: Do the cables have viscous dampers installed at deck or tower levels? no

Q4-19: Do the cables have cross cables installed between them?
Q4-20: Do cables have other dampers (other than viscous or neoprene rings) to control vibrations?

no

Q4-21: Has cracking of the cable sheathing or sheathing connections been noted?

\section{not applicable}

Q4-22: Has cracking or misalignment of the guide pipes been noted?

\section{not applicable}

Q4-23: If there is protective tape wrapped around the cable sheathing; have there been reports of deterioration of the tape?

\section{not applicable}

Q4-24: Have any problems associated with neoprene boots been noted?

\section{no}

Q4-25: Types of non-destructive tests that any of the cables on this bridge have been subjected to?

\section{other-laser-based force measurements}

Q4-26: Types of sensor-based, long-term monitoring performed on the cables?

\section{not performed}

Q4-27: Have the cables on this bridge (or any of their components) been repaired? 
Q4-28: Has the sheathing been partially removed on any of the cables to examine condition of grout (if applicable) and/or the MTE?

\section{not applicable}

Q4-29: Can the strands or cables be replaced if needed?

yes

Q4-30: Do you have an inspection and maintenance manual for this bridge?

no

Q5: Based on your experience and in general, do you believe that the current inspection, testing, monitoring, and repair methods available to you for stay cables are effective and adequate?

yes

Q6: Please comment on the effectiveness of any non-destructive test methods for inspections of stay cables that you may be familiar with. These methods include (but are not limited to) ultrasonic testing, magnetic inspections, laser-based force measurements, $\mathrm{X}$-ray imaging, etc. If possible, please comment on issues such as practicality, cost, duration, impact on traffic, and any other factors that you consider important.

\section{We have performed laser-based force on} Galipeault bridge.

Q7: Please comment on the effectiveness of any cable vibration control measures that you may be familiar with. Examples include installation of cross cables, viscous dampers, neoprene rings, etc.

Q8: Please comment on the effectiveness of any sensor-based, long-term monitoring systems for stay cables that you may be familiar with. Examples include acoustic monitoring, vibration monitoring, force measurements, strain measurements, etc.

No long-term monitoring on our stay cable bridges at the present time.

Q9: What would you recommend that the cable suppliers incorporate into their systems to make cables more accessible and inspectable?

\section{no answer}

Q10: Do you believe that an up-to-date resource such as a national database of information on stay cable inspection methods, repairs, and testing would be a useful tool? yes

Q11: What do you see as the single most important problem in stay cable maintenance?

\section{fatigue}

Q12: Please comment on any other methods for inspections, testing, monitoring, and repair of stay cable (including conventional methods) that you have found beneficial and are not listed above.

no answer

Additional comments?

We have had a serious problem on Galipeault bridge no. 1-failure of an anchorage plate at one abutment (corrosion and fatigue failure) Emergency repairs were performed. 


\section{NCHRP SYNTHESIS TOPIC 35-07-INSPECTION AND MAINTENANCE OF BRIDGE STAY CABLE SYSTEMS}

Papineau

Quebec, Canada

\section{Papineau}

State/Province:

Agency: $\quad$ Ministry of Transportation

Respondent: $\quad$ Martin, Talbot

Span Length: $\quad \mathbf{7 9 0} \mathrm{ft}$

Year Built: 1969

Q4-4: Type of main tension element (MTE)?

steel wire-strands 2 5/16-in. and 1 5/8-in. diameter. Strand fabricated from 0.192-in. diameter galvanized wire

Q4-5: Coating/treatment on main tension element within free length of cable?

\section{galvanized steel-and polyethylene coating}

Q4-6: Are the coatings/treatments on main tension element discontinued or removed within the anchorage zone?

\section{no}

Q4-7: Type of grout used?

\section{not applicable}

Q4-8: Are filler materials used in the anchorage zone?

\section{no filler}

Q4-9: Type of anchorage?

other-cylindrical socket into which a threaded rod is screwed
Q4-10: Do cables go over "saddles" on the pylons?

yes

Q4-11: Type of cable sheathing used?

other-polyethylene coating

Q4-12: Have rain-wind-induced cable vibrations been observed on this bridge?

no

Q4-13: Have MTE corrosion problems been noted?

yes, corrosion on threaded rod

Q4-14: Do cables have neoprene rings near the top and bottom anchorages? yes

Q4-15: If there are neoprene rings on the cables; have there been any reports of movements of the rings out of their positions?

\section{no, not known}

Q4-16: Has moisture been found in any of the internal components of stay cables such as the bottom anchorage areas?

no

Q4-17: Has fatigue of MTE or other components of stay cables been observed? no

Q4-18: Do the cables have viscous dampers installed at deck or tower levels?
Q4-19: Do the cables have cross cables installed between them?

no

Q4-20: Do cables have other dampers (other than viscous or neoprene rings) to control vibrations?

no

Q4-21: Has cracking of the cable sheathing or sheathing connections been noted?

no

Q4-22: Has cracking or misalignment of the guide pipes been noted?

\section{not applicable}

Q4-23: If there is protective tape wrapped around the cable sheathing; have there been reports of deterioration of the tape?

\section{not applicable}

Q4-24: Have any problems associated with neoprene boots been noted?

no

Q4-25: Types of non-destructive tests that any of the cables on this bridge have been subjected to?

\section{not performed}

Q4-26: Types of sensor-based, long-term monitoring performed on the cables?

not performed 
Q4-27: Have the cables on this bridge (or any of their components) been repaired?

no

Q4-28: Has the sheathing been partially removed on any of the cables to examine condition of grout (if applicable) and/or the MTE?

no

Q4-29: Can the strands or cables be replaced if needed?

no

Q4-30: Do you have an inspection and maintenance manual for this bridge?

no

Q5: Based on your experience and in general, do you believe that the current inspection, testing, monitoring, and repair methods available to you for stay cables are effective and adequate?

yes

Q6: Please comment on the effectiveness of any non-destructive test methods for inspections of stay cables that you may be familiar with. These methods include (but are not limited to) ultrasonic testing, magnetic inspections, laser-based force measurements, $\mathrm{X}$-ray imaging, etc. If possible, please comment on issues such as practicality, cost, duration, impact on traffic, and any other factors that you consider important.
We have performed laser-based force on Galipeault bridge.

Q7: Please comment on the effectiveness of any cable vibration control measures that you may be familiar with. Examples include installation of cross cables, viscous dampers, neoprene rings, etc.

Q8: Please comment on the effectiveness of any sensor-based, long-term monitoring systems for stay cables that you may be familiar with. Examples include acoustic monitoring, vibration monitoring, force measurements, strain measurements, etc.

No long-term monitoring on our stay cable bridges at the present time.

Q9: What would you recommend that the cable suppliers incorporate into their systems to make cables more accessible and inspectable?

\section{no answer}

Q10: Do you believe that an up-to-date resource such as a national database of information on stay cable inspection methods, repairs, and testing would be a useful tool? yes

Q11: What do you see as the single most important problem in stay cable maintenance?

\section{fatigue}

Q12: Please comment on any other methods for inspections, testing, monitoring, and repair of stay cable (including conventional methods) that you have found beneficial and are not listed above. no answer

Additional comments?

We have had a serious problem on Galipeault bridge no. 1-failure of an anchorage plate at one abutment (corrosion and fatigue failure). Emergency repairs were performed. 


\section{NCHRP SYNTHESIS TOPIC 35-07-INSPECTION AND MAINTENANCE OF BRIDGE STAY CABLE SYSTEMS}

Price

Quebec, Canada

Questionnaire Results

Survey performed in 2004

\section{Price}

State/Province:

Agency:

Quebec, Canada

Respondent: Ministry of Transportation

Martin, Talbot

Span Length: $\quad \mathbf{4 5 0} \mathrm{ft}$

Year Built: 1972

Q4-4: Type of main tension element (MTE)?

steel wire-galvanized bridge strands. 2.5-in. and 2.56-in. diameter.

Q4-5: Coating/treatment on main tension element within free length of cable? 0.209 in. thickness

Q4-6: Are the coatings/treatments on main tension element discontinued or removed within the anchorage zone?

no

Q4-7: Type of grout used?

grout not used

Q4-8: Are filler materials used in the anchorage zone?

\section{no filler}

Q4-9: Type of anchorage?

other-cylindrical socket into which a threaded rod is screwed

Q4-10: Do cables go over "saddles" on the pylons?

no

Q4-11: Type of cable sheathing used? other-polyethylene coating

Q4-12: Have rain-wind-induced cable vibrations been observed on this bridge?

no, strong wind vibration

Q4-13: Have MTE corrosion problems been noted?

no

Q4-14: Do cables have neoprene rings near the top and bottom anchorages?

yes

Q4-15: If there are neoprene rings on the cables; have there been any reports of movements of the rings out of their positions?

yes-due to shearing off of retainers

Q4-16: Has moisture been found in any of the internal components of stay cables such as the bottom anchorage areas?

no

Q4-17: Has fatigue of MTE or other components of stay cables been observed?

yes, see Question 4-27

Q4-18: Do the cables have viscous dampers installed at deck or tower levels?

no

Q4-19: Do the cables have cross cables installed between them? no

Q4-20: Do cables have other dampers (other than viscous or neoprene rings) to control vibrations?

no

Q4-21: Has cracking of the cable sheathing or sheathing connections been noted?

no

Q4-22: Has cracking or misalignment of the guide pipes been noted?

\section{not applicable}

Q4-23: If there is protective tape wrapped around the cable sheathing; have there been reports of deterioration of the tape?

\section{not applicable}

Q4-24: Have any problems associated with neoprene boots been noted?

no

Q4-25: Types of non-destructive tests that any of the cables on this bridge have been subjected to?

\section{not performed}

Q4-26: Types of sensor-based, long-term monitoring performed on the cables?

\section{not performed}

Q4-27: Have the cables on this bridge (or any of their components) been repaired? 
Price

Quebec, Canada

\section{NCHRP SYNTHESIS TOPIC 35-07-INSPECTION AND MAINTENANCE OF BRIDGE STAY CABLE SYSTEMS}

yes-broken anchor bolt. Failure of two 5-in. anchor bolts in the anchorage zone

Q4-28: Has the sheathing been partially removed on any of the cables to examine condition of grout (if applicable) and/or the MTE?

no

Q4-29: Can the strands or cables be replaced if needed?

yes

Q4-30: Do you have an inspection and maintenance manual for this bridge?

Q5: Based on your experience and in general, any sensor-based, long-term monitoring do you believe that the current inspection, testing, monitoring, and repair methods available to you for stay cables are effective and adequate?

Q6: Please comment on the effectiveness of any non-destructive test methods for inspections of stay cables that you may be familiar with. These methods include (but are not limited to) ultrasonic testing, magnetic inspections, laser-based force measurements, $\mathrm{X}$-ray imaging, etc. If possible, please comment on issues such as practicality, cost, duration, impact on traffic, and any other factors that you consider important.

Q7: Please comment on the effectiveness of any cable vibration control measures that you may be familiar with. Examples include

installation of cross cables, viscous dampers, neoprene rings, etc.

Neoprene rings have reduced cable vibrations on the Price Bridge (no. 3).

Q8: Please comment on the effectiveness of systems for stay cables that you may be familiar with. Examples include acoustic monitoring, vibration monitoring, force measurements, strain measurements, etc.

Q9: What would you recommend that the cable suppliers incorporate into their systems to make cables more accessible and inspectable?

Q10: Do you believe that an up-to-date resource such as a national database of information on stay cable inspection methods, repairs, and testing would be a useful tool?

Q11: What do you see as the single most important problem in stay cable maintenance?

Q12: Please comment on any other methods for inspections, testing, monitoring, and repair of stay cable (including conventional methods) that you have found beneficial and are not listed above.

Additional comments?

We also had a failure of an anchorage plate on Price Bridge (no. 3) during the 1988 Saguenay earthquake $(M L=6.0)$. It was the first documented structural damage to a steel bridge caused by an earthquake in Canada.
Questionnaire Results

Survey performed in 2004 


\section{NCHRP SYNTHESIS TOPIC 35-07-INSPECTION AND MAINTENANCE OF BRIDGE STAY CABLE SYSTEMS}

Freyssinet

Questionnaire Results

Survey performed in 2004

State/Province: Freyssinet

Agency: $\quad$ Freyssinet LLC

Respondent: Andrew Micklus

Span Length: $\quad f t$

Year Built:

Q4-4: Type of main tension element (MTE)?

Q4-5: Coating/treatment on main tension element within free length of cable?

Q4-6: Are the coatings/treatments on main tension element discontinued or removed within the anchorage zone?

Q4-8: Are filler materials used in the anchorage zone?

Q4-9: Type of anchorage?

Q4-10: Do cables go over "saddles" on the pylons?

Q4-11: Type of cable sheathing used?

Q4-12: Have rain-wind-induced cable vibrations been observed on this bridge?

Q4-13: Have MTE corrosion problems been noted?

Q4-14: Do cables have neoprene rings near the top and bottom anchorages?

Q4-15: If there are neoprene rings on the cables; have there been any reports of movements of the rings out of their positions?

Q4-16: Has moisture been found in any of the internal components of stay cables such as the bottom anchorage areas?

Q4-17: Has fatigue of MTE or other components of stay cables been observed?

Q4-18: Do the cables have viscous dampers installed at deck or tower levels?

Q4-19: Do the cables have cross cables installed between them?

Q4-20: Do cables have other dampers (other than viscous or neoprene rings) to control vibrations?

Q4-21: Has cracking of the cable sheathing or sheathing connections been noted?

Q4-22: Has cracking or misalignment of the guide pipes been noted?

Q4-23: If there is protective tape wrapped around the cable sheathing; have there been reports of deterioration of the tape?

Q4-24: Have any problems associated with neoprene boots been noted?

Q4-25: Types of non-destructive tests that any of the cables on this bridge have been subjected to?

Q4-26: Types of sensor-based, long-term monitoring performed on the cables?

Q4-27: Have the cables on this bridge (or any of their components) been repaired?

Q4-28: Has the sheathing been partially removed on any of the cables to examine condition of grout (if applicable) and/or the MTE?

Q4-29: Can the strands or cables be replaced if needed?

Q4-30: Do you have an inspection and maintenance manual for this bridge?

Q5: Based on your experience and in general, do you believe that the current inspection, testing, monitoring, and repair methods available to you for stay cables are effective and adequate?

yes. Freyssinet has installed its stay system on three projects:

Bill Emerson Bridge over the Mississippi River at Cape Girardeau, Missouri

I-93 over the Charles River in Boston, Mass.

Cooper River Replacement Bridge in Charleston, S.C.

The Cape Giraredeau Bridge was required to be grouted by the Owner and Engineer.

Freyssinet proposed ungrouted stays but this was unacceptable for reasons unknown. The thought was the Owner and Engineer did not want to be the first in United States to allow ungrouted stays. The Charles River was designed to use grouted stays, but Freyssinet was able to convince the Owner and Engineer that ungrouted stays were superior, mainly due to the improved inspectability and replaceability but also to avoid the common problems associated with grouted cables (introduce moisture, increase local bending moments at the anchorages, more mass to 


\section{NCHRP SYNTHESIS TOPIC 35-07-INSPECTION AND MAINTENANCE OF BRIDGE STAY CABLE SYSTEMS}

Freyssinet

Questionnaire Results

Survey performed in 2004

dampen potential damage to the HDPE stay pipe if high grouting pressures are used. Also during grouting everything gets warm (or very hot if grouted during the summer in warm or even moderate climates). When colder winter temperatures arrive, the pipes develop very high tensile stresses as the pipe tries to thermally contract but is restrained since the grout has a much lower thermal coefficient of expansion and contraction. The cables on Cooper River Bridge are state of the art ungrouted stays with capacity to add approximately 5\% strand in the future and the stays are fitted with engineered vibration suppression devices. Internal hydraulic and external hydraulic damping devices are being installed and provisions provide for the possible addition of cable ties (damping ropes) in the future on selected longer stays that have been identified as having the potential to experience parametric excitation.

Q6: Please comment on the effectiveness of any non-destructive test methods for inspections of stay cables that you may be familiar with. These methods include (but are not limited to) ultrasonic testing, magnetic inspections, laser-based force measurements, $\mathrm{X}$-ray imaging, etc. If possible, please comment on issues such as practicality, cost, duration, impact on traffic, and any other factors that you consider important.

With ungrouted stays, individual strands may be detensioned, inspected, retensioned, or removed and/or replaced. Load cells may be left in place to monitor strands individually. Acoustic monitoring sytems can be installed to detect wire breakage and determine the break locations very accurately

Q7: Please comment on the effectiveness of any cable vibration control measures that you may be familiar with. Examples include installation of cross cables, viscous dampers, neoprene rings, etc.

External helix placed on the surface of the stay pipes has been proven to eliminate rainwind-induced cable vibrations. Freyssinet developed this on the Normandie Bridge in France. Freyssinet offered this on Cape Girardeau and Charles River Projects and both sites elected to add external helix via a change order due to the very real threat of serious rain-wind-induced vibrations and the high level of effectiveness offered by the external helix.

Q8: Please comment on the effectiveness of any sensor-based, long-term monitoring systems for stay cables that you may be familiar with. Examples include acoustic monitoring, vibration monitoring, force measurements, strain measurements, etc.

We believe acoustical monitoring is an effective method to record wire failures. Permanent load cells are good for monitoring loads, especially with unbonded monostrands when it can be established that the load is equal in all individual strands within reasonable tolerances such that by monitoring 1 strand, the load in cable is known.
Q9: What would you recommend that the cable suppliers incorporate into their systems to make cables more accessible and inspectable?

Ability to de-tension, inspect, and retension individual strands, Ability to de-tension remove, and replace individual strands. Ability to add strands to each cable or cable group (avg. 5\%).

Q10: Do you believe that an up-to-date resource such as a national database of information on stay cable inspection methods, repairs, and testing would be a useful tool?

yes

Q11: What do you see as the single most important problem in stay cable maintenance?

\section{Inspectability in the anchorage area}

Q12: Please comment on any other methods for inspections, testing, monitoring, and repair of stay cable (including conventional methods) that you have found beneficial and are not listed above.

no answer

Additional comments? 


\section{NCHRP SYNTHESIS TOPIC 35-07-INSPECTION AND MAINTENANCE OF BRIDGE STAY CABLE SYSTEMS}

\section{Questions:}

Q4.4 Type of main tension element (MTE)?

Q4.5 Coating/treatment on main tension element within free length of cable?

Q4.6 Are the coatings/treatments on main tension element discontinued or removed within the anchorage zone?

\section{Responses:}

\begin{tabular}{|c|c|c|c|c|}
\hline State & Bridge & Q4.4 & Q4.5 & Q4.6 \\
\hline Alabama & Cochrane Africatown & seven-wire steel strand & bare & NA \\
\hline Alaska & $\begin{array}{l}\text { Sitka Harbor Bridge, Sitka, } \\
\text { Alaska }\end{array}$ & $\begin{array}{l}\text { other-galvanized } \\
\text { bridge strand }\end{array}$ & galvanized steel & not known \\
\hline Alaska & $\begin{array}{l}\text { Captain William Moore } \\
\text { Bridge, Skagway }\end{array}$ & $\begin{array}{l}\text { other-ASTM Desig } \\
\text { A586-86 }\end{array}$ & galvanized steel & not known \\
\hline California & $\begin{array}{l}\text { Sacramento River } \\
\text { (Meridian) }\end{array}$ & steel wire & galvanized steel & no \\
\hline Delaware & $\begin{array}{l}\text { Br. 1-902, SR-1 over the } \\
\text { Chesapeake and Delaware } \\
\text { Canal, St. Georges, New } \\
\text { Castle County, Delaware }\end{array}$ & seven-wire steel strand & bare & not applicable \\
\hline Florida & Dame Point Bridge & steel bar or threadbar & $\begin{array}{l}\text { epoxy-coated on } \\
\text { outside only }\end{array}$ & not known \\
\hline Georgia & $\begin{array}{l}\text { Talmadge Memorial } \\
\text { Bridge, Savannah }\end{array}$ & seven-wire steel strand & bare & NA \\
\hline Georgia & $\begin{array}{l}\text { Sidney Lanier Bridge, } \\
\text { Brunswick }\end{array}$ & seven-wire steel strand & bare & N/A \\
\hline Illinois & $\begin{array}{l}\text { Quincy Bayview Bridge at } \\
\text { Quincy, IL }\end{array}$ & seven-wire steel strand & $\begin{array}{l}\text { epoxy-coated on } \\
\text { outside only }\end{array}$ & not known \\
\hline Illinois & Clark Bridge at Alton, IL & seven-wire steel strand & $\begin{array}{l}\text { epoxy-coated on } \\
\text { outside only }\end{array}$ & not known \\
\hline Indiana & 46-03-7495 EBL & seven-wire steel strand & I think they are bare?? & not known \\
\hline Indiana & I65-68-7910 & seven-wire steel strand & I think they are bare?? & not known \\
\hline Iowa & Burlington, IA & $\begin{array}{l}\text { seven-wire steel } \\
\text { strand-epoxy-coated, } \\
0.6 \text {-in. strand in grouted } \\
\text { polyethylene pipe }\end{array}$ & $\begin{array}{l}\text { epoxy-coated on } \\
\text { outside only-epoxy- } \\
\text { coated seven wire } \\
\text { strand }\end{array}$ & yes \\
\hline Kentucky & $\begin{array}{l}\text { William Natcher Bridge, } \\
\text { Owensboro, KY }\end{array}$ & seven-wire steel strand & greased-and-sheathed & $\begin{array}{l}\text { Yes-tubes attached to } \\
\text { the anchor block } \\
\text { provide corrosion } \\
\text { protection }\end{array}$ \\
\hline Kentucky & $\begin{array}{l}\text { William H. Harsha Bridge, } \\
\text { Maysville, KY }\end{array}$ & seven-wire steel strand & greased-and-sheathed & yes \\
\hline Louisiana & $\begin{array}{l}\text { Mississippi River Bridge at } \\
\text { Luling, LA }\end{array}$ & steel wire & bare & not applicable \\
\hline \multicolumn{5}{|l|}{ Mississippi } \\
\hline Massachusetts & $\begin{array}{l}\text { Leonard P. Zakim Bunker } \\
\text { Hill Bridge, Boston, MA }\end{array}$ & seven-wire steel strand & greased-and-sheathed & $\begin{array}{l}\text { Yes-sheathing } \\
\text { removed in the } \\
\text { anchorage zone }\end{array}$ \\
\hline Missouri & $\begin{array}{l}\text { Bill Emerson Memorial } \\
\text { Bridge, Cape Girardeau }\end{array}$ & seven-wire steel strand & greased-and-sheathed & yes \\
\hline Ohio & $\begin{array}{l}\text { Maumee River Bridge, } \\
\text { Toledo }\end{array}$ & seven-wire steel strand & $\begin{array}{l}\text { epoxy-coated inside and } \\
\text { outside }\end{array}$ & yes \\
\hline South Carolina & Cooper River Bridge & seven-wire steel strand & $\begin{array}{l}\text { other-waxed and } \\
\text { sheathed }\end{array}$ & yes \\
\hline Texas & Veterans Memorial Bridge & seven-wire steel strand & bare & $\begin{array}{l}\text { N/A-grouted though } \\
\text { entire length and } \\
\text { anchorage }\end{array}$ \\
\hline Texas & Fred Hartman Bridge & seven-wire steel strand & bare & $\begin{array}{l}\text { N/A-grouted though } \\
\text { entire length and } \\
\text { anchorage }\end{array}$ \\
\hline
\end{tabular}




\section{NCHRP SYNTHESIS TOPIC 35-07-INSPECTION AND MAINTENANCE OF BRIDGE STAY CABLE SYSTEMS}

\begin{tabular}{|c|c|c|c|c|}
\hline State & Bridge & Q4.4 & Q4.5 & Q4.6 \\
\hline Virginia & $\begin{array}{l}\text { I-295 over James River } \\
\text { (Varina-Enon Bridge) }\end{array}$ & seven-wire steel strand & bare & N/A \\
\hline Washington & $\begin{array}{l}\text { Gum Street-Kennewick, } \\
\text { WA }\end{array}$ & steel wire & bare & N/A \\
\hline Washington & Thea-Foss Tacoma, WA & seven-wire steel strand & bare & N/A \\
\hline Wisconsin & $\begin{array}{l}\text { Sixth Street Viaduct, North } \\
\text { Cable Stay }\end{array}$ & seven-wire steel strand & greased-and-sheathed & $\begin{array}{l}\text { yes-removed within } \\
\text { anchor zone }\end{array}$ \\
\hline Wisconsin & $\begin{array}{l}\text { Sixth Street Viaduct, South } \\
\text { Cable Stay }\end{array}$ & seven-wire steel strand & greased-and-sheathed & $\begin{array}{l}\text { yes-removed within } \\
\text { anchor zone }\end{array}$ \\
\hline Alberta/Calgary & Prince's Island (Pedestrian) & steel wire & galvanized steel & not known \\
\hline Alberta/Calgary & Carburn Park (Pedestrian) & steel bar or threadbar & galvanized steel & not known \\
\hline Alberta/Calgary & McMahon (Pedestrian) & steel bar or threadbar & galvanized steel & no \\
\hline Alberta/Calgary & Fox Hollow (Pedestrian) & steel bar or threadbar & galvanized steel & no \\
\hline Alberta/Calgary & Stoney Trail (Pedestrian) & steel bar or threadbar & galvanized steel & no \\
\hline British Columbia & Alex Fraser Bridge & $\begin{array}{l}\text { Other-7.1-mm } \\
\text { diameter galvanized } \\
\text { wire to ASTM A586; } \\
\text { ult. strength = } 1520 \\
\text { MPa; long lay strand } \\
\text { assemblies with } 109 \text { to } \\
283 \text { wires per assembly }\end{array}$ & $\begin{array}{l}\text { Greased-and- } \\
\text { sheathed-galvanized; } \\
\text { galvanized wire cable } \\
\text { jacketed in } \\
\text { polyethylene tube and } \\
\text { filled with petroleum } \\
\text { wax blocking } \\
\text { compound }\end{array}$ & $\begin{array}{l}\text { Yes-zinc-filled cast } \\
\text { steel socket at end; } \\
\text { grease discontinued in } \\
\text { anchorages }\end{array}$ \\
\hline Manitoba/Winnipeg & Esplanade Riel & seven-wire steel strand & $\begin{array}{l}\text { Galvanized steel, } \\
\text { further coated with high } \\
\text { density polyethylene }\end{array}$ & $\begin{array}{l}\text { yes, HDPE coating is } \\
\text { removed }\end{array}$ \\
\hline New Brunswick & Hawkshaw & $\begin{array}{l}\text { Steel wire-2-3/8-in. } \\
\text { diameter galvanized } \\
\text { steel cables. Located } \\
\text { near Nackawic NB over } \\
\text { the Saint John River } \\
\text { between Rte } 2 \text { and Rte } \\
105\end{array}$ & $\begin{array}{l}\text { Galvanized steel- } \\
\text { cables are wrapped } 5 \mathrm{ft} \\
\text { above deck with } \\
\text { galvanized wire, also in } \\
\text { this area they are coated } \\
\text { with Denso Paste and } \\
\text { tape }\end{array}$ & no \\
\hline New Brunswick & Longs Creek \#1 & $\begin{array}{l}\text { Located on Rte } 102 \\
\text { west of Fredricton, NB }\end{array}$ & galvanized steel & no \\
\hline New Brunswick & Nackawic River & $\begin{array}{l}\text { Located on Rte. } 105 \text { in } \\
\text { the town of Nackawic }\end{array}$ & galvanized steel & no \\
\hline Quebec, Canada & Galipeault & $\begin{array}{l}\text { Steel wire-2 9/16-in. } \\
\text { diameter bridge strand } \\
\text { cable type = } 1 \text { x } 140 \\
\text { wires }\end{array}$ & galvanized steel & no \\
\hline Quebec, Canada & Papineau & $\begin{array}{l}\text { Steel wire-strands } 2 \\
5 / 16 \text {-in. and } 15 / 8 \text {-in. } \\
\text { diameter. Strand } \\
\text { fabricated from } 0.192 \text { - } \\
\text { in. diameter galvanized } \\
\text { wire }\end{array}$ & $\begin{array}{l}\text { Galvanized steel-and } \\
\text { polyethylene coating }\end{array}$ & no \\
\hline Quebec, Canada & Price & $\begin{array}{l}\text { Steel wire-galvanized } \\
\text { bridge strands. } 2.5 \text {-in. } \\
\text { and } 2.56 \text {-in. diameter }\end{array}$ & $\begin{array}{l}\text { Galvanized steel_-and } \\
\text { polyethylene coating } \\
0.209 \text {-in. thickness }\end{array}$ & no \\
\hline
\end{tabular}




\section{NCHRP SYNTHESIS TOPIC 35-07-INSPECTION AND MAINTENANCE OF BRIDGE STAY CABLE SYSTEMS}

\section{Questions:}

Q4.7 Type of grout used?

Q4.8 Are filler materials used in the anchorage zone?

Q4.9 Type of anchorage?

\section{Responses:}

\begin{tabular}{|c|c|c|c|c|}
\hline State & Bridge & Q4.7 & Q4.8 & Q4.9 \\
\hline Alabama & Cochrane Africatown & $\begin{array}{l}\text { cement-water } \\
\text { admixtures }\end{array}$ & yes, other & $\begin{array}{l}\text { conical socket with } \\
\text { wedges }\end{array}$ \\
\hline Alaska & $\begin{array}{l}\text { Sitka Harbor Bridge, Sitka, } \\
\text { Alaska }\end{array}$ & not known & $\begin{array}{l}\text { yes, other-liquid } \\
\text { polymer sealer }\end{array}$ & $\begin{array}{l}\text { conical socket with } \\
\text { wedges }\end{array}$ \\
\hline Alaska & $\begin{array}{l}\text { Captain William Moore } \\
\text { Bridge, Skagway }\end{array}$ & not known & yes, grease & $\begin{array}{l}\text { conical socket with } \\
\text { wedges }\end{array}$ \\
\hline California & $\begin{array}{l}\text { Sacramento River } \\
\text { (Meridian) }\end{array}$ & grout not used & yes, grease & $\begin{array}{l}\text { Other-main cables are } \\
\text { swedged onto a steel } \\
\text { conical threaded } \\
\text { coupler that is attached } \\
\text { to a threaded HS steel } \\
\text { rod, which uses a } \\
\text { spherical anchor socket } \\
\text { and anchor nut to } \\
\text { provide anchorage } \\
\text { connection. This system } \\
\text { appears to be uniquely } \\
\text { designed }\end{array}$ \\
\hline Delaware & $\begin{array}{l}\text { Br. 1-902, SR-1 over the } \\
\text { Chesapeake and Delaware } \\
\text { Canal, St. Georges, New } \\
\text { Castle County, Delaware }\end{array}$ & $\begin{array}{l}\text { cement-water } \\
\text { admixtures }\end{array}$ & yes, grout & $\begin{array}{l}\text { conical socket with } \\
\text { wedges }\end{array}$ \\
\hline Florida & Dame Point Bridge & $\begin{array}{l}\text { not known-a cement } \\
\text { grout was used }\end{array}$ & yes, grout & wedges \\
\hline Georgia & $\begin{array}{l}\text { Talmadge Memorial } \\
\text { Bridge, Savannah }\end{array}$ & cement-water & $\begin{array}{l}\text { yes, other-steel shot } \\
\text { and epoxy }\end{array}$ & $\begin{array}{l}\text { other-American } \\
\text { Stronghold system }\end{array}$ \\
\hline Georgia & $\begin{array}{l}\text { Sidney Lanier Bridge, } \\
\text { Brunswick }\end{array}$ & cement-water & yes-grout & $\begin{array}{l}\text { conical socket with } \\
\text { wedges }\end{array}$ \\
\hline Illinois & $\begin{array}{l}\text { Quincy Bayview Bridge at } \\
\text { Quincy, IL }\end{array}$ & not known & not known & not known \\
\hline Illinois & Clark Bridge at Alton, IL & not known & not known & not known \\
\hline Indiana & 46-03-7495 EBL & $\begin{array}{l}\text { cement-water } \\
\text { admixtures }\end{array}$ & not known & $\begin{array}{l}\text { conical socket with } \\
\text { wedges }\end{array}$ \\
\hline Indiana & I65-68-7910 & $\begin{array}{l}\text { cement-water } \\
\text { admixtures }\end{array}$ & not known & $\begin{array}{l}\text { conical socket with } \\
\text { wedges }\end{array}$ \\
\hline Iowa & Burlington, IA & $\begin{array}{l}\text { not known—-grout was } \\
\text { used but not sure of } \\
\text { content }\end{array}$ & $\begin{array}{l}\text { yes, other-epoxy } \\
\text { compound with zinc } \\
\text { dust and steel ball }\end{array}$ & $\begin{array}{l}\text { "Hi-Am" type-VSL } \\
\text { Stay Cable System } 250\end{array}$ \\
\hline Kentucky & $\begin{array}{l}\text { William Natcher Bridge, } \\
\text { Owensboro, KY }\end{array}$ & $\begin{array}{l}\text { commercial } \\
\text { prepackaged grouts }\end{array}$ & yes, grease & wedges \\
\hline Kentucky & $\begin{array}{l}\text { William H. Harsha Bridge, } \\
\text { Maysville, KY }\end{array}$ & $\begin{array}{l}\text { cement-water } \\
\text { admixtures }\end{array}$ & yes, grease & $\begin{array}{l}\text { conical socket with } \\
\text { wedges }\end{array}$ \\
\hline Louisiana & $\begin{array}{l}\text { Mississippi River Bridge at } \\
\text { Luling, LA }\end{array}$ & cement-water & yes, other & $\begin{array}{l}\text { "Hi-Am" type-each } \\
\text { wire also passes } \\
\text { through a plate and has } \\
\text { a button head anchor }\end{array}$ \\
\hline \multicolumn{5}{|l|}{ Mississippi } \\
\hline Massachusetts & $\begin{array}{l}\text { Leonard P. Zakim Bunker } \\
\text { Hill Bridge, Boston, MA }\end{array}$ & grout not used & yes, other-wax & wedges \\
\hline Missouri & $\begin{array}{l}\text { Bill Emerson Memorial } \\
\text { Bridge, Cape Girardeau }\end{array}$ & $\begin{array}{l}\text { cement-water } \\
\text { admixtures }\end{array}$ & yes, grease & wedges \\
\hline Ohio & $\begin{array}{l}\text { Maumee River Bridge, } \\
\text { Toledo }\end{array}$ & grout not used & yes, grease & wedges \\
\hline South Carolina & Cooper River Bridge & grout not used & yes, other & wedges \\
\hline
\end{tabular}




\section{NCHRP SYNTHESIS TOPIC 35-07-INSPECTION AND MAINTENANCE OF BRIDGE STAY CABLE SYSTEMS}

\begin{tabular}{|c|c|c|c|c|}
\hline State & Bridge & Q4.7 & Q4.8 & Q4.9 \\
\hline Texas & Veterans Memorial Bridge & $\begin{array}{l}\text { cement-water } \\
\text { admixtures }\end{array}$ & yes, other-grout & $\begin{array}{l}\text { conical socket with } \\
\text { wedges }\end{array}$ \\
\hline Texas & Fred Hartman Bridge & $\begin{array}{l}\text { cement-water } \\
\text { admixtures }\end{array}$ & yes, other-grout & $\begin{array}{l}\text { conical socket with } \\
\text { wedges }\end{array}$ \\
\hline Virginia & $\begin{array}{l}\text { I-295 over James River } \\
\text { (Varina-Enon Bridge) }\end{array}$ & $\begin{array}{l}\text { cement-water } \\
\text { admixtures }\end{array}$ & yes, grout & $\begin{array}{l}\text { conical socket with } \\
\text { wedges }\end{array}$ \\
\hline Washington & $\begin{array}{l}\text { Gum Street-Kennewick, } \\
\text { WA }\end{array}$ & cement-water & yes, grease & "Hi-Am"-type \\
\hline Washington & Thea-Foss Tacoma, WA & cement-water & yes, grease & wedges \\
\hline Wisconsin & $\begin{array}{l}\text { Sixth Street Viaduct, North } \\
\text { Cable Stay }\end{array}$ & grout not used & $\begin{array}{l}\text { yes, grease, greased at } \\
\text { butt end and top end }\end{array}$ & $\begin{array}{l}\text { conical socket with } \\
\text { wedges }\end{array}$ \\
\hline Wisconsin & $\begin{array}{l}\text { Sixth Street Viaduct, South } \\
\text { Cable Stay }\end{array}$ & grout not used & $\begin{array}{l}\text { yes, grease, greased at } \\
\text { butt end and top end }\end{array}$ & $\begin{array}{l}\text { conical socket with } \\
\text { wedges }\end{array}$ \\
\hline Alberta/Calgary & Prince's Island (Pedestrian) & grout not used & no filler & $\begin{array}{l}\text { conical socket with } \\
\text { wedges }\end{array}$ \\
\hline Alberta/Calgary & Carburn Park (Pedestrian) & grout not used & no filler & $\begin{array}{l}\text { other-threaded } \\
\text { couplers }\end{array}$ \\
\hline Alberta/Calgary & McMahon (Pedestrian) & grout not used & no filler & $\begin{array}{l}\text { other-threaded } \\
\text { coupler }\end{array}$ \\
\hline Alberta/Calgary & Fox Hollow (Pedestrian) & grout not used & no filler & $\begin{array}{l}\text { other-threaded } \\
\text { coupler }\end{array}$ \\
\hline Alberta/Calgary & Stoney Trail (Pedestrian) & grout not used & no filler & $\begin{array}{l}\text { other-threaded } \\
\text { couplers/nuts }\end{array}$ \\
\hline British Columbia & Alex Fraser Bridge & grout not used & $\begin{array}{l}\text { yes, other-cast steel } \\
\text { socket anchorage is } \\
\text { filled with zinc }\end{array}$ & $\begin{array}{l}\text { zinc-filled cast steel } \\
\text { socket }\end{array}$ \\
\hline Manitoba/Winnipeg & Esplanade Riel & grout not used & yes, other, epoxy filler & $\begin{array}{l}\text { conical socket with } \\
\text { wedges }\end{array}$ \\
\hline New Brunswick & Hawkshaw & grout not used & no filler & $\begin{array}{l}\text { other-2-3/8-in. forged } \\
\text { open strand }\end{array}$ \\
\hline New Brunswick & Longs Creek \#1 & grout not used & no filler & other \\
\hline New Brunswick & Nackawic River & grout not used & no filler & other \\
\hline Quebec, Canada & Galipeault & grout not used & no filler & $\begin{array}{l}\text { other-closed and open } \\
\text { socket }\end{array}$ \\
\hline Quebec, Canada & Papineau & not applicable & no filler & $\begin{array}{l}\text { other-cylindrical } \\
\text { socket into which a } \\
\text { threaded rod is screwed }\end{array}$ \\
\hline Quebec, Canada & Price & grout not used & no filler & $\begin{array}{l}\text { other-cylindrical } \\
\text { socket into which a } \\
\text { threaded rod is screwed }\end{array}$ \\
\hline
\end{tabular}




\section{NCHRP SYNTHESIS TOPIC 35-07-INSPECTION AND MAINTENANCE OF BRIDGE STAY CABLE SYSTEMS}

\section{Questions:}

Q4.10 Do cables go over "saddles" on the pylons?

Q4.11 Type of cable sheathing used?

Q4.12 Have rain-wind-induced cable vibrations been observed on this bridge?

\section{Responses:}

\begin{tabular}{|c|c|c|c|c|}
\hline State & Bridge & Q4.10 & Q4.11 & Q4.12 \\
\hline Alabama & Cochrane Africatown & no & $\begin{array}{l}\text { HDPE with PVF Tedlar } \\
\text { tape }\end{array}$ & yes \\
\hline Alaska & $\begin{array}{l}\text { Sitka Harbor Bridge, Sitka, } \\
\text { Alaska }\end{array}$ & no & no sheathing & not known \\
\hline Alaska & $\begin{array}{l}\text { Captain William Moore } \\
\text { Bridge, Skagway }\end{array}$ & no & no sheathing & not known \\
\hline California & $\begin{array}{l}\text { Sacramento River } \\
\text { (Meridian) }\end{array}$ & yes & no sheathing & no \\
\hline Delaware & $\begin{array}{l}\text { Br. 1-902, SR-1 over the } \\
\text { Chesapeake and Delaware } \\
\text { Canal, St. Georges, New } \\
\text { Castle County, Delaware }\end{array}$ & yes & steel pipe & no \\
\hline Florida & Dame Point Bridge & no & steel pipe & no \\
\hline Georgia & $\begin{array}{l}\text { Talmadge Memorial } \\
\text { Bridge, Savannah }\end{array}$ & no & $\begin{array}{l}\text { HDPE with PVF Tedlar } \\
\text { tape }\end{array}$ & yes \\
\hline Georgia & $\begin{array}{l}\text { Sidney Lanier Bridge, } \\
\text { Brunswick }\end{array}$ & no & $\begin{array}{l}\text { HDPE with PVF Tedlar } \\
\text { tape }\end{array}$ & no \\
\hline Illinois & $\begin{array}{l}\text { Quincy Bayview Bridge at } \\
\text { Quincy, IL }\end{array}$ & no & $\begin{array}{l}\text { UV-resistant HDPE. } \\
\text { Contract in } 2003 \text { to } \\
\text { wrap cables with } \\
\text { elastomeric wrap }\end{array}$ & no \\
\hline Illinois & Clark Bridge at Alton, IL & yes & $\begin{array}{l}\text { No answer, plans gave } \\
\text { contractor option of } \\
\text { steel or HDPE }\end{array}$ & $\begin{array}{l}\text { yes-prior to } \\
\text { installation of cross } \\
\text { cables }\end{array}$ \\
\hline Indiana & 46-03-7495 EBL & no & polyethylene stay pipes & no \\
\hline Indiana & I65-68-7910 & no & $\begin{array}{l}\text { polyethylene stay pipes } \\
\text { with pressure sensitive } \\
\text { PVF tape }\end{array}$ & no \\
\hline Iowa & Burlington, IA & no & $\begin{array}{l}\text { HDPE with PVF Tedlar } \\
\text { tape }\end{array}$ & yes \\
\hline Kentucky & $\begin{array}{l}\text { William Natcher Bridge, } \\
\text { Owensboro, KY }\end{array}$ & no & $\begin{array}{l}\text { UV-resistant HDPE } \\
\text { with spiral on surface }\end{array}$ & no \\
\hline Kentucky & $\begin{array}{l}\text { William H. Harsha Bridge, } \\
\text { Maysville, KY }\end{array}$ & no & $\begin{array}{l}\text { UV-resistant HDPE } \\
\text { with spiral on surface }\end{array}$ & no \\
\hline Louisiana & $\begin{array}{l}\text { Mississippi River Bridge at } \\
\text { Luling, LA }\end{array}$ & no & $\begin{array}{l}\text { HDPE with PVF } \\
\text { (Tedlar) tape }\end{array}$ & $\begin{array}{l}\text { no-very infrequent, } \\
\text { large amplitude motion } \\
\text { observed, but not } \\
\text { detected }\end{array}$ \\
\hline \multicolumn{5}{|l|}{ Mississippi } \\
\hline Massachusetts & $\begin{array}{l}\text { Leonard P. Zakim Bunker } \\
\text { Hill Bridge, Boston, MA }\end{array}$ & no & $\begin{array}{l}\text { UV-resistant HDPE } \\
\text { with spiral on surface }\end{array}$ & no \\
\hline Missouri & $\begin{array}{l}\text { Bill Emerson Memorial } \\
\text { Bridge, Cape Girardeau }\end{array}$ & no & $\begin{array}{l}\text { UV-resistant HDPE } \\
\text { with spiral on surface }\end{array}$ & no \\
\hline Ohio & $\begin{array}{l}\text { Maumee River Bridge, } \\
\text { Toledo }\end{array}$ & $\begin{array}{l}\text { Yes-This project } \\
\text { actually uses a "cradle," } \\
\text { which separates } \\
\text { individual strands } \\
\text { within the curved area, } \\
\text { avoiding contact stress } \\
\text { between them. In that } \\
\text { respect, it is different } \\
\text { than conventional } \\
\text { "saddles" }\end{array}$ & other-stainless steel & no \\
\hline
\end{tabular}


NCHRP SYNTHESIS TOPIC 35-07-INSPECTION AND MAINTENANCE OF BRIDGE STAY CABLE SYSTEMS

\begin{tabular}{|c|c|c|c|c|}
\hline State & Bridge & Q4.10 & Q4.11 & Q4.12 \\
\hline South Carolina & Cooper River Bridge & no & $\begin{array}{l}\text { UV-resistant HDPE } \\
\text { with spiral on surface }\end{array}$ & N/A \\
\hline Texas & Veterans Memorial Bridge & yes & $\begin{array}{l}\text { HDPE with PVF Tedlar } \\
\text { tape }\end{array}$ & yes \\
\hline Texas & Fred Hartman Bridge & no & $\begin{array}{l}\text { HDPE with PVF Tedlar } \\
\text { tape }\end{array}$ & yes \\
\hline Virginia & $\begin{array}{l}\text { I-295 over James River } \\
\text { (Varina-Enon Bridge) }\end{array}$ & yes & $\begin{array}{l}\text { HDPE with PVF Tedlar } \\
\text { tape }\end{array}$ & $\begin{array}{l}\text { Not known. No such } \\
\text { vibrations have been } \\
\text { observed on the } \\
\text { Varina-Enon Bridge }\end{array}$ \\
\hline Washington & $\begin{array}{l}\text { Gum Street-Kennewick, } \\
\text { WA }\end{array}$ & no & $\begin{array}{l}\text { HDPE with PVF Tedlar } \\
\text { tape }\end{array}$ & no \\
\hline Washington & Thea-Foss Tacoma, WA & no & no answer & no \\
\hline Wisconsin & $\begin{array}{l}\text { Sixth Street Viaduct, North } \\
\text { Cable Stay }\end{array}$ & no & $\begin{array}{l}\text { UV-resistant HDPE } \\
\text { with spiral on surface, } \\
\text { white co-extruded } \\
\text { HDPE }\end{array}$ & $\begin{array}{l}\text { no-vibration not } \\
\text { expected for this small } \\
\text { cable-stayed bridge }\end{array}$ \\
\hline Wisconsin & $\begin{array}{l}\text { Sixth Street Viaduct, South } \\
\text { Cable Stay }\end{array}$ & no & $\begin{array}{l}\text { UV-resistant HDPE } \\
\text { with spiral on surface, } \\
\text { white co-extruded } \\
\text { HDPE }\end{array}$ & $\begin{array}{l}\text { no-vibration not } \\
\text { expected for this small } \\
\text { cable-stayed bridge }\end{array}$ \\
\hline Alberta/Calgary & Prince's Island (Pedestrian) & no & no sheathing & yes \\
\hline Alberta/Calgary & Carburn Park (Pedestrian) & no & no sheathing & not known \\
\hline Alberta/Calgary & McMahon (Pedestrian) & no & no sheathing & no \\
\hline Alberta/Calgary & Fox Hollow (Pedestrian) & no & no sheathing & yes \\
\hline Alberta/Calgary & Stoney Trail (Pedestrian) & no & no sheathing & not known \\
\hline British Columbia & Alex Fraser Bridge & no & UV-resistant HDPE & yes \\
\hline Manitoba/Winnipeg & Esplanade Riel & no & $\begin{array}{l}\text { UV-resistant HDPE } \\
\text { with spiral on surface }\end{array}$ & no \\
\hline New Brunswick & Hawkshaw & no & no sheathing & yes \\
\hline New Brunswick & Longs Creek \#1 & no & no sheathing & yes \\
\hline New Brunswick & Nackawic River & no & no sheathing & yes \\
\hline Quebec, Canada & Galipeault & no & no sheathing & no \\
\hline Quebec, Canada & Papineau & yes & $\begin{array}{l}\text { other-polyethylene } \\
\text { coating }\end{array}$ & no \\
\hline Quebec, Canada & Price & no & $\begin{array}{l}\text { other-polyethylene } \\
\text { coating }\end{array}$ & $\begin{array}{l}\text { no, strong wind } \\
\text { vibration }\end{array}$ \\
\hline
\end{tabular}




\section{NCHRP SYNTHESIS TOPIC 35-07-INSPECTION AND MAINTENANCE OF BRIDGE STAY CABLE SYSTEMS}

\section{Questions:}

Q4.13 Have MTE corrosion problems been noted?

Q4.14 Do cables have neoprene rings near the top and bottom anchorages?

Q4.15 If there are neoprene rings on the cables, have there been any reports of movements of the rings out of their positions?

\section{Responses:}

\begin{tabular}{|c|c|c|c|c|}
\hline State & Bridge & Q4.13 & Q4.14 & Q4.15 \\
\hline Alabama & Cochrane Africatown & no & yes & $\begin{array}{l}\text { yes-due to loosening } \\
\text { of retainers, and yes-- } \\
\text { due to shearing off of } \\
\text { retainers }\end{array}$ \\
\hline Alaska & $\begin{array}{l}\text { Sitka Harbor Bridge, Sitka, } \\
\text { Alaska }\end{array}$ & no & no & not applicable \\
\hline Alaska & $\begin{array}{l}\text { Captain William Moore } \\
\text { Bridge, Skagway }\end{array}$ & no & no & not applicable \\
\hline California & $\begin{array}{l}\text { Sacramento River } \\
\text { (Meridian) }\end{array}$ & no & no & N/A \\
\hline Delaware & $\begin{array}{l}\text { Br. 1-902, SR-1 over the } \\
\text { Chesapeake and Delaware } \\
\text { Canal, St. Georges, New } \\
\text { Castle County, Delaware }\end{array}$ & $\begin{array}{l}\text { Not known-moisture } \\
\text { infiltration is suspected; } \\
\text { however, due to the } \\
\text { limitations of available } \\
\text { inspection methods, } \\
\text { definitive evidence of } \\
\text { corrosion is not } \\
\text { available }\end{array}$ & yes & $\begin{array}{l}\text { yes-due to loosening } \\
\text { of retainers. Movement } \\
\text { observed in outer } \\
\text { neoprene ring of } \\
\text { anchorage set. No } \\
\text { retaining devices were } \\
\text { present }\end{array}$ \\
\hline Florida & Dame Point Bridge & no & no & N/A \\
\hline Georgia & $\begin{array}{l}\text { Talmadge Memorial } \\
\text { Bridge, Savannah }\end{array}$ & no & yes & $\begin{array}{l}\text { yes-due to loosening } \\
\text { of retainers, and yes-- } \\
\text { due to shearing off of } \\
\text { retainers }\end{array}$ \\
\hline Georgia & $\begin{array}{l}\text { Sidney Lanier Bridge, } \\
\text { Brunswick }\end{array}$ & no & yes & no, not known \\
\hline Illinois & $\begin{array}{l}\text { Quincy Bayview Bridge at } \\
\text { Quincy, IL }\end{array}$ & not known & yes & no, not known \\
\hline Illinois & Clark Bridge at Alton, IL & no & yes & no, not known \\
\hline Indiana & 46-03-7495 EBL & no & yes & no, not known \\
\hline Indiana & I65-68-7910 & no & yes & no, not known \\
\hline Iowa & Burlington, IA & not known & yes & no, not known \\
\hline Kentucky & $\begin{array}{l}\text { William Natcher Bridge, } \\
\text { Owensboro, KY }\end{array}$ & not known & yes & no, not known \\
\hline Kentucky & $\begin{array}{l}\text { William H. Harsha Bridge, } \\
\text { Maysville, KY }\end{array}$ & no & no & not applicable \\
\hline Louisiana & $\begin{array}{l}\text { Mississippi River Bridge at } \\
\text { Luling, LA }\end{array}$ & $\begin{array}{l}\text { yes-see CTL report of } \\
\text { July } 2004\end{array}$ & yes & $\begin{array}{l}\text { yes_due to other } \\
\text { reasons }\end{array}$ \\
\hline \multicolumn{5}{|l|}{ Mississippi } \\
\hline Massachusetts & $\begin{array}{l}\text { Leonard P. Zakim Bunker } \\
\text { Hill Bridge, Boston, MA }\end{array}$ & no & $\begin{array}{l}\text { no-internal dampers } \\
\text { at deck level, stuffing } \\
\text { box with HDPE drilled } \\
\text { plate and compressive } \\
\text { material at pylon }\end{array}$ & not applicable \\
\hline Missouri & $\begin{array}{l}\text { Bill Emerson Memorial } \\
\text { Bridge, Cape Girardeau }\end{array}$ & no & yes & no, not known \\
\hline Ohio & $\begin{array}{l}\text { Maumee River Bridge, } \\
\text { Toledo }\end{array}$ & no & no & not applicable \\
\hline South Carolina & Cooper River Bridge & N/A & N/A & N/A \\
\hline Texas & Veterans Memorial Bridge & no & yes & $\begin{array}{l}\text { yes-due to loosening } \\
\text { of retainers }\end{array}$ \\
\hline Texas & Fred Hartman Bridge & no & yes & $\begin{array}{l}\text { yes-due to shearing } \\
\text { off of retainers }\end{array}$ \\
\hline
\end{tabular}




\section{NCHRP SYNTHESIS TOPIC 35-07-INSPECTION AND MAINTENANCE OF BRIDGE STAY CABLE SYSTEMS}

\begin{tabular}{|c|c|c|c|c|}
\hline State & Bridge & Q4.13 & Q4.14 & Q4.15 \\
\hline Virginia & $\begin{array}{l}\text { I-295 over James River } \\
\text { (Varina-Enon Bridge) }\end{array}$ & not known & $\begin{array}{l}\text { yes-only at the } \\
\text { bottom anchorages, } \\
\text { since the stays are } \\
\text { continuous over the } \\
\text { pylons }\end{array}$ & $\begin{array}{l}\text { yes-due to other } \\
\text { reasons. Due to the } \\
\text { misalignment of stay } \\
\text { and guide pipes and no } \\
\text { positive restraint was } \\
\text { provided to keep } \\
\text { neoprene ring from } \\
\text { moving outward }\end{array}$ \\
\hline Washington & $\begin{array}{l}\text { Gum Street-Kennewick, } \\
\text { WA }\end{array}$ & no & not known & no, not known \\
\hline Washington & Thea-Foss Tacoma, WA & no & yes & no, not known \\
\hline Wisconsin & $\begin{array}{l}\text { Sixth Street Viaduct, North } \\
\text { Cable Stay }\end{array}$ & no & no at top, yes at bottom & no, not known \\
\hline Wisconsin & $\begin{array}{l}\text { Sixth Street Viaduct, South } \\
\text { Cable Stay }\end{array}$ & no & no at top, yes at bottom & no, not known \\
\hline Alberta/Calgary & Prince's Island (Pedestrian) & not known & no & not applicable \\
\hline Alberta/Calgary & Carburn Park (Pedestrian) & not known & no & not applicable \\
\hline Alberta/Calgary & McMahon (Pedestrian) & not known & no & not applicable \\
\hline Alberta/Calgary & Fox Hollow (Pedestrian) & yes & no & not applicable \\
\hline Alberta/Calgary & Stoney Trail (Pedestrian) & no & no & not applicable \\
\hline British Columbia & Alex Fraser Bridge & no & yes & $\begin{array}{l}\text { yes-due to other } \\
\text { reasons }\end{array}$ \\
\hline Manitoba/Winnipeg & Esplanade Riel & no & $\begin{array}{l}\text { yes-these provide } \\
\text { damping }\end{array}$ & no, not known \\
\hline New Brunswick & Hawkshaw & no & no & not applicable \\
\hline New Brunswick & Longs Creek \#1 & no & no & not applicable \\
\hline New Brunswick & Nackawic River & no & no & not applicable \\
\hline Quebec, Canada & Galipeault & no & no & not applicable \\
\hline Quebec, Canada & Papineau & $\begin{array}{l}\text { yes-corrosion on } \\
\text { threaded rod }\end{array}$ & yes & no, not known \\
\hline Quebec, Canada & Price & no & yes & $\begin{array}{l}\text { yes-due to shearing off } \\
\text { of retainers }\end{array}$ \\
\hline
\end{tabular}




\section{NCHRP SYNTHESIS TOPIC 35-07-INSPECTION AND MAINTENANCE OF BRIDGE STAY CABLE SYSTEMS}

\section{Questions:}

Q4.16 Has moisture been found in any of the internal components of stay cables such as the bottom anchorage areas?

Q4.17 Has fatigue of MTE or other components of stay cables been observed?

Q4.18 Do the cables have viscous dampers installed at deck or tower levels?

\section{Responses:}

\begin{tabular}{|c|c|c|c|c|}
\hline State & Bridge & Q4.16 & Q4.17 & Q4.18 \\
\hline Alabama & Cochrane Africatown & yes & no & $\begin{array}{l}\text { yes-retrofitted to } \\
\text { correct vibrations }\end{array}$ \\
\hline Alaska & $\begin{array}{l}\text { Sitka Harbor Bridge, Sitka, } \\
\text { Alaska }\end{array}$ & $\begin{array}{l}\text { yes-area around each } \\
\text { cable was filled with } \\
\text { grease }\end{array}$ & no & no \\
\hline Alaska & $\begin{array}{l}\text { Captain William Moore } \\
\text { Bridge, Skagway }\end{array}$ & $\begin{array}{l}\text { yes-area around each } \\
\text { cable was filled with } \\
\text { grease }\end{array}$ & no & no \\
\hline California & $\begin{array}{l}\text { Sacramento River } \\
\text { (Meridian) }\end{array}$ & not tested, not known & no & no \\
\hline Delaware & $\begin{array}{l}\text { Br. 1-902, SR-1 over the } \\
\text { Chesapeake and Delaware } \\
\text { Canal, St. Georges, New } \\
\text { Castle County, Delaware }\end{array}$ & $\begin{array}{l}\text { Not known- } \\
\text { efflorescence from } \\
\text { anchorages as well as } \\
\text { protective pipe splice } \\
\text { sleeves leads inspectors } \\
\text { to believe moisture is } \\
\text { infiltrating the cable } \\
\text { stay system }\end{array}$ & no & no \\
\hline Florida & Dame Point Bridge & yes & no & no \\
\hline Georgia & $\begin{array}{l}\text { Talmadge Memorial } \\
\text { Bridge, Savannah }\end{array}$ & no & no & no \\
\hline Georgia & $\begin{array}{l}\text { Sidney Lanier Bridge, } \\
\text { Brunswick }\end{array}$ & no & no & no \\
\hline Illinois & $\begin{array}{l}\text { Quincy Bayview Bridge at } \\
\text { Quincy, IL }\end{array}$ & yes & no & no \\
\hline Illinois & Clark Bridge at Alton, IL & $\begin{array}{l}\text { Not known-some rust } \\
\text { visible at a few } \\
\text { anchorages }\end{array}$ & no & no \\
\hline Indiana & 46-03-7495 EBL & not tested & no & no \\
\hline Indiana & I65-68-7910 & not tested & no & no \\
\hline Iowa & Burlington, IA & not known & no & no \\
\hline Kentucky & $\begin{array}{l}\text { William Natcher Bridge, } \\
\text { Owensboro, KY }\end{array}$ & $\begin{array}{l}\text { yes-moisture was } \\
\text { detected during } \\
\text { construction when a } \\
\text { cable slipped the wedge } \\
\text { and had to be replaced, } \\
\text { but not since }\end{array}$ & no & no \\
\hline Kentucky & $\begin{array}{l}\text { William H. Harsha Bridge, } \\
\text { Maysville, KY }\end{array}$ & no & no & no \\
\hline Louisiana & $\begin{array}{l}\text { Mississippi River Bridge at } \\
\text { Luling, LA }\end{array}$ & $\begin{array}{l}\text { yes-see July } 2004 \\
\text { CTL report }\end{array}$ & no & no \\
\hline \multicolumn{5}{|l|}{ Mississippi } \\
\hline Massachusetts & $\begin{array}{l}\text { Leonard P. Zakim Bunker } \\
\text { Hill Bridge, Boston, MA }\end{array}$ & no & no & $\begin{array}{l}\text { yes, from the } \\
\text { beginning-internal } \\
\text { dampers at deck level }\end{array}$ \\
\hline Missouri & $\begin{array}{l}\text { Bill Emerson Memorial } \\
\text { Bridge, Cape Girardeau }\end{array}$ & no & no & no \\
\hline Ohio & $\begin{array}{l}\text { Maumee River Bridge, } \\
\text { Toledo }\end{array}$ & no & no & $\begin{array}{l}\text { yes-from the } \\
\text { beginning }\end{array}$ \\
\hline South Carolina & Cooper River Bridge & N/A & N/A & $\begin{array}{l}\text { yes-from the } \\
\text { beginning }\end{array}$ \\
\hline
\end{tabular}




\section{NCHRP SYNTHESIS TOPIC 35-07_INSPECTION AND MAINTENANCE OF BRIDGE STAY CABLE SYSTEMS}

\begin{tabular}{|c|c|c|c|c|}
\hline State & Bridge & Q4.16 & Q4.17 & Q4.18 \\
\hline Texas & Veterans Memorial Bridge & no & no & $\begin{array}{l}\text { yes-retrofitted to } \\
\text { correct vibrations- } \\
\text { presently being } \\
\text { installed }\end{array}$ \\
\hline Texas & Fred Hartman Bridge & no & $\begin{array}{l}\text { yes-possible wire } \\
\text { breaks have been } \\
\text { detected by acoustic } \\
\text { monitoring system }\end{array}$ & $\begin{array}{l}\text { yes-retrofitted to } \\
\text { correct vibrations; } \\
\text { presently being } \\
\text { installed }\end{array}$ \\
\hline Virginia & $\begin{array}{l}\text { I-295 over James River } \\
\text { (Varina-Enon Bridge) }\end{array}$ & no & $\begin{array}{l}\text { no-the forces } \\
\text { obtained in the initial } \\
\text { in-depth inspection } \\
\text { indicated a good } \\
\text { correlation with the } \\
\text { designer's predicted } \\
\text { forces }\end{array}$ & $\begin{array}{l}\text { no-details are } \\
\text { included in the } \\
\text { maintenance manual } \\
\text { (Appendix F) as an } \\
\text { alternate stay damper } \\
\text { system }\end{array}$ \\
\hline Washington & $\begin{array}{l}\text { Gum Street-Kennewick, } \\
\text { WA }\end{array}$ & no & no & no \\
\hline Washington & Thea-Foss Tacoma, WA & no & no & no \\
\hline Wisconsin & $\begin{array}{l}\text { Sixth Street Viaduct, North } \\
\text { Cable Stay }\end{array}$ & no & no & no \\
\hline Wisconsin & $\begin{array}{l}\text { Sixth Street Viaduct, South } \\
\text { Cable Stay }\end{array}$ & no & no & no \\
\hline Alberta/Calgary & Prince's Island (Pedestrian) & not tested & not known & no \\
\hline Alberta/Calgary & Carburn Park (Pedestrian) & not tested & no & no \\
\hline Alberta/Calgary & McMahon (Pedestrian) & not tested & no & no \\
\hline Alberta/Calgary & Fox Hollow (Pedestrian) & no & yes & no \\
\hline Alberta/Calgary & Stoney Trail (Pedestrian) & no & no & no \\
\hline British Columbia & Alex Fraser Bridge & no & no & no \\
\hline Manitoba/Winnipeg & Esplanade Riel & no & no & $\begin{array}{l}\text { no-damping via } \\
\text { neoprene rings }\end{array}$ \\
\hline New Brunswick & Hawkshaw & not tested & no & $\begin{array}{l}\text { yes-retrofitted to } \\
\text { correct vibrations. } \\
\text { Wood clamps placed at } \\
1 / 3 \text { points of the six } \\
\text { cables }\end{array}$ \\
\hline New Brunswick & Longs Creek \#1 & not tested & no & $\begin{array}{l}\text { yes-retrofitted to } \\
\text { correct vibrations }\end{array}$ \\
\hline New Brunswick & Nackawic River & not tested & no & $\begin{array}{l}\text { yes-retrofitted to } \\
\text { correct vibrations }\end{array}$ \\
\hline Quebec, Canada & Galipeault & no & no & no \\
\hline Quebec, Canada & Papineau & no & no & no \\
\hline Quebec, Canada & Price & no & $\begin{array}{l}\text { yes-see question no. } \\
4-27\end{array}$ & no \\
\hline
\end{tabular}




\section{NCHRP SYNTHESIS TOPIC 35-07-INSPECTION AND MAINTENANCE OF BRIDGE STAY CABLE SYSTEMS}

\section{Questions:}

Q4.19 Do the cables have cross cables installed between them?

Q4.20 Do cables have other dampers (other than viscous or neoprene rings) to control vibrations?

Q4.21 Has cracking of the cable sheathing or sheathing connections been noted?

\section{Responses:}

\begin{tabular}{|c|c|c|c|c|}
\hline State & Bridge & Q4.19 & Q4.20 & Q4.21 \\
\hline Alabama & Cochrane Africatown & no & no & no \\
\hline Alaska & $\begin{array}{l}\text { Sitka Harbor Bridge, Sitka, } \\
\text { Alaska }\end{array}$ & no & no & not applicable \\
\hline Alaska & $\begin{array}{l}\text { Captain William Moore } \\
\text { Bridge, Skagway }\end{array}$ & no & no & not applicable \\
\hline California & $\begin{array}{l}\text { Sacramento River } \\
\text { (Meridian) }\end{array}$ & no & $\begin{array}{l}\text { Cables utilize clamps } \\
\text { near the saddles to } \\
\text { retain separation of the } \\
\text { cable groups; these may } \\
\text { provide some } \\
\text { unintentional damping }\end{array}$ & N/A \\
\hline Delaware & $\begin{array}{l}\text { Br. 1-902, SR-1 over the } \\
\text { Chesapeake and Delaware } \\
\text { Canal, St. Georges, New } \\
\text { Castle County, Delaware }\end{array}$ & no & no & $\begin{array}{l}\text { yes, sheathing- } \\
\text { cracking of the steel } \\
\text { protective pipe has been } \\
\text { noted on the upper- } \\
\text { most stay cable of the } \\
\text { north pylon. Cracking } \\
\text { has been attributed to } \\
\text { the position of a } \\
\text { construction grout vent } \\
\text { hole at a high stress } \\
\text { location }\end{array}$ \\
\hline Florida & Dame Point Bridge & $\begin{array}{l}\text { yes-from the } \\
\text { beginning }\end{array}$ & no & yes-connections \\
\hline Georgia & $\begin{array}{l}\text { Talmadge Memorial } \\
\text { Bridge, Savannah }\end{array}$ & no & no & no \\
\hline Georgia & $\begin{array}{l}\text { Sidney Lanier Bridge, } \\
\text { Brunswick }\end{array}$ & no & no & no \\
\hline Illinois & $\begin{array}{l}\text { Quincy Bayview Bridge at } \\
\text { Quincy, IL }\end{array}$ & no & no & yes_-sheathing \\
\hline Illinois & Clark Bridge at Alton, IL & $\begin{array}{l}\text { yes-retrofitted to } \\
\text { correct vibrations }\end{array}$ & no & not known \\
\hline Indiana & 46-03-7495 EBL & $\begin{array}{l}\text { yes-from the } \\
\text { beginning }\end{array}$ & no & no \\
\hline Indiana & I65-68-7910 & no & no & no \\
\hline Iowa & Burlington, IA & $\begin{array}{l}\text { yes-retrofitted to } \\
\text { correct vibrations }\end{array}$ & yes, other-Tie cables & no \\
\hline Kentucky & $\begin{array}{l}\text { William Natcher Bridge, } \\
\text { Owensboro, KY }\end{array}$ & $\begin{array}{l}\text { yes-from the } \\
\text { beginning }\end{array}$ & no & no \\
\hline Kentucky & $\begin{array}{l}\text { William H. Harsha Bridge, } \\
\text { Maysville, KY }\end{array}$ & $\begin{array}{l}\text { yes-from the } \\
\text { beginning }\end{array}$ & no & no answer \\
\hline Louisiana & $\begin{array}{l}\text { Mississippi River Bridge at } \\
\text { Luling, LA }\end{array}$ & no & no & yes-sheathing \\
\hline \multicolumn{5}{|l|}{ Mississippi } \\
\hline Massachusetts & $\begin{array}{l}\text { Leonard P. Zakim Bunker } \\
\text { Hill Bridge, Boston, MA }\end{array}$ & $\begin{array}{l}\text { yes-from the } \\
\text { beginning }\end{array}$ & no & no \\
\hline Missouri & $\begin{array}{l}\text { Bill Emerson Memorial } \\
\text { Bridge, Cape Girardeau }\end{array}$ & yes-from the beginning & no & no \\
\hline Ohio & $\begin{array}{l}\text { Maumee River Bridge, } \\
\text { Toledo }\end{array}$ & no & no & no \\
\hline South Carolina & Cooper River Bridge & $\begin{array}{l}\text { no-bridge not } \\
\text { finished. A provisional } \\
\text { feature if needed }\end{array}$ & $\begin{array}{l}\text { yes-external hydraulic } \\
\text { dampers }\end{array}$ & N/A \\
\hline Texas & Veterans Memorial Bridge & no & no & no \\
\hline
\end{tabular}




\section{NCHRP SYNTHESIS TOPIC 35-07-INSPECTION AND MAINTENANCE OF BRIDGE STAY CABLE SYSTEMS}

\begin{tabular}{|c|c|c|c|c|}
\hline State & Bridge & Q4.19 & Q4.20 & Q4.21 \\
\hline Texas & Fred Hartman Bridge & $\begin{array}{l}\text { yes-retrofitted to } \\
\text { correct vibrations; } \\
\text { presently being } \\
\text { installed }\end{array}$ & no & no \\
\hline Virginia & $\begin{array}{l}\text { I-295 over James River } \\
\text { (Varina-Enon Bridge) }\end{array}$ & no & no & no \\
\hline Washington & $\begin{array}{l}\text { Gum Street-Kennewick, } \\
\text { WA }\end{array}$ & no & no & no \\
\hline Washington & Thea-Foss Tacoma, WA & no & no & no \\
\hline Wisconsin & $\begin{array}{l}\text { Sixth Street Viaduct, North } \\
\text { Cable Stay }\end{array}$ & no & no & no \\
\hline Wisconsin & $\begin{array}{l}\text { Sixth Street Viaduct, South } \\
\text { Cable Stay }\end{array}$ & no & no & no \\
\hline Alberta/Calgary & Prince's Island (Pedestrian) & no & no & not applicable \\
\hline Alberta/Calgary & Carburn Park (Pedestrian) & no & no & not applicable \\
\hline Alberta/Calgary & McMahon (Pedestrian) & $\begin{array}{l}\text { yes-from the } \\
\text { beginning }\end{array}$ & no & not applicable \\
\hline Alberta/Calgary & Fox Hollow (Pedestrian) & $\begin{array}{l}\text { yes-retrofitted to } \\
\text { correct vibrations }\end{array}$ & no & not applicable \\
\hline Alberta/Calgary & Stoney Trail (Pedestrian) & $\begin{array}{l}\text { yes-from the } \\
\text { beginning }\end{array}$ & no & no \\
\hline British Columbia & Alex Fraser Bridge & no & no & no \\
\hline Manitoba/Winnipeg & Esplanade Riel & no & no & no \\
\hline New Brunswick & Hawkshaw & no & $\begin{array}{l}\text { yes-other dampers, } \\
\text { wood clamps }\end{array}$ & not applicable \\
\hline New Brunswick & Longs Creek \#1 & no & yes-other dampers & not applicable \\
\hline New Brunswick & Nackawic River & no & yes-other dampers & not applicable \\
\hline Quebec, Canada & Galipeault & no & no & not applicable \\
\hline Quebec, Canada & Papineau & no & no & no \\
\hline Quebec, Canada & Price & no & no & no \\
\hline
\end{tabular}




\section{NCHRP SYNTHESIS TOPIC 35-07-INSPECTION AND MAINTENANCE OF BRIDGE STAY CABLE SYSTEMS}

\section{Questions:}

Q4.22 Has cracking or misalignment of the guide pipes been noted?

Q4.23 If there is protective tape wrapped around the cable sheathing; have there been reports of deterioration of the tape?

Q4.24 Have any problems associated with neoprene boots been noted?

\section{Responses:}

\begin{tabular}{|c|c|c|c|c|}
\hline State & Bridge & Q4.22 & Q4.23 & Q4.24 \\
\hline Alabama & Cochrane Africatown & yes-misalignment & yes-minor damage & yes \\
\hline Alaska & $\begin{array}{l}\text { Sitka Harbor Bridge, Sitka, } \\
\text { Alaska }\end{array}$ & not known & not applicable & no \\
\hline Alaska & $\begin{array}{l}\text { Captain William Moore } \\
\text { Bridge, Skagway }\end{array}$ & not known & not applicable & no \\
\hline California & $\begin{array}{l}\text { Sacramento River } \\
\text { (Meridian) }\end{array}$ & N/A & N/A & $\begin{array}{l}\text { The neoprene seals } \\
\text { noted above that retain } \\
\text { grease in the anchorage } \\
\text { areas leak }\end{array}$ \\
\hline Delaware & $\begin{array}{l}\text { Br. 1-902, SR-1 over the } \\
\text { Chesapeake and Delaware } \\
\text { Canal, St. Georges, New } \\
\text { Castle County, Delaware }\end{array}$ & no & $\begin{array}{l}\text { not applicable-the } \\
\text { protective steel pipe is } \\
\text { painted }\end{array}$ & $\begin{array}{l}\text { yes-minor tearing of } \\
\text { one neoprene boot has } \\
\text { been observed }\end{array}$ \\
\hline Florida & Dame Point Bridge & no & N/A & no \\
\hline Georgia & $\begin{array}{l}\text { Talmadge Memorial } \\
\text { Bridge, Savannah }\end{array}$ & yes_cracking & no & no \\
\hline Georgia & $\begin{array}{l}\text { Sidney Lanier Bridge, } \\
\text { Brunswick }\end{array}$ & no & no & no \\
\hline Illinois & $\begin{array}{l}\text { Quincy Bayview Bridge at } \\
\text { Quincy, IL }\end{array}$ & no & $\begin{array}{l}\text { N/A-see comment } \\
\text { above about wrapping } \\
\text { in } 2003\end{array}$ & no \\
\hline Illinois & Clark Bridge at Alton, IL & no & no & no \\
\hline Indiana & 46-03-7495 EBL & no & N/A & no \\
\hline Indiana & I65-68-7910 & not applicable & no & no \\
\hline Iowa & Burlington, IA & no & yes-minor damage & no \\
\hline Kentucky & $\begin{array}{l}\text { William Natcher Bridge, } \\
\text { Owensboro, KY }\end{array}$ & no & no & no \\
\hline Kentucky & $\begin{array}{l}\text { William H. Harsha Bridge, } \\
\text { Maysville, KY }\end{array}$ & no & not applicable & no \\
\hline Louisiana & $\begin{array}{l}\text { Mississippi River Bridge at } \\
\text { Luling, LA }\end{array}$ & no & $\begin{array}{l}\text { yes-moderate } \\
\text { damage-damaged } \\
\text { areas of undetermined } \\
\text { cause. Look to be } \\
\text { impact but very high } \\
\text { off deck }\end{array}$ & $\begin{array}{l}\text { yes-not boots, } \\
\text { washers-split } \\
\text { neoprene washers are } \\
\text { held in place by bolts } \\
\text { and caulked }\end{array}$ \\
\hline \multicolumn{5}{|l|}{ Mississippi } \\
\hline Massachusetts & $\begin{array}{l}\text { Leonard P. Zakim Bunker } \\
\text { Hill Bridge, Boston, MA }\end{array}$ & no & not applicable & no-not applicable \\
\hline Missouri & $\begin{array}{l}\text { Bill Emerson Memorial } \\
\text { Bridge, Cape Girardeau }\end{array}$ & no & no & no \\
\hline Ohio & $\begin{array}{l}\text { Maumee River Bridge, } \\
\text { Toledo }\end{array}$ & no & not applicable & no \\
\hline South Carolina & Cooper River Bridge & not known & N/A & not known \\
\hline Texas & Veterans Memorial Bridge & no & yes-minor damage & no \\
\hline Texas & Fred Hartman Bridge & no & yes-minor damage & no \\
\hline Virginia & $\begin{array}{l}\text { I-295 over James River } \\
\text { (Varina-Enon Bridge) }\end{array}$ & yes-misalignment & no & $\begin{array}{l}\text { yes-minor cracks and } \\
\text { tears have been noted in } \\
6 \text { of the } 52 \text { neoprene } \\
\text { boots }\end{array}$ \\
\hline Washington & $\begin{array}{l}\text { Gum Street-Kennewick, } \\
\text { WA }\end{array}$ & no & yes-extensive damage & yes \\
\hline Washington & Thea-Foss Tacoma, WA & no & yes-minor damage & no \\
\hline
\end{tabular}




\section{NCHRP SYNTHESIS TOPIC 35-07-INSPECTION AND MAINTENANCE OF BRIDGE STAY CABLE SYSTEMS}

\begin{tabular}{|c|c|c|c|c|}
\hline State & Bridge & Q4.22 & Q4.23 & Q4.24 \\
\hline Wisconsin & $\begin{array}{l}\text { Sixth Street Viaduct, North } \\
\text { Cable Stay }\end{array}$ & $\begin{array}{l}\text { yes-misalignment, } \\
\text { top guide pipes not } \\
\text { concentric with PE is } \\
\text { the only misalignment }\end{array}$ & no & no \\
\hline Wisconsin & $\begin{array}{l}\text { Sixth Street Viaduct, South } \\
\text { Cable Stay }\end{array}$ & $\begin{array}{l}\text { yes-misalignment, } \\
\text { top guide pipes not } \\
\text { concentric with PE is } \\
\text { the only misalignment }\end{array}$ & no & no \\
\hline Alberta/Calgary & Prince's Island (Pedestrian) & not applicable & not applicable & not known \\
\hline Alberta/Calgary & Carburn Park (Pedestrian) & not applicable & not applicable & not known \\
\hline Alberta/Calgary & McMahon (Pedestrian) & not applicable & not applicable & not known \\
\hline Alberta/Calgary & Fox Hollow (Pedestrian) & not applicable & not applicable & no \\
\hline Alberta/Calgary & Stoney Trail (Pedestrian) & no & not known & no \\
\hline British Columbia & Alex Fraser Bridge & not applicable & $\begin{array}{l}\text { not applicable-repairs } \\
\text { used protective tape, no } \\
\text { deterioration observed }\end{array}$ & $\begin{array}{l}\text { yes-shifting and } \\
\text { splitting }\end{array}$ \\
\hline Manitoba/Winnipeg & Esplanade Riel & no & not applicable & no \\
\hline New Brunswick & Hawkshaw & not applicable & no & \\
\hline New Brunswick & Longs Creek \#1 & not applicable & yes-minor damage & \\
\hline New Brunswick & Nackawic River & not applicable & no & \\
\hline Quebec, Canada & Galipeault & not applicable & not applicable & no \\
\hline Quebec, Canada & Papineau & not applicable & not applicable & no \\
\hline Quebec, Canada & Price & not applicable & not applicable & no \\
\hline
\end{tabular}




\section{NCHRP SYNTHESIS TOPIC 35-07-INSPECTION AND MAINTENANCE OF BRIDGE STAY CABLE SYSTEMS}

\section{Questions:}

Q4.25 Types of non-destructive tests that any of the cables on this bridge have been subjected to?

Q4.26 Types of sensor-based, long-term monitoring performed on the cables?

Q4.27 Have the cables on this bridge (or any of their components) been repaired?

\section{Responses:}

\begin{tabular}{|c|c|c|c|c|}
\hline State & Bridge & Q4.25 & Q4.26 & Q4.27 \\
\hline Alabama & Cochrane Africatown & $\begin{array}{l}\text { Ultrasonic and } \\
\text { vibration-based force } \\
\text { measurements }\end{array}$ & vibration monitoring & $\begin{array}{l}\text { yes-some neoprene } \\
\text { boots were replaced }\end{array}$ \\
\hline Alaska & $\begin{array}{l}\text { Sitka Harbor Bridge, Sitka, } \\
\text { Alaska }\end{array}$ & $\begin{array}{l}\text { Vibration-based force } \\
\text { measurements }\end{array}$ & not performed & $\begin{array}{l}\text { no-during mid-1990s } \\
\text { cables were removed, } \\
\text { inspected, and replaced } \\
\text { after no defects } \\
\text { observed }\end{array}$ \\
\hline Alaska & $\begin{array}{l}\text { Captain William Moore } \\
\text { Bridge, Skagway }\end{array}$ & $\begin{array}{l}\text { Vibration-based force } \\
\text { measurements }\end{array}$ & not performed & $\begin{array}{l}\text { Bridge redesigned for } \\
\text { higher load capacity. } \\
\text { New cables were } \\
\text { installed during mid- } \\
\text { 1990s }\end{array}$ \\
\hline California & $\begin{array}{l}\text { Sacramento River } \\
\text { (Meridian) }\end{array}$ & $\begin{array}{l}\text { X-ray, primary } \\
\text { inspection method is } \\
\text { VT. "MINAC" } \\
\text { Radiographic } \\
\text { inspection was used } \\
\text { once in } 1989 \text { to inspect } \\
\text { the swedged anchorage } \\
\text { components as a } \\
\text { demonstration of the } \\
\text { technology }\end{array}$ & not performed & no \\
\hline Delaware & $\begin{array}{l}\text { Br. 1-902, SR-1 over the } \\
\text { Chesapeake and Delaware } \\
\text { Canal, St. Georges, New } \\
\text { Castle County, Delaware }\end{array}$ & $\begin{array}{l}\text { Other-a borescope has } \\
\text { been utilized to view } \\
\text { the guidepipe area of } \\
\text { select cable stays for } \\
\text { moisture, fatigue, } \\
\text { deterioration, and } \\
\text { corrosion. An attempt } \\
\text { was made to remove } \\
\text { select anchorage caps; } \\
\text { however, grout inside } \\
\text { the anchorage caps } \\
\text { made removal difficult. } \\
\text { High-powered X-ray } \\
\text { inspection of the cable } \\
\text { stays was considered. } \\
\text { This method has not } \\
\text { been employed due to } \\
\text { concerns for protection } \\
\text { of the public and } \\
\text { personnel during } \\
\text { testing, access } \\
\text { limitations, and } \\
\text { uncertainty of the results } \\
\text { of such investigations } \\
\text { due to the complicated } \\
\text { geometry of the subject } \\
\text { area }\end{array}$ & $\begin{array}{l}\text { Not performed. } \\
\text { Vibration monitoring } \\
\text { equipment has been } \\
\text { installed on the cable } \\
\text { stays by FHWA. } \\
\text { However, this } \\
\text { equipment is currently } \\
\text { not operating and data } \\
\text { are not available. }\end{array}$ & $\begin{array}{l}\text { yes-the out of } \\
\text { position neoprene } \\
\text { dampers have been } \\
\text { repositioned and set } \\
\text { screws have been } \\
\text { installed to secure the } \\
\text { position of the outer } \\
\text { neoprene damper rings } \\
\text { on all cable stays }\end{array}$ \\
\hline Florida & Dame Point Bridge & not performed & not performed & no \\
\hline Georgia & $\begin{array}{l}\text { Talmadge Memorial } \\
\text { Bridge, Savannah }\end{array}$ & $\begin{array}{l}\text { Vibration-based force } \\
\text { measurements }\end{array}$ & not performed & no \\
\hline
\end{tabular}




\section{NCHRP SYNTHESIS TOPIC 35-07-INSPECTION AND MAINTENANCE OF BRIDGE STAY CABLE SYSTEMS}

\begin{tabular}{|c|c|c|c|c|}
\hline State & Bridge & Q4.25 & Q4.26 & Q4.27 \\
\hline Georgia & $\begin{array}{l}\text { Sidney Lanier Bridge, } \\
\text { Brunswick }\end{array}$ & not performed & not performed & no \\
\hline Illinois & $\begin{array}{l}\text { Quincy Bayview Bridge at } \\
\text { Quincy, IL }\end{array}$ & not performed & $\begin{array}{l}\text { acoustic wire break } \\
\text { detection }\end{array}$ & $\begin{array}{l}\text { yes-previous } \\
\text { intermittent wrapping. } \\
\text { See comment above } \\
\text { about complete } \\
\text { wrapping in } 2003 \\
\end{array}$ \\
\hline Illinois & Clark Bridge at Alton, IL & not performed & not performed & no \\
\hline Indiana & 46-03-7495 EBL & not performed & not performed & no \\
\hline Indiana & I65-68-7910 & not performed & not performed & no \\
\hline Iowa & Burlington, IA & $\begin{array}{l}\text { Vibration-based force } \\
\text { measurements. } \\
\text { Vibration } \\
\text { measurements were } \\
\text { done during } \\
\text { construction to } \\
\text { determine amount of } \\
\text { force in cables }\end{array}$ & not performed & no \\
\hline Kentucky & $\begin{array}{l}\text { William Natcher Bridge, } \\
\text { Owensboro, KY }\end{array}$ & not performed & not performed & no \\
\hline Kentucky & $\begin{array}{l}\text { William H. Harsha Bridge, } \\
\text { Maysville, KY }\end{array}$ & not performed & not performed & no \\
\hline Louisiana & $\begin{array}{l}\text { Mississippi River Bridge at } \\
\text { Luling, LA }\end{array}$ & $\begin{array}{l}\text { Vibration-based force } \\
\text { measurements }\end{array}$ & vibration monitoring & $\begin{array}{l}\text { yes-splits in early } \\
\text { years repaired by heat } \\
\text { welding, wrapped with } \\
\text { Tedlar tape }\end{array}$ \\
\hline \multicolumn{5}{|l|}{ Mississippi } \\
\hline Massachusetts & $\begin{array}{l}\text { Leonard P. Zakim Bunker } \\
\text { Hill Bridge, Boston, MA }\end{array}$ & not performed & not performed & no \\
\hline Missouri & $\begin{array}{l}\text { Bill Emerson Memorial } \\
\text { Bridge, Cape Girardeau }\end{array}$ & not performed & not performed & $\begin{array}{l}\text { yes-splices were } \\
\text { added to HDPE } \\
\text { sheathing during } \\
\text { construction of a couple } \\
\text { of cables }\end{array}$ \\
\hline Ohio & $\begin{array}{l}\text { Maumee River Bridge, } \\
\text { Toledo }\end{array}$ & not performed & not performed & no \\
\hline South Carolina & Cooper River Bridge & not performed & not performed & no \\
\hline Texas & Veterans Memorial Bridge & $\begin{array}{l}\text { Vibration-based force } \\
\text { measurements, used to } \\
\text { aid in the design of } \\
\text { viscous dampers for the } \\
\text { bridge. Performed } \\
\text { periodically to compare } \\
\text { predampened response } \\
\text { to post-dampened } \\
\text { response }\end{array}$ & $\begin{array}{l}\text { Acoustic wire break } \\
\text { detection, vibration } \\
\text { monitoring, other. Have } \\
\text { long-term weather } \\
\text { monitoring to associate } \\
\text { with oscillation events }\end{array}$ & $\begin{array}{l}\text { yes-retightened the } \\
\text { retainers for the } \\
\text { neoprene rings }\end{array}$ \\
\hline Texas & Fred Hartman Bridge & $\begin{array}{l}\text { Vibration-based force } \\
\text { measurements, used to } \\
\text { aid in the design of } \\
\text { viscous dampers for the } \\
\text { bridge. Performed } \\
\text { periodically to compare } \\
\text { predampened response } \\
\text { to post-dampened } \\
\text { response }\end{array}$ & $\begin{array}{l}\text { Acoustic wire break } \\
\text { detection, vibration } \\
\text { monitoring, other- } \\
\text { have long-term weather } \\
\text { monitoring to associate } \\
\text { with oscillation events }\end{array}$ & $\begin{array}{l}\text { yes-rewelded and } \\
\text { stiffened guide pipe. } \\
\text { Replaced initial } \\
\text { restrainer system after } \\
\text { fatigue and failure of } \\
\text { original restrainer } \\
\text { cables }\end{array}$ \\
\hline Virginia & $\begin{array}{l}\text { I-295 over James River } \\
\text { (Varina-Enon Bridge) }\end{array}$ & $\begin{array}{l}\text { Vibration-based force } \\
\text { measurements. Tension } \\
\text { force measurement tests } \\
\text { were performed by } \\
\text { Construction } \\
\text { Technology Laboratory, } \\
\text { Inc. (CTL) in April } \\
1999\end{array}$ & not known & no \\
\hline Washington & $\begin{array}{l}\text { Gum Street-Kennewick, } \\
\text { WA }\end{array}$ & magnetic & not performed & no \\
\hline
\end{tabular}




\section{NCHRP SYNTHESIS TOPIC 35-07-INSPECTION AND MAINTENANCE OF BRIDGE STAY CABLE SYSTEMS}

\begin{tabular}{|c|c|c|c|c|}
\hline State & Bridge & Q4.25 & Q4.26 & Q4.27 \\
\hline Washington & Thea-Foss Tacoma, WA & not performed & not performed & no \\
\hline Wisconsin & $\begin{array}{l}\text { Sixth Street Viaduct, North } \\
\text { Cable Stay }\end{array}$ & $\begin{array}{l}\text { Not performed. By } \\
\text { requirements of } \\
\text { supplier, full-scale stay } \\
\text { cable fatigue tests by } \\
\text { Construction } \\
\text { Technology } \\
\text { Laboratories in Skokie, } \\
\text { IL and Technical } \\
\text { University of Munich; } \\
\text { no wire breaks during } 2 \\
\text { million cycle fatigue } \\
\text { tests. During reload and } \\
\text { static tests, failed to } \\
\text { meet min. tensile force } \\
\text { of } 95 \% \text { GUTS (only } \\
90 \% \text { ). Therefore, added } \\
\text { strands at all locations }\end{array}$ & not performed & no \\
\hline Wisconsin & $\begin{array}{l}\text { Sixth Street Viaduct, South } \\
\text { Cable Stay }\end{array}$ & $\begin{array}{l}\text { Not performed. By } \\
\text { requirements of } \\
\text { supplier, full-scale stay } \\
\text { cable fatigue tests by } \\
\text { Construction } \\
\text { Technology } \\
\text { Laboratories in Skokie, } \\
\text { IL and Technical } \\
\text { University of Munich; } \\
\text { no wire breaks during } 2 \\
\text { million cycle fatigue } \\
\text { tests. During reload and } \\
\text { static tests, failed to } \\
\text { meet min. tensile force } \\
\text { of } 95 \% \text { GUTS (only } \\
90 \% \text { ). Therefore, added } \\
\text { strands at all locations }\end{array}$ & not performed & no \\
\hline Alberta/Calgary & Prince's Island (Pedestrian) & not performed & not performed & no \\
\hline Alberta/Calgary & Carburn Park (Pedestrian) & not performed & not performed & no \\
\hline Alberta/Calgary & McMahon (Pedestrian) & not performed & not performed & no \\
\hline Alberta/Calgary & Fox Hollow (Pedestrian) & $\begin{array}{l}\text { magnetic, ultrasonic, } \\
\text { and vibration-based } \\
\text { force measurements }\end{array}$ & not performed & $\begin{array}{l}\text { yes-two bars failed } \\
\text { and were replaced. One } \\
\text { additional bar replaced } \\
\text { due to corrosion }\end{array}$ \\
\hline Alberta/Calgary & Stoney Trail (Pedestrian) & not performed & not performed & no \\
\hline British Columbia & Alex Fraser Bridge & not performed & $\begin{array}{l}\text { Acoustic wire break } \\
\text { detection-performed } \\
\text { short term, now } \\
\text { discontinued } \\
\end{array}$ & $\begin{array}{l}\text { yes_boots replaced or } \\
\text { repaired, sheaths } \\
\text { repaired }\end{array}$ \\
\hline Manitoba/Winnipeg & Esplanade Riel & $\begin{array}{l}\text { Not performed. } \\
\text { Vibration-based force } \\
\text { measurements on } \\
\text { selected MTE will be } \\
\text { performed and } \\
\text { continuously monitored } \\
\text { using a permanent } \\
\text { SHM system }\end{array}$ & vibration monitoring & $\begin{array}{l}\text { yes-extensions to } \\
\text { permit additional } \\
\text { thermal contraction } \\
\text { capability of the HDPE } \\
\text { sheathing installed. } \\
\text { Warranty covered this }\end{array}$ \\
\hline New Brunswick & Hawkshaw & not performed & not performed & no \\
\hline New Brunswick & Longs Creek \#1 & not performed & not performed & no \\
\hline New Brunswick & Nackawic River & not performed & not performed & no \\
\hline Quebec, Canada & Galipeault & $\begin{array}{l}\text { other-laser-based } \\
\text { force measurements }\end{array}$ & not performed & no \\
\hline Quebec, Canada & Papineau & not performed & not performed & no \\
\hline Quebec, Canada & Price & not performed & not performed & $\begin{array}{l}\text { yes-broken anchor } \\
\text { bolt. Failure of two 5- } \\
\text { in. anchor bolts in the } \\
\text { anchorage zone }\end{array}$ \\
\hline
\end{tabular}




\section{NCHRP SYNTHESIS TOPIC 35-07-INSPECTION AND MAINTENANCE OF BRIDGE STAY CABLE SYSTEMS}

\section{Questions:}

Q4.28 Has the sheathing been partially removed on any of the cables to examine condition of grout (if applicable) and/or the MTE?

Q4.29 Can the strands or cables be replaced if needed?

Q4.30 Do you have an inspection and maintenance manual for this bridge?

\section{Responses:}

\begin{tabular}{|c|c|c|c|c|}
\hline State & Bridge & Q4.28 & Q4.29 & Q4.30 \\
\hline Alabama & Cochrane Africatown & $\begin{array}{l}\text { yes-thorough } \\
\text { inspection performed. } \\
\text { Selected cables were } \\
\text { opened up where voids } \\
\text { in grout were detected }\end{array}$ & $\begin{array}{l}\text { yes-individual strands } \\
\text { cannot be replaced, but } \\
\text { an entire stay can be } \\
\text { replaced }\end{array}$ & yes \\
\hline Alaska & $\begin{array}{l}\text { Sitka Harbor Bridge, Sitka, } \\
\text { Alaska }\end{array}$ & not applicable & yes & no \\
\hline Alaska & $\begin{array}{l}\text { Captain William Moore } \\
\text { Bridge, Skagway }\end{array}$ & not applicable & yes & no \\
\hline California & $\begin{array}{l}\text { Sacramento River } \\
\text { (Meridian) }\end{array}$ & N/A & $\begin{array}{l}\text { yes-as this swing } \\
\text { bridge only fully } \\
\text { utilizes the cables to } \\
\text { support the spans in the } \\
\text { open condition, cable } \\
\text { replacement would be } \\
\text { relatively } \\
\text { straightforward }\end{array}$ & no \\
\hline Delaware & $\begin{array}{l}\text { Br. 1-902, SR-1 over the } \\
\text { Chesapeake and Delaware } \\
\text { Canal, St. Georges, New } \\
\text { Castle County, Delaware }\end{array}$ & $\begin{array}{l}\text { no-limited } \\
\text { investigation of the } \\
\text { cable stay grout has } \\
\text { been performed via the } \\
\text { open construction grout } \\
\text { vents in the saddle pipe } \\
\text { area of the cable stay }\end{array}$ & $\begin{array}{l}\text { yes-the original } \\
\text { design accounted for } \\
\text { the replacement of the } \\
\text { stay cables (one at a } \\
\text { time) }\end{array}$ & yes \\
\hline Florida & Dame Point Bridge & no & no & yes \\
\hline Georgia & $\begin{array}{l}\text { Talmadge Memorial } \\
\text { Bridge, Savannah }\end{array}$ & $\begin{array}{l}\text { yes-some removal } \\
\text { and inspection was } \\
\text { done in } 2002 \text {. Grout } \\
\text { was found to be } \\
\text { satisfactory }\end{array}$ & yes & yes \\
\hline Georgia & $\begin{array}{l}\text { Sidney Lanier Bridge, } \\
\text { Brunswick }\end{array}$ & no answer & yes & yes \\
\hline Illinois & $\begin{array}{l}\text { Quincy Bayview Bridge at } \\
\text { Quincy, IL }\end{array}$ & no & yes & no \\
\hline Illinois & Clark Bridge at Alton, IL & no & yes & $\begin{array}{l}\text { yes, not included for } \\
\text { security reasons }\end{array}$ \\
\hline Indiana & 46-03-7495 EBL & no & $\begin{array}{l}\text { Not known-I would } \\
\text { hope that they could be } \\
\text { if needed }\end{array}$ & yes \\
\hline Indiana & I65-68-7910 & no & $\begin{array}{l}\text { Not known-I would } \\
\text { hope that they could be } \\
\text { if needed }\end{array}$ & yes \\
\hline Iowa & Burlington, IA & no & yes & yes \\
\hline Kentucky & $\begin{array}{l}\text { William Natcher Bridge, } \\
\text { Owensboro, KY }\end{array}$ & no & $\begin{array}{l}\text { yes_cable only. } \\
\text { Strand could not be } \\
\text { replaced }\end{array}$ & yes \\
\hline Kentucky & $\begin{array}{l}\text { William H. Harsha Bridge, } \\
\text { Maysville, KY }\end{array}$ & no & yes & yes \\
\hline Louisiana & $\begin{array}{l}\text { Mississippi River Bridge at } \\
\text { Luling, LA }\end{array}$ & $\begin{array}{l}\text { no-planned for next } \\
\text { inspection contract } \\
\text { phase with CTL }\end{array}$ & yes-not easily & no \\
\hline Mississippi & & & & \\
\hline
\end{tabular}


NCHRP SYNTHESIS TOPIC 35-07_INSPECTION AND MAINTENANCE OF BRIDGE STAY CABLE SYSTEMS

\begin{tabular}{|c|c|c|c|c|}
\hline State & Bridge & Q4.28 & Q4.29 & Q4.30 \\
\hline Massachusetts & $\begin{array}{l}\text { Leonard P. Zakim Bunker } \\
\text { Hill Bridge, Boston, MA }\end{array}$ & no & yes & yes \\
\hline Missouri & $\begin{array}{l}\text { Bill Emerson Memorial } \\
\text { Bridge, Cape Girardeau }\end{array}$ & no & yes & no \\
\hline Ohio & $\begin{array}{l}\text { Maumee River Bridge, } \\
\text { Toledo }\end{array}$ & no & yes & no answer \\
\hline South Carolina & Cooper River Bridge & not known & yes & $\begin{array}{l}\text { yes-required } \\
\text { submittal upon } \\
\text { completion in } 2005\end{array}$ \\
\hline Texas & Veterans Memorial Bridge & no & yes & yes \\
\hline Texas & Fred Hartman Bridge & $\begin{array}{l}\text { yes-sheathing was } \\
\text { removed to observe the } \\
\text { condition of grout. } \\
\text { Grout appeared to be in } \\
\text { good/sound condition }\end{array}$ & yes & yes \\
\hline Virginia & $\begin{array}{l}\text { I-295 over James River } \\
\text { (Varina-Enon Bridge) }\end{array}$ & no & yes & yes \\
\hline Washington & $\begin{array}{l}\text { Gum Street-Kennewick, } \\
\text { WA }\end{array}$ & no & not known & yes \\
\hline Washington & Thea-Foss Tacoma, WA & no & not known & yes \\
\hline Wisconsin & $\begin{array}{l}\text { Sixth Street Viaduct, North } \\
\text { Cable Stay }\end{array}$ & no & yes & yes \\
\hline Wisconsin & $\begin{array}{l}\text { Sixth Street Viaduct, South } \\
\text { Cable Stay }\end{array}$ & no & yes & yes \\
\hline Alberta/Calgary & Prince's Island (Pedestrian) & not applicable & no & no \\
\hline Alberta/Calgary & Carburn Park (Pedestrian) & not applicable & yes & no \\
\hline Alberta/Calgary & McMahon (Pedestrian) & not applicable & yes & no \\
\hline Alberta/Calgary & Fox Hollow (Pedestrian) & not applicable & yes & no \\
\hline Alberta/Calgary & Stoney Trail (Pedestrian) & no & yes & no \\
\hline British Columbia & Alex Fraser Bridge & no & yes & yes \\
\hline Manitoba/Winnipeg & Esplanade Riel & no & yes & $\begin{array}{l}\text { no-since this is a new } \\
\text { bridge this should be an } \\
\text { upcoming deliverable } \\
\text { from our consultant }\end{array}$ \\
\hline New Brunswick & Hawkshaw & not applicable & not known & no \\
\hline New Brunswick & Longs Creek \#1 & not applicable & not known & no \\
\hline New Brunswick & Nackawic River & not applicable & not known & no \\
\hline Quebec, Canada & Galipeault & not applicable & yes & no \\
\hline Quebec, Canada & Papineau & no & no & no \\
\hline Quebec, Canada & Price & no & yes & no \\
\hline
\end{tabular}




\section{NCHRP SYNTHESIS TOPIC 35-07-INSPECTION AND MAINTENANCE OF BRIDGE STAY CABLE SYSTEMS}

\section{Questions:}

Q5 Based on your experience and in general, do you believe that the current inspection, testing, monitoring, and repair methods available to you for stay cables are effective and adequate?

Q6 Please comment on the effectiveness of any non-destructive test methods for inspections of stay cables that you may be familiar with. These methods include (but are not limited to) ultrasonic testing, magnetic inspections, laser-based force measurements, X-ray imaging, etc. If possible, please comment on issues such as practicality, cost, duration, impact on traffic, and any other factors that you consider important.

Q7 Please comment on the effectiveness of any cable vibration control measures that you may be familiar with. Examples include installation of cross cables, viscous dampers, neoprene rings, etc.

\section{Responses:}

\begin{tabular}{|c|c|c|c|c|}
\hline State & Bridge & Q5 & Q6 & Q7 \\
\hline Alabama & Cochrane Africatown & yes & $\begin{array}{l}\text { Several non- } \\
\text { destructive tests were } \\
\text { run after an extreme } \\
\text { oscillation event. } \\
\text { Practically all the } \\
\text { above were performed } \\
\text { to determine if there } \\
\text { was any loss of force } \\
\text { in the stays. } \\
\text { Geometric, physical, } \\
\text { and visual tests were } \\
\text { performed. The only } \\
\text { discoveries were } \\
\text { deficiencies in the } \\
\text { original construction, } \\
\text { which were corrected }\end{array}$ & $\begin{array}{l}\text { We realigned stay } \\
\text { pipes and replaced } \\
\text { neoprene rings and } \\
\text { keeper rings. Also, } \\
\text { external hydraulic } \\
\text { dampers were installed } \\
\text { on the longer stays }\end{array}$ \\
\hline Alaska & $\begin{array}{l}\text { Sitka Harbor Bridge, } \\
\text { Sitka, Alaska }\end{array}$ & $\begin{array}{l}\text { Not known-the cables on } \\
\text { both bridges were } \\
\text { inspected during the mid- } \\
\text { 1990s. Cables on Captain } \\
\text { William Moore were } \\
\text { replaced due to an upgrade } \\
\text { of the structure. Cables on } \\
\text { the Sitka Harbor Bridge, } \\
\text { were removed, inspected, } \\
\text { and reinstalled. No } \\
\text { problems were reported } \\
\text { with any of the cables } \\
\text { during the mid-1990 } \\
\text { inspection }\end{array}$ & $\begin{array}{l}\text { The fundamental } \\
\text { frequency of the cables } \\
\text { was recorded. Alaska } \\
\text { DOT\&PF will monitor } \\
\text { the cables and attempt } \\
\text { to determine if the } \\
\text { fundamental frequency } \\
\text { of the cables has } \\
\text { changed }\end{array}$ & N/A \\
\hline Alaska & $\begin{array}{l}\text { Captain William Moore } \\
\text { Bridge, Skagway }\end{array}$ & $\begin{array}{l}\text { Not known-the cables on } \\
\text { both bridges were } \\
\text { inspected during the mid- } \\
\text { 1990s. Cables on Captain } \\
\text { William Moore were } \\
\text { replaced due to an upgrade } \\
\text { of the structure. Cables on } \\
\text { the Sitka Harbor Bridge } \\
\text { were removed, inspected, } \\
\text { and reinstalled. No } \\
\text { problems were reported } \\
\text { with any of the cables } \\
\text { during the mid-1990 } \\
\text { inspection }\end{array}$ & $\begin{array}{l}\text { The fundamental } \\
\text { frequency of the cables } \\
\text { was recorded. Alaska } \\
\text { DOT\&PF will monitor } \\
\text { the cables and attempt } \\
\text { to determine if the } \\
\text { fundamental frequency } \\
\text { of the cables has } \\
\text { changed }\end{array}$ & N/A \\
\hline
\end{tabular}


NCHRP SYNTHESIS TOPIC 35-07-INSPECTION AND MAINTENANCE OF BRIDGE STAY CABLE SYSTEMS

\begin{tabular}{|c|c|c|c|c|}
\hline State & Bridge & Q5 & Q6 & Q7 \\
\hline California & $\begin{array}{l}\text { Sacramento River } \\
\text { (Meridian) }\end{array}$ & not known & $\begin{array}{l}\text { Used radiographic } \\
\text { testing once on this } \\
\text { structure. It was costly } \\
\text { and impractical, but } \\
\text { did appear to give } \\
\text { satisfactory results. } \\
\text { Would not use this } \\
\text { method for routine } \\
\text { inspections on this } \\
\text { bridge }\end{array}$ & no answer \\
\hline Delaware & $\begin{array}{l}\text { Br. 1-902, SR-1 over the } \\
\text { Chesapeake and } \\
\text { Delaware Canal, St. } \\
\text { Georges, New Castle } \\
\text { County, Delaware }\end{array}$ & $\begin{array}{l}\text { no- the use of the steel } \\
\text { protective pipe limits the } \\
\text { inspection methods } \\
\text { available to investigate the } \\
\text { condition of the stay cables }\end{array}$ & $\begin{array}{l}\text { The presence of the } \\
\text { steel protective pipe } \\
\text { limits the effectiveness } \\
\text { of many available } \\
\text { testing methods, } \\
\text { particularly magnetic- } \\
\text { based methods. As } \\
\text { noted above, X-ray } \\
\text { imaging of the cable } \\
\text { stays was considered } \\
\text { and dismissed. Several } \\
\text { concerns were } \\
\text { encountered with this } \\
\text { method including } \\
\text { protection of public } \\
\text { and working personnel } \\
\text { during the exposure, } \\
\text { access, and holding the } \\
\text { equipment at the } \\
\text { higher elevations of } \\
\text { the cable stay, and } \\
\text { scheduling of the } \\
\text { equipment. } \\
\text { Interpretation of the } \\
\text { image was also a } \\
\text { concern. It is believed } \\
\text { that the multiple } \\
\text { materials (steel, grout, } \\
\text { steel strand) that } \\
\text { comprise the cable } \\
\text { stays combined with } \\
\text { the changing geometry } \\
\text { would make } \\
\text { interpretation of the } \\
\text { image difficult and } \\
\text { would not allow for an } \\
\text { accurate understanding } \\
\text { of the conditions. Our } \\
\text { understanding is that } \\
\text { the X-ray imaging } \\
\text { would only be able to } \\
\text { detect gross section } \\
\text { loss of the stay and is } \\
\text { not precise enough to } \\
\text { discern the onset or } \\
\text { early stages of } \\
\text { corrosion. Finally, } \\
\text { when the X-ray } \\
\text { imaging method was } \\
\text { considered, it only } \\
\text { allowed a view of a } \\
\text { discrete section of the } \\
\text { cable stay as opposed } \\
\text { to a global or } \\
\text { "traveling" operation, } \\
\text { which would allow an }\end{array}$ & $\begin{array}{l}\text { The neoprene dampers } \\
\text { of the C\&D Canal } \\
\text { Bridge appear to } \\
\text { operating adequately, } \\
\text { particularly since the } \\
\text { repositioning and } \\
\text { installation of set } \\
\text { screws into the outer } \\
\text { neoprene rings. } \\
\text { Excessive vibration of } \\
\text { the stay cables has not } \\
\text { been noted. No other } \\
\text { cable stay damping } \\
\text { systems or grout spalls } \\
\text { have been observed in } \\
\text { the grout bedding } \\
\text { present on the bridge } \\
\text { (cable stays saddle } \\
\text { area) where the upper } \\
\text { stays (13 thru 16) enter } \\
\text { the pylon. This } \\
\text { spalling has been } \\
\text { attributed to minor } \\
\text { vibrations of the stays }\end{array}$ \\
\hline
\end{tabular}




\section{NCHRP SYNTHESIS TOPIC 35-07-INSPECTION AND MAINTENANCE OF BRIDGE STAY CABLE SYSTEMS}

\begin{tabular}{|c|c|c|c|c|}
\hline State & Bridge & Q5 & Q6 & Q7 \\
\hline & & & $\begin{array}{l}\text { investigation of the } \\
\text { entire length of the } \\
\text { cable stay. } \\
\text { Implementation of } \\
\text { laser-based cable stay } \\
\text { force measurements } \\
\text { are being considered } \\
\text { by the department to } \\
\text { establish baseline force } \\
\text { data for the cable stays }\end{array}$ & \\
\hline Florida & Dame Point Bridge & not known & $\begin{array}{l}\text { Non-destructive testing } \\
\text { is needed to determine } \\
\text { the condition of } \\
\text { tension bars inside the } \\
\text { steel casing of the } \\
\text { cables }\end{array}$ & $\begin{array}{l}\text { Cross cables are } \\
\text { installed on the bridge } \\
\text { and from time to time } \\
\text { they sag and need to be } \\
\text { retightened }\end{array}$ \\
\hline Georgia & $\begin{array}{l}\text { Talmadge Memorial } \\
\text { Bridge, Savannah }\end{array}$ & yes & $\begin{array}{l}\text { Laser-based force } \\
\text { measurements will } \\
\text { give results that will } \\
\text { indicate if a cable is } \\
\text { deviating from the } \\
\text { trending values of the } \\
\text { other cables. It may } \\
\text { not give you an } \\
\text { accurate value of the } \\
\text { force in a cable. It is } \\
\text { relatively easy and } \\
\text { inexpensive to perform }\end{array}$ & $\begin{array}{l}\text { These methods are all } \\
\text { effective in controlling } \\
\text { free vibrations of the } \\
\text { cables. Helical strakes } \\
\text { formed in the cable } \\
\text { neoprene sheathing are } \\
\text { also effective }\end{array}$ \\
\hline Georgia & $\begin{array}{l}\text { Sidney Lanier Bridge, } \\
\text { Brunswick }\end{array}$ & yes & $\begin{array}{l}\text { Laser-based force } \\
\text { measurements will } \\
\text { give results that will } \\
\text { indicate if a cable is } \\
\text { deviating from the } \\
\text { trending values of the } \\
\text { other cables. It may } \\
\text { not give you an } \\
\text { accurate value of the } \\
\text { force in a cable. It is } \\
\text { relatively easy and } \\
\text { inexpensive to perform }\end{array}$ & $\begin{array}{l}\text { These methods are all } \\
\text { effective in controlling } \\
\text { free vibrations of the } \\
\text { cables. Helical strakes } \\
\text { formed in the cable } \\
\text { neoprene sheathing are } \\
\text { also effective }\end{array}$ \\
\hline Illinois & $\begin{array}{l}\text { Quincy Bayview Bridge } \\
\text { at Quincy, IL }\end{array}$ & no & no answer & $\begin{array}{l}\text { Cross cables on the } \\
\text { Clark Bridge have } \\
\text { been effective }\end{array}$ \\
\hline Illinois & Clark Bridge at Alton, IL & no & no answer & $\begin{array}{l}\text { Cross cables on the } \\
\text { Clark Bridge have } \\
\text { been effective }\end{array}$ \\
\hline Indiana & 46-03-7495 EBL & $\begin{array}{l}\text { no-we will be having } \\
\text { these two bridges } \\
\text { inspected and tested by a } \\
\text { consultant in the next } 1-2 \\
\text { year time frame. We are } \\
\text { just beginning to get a } \\
\text { good understanding of the } \\
\text { possible problems that we } \\
\text { may encounter on these } \\
\text { bridges over the coming } \\
\text { years }\end{array}$ & $\begin{array}{l}\text { We have not yet done } \\
\text { any testing on these } \\
\text { two cable-stayed } \\
\text { bridges, but probably } \\
\text { will be doing so in the } \\
\text { next } 1-2 \text { years }\end{array}$ & $\begin{array}{l}\text { The ones on the SR-46 } \\
\text { bridge seem to be OK. } \\
\text { There are also some on } \\
\text { the new US-231 bridge } \\
\text { over the Ohio River } \\
\text { that we share with } \\
\text { Kentucky (Kentucky } \\
\text { is the lead state for this } \\
\text { bridge). They seem to } \\
\text { be OK also. However, } \\
\text { I have not been at } \\
\text { either of these bridges } \\
\text { during bad weather }\end{array}$ \\
\hline Indiana & I65-68-7910 & $\begin{array}{l}\text { no-we will be having } \\
\text { these two bridges } \\
\text { inspected and tested by a } \\
\text { consultant in the next } 1-2 \\
\text { year time frame. We are } \\
\text { just beginning to get a } \\
\text { good understanding of the }\end{array}$ & $\begin{array}{l}\text { We have not yet done } \\
\text { any testing on these } \\
\text { two cable-stayed } \\
\text { bridges, but probably } \\
\text { will be doing so in the } \\
\text { next } 1-2 \text { years }\end{array}$ & $\begin{array}{l}\text { The ones on the SR-46 } \\
\text { bridge seem to be OK. } \\
\text { There are also some on } \\
\text { the new US-231 bridge } \\
\text { over the Ohio River } \\
\text { that we share with } \\
\text { Kentucky (Kentucky is }\end{array}$ \\
\hline
\end{tabular}


NCHRP SYNTHESIS TOPIC 35-07_INSPECTION AND MAINTENANCE OF BRIDGE STAY CABLE SYSTEMS

\begin{tabular}{|c|c|c|c|c|}
\hline State & Bridge & Q5 & Q6 & Q7 \\
\hline & & $\begin{array}{l}\text { possible problems that we } \\
\text { may encounter on these } \\
\text { bridges over the coming } \\
\text { years }\end{array}$ & & $\begin{array}{l}\text { the lead state for this } \\
\text { bridge). They seem to } \\
\text { be OK also. However, } \\
\text { I have not been at } \\
\text { either of these bridges } \\
\text { during bad weather }\end{array}$ \\
\hline Iowa & Burlington, IA & $\begin{array}{l}\text { no-need way to inspect } \\
\text { cable }\end{array}$ & $\begin{array}{l}\text { Have not had } \\
\text { experience with non- } \\
\text { destructive test } \\
\text { methods }\end{array}$ & $\begin{array}{l}\text { Have not had vibration } \\
\text { problems since cross } \\
\text { cables were installed }\end{array}$ \\
\hline Kentucky & $\begin{array}{l}\text { William Natcher Bridge, } \\
\text { Owensboro, KY }\end{array}$ & $\begin{array}{l}\text { no-there are technical } \\
\text { limitations that prevent } \\
\text { inspection of the stay } \\
\text { cables, especially the } \\
\text { anchorage area. Technical } \\
\text { breakthrough is required }\end{array}$ & $\begin{array}{l}\text { The only problem is } \\
\text { the anchorage area. So } \\
\text { far no method is } \\
\text { available for } \\
\text { inspection. (PB) I see } \\
\text { additional problems } \\
\text { with inspection of the } \\
\text { grout-filled cables. } \\
\text { (DKD) }\end{array}$ & $\begin{array}{l}\text { Wind damper is a high } \\
\text { tech method that is } \\
\text { very effective in most } \\
\text { cases. However, the } \\
\text { dampers are delicate } \\
\text { mechanism that needs } \\
\text { constant maintenance } \\
\text { like any machine. } \\
\text { Only the exterior } \\
\text { dampers allow } \\
\text { inspection and } \\
\text { maintenance. Internal } \\
\text { dampers are difficult to } \\
\text { access for inspection. } \\
\text { Any inspection and } \\
\text { maintenance and/or } \\
\text { replacement will be a } \\
\text { major project. } \\
\text { Another major concern } \\
\text { is that the method to } \\
\text { determine the damper's } \\
\text { condition is still not } \\
\text { available. Therefore, } \\
\text { after only a few years, } \\
\text { no one will know } \\
\text { whether the installed } \\
\text { dampers are still } \\
\text { working. On the other } \\
\text { hand, the cross cables } \\
\text { will work as long as } \\
\text { they are in place. The } \\
\text { condition of the cross } \\
\text { cables can be easily } \\
\text { observed from the } \\
\text { deck. Replacement of } \\
\text { the cross ties is not a } \\
\text { major operation. } \\
\text { Therefore, before the } \\
\text { damper is improved, } \\
\text { the cross cable is the } \\
\text { better and sure } \\
\text { solution. (PB) }\end{array}$ \\
\hline Kentucky & $\begin{array}{l}\text { William H. Harsha } \\
\text { Bridge, Maysville, KY }\end{array}$ & $\begin{array}{l}\text { no-there are technical } \\
\text { limitations that prevent } \\
\text { inspection of the stay } \\
\text { cables, especially the } \\
\text { anchorage area. Technical } \\
\text { breakthrough is required }\end{array}$ & $\begin{array}{l}\text { The only problem is } \\
\text { the anchorage area. So } \\
\text { far no method is } \\
\text { available for } \\
\text { inspection. (PB) I see } \\
\text { additional problems } \\
\text { with inspection of the } \\
\text { grout-filled cables. } \\
\text { (DKD) }\end{array}$ & $\begin{array}{l}\text { Wind damper is a high } \\
\text { tech method that is } \\
\text { very effective in most } \\
\text { cases. However, the } \\
\text { dampers are delicate } \\
\text { mechanisms that need } \\
\text { constant maintenance } \\
\text { like any machine. } \\
\text { Only the exterior } \\
\text { dampers allow } \\
\text { inspection and } \\
\text { maintenance. Internal } \\
\text { dampers are difficult to } \\
\text { access for inspection. }\end{array}$ \\
\hline
\end{tabular}




\section{NCHRP SYNTHESIS TOPIC 35-07-INSPECTION AND MAINTENANCE OF BRIDGE STAY CABLE SYSTEMS}

\begin{tabular}{|c|c|c|c|c|}
\hline State & Bridge & Q5 & Q6 & Q7 \\
\hline & & & & $\begin{array}{l}\text { Any inspection and } \\
\text { maintenance and/or } \\
\text { replacement will be a } \\
\text { major project. } \\
\text { Another major concern } \\
\text { is that the method to } \\
\text { determine the damper's } \\
\text { condition is still not } \\
\text { available. Therefore, } \\
\text { after only a few years, } \\
\text { no one will know } \\
\text { whether the installed } \\
\text { dampers are still } \\
\text { working. On the other } \\
\text { hand, the cross cables } \\
\text { will work as long as } \\
\text { they are in place. The } \\
\text { condition of the cross } \\
\text { cables can be easily } \\
\text { observed from the } \\
\text { deck. Replacement of } \\
\text { the cross ties is not a } \\
\text { major operation. } \\
\text { Therefore, before the } \\
\text { damper is improved, } \\
\text { the cross cable is the } \\
\text { better and sure } \\
\text { solution. (PB) }\end{array}$ \\
\hline Louisiana & $\begin{array}{l}\text { Mississippi River Bridge } \\
\text { at Luling, LA }\end{array}$ & $\begin{array}{l}\text { Not known-our vibration } \\
\text { tests over time have } \\
\text { indicated consistent cable } \\
\text { loads; we are still unable to } \\
\text { call the wires pristine }\end{array}$ & $\begin{array}{l}\text { Vibration-based cable } \\
\text { load determination- } \\
\text { effective and } \\
\text { inexpensive; X-ray- } \\
\text { expensive, slow, very } \\
\text { questionable ability to } \\
\text { detect wire defects; } \\
\text { Magnetic inspection- } \\
\text { used to rapidly, } \\
\text { effectively inspect } \\
\text { mine cables- but the } \\
\text { cables move past the } \\
\text { inspection unit, which } \\
\text { would need to be } \\
\text { reversed on a cable } \\
\text { bridge; Impulse } \\
\text { radar-good for } \\
\text { detecting grout defects; } \\
\text { Sonic methods- } \\
\text { dampened to the point } \\
\text { of being ineffective }\end{array}$ & $\begin{array}{l}\text { Luling has neoprene } \\
\text { rings, but these are } \\
\text { relatively very small } \\
\text { considering the large } \\
\text { diameter of the Luling } \\
\text { cables and are there } \\
\text { mainly to seal the } \\
\text { anchors, but perhaps } \\
\text { they also dampen the } \\
\text { cables. CTL will check } \\
\text { into this }\end{array}$ \\
\hline Mississippi & & $\begin{array}{l}\text { Not known-we are } \\
\text { several years away from } \\
\text { completion of the first } \\
\text { cable-stayed bridge for } \\
\text { which Arkansas will have } \\
\text { responsibility for } \\
\text { inspection/maintenance/not } \\
\text { known }\end{array}$ & $\begin{array}{l}\text { No comment/not } \\
\text { known }\end{array}$ & $\begin{array}{l}\text { No comment-we are } \\
\text { currently constructing } \\
\text { a cable-stayed bridge } \\
\text { on US- } 82 \text { over the } \\
\text { Mississippi River near } \\
\text { Greenville, MS. } \\
\text { Mississippi is } \\
\text { responsible for } \\
\text { overseeing the } \\
\text { construction and } \\
\text { Arkansas will be } \\
\text { responsible for the } \\
\text { maintenance. We are } \\
\text { sharing the costs } \\
\text { associated with both } \\
\text { construction and } \\
\text { maintenance. We are }\end{array}$ \\
\hline
\end{tabular}




\section{NCHRP SYNTHESIS TOPIC 35-07-INSPECTION AND MAINTENANCE OF BRIDGE STAY CABLE SYSTEMS}

\begin{tabular}{|c|c|c|c|c|}
\hline State & Bridge & Q5 & Q6 & Q7 \\
\hline & & & & $\begin{array}{l}\text { using cable ties and } \\
\text { cable stay sheathing } \\
\text { with a helical drip } \\
\text { bead to control the } \\
\text { cable vibration. We } \\
\text { considered using } \\
\text { dampners and a } \\
\text { combination of } \\
\text { dampners and cable } \\
\text { ties. However, we } \\
\text { were not comfortable } \\
\text { with the reliability of } \\
\text { dampners and felt the } \\
\text { cable ties have a long } \\
\text { standing proven } \\
\text { record. A visual } \\
\text { inspection would show } \\
\text { problems with the ties, } \\
\text { where with the } \\
\text { dampners it is not so } \\
\text { easy to determine if } \\
\text { they are working } \\
\text { properly }\end{array}$ \\
\hline Massachusetts & $\begin{array}{l}\text { Leonard P. Zakim Bunker } \\
\text { Hill Bridge, Boston, MA }\end{array}$ & yes & $\begin{array}{l}\text { Have not yet used any } \\
\text { NDT methods for stay } \\
\text { cable inspection }\end{array}$ & $\begin{array}{l}\text { It is our opinion that } \\
\text { neoprene rings will not } \\
\text { work as intended. } \\
\text { Either internal or } \\
\text { external viscous } \\
\text { dampers are needed. } \\
\text { Cross cables are not } \\
\text { needed in shorter spans }\end{array}$ \\
\hline Missouri & $\begin{array}{l}\text { Bill Emerson Memorial } \\
\text { Bridge, Cape Girardeau }\end{array}$ & $\begin{array}{l}\text { Not known-MoDOT has } \\
\text { no related experience }\end{array}$ & $\begin{array}{l}\text { MoDOT has no related } \\
\text { experience }\end{array}$ & $\begin{array}{l}\text { Cross cables have been } \\
\text { installed on this bridge } \\
\text { as the most effective, } \\
\text { positive method to } \\
\text { eliminate cable } \\
\text { vibrations. We } \\
\text { understand that } \\
\text { worldwide research is } \\
\text { being conducted to } \\
\text { maximize the } \\
\text { efficiency of dampers } \\
\text { and to determine, } \\
\text { mathematically, when } \\
\text { they are and are not } \\
\text { required }\end{array}$ \\
\hline Ohio & $\begin{array}{l}\text { Maumee River Bridge, } \\
\text { Toledo }\end{array}$ & $\begin{array}{l}\text { yes-while better methods } \\
\text { may be developed in the } \\
\text { future, the current methods } \\
\text { are both effective and } \\
\text { adequate. The most likely } \\
\text { location of cable issues on } \\
\text { all such bridges is at the } \\
\text { anchor areas. By the nature } \\
\text { of the anchor being } \\
\text { embedded in massive } \\
\text { concrete or steel areas, } \\
\text { direct access to inspect the } \\
\text { MTE is generally } \\
\text { impractical }\end{array}$ & no answer & $\begin{array}{l}\text { Volumes can be } \\
\text { written on this topic. } \\
\text { The short version is } \\
\text { that any actual } \\
\text { "damping" added to } \\
\text { the cable is highly } \\
\text { effective since by its } \\
\text { nature the cable has } \\
\text { very little. Other } \\
\text { control measures have } \\
\text { had various degrees of } \\
\text { success. In most cases, } \\
\text { the success or lack of } \\
\text { success has been } \\
\text { related to the actual } \\
\text { details, not so much in } \\
\text { the selected approach } \\
\text { to the issue }\end{array}$ \\
\hline South Carolina & Cooper River Bridge & yes & no comment & $\begin{array}{l}\text { Viscous dampers for } \\
\text { all cables and }\end{array}$ \\
\hline
\end{tabular}




\section{NCHRP SYNTHESIS TOPIC 35-07-INSPECTION AND MAINTENANCE OF BRIDGE STAY CABLE SYSTEMS}

\begin{tabular}{|c|c|c|c|c|}
\hline State & Bridge & Q5 & Q6 & Q7 \\
\hline & & & & $\begin{array}{l}\text { additional external } \\
\text { dampers for the } \\
\text { longest cables are in } \\
\text { plans and will be } \\
\text { installed. Cross cable } \\
\text { dampers are a future } \\
\text { consideration. } \\
\text { Provisions for future } \\
\text { installation of cross } \\
\text { cables will be } \\
\text { installed. If the system } \\
\text { of viscous and external } \\
\text { dampers is inadequate, } \\
\text { the cross cables can be } \\
\text { installed }\end{array}$ \\
\hline Texas & $\begin{array}{l}\text { Veterans Memorial } \\
\text { Bridge }\end{array}$ & $\begin{array}{l}\text { yes-owners are unable to } \\
\text { non-destructively evaluate } \\
\text { the condition of stay cables } \\
\text { and anchorages }\end{array}$ & $\begin{array}{l}\text { TxDOT has employed } \\
\text { vibration-based force } \\
\text { measurements to refine } \\
\text { the model used for } \\
\text { designing viscous } \\
\text { dampers on each of the } \\
\text { cable stay bridges. The } \\
\text { technique seemed to } \\
\text { give good correlation } \\
\text { cable dimensions and } \\
\text { damping requirements. } \\
\text { The technique requires } \\
\text { some traffic control } \\
\text { and depending on the } \\
\text { number of lanes } \\
\text { carried by the structure } \\
\text { could produce minor to } \\
\text { significant traffic } \\
\text { disruption. At least one } \\
\text { lane and the shoulder } \\
\text { will need to be closed; } \\
\text { therefore, if the bridge } \\
\text { is narrow with a small } \\
\text { number of lanes } \\
\text { carrying two-way } \\
\text { traffic the disruption } \\
\text { could be considerable. } \\
\text { This could last for } \\
\text { several weeks if there } \\
\text { are a large number of } \\
\text { stays that need to be } \\
\text { tested. The cost can } \\
\text { run anywhere from } \\
\$ 50,000 \text { to } \$ 75,000 \text { per } \\
\text { bridge per test event } \\
\text { depending on the size } \\
\text { of the structure }\end{array}$ & $\begin{array}{l}\text { The only cable } \\
\text { vibration control } \\
\text { measures that Texas } \\
\text { has experience with at } \\
\text { this time are cross tie } \\
\text { cables and neoprene } \\
\text { rings. The neoprene } \\
\text { rings do not appear to } \\
\text { offer a measurable } \\
\text { amount of dampening } \\
\text { and based on the } \\
\text { department's } \\
\text { experience should not } \\
\text { be considered as a } \\
\text { primary damping } \\
\text { mechanism. The cross } \\
\text { tie system that the } \\
\text { department has } \\
\text { employed has been } \\
\text { effective in reducing } \\
\text { the extreme vibration } \\
\text { events, but vibrations } \\
\text { of an amplitude that } \\
\text { causes concern still } \\
\text { occur. Texas is } \\
\text { presently installing } \\
\text { viscous damping } \\
\text { systems of each of the } \\
\text { cable stay bridges in } \\
\text { the state. On the Fred } \\
\text { Hartman Bridge these } \\
\text { will be installed in } \\
\text { conjunction with cross } \\
\text { tie cables. It is hoped } \\
\text { that this combination } \\
\text { will effectively } \\
\text { eliminate the } \\
\text { occurrence and } \\
\text { amplitude of any } \\
\text { vibrations }\end{array}$ \\
\hline Texas & Fred Hartman Bridge & $\begin{array}{l}\text { yes-owners are unable to } \\
\text { non-destructively evaluate } \\
\text { the condition of stay cables } \\
\text { and anchorages }\end{array}$ & $\begin{array}{l}\text { TxDOT has employed } \\
\text { vibration-based force } \\
\text { measurements to refine } \\
\text { the model used for } \\
\text { designing viscous } \\
\text { dampers on each of the } \\
\text { cable stay bridges. The } \\
\text { technique seemed to } \\
\text { give good correlation } \\
\text { cable dimensions and } \\
\text { damping requirements. }\end{array}$ & $\begin{array}{l}\text { The only cable } \\
\text { vibration control } \\
\text { measures that Texas } \\
\text { has experience with at } \\
\text { this time are cross tie } \\
\text { cables and neoprene } \\
\text { rings. The neoprene } \\
\text { rings do not appear to } \\
\text { offer a measurable } \\
\text { amount of dampening, } \\
\text { and based on the }\end{array}$ \\
\hline
\end{tabular}




\section{NCHRP SYNTHESIS TOPIC 35-07-INSPECTION AND MAINTENANCE OF BRIDGE STAY CABLE SYSTEMS}

\begin{tabular}{|c|c|c|c|c|}
\hline State & Bridge & Q5 & Q6 & Q7 \\
\hline & & & $\begin{array}{l}\text { The technique requires } \\
\text { some traffic control } \\
\text { and depending on the } \\
\text { number of lanes } \\
\text { carried by the structure } \\
\text { could produce minor to } \\
\text { significant traffic } \\
\text { disruption. At least one } \\
\text { lane and the shoulder } \\
\text { will need to be closed; } \\
\text { therefore, if the bridge } \\
\text { is narrow with a small } \\
\text { number of lanes } \\
\text { carrying two-way } \\
\text { traffic the disruption } \\
\text { could be considerable. } \\
\text { This could last for } \\
\text { several weeks if there } \\
\text { are a large number of } \\
\text { stays that need to be } \\
\text { tested. The cost can } \\
\text { run anywhere from } \\
\$ 50,000 \text { to } \$ 75,000 \text { per } \\
\text { bridge per test event } \\
\text { depending on the size } \\
\text { of the structure }\end{array}$ & $\begin{array}{l}\text { department's } \\
\text { experience should not } \\
\text { be considered as a } \\
\text { primary damping } \\
\text { mechanism. The cross } \\
\text { tie system that the } \\
\text { department has } \\
\text { employed has been } \\
\text { effective in reducing } \\
\text { the extreme vibration } \\
\text { events, but vibrations } \\
\text { of an amplitude that } \\
\text { causes concern still } \\
\text { occur. Texas is } \\
\text { presently installing } \\
\text { viscous damping } \\
\text { systems of each of the } \\
\text { cable stay bridges in } \\
\text { the state. On the Fred } \\
\text { Hartman Bridge these } \\
\text { will be installed in } \\
\text { conjunction with cross } \\
\text { tie cables. It is hoped } \\
\text { that this combination } \\
\text { will effectively } \\
\text { eliminate the } \\
\text { occurrence and } \\
\text { amplitude of any } \\
\text { vibrations }\end{array}$ \\
\hline Virginia & $\begin{array}{l}\text { I-295 over James River } \\
\text { (Varina-Enon Bridge) }\end{array}$ & yes & $\begin{array}{l}\text { Laser-based force } \\
\text { measurements were } \\
\text { utilized in the initial } \\
\text { in-depth inspection of } \\
\text { this bridge in } 1999 \text {. } \\
\text { The cost incurred was } \\
\text { approximately } \$ 35,000 \\
\text { with minimum impact } \\
\text { on traffic }\end{array}$ & $\begin{array}{l}\text { Neoprene rings were } \\
\text { installed on the } \\
\text { Varina-Enon Bridge } \\
\text { as the primary stay } \\
\text { damping system. This } \\
\text { is a relatively cost- } \\
\text { effective system and } \\
\text { appears to be } \\
\text { performing } \\
\text { satisfactorily on this } \\
\text { bridge. We have } \\
\text { experienced some } \\
\text { difficulty in the } \\
\text { installation and } \\
\text { removal of these rings. } \\
\text { Details of an alternate } \\
\text { stay damping system } \\
\text { utilizing shock } \\
\text { absorbers have been } \\
\text { included in the Manual } \\
\text { for Inspection and } \\
\text { Maintenance of the } \\
\text { Varina-Enon Bridge }\end{array}$ \\
\hline Washington & $\begin{array}{l}\text { Gum Street-Kennewick, } \\
\text { WA }\end{array}$ & yes & N/A & N/A \\
\hline Washington & Thea-Foss Tacoma, WA & yes & N/A & N/A \\
\hline Wisconsin & $\begin{array}{l}\text { Sixth Street Viaduct, } \\
\text { North Cable Stay }\end{array}$ & $\begin{array}{l}\text { Not known-no previous } \\
\text { experience with cable- } \\
\text { stayed structure }\end{array}$ & $\begin{array}{l}\text { City inspection forces } \\
\text { are neither qualified } \\
\text { nor equipped for non- } \\
\text { destructive testing. } \\
\text { Four single strands are } \\
\text { to be removed (one at } \\
\text { each pylon) for } \\
\text { inspection for rust } \\
\text { every } 10 \text { years starting } \\
\text { in year } 2014\end{array}$ & no vibrations noted \\
\hline Wisconsin & Sixth Street Viaduct, & Not known-no previous & City inspection forces & no vibrations noted \\
\hline
\end{tabular}




\section{NCHRP SYNTHESIS TOPIC 35-07-INSPECTION AND MAINTENANCE OF BRIDGE STAY CABLE SYSTEMS}

\begin{tabular}{|c|c|c|c|c|}
\hline State & Bridge & Q5 & Q6 & Q7 \\
\hline & South Cable Stay & $\begin{array}{l}\text { experience with cable- } \\
\text { stayed structure }\end{array}$ & $\begin{array}{l}\text { are neither qualified } \\
\text { nor equipped for non- } \\
\text { destructive testing. } \\
\text { Four single strands are } \\
\text { to be removed (one at } \\
\text { each pylon) for } \\
\text { inspection for rust } \\
\text { every } 10 \text { years starting } \\
\text { in year } 2014\end{array}$ & \\
\hline Alberta/Calgary & $\begin{array}{l}\text { Prince's Island } \\
\text { (Pedestrian) }\end{array}$ & yes & no answer & $\begin{array}{l}\text { The installation of } \\
\text { cross cables have } \\
\text { greatly reduced the } \\
\text { cable vibration }\end{array}$ \\
\hline Alberta/Calgary & Carburn Park (Pedestrian) & yes & no answer & $\begin{array}{l}\text { The installation of } \\
\text { cross cables have } \\
\text { greatly reduced the } \\
\text { cable vibration }\end{array}$ \\
\hline Alberta/Calgary & McMahon (Pedestrian) & yes & no answer & $\begin{array}{l}\text { The installation of } \\
\text { cross cables have } \\
\text { greatly reduced the } \\
\text { cable vibration }\end{array}$ \\
\hline Alberta/Calgary & Fox Hollow (Pedestrian) & yes & no answer & $\begin{array}{l}\text { The installation of } \\
\text { cross cables have } \\
\text { greatly reduced the } \\
\text { cable vibration }\end{array}$ \\
\hline Alberta/Calgary & Stoney Trail (Pedestrian) & yes & no answer & $\begin{array}{l}\text { The installation of } \\
\text { cross cables have } \\
\text { greatly reduced the } \\
\text { cable vibration }\end{array}$ \\
\hline British Columbia & Alex Fraser Bridge & yes & not used & $\begin{array}{l}\text { Neoprene ring } \\
\text { dampers alone do not } \\
\text { prevent cable vibration }\end{array}$ \\
\hline Manitoba/Winnipeg & Esplanade Riel & $\begin{array}{l}\text { Not known-we require } \\
\text { training and awareness in } \\
\text { the near future to properly } \\
\text { maintain the one new } \\
\text { bridge we have }\end{array}$ & $\begin{array}{l}\text { We do not yet have } \\
\text { enough experience to } \\
\text { respond to this } \\
\text { question at this time. } \\
\text { We are aware of all the } \\
\text { techniques you } \\
\text { mention above. Force } \\
\text { measurements on } \\
\text { selected MTE will be } \\
\text { performed as part of } \\
\text { the SHM system with } \\
\text { the use of uniaxial } \\
\text { accelerometers to } \\
\text { determine frequency of } \\
\text { the cable and relate } \\
\text { back to force }\end{array}$ & $\begin{array}{l}\text { We have yet to pass } \\
\text { judgment on the } \\
\text { effectiveness of the } \\
\text { control measures. We } \\
\text { specified the } \\
\text { requirement for } \\
\text { damping at the } \\
\text { anchorages. The } \\
\text { supplier choose to do } \\
\text { this via neoprene rings }\end{array}$ \\
\hline New Brunswick & Hawkshaw & yes & $\begin{array}{l}\text { None of this testing } \\
\text { done on any of the } \\
\text { three structures. } \\
\text { Probably there would } \\
\text { be a significant cost to } \\
\text { do these tests }\end{array}$ & $\begin{array}{l}\text { See comments } \\
\text { Question 4-12 }\end{array}$ \\
\hline New Brunswick & Longs Creek \#1 & yes & $\begin{array}{l}\text { None of this testing } \\
\text { done on any of the } \\
\text { three structures. } \\
\text { Probably there would } \\
\text { be a significant cost to } \\
\text { do these tests }\end{array}$ & $\begin{array}{l}\text { See comments } \\
\text { Question 4-12 }\end{array}$ \\
\hline New Brunswick & Nackawic River & yes & $\begin{array}{l}\text { None of this testing } \\
\text { done on any of the } \\
\text { three structures. } \\
\text { Probably there would } \\
\text { be a significant cost to } \\
\text { do these tests }\end{array}$ & $\begin{array}{l}\text { See comments } \\
\text { Question 4-12 }\end{array}$ \\
\hline
\end{tabular}


NCHRP SYNTHESIS TOPIC 35-07-INSPECTION AND MAINTENANCE OF BRIDGE STAY CABLE SYSTEMS

\begin{tabular}{|c|c|c|c|c|}
\hline State & Bridge & Q5 & Q6 & Q7 \\
\hline Quebec, Canada & Galipeault & yes & $\begin{array}{l}\text { We have performed } \\
\text { laser-based force on } \\
\text { Galipeault Bridge }\end{array}$ & \\
\hline Quebec, Canada & Papineau & yes & $\begin{array}{l}\text { We have performed } \\
\text { laser-based force on } \\
\text { Galipeault Bridge }\end{array}$ & \\
\hline \multirow[t]{2}{*}{ Quebec, Canada } & Price & & $\begin{array}{l}\text { Neoprene rings have } \\
\text { reduced cable } \\
\text { vibrations on the Price } \\
\text { bridge (no. 3) }\end{array}$ & \\
\hline & Freyssinet & $\begin{array}{l}\text { Yes-Freyssinet has } \\
\text { installed its stay system on } \\
\text { three projects. } \\
\text { Bill Emerson Bridge over } \\
\text { the Mississippi River at } \\
\text { Cape Girardeau, MO; } \\
\text { I-93 over the Charles River } \\
\text { in Boston, MA; and } \\
\text { Cooper River Replacement } \\
\text { Bridge in Charleston, SC. } \\
\text { The Cape Girardeau } \\
\text { Bridge was required to be } \\
\text { grouted by the Owner and } \\
\text { Engineer. Freyssinet } \\
\text { proposed ungrouted stays } \\
\text { but this was unacceptable } \\
\text { for reasons unknown. The } \\
\text { thought was the Owner and } \\
\text { Engineer did not want to } \\
\text { be the first in U.S. to allow } \\
\text { ungrouted stays. The } \\
\text { Charles River was } \\
\text { designed to use grouted } \\
\text { stays, but Freyssinet was } \\
\text { able to convince the Owner } \\
\text { and Engineer that } \\
\text { ungrouted stays were } \\
\text { superior, mainly due to the } \\
\text { improved inspectability } \\
\text { and replaceability, but also } \\
\text { to avoid the common } \\
\text { problems associated with } \\
\text { grouted cables (introduce } \\
\text { moisture, increase local } \\
\text { bending moments at the } \\
\text { anchorages, more mass to } \\
\text { dampen, potential damage } \\
\text { to the HDPE stay pipe if } \\
\text { high grouting pressures are } \\
\text { used). Also, during } \\
\text { grouting everything gets } \\
\text { warm (or very hot if } \\
\text { grouted during the summer } \\
\text { in warm or even moderate } \\
\text { climates). When colder } \\
\text { winter temperatures arrive, } \\
\text { the pipes develop very } \\
\text { high-tensile stresses as the } \\
\text { pipe tries to thermally } \\
\text { contract, but is restrained } \\
\text { since the grout has a much } \\
\text { lower thermal coefficient } \\
\text { of expansion and } \\
\text { contraction. The cables on } \\
\text { the Cooper River Bridge } \\
\text { are state of the art } \\
\end{array}$ & $\begin{array}{l}\text { With ungrouted stays, } \\
\text { individual strands may } \\
\text { be detensioned, } \\
\text { inspected, retensioned, } \\
\text { or removed and/or } \\
\text { replaced. Load cells } \\
\text { may be left in place to } \\
\text { monitor strands } \\
\text { individually. Acoustic } \\
\text { monitoring systems } \\
\text { can be installed to } \\
\text { detect wire breakage } \\
\text { and determine the } \\
\text { break locations very } \\
\text { accurately }\end{array}$ & $\begin{array}{l}\text { External helix placed } \\
\text { on the surface of the } \\
\text { stay pipes has been } \\
\text { proven to eliminate } \\
\text { rain-wind-induced } \\
\text { cable vibrations. } \\
\text { Freyssinet developed } \\
\text { this on the Normandie } \\
\text { Bridge in France. } \\
\text { Freyssinet offered this } \\
\text { on Cape Girardeau and } \\
\text { Charles River projects } \\
\text { and both sites elected } \\
\text { to add external helix } \\
\text { via a change order due } \\
\text { the very real threat of } \\
\text { serious rain-wind- } \\
\text { induced vibrations and } \\
\text { the high level of } \\
\text { effectiveness offered } \\
\text { by the external helix }\end{array}$ \\
\hline
\end{tabular}


NCHRP SYNTHESIS TOPIC 35-07-INSPECTION AND MAINTENANCE OF BRIDGE STAY CABLE SYSTEMS

\begin{tabular}{|c|c|c|c|c|}
\hline State & Bridge & Q5 & Q6 & Q7 \\
\hline & & $\begin{array}{l}\text { ungrouted stays with } \\
\text { capacity to add } \\
\text { approximately } 5 \% \text { strand } \\
\text { in the future and the stays } \\
\text { are fitted with engineered } \\
\text { vibration suppression } \\
\text { devices. Internal hydraulic } \\
\text { and external hydraulic } \\
\text { damping devices are being } \\
\text { installed and provisions } \\
\text { provide for the possible } \\
\text { addition of cable ties } \\
\text { (damping ropes) in the } \\
\text { future on selected longer } \\
\text { stays that have been } \\
\text { identified as having the } \\
\text { potential to experience } \\
\text { parametric excitation }\end{array}$ & & \\
\hline
\end{tabular}




\section{NCHRP SYNTHESIS TOPIC 35-07-INSPECTION AND MAINTENANCE OF BRIDGE STAY CABLE SYSTEMS}

\section{Questions:}

Q8 Please comment on the effectiveness of any sensor-based, long-term monitoring systems for stay cables that you may be familiar with. Examples include acoustic monitoring, vibration monitoring, force measurements, strain measurements, etc.

Q9 What would you recommend that the cable suppliers incorporate into their systems to make cables more accessible and inspectable?

Q10 Do you believe that an up-to-date resource such as a national database of information on stay cable inspection methods, repairs, and testing would be a useful tool?

\section{Responses:}

\begin{tabular}{|c|c|c|c|c|}
\hline State & Bridge & Q8 & Q9 & Q10 \\
\hline Alabama & Cochrane Africatown & $\begin{array}{l}\text { Check with A.G. } \\
\text { Lichtenstein }\end{array}$ & $\begin{array}{l}\text { Provide access on } \\
\text { inside and outside of } \\
\text { tower anchorage }\end{array}$ & not known \\
\hline Alaska & $\begin{array}{l}\text { Sitka Harbor Bridge, Sitka, } \\
\text { Alaska }\end{array}$ & N/A & N/A & yes \\
\hline Alaska & $\begin{array}{l}\text { Captain William Moore } \\
\text { Bridge, Skagway }\end{array}$ & N/A & N/A & yes \\
\hline California & $\begin{array}{l}\text { Sacramento River } \\
\text { (Meridian) }\end{array}$ & $\begin{array}{l}\text { Acoustic monitoring } \\
\text { appears to have great } \\
\text { value and promise. } \\
\text { Would recommend that } \\
\text { this technology be fully } \\
\text { developed }\end{array}$ & $\begin{array}{l}\text { Fiber optic strain } \\
\text { gauges and redundant } \\
\text { systems }\end{array}$ & yes \\
\hline Delaware & $\begin{array}{l}\text { Br. 1-902, SR-1 over the } \\
\text { Chesapeake and Delaware } \\
\text { Canal, St. Georges, New } \\
\text { Castle County, Delaware }\end{array}$ & $\begin{array}{l}\text { The current sensor- } \\
\text { based, long-term } \\
\text { monitoring system } \\
\text { installed on the bridge } \\
\text { is not operable and } \\
\text { therefore comment } \\
\text { cannot be made. The } \\
\text { department is } \\
\text { considering the addition } \\
\text { of force measurement } \\
\text { (deck-based laser } \\
\text { method) to the list of } \\
\text { inspection items } \\
\text { required for the bridge }\end{array}$ & $\begin{array}{l}\text { We would recommend } \\
\text { the development of } \\
\text { individual strand } \\
\text { monitoring capabilities } \\
\text { which encompass the } \\
\text { strands from anchorage } \\
\text { to anchorage }\end{array}$ & yes \\
\hline Florida & Dame Point Bridge & none & Not familiar with this & yes \\
\hline Georgia & $\begin{array}{l}\text { Talmadge Memorial } \\
\text { Bridge, Savannah }\end{array}$ & $\begin{array}{l}\text { These are all effective, } \\
\text { but they are generally } \\
\text { expensive and have not } \\
\text { been used on Georgia's } \\
\text { bridges }\end{array}$ & $\begin{array}{l}\text { For non-box bridges, an } \\
\text { inspection traveler } \\
\text { should be installed on } \\
\text { the cable-stayed bridge. } \\
\text { This should be done by } \\
\text { the owner }\end{array}$ & yes \\
\hline Georgia & $\begin{array}{l}\text { Sidney Lanier Bridge, } \\
\text { Brunswick }\end{array}$ & $\begin{array}{l}\text { These are all effective, } \\
\text { but they are generally } \\
\text { expensive and have not } \\
\text { been used on Georgia's } \\
\text { bridges }\end{array}$ & $\begin{array}{l}\text { For non-box bridges, an } \\
\text { inspection traveler } \\
\text { should be installed on } \\
\text { the cable-stayed bridge. } \\
\text { This should be done by } \\
\text { the owner }\end{array}$ & yes \\
\hline Illinois & $\begin{array}{l}\text { Quincy Bayview Bridge at } \\
\text { Quincy, IL }\end{array}$ & $\begin{array}{l}\text { An acoustic monitoring } \\
\text { system was installed } \\
\text { (approximately a year } \\
\text { and a half ago) on one- } \\
\text { fourth of the stays of } \\
\text { the Quincy Bayview } \\
\text { Bridge. This was done } \\
\text { due to concern over } \\
\text { water in the cable }\end{array}$ & no answer & yes \\
\hline
\end{tabular}




\section{NCHRP SYNTHESIS TOPIC 35-07-INSPECTION AND MAINTENANCE OF BRIDGE STAY CABLE SYSTEMS}

\begin{tabular}{|c|c|c|c|c|}
\hline State & Bridge & Q8 & Q9 & Q10 \\
\hline & & $\begin{array}{l}\text { anchorages and to } \\
\text { evaluate the } \\
\text { technology. The system } \\
\text { appears to be } \\
\text { functioning properly } \\
\text { and so far has provided } \\
\text { information on one } \\
\text { "event" that has been } \\
\text { classified as a wire } \\
\text { break }\end{array}$ & & \\
\hline Illinois & Clark Bridge at Alton, IL & $\begin{array}{l}\text { An acoustic monitoring } \\
\text { system was installed } \\
\text { (approximately a year } \\
\text { and a half ago) on one- } \\
\text { fourth of the stays of } \\
\text { the Quincy Bayview } \\
\text { Bridge. This was done } \\
\text { due to concern over } \\
\text { water in the cable } \\
\text { anchorages and to } \\
\text { evaluate the } \\
\text { technology. The system } \\
\text { appears to be } \\
\text { functioning properly } \\
\text { and so far has provided } \\
\text { information on one } \\
\text { "event" that has been } \\
\text { classified as a wire } \\
\text { break }\end{array}$ & no answer & yes \\
\hline Indiana & 46-03-7495 EBL & Have not used any yet. & ?? & yes \\
\hline Indiana & I65-68-7910 & Have not used any yet. & $? ?$ & yes \\
\hline Iowa & Burlington, IA & $\begin{array}{l}\text { Have not had } \\
\text { experience with long- } \\
\text { term monitoring }\end{array}$ & no answer & yes \\
\hline Kentucky & $\begin{array}{l}\text { William Natcher Bridge, } \\
\text { Owensboro, KY }\end{array}$ & $\begin{array}{l}\text { There are two problems } \\
\text { on the monitoring } \\
\text { systems. First, who } \\
\text { will analyze the large } \\
\text { amount of data } \\
\text { collected? Second, how } \\
\text { long will the sensors } \\
\text { and the computer } \\
\text { system last? We are } \\
\text { talking about } 100 \text {-year } \\
\text { life span. The reality is } \\
\text { that the monitoring } \\
\text { system will fail or } \\
\text { become obsolete within } \\
\text { approximately } 10 \text { years } \\
\text { when the bridge is not } \\
\text { expected to have any } \\
\text { problems. (PB) }\end{array}$ & $\begin{array}{l}\text { It does not seem } \\
\text { possible that the cable } \\
\text { suppliers can do any } \\
\text { more. (PB) }\end{array}$ & $\begin{array}{l}\text { yes-the resource does } \\
\text { not exist so far. We } \\
\text { (Parsons Brinkerhoff) } \\
\text { are developing them } \\
\text { right now. (PB) }\end{array}$ \\
\hline Kentucky & $\begin{array}{l}\text { William H. Harsha Bridge, } \\
\text { Maysville, KY }\end{array}$ & $\begin{array}{l}\text { There are two problems } \\
\text { on the monitoring } \\
\text { systems. First, who } \\
\text { will analyze the large } \\
\text { amount of data } \\
\text { collected? Second, how } \\
\text { long will the sensors } \\
\text { and the computer } \\
\text { system last? We are } \\
\text { talking about } 100 \text {-year } \\
\text { life span. The reality is } \\
\text { that the monitoring } \\
\text { system will fail or } \\
\text { become obsolete within }\end{array}$ & $\begin{array}{l}\text { It does not seem } \\
\text { possible that the cable } \\
\text { suppliers can do any } \\
\text { more. (PB) }\end{array}$ & $\begin{array}{l}\text { yes-the resource does } \\
\text { not exist so far. We } \\
\text { (Parsons Brinkerhoff) } \\
\text { are developing them } \\
\text { right now. (PB) }\end{array}$ \\
\hline
\end{tabular}




\section{NCHRP SYNTHESIS TOPIC 35-07-INSPECTION AND MAINTENANCE OF BRIDGE STAY CABLE SYSTEMS}

\begin{tabular}{|c|c|c|c|c|}
\hline State & Bridge & Q8 & Q9 & Q10 \\
\hline & & $\begin{array}{l}\text { approximately } 10 \text { years } \\
\text { when the bridge is not } \\
\text { expected to have any } \\
\text { problems. (PB) }\end{array}$ & & \\
\hline Louisiana & $\begin{array}{l}\text { Mississippi River Bridge at } \\
\text { Luling, LA }\end{array}$ & $\begin{array}{l}\text { Vibration monitoring } \\
\text { has been ongoing at } \\
\text { Luling for } 20 \text { years in } \\
\text { anticipation of a } \\
\text { hurricane striking the } \\
\text { bridge-no significant } \\
\text { long duration winds } \\
\text { have occurred }\end{array}$ & $\begin{array}{l}\text { I like the idea of } \\
\text { hermetically sealed, } \\
\text { ungrouted cables with } \\
\text { fiber optic sensors } \\
\text { throughout or exposed } \\
\text { wire that can be directly } \\
\text { inspected }\end{array}$ & yes \\
\hline Mississippi & & $\begin{array}{l}\text { No comment/not } \\
\text { known }\end{array}$ & $\begin{array}{l}\text { No comment/no } \\
\text { comment }\end{array}$ & Not known/yes \\
\hline Massachusetts & $\begin{array}{l}\text { Leonard P. Zakim Bunker } \\
\text { Hill Bridge, Boston, MA }\end{array}$ & none & $\begin{array}{l}\text { Transparent outer pipe, } \\
\text { eliminate grout }\end{array}$ & yes \\
\hline Missouri & $\begin{array}{l}\text { Bill Emerson Memorial } \\
\text { Bridge, Cape Girardeau }\end{array}$ & $\begin{array}{l}\text { MoDOT has no related } \\
\text { experience }\end{array}$ & $\begin{array}{l}\text { Perhaps a permanent } \\
\text { load cell that would } \\
\text { permit real-time } \\
\text { readings of cable forces } \\
\text { at any time during the } \\
\text { life of the bridge }\end{array}$ & yes \\
\hline Ohio & $\begin{array}{l}\text { Maumee River Bridge, } \\
\text { Toledo }\end{array}$ & no answer & $\begin{array}{l}\text { Access is a very sharp } \\
\text { two-edged sword. If } \\
\text { you can more easily } \\
\text { access the cable, so can } \\
\text { corrosive elements (not } \\
\text { to mention potential } \\
\text { terrorist/security } \\
\text { considerations) }\end{array}$ & $\begin{array}{l}\text { Not known-while } \\
\text { information can be } \\
\text { useful, it can also be } \\
\text { misinterpreted. The best } \\
\text { resource is direct } \\
\text { contact with those who } \\
\text { have hands-on } \\
\text { knowledge related to } \\
\text { the specific area that an } \\
\text { individual may be } \\
\text { making inquiries }\end{array}$ \\
\hline South Carolina & Cooper River Bridge & none & $\begin{array}{l}\text { Include a maintenance } \\
\text { manual with clear } \\
\text { instructions for both } \\
\text { specific wires or full } \\
\text { cables }\end{array}$ & yes \\
\hline Texas & Veterans Memorial Bridge & $\begin{array}{l}\text { The department has } \\
\text { installed an acoustic } \\
\text { monitoring system to } \\
\text { identify possible wire } \\
\text { breaks at the Fred } \\
\text { Hartman Bridge. The } \\
\text { system seems to work } \\
\text { well and has identified } \\
\text { several possible wire } \\
\text { breaks. Prior to its } \\
\text { installation, the system } \\
\text { was tested on a cable } \\
\text { mock-up at the } \\
\text { Ferguson Structural } \\
\text { Lab of the University of } \\
\text { Texas at Austin, where } \\
\text { research is underway to } \\
\text { determine the effects of } \\
\text { stay cable vibrations on } \\
\text { the fatigue life of the } \\
\text { cables. This allowed the } \\
\text { department to test the } \\
\text { monitoring system to } \\
\text { see how accurately it } \\
\text { could identify } \\
\text { occurrence and location } \\
\text { of wire breaks since } \\
\text { numerous wire breaks }\end{array}$ & $\begin{array}{l}\text { Current grouted and } \\
\text { sheathed systems do not } \\
\text { allow for visual } \\
\text { inspection. New stay } \\
\text { systems (perhaps } \\
\text { ungrouted, unsheathed } \\
\text { systems consisting of } \\
\text { bare corrosion-resistant } \\
\text { tension members) need } \\
\text { to be developed that } \\
\text { allow for inspection of } \\
\text { the entire stay length. } \\
\text { Research is also needed } \\
\text { to develop rapid, } \\
\text { economical evaluation } \\
\text { (NDE) methods to } \\
\text { determine conditions of } \\
\text { stay cables }\end{array}$ & yes \\
\hline
\end{tabular}




\section{NCHRP SYNTHESIS TOPIC 35-07-INSPECTION AND MAINTENANCE OF BRIDGE STAY CABLE SYSTEMS}

\begin{tabular}{|c|c|c|c|c|}
\hline State & Bridge & Q8 & Q9 & Q10 \\
\hline & & $\begin{array}{l}\text { were generated. The } \\
\text { correlation between the } \\
\text { monitoring system } \\
\text { results and the } \\
\text { autopsied cables was } \\
\text { very good }\end{array}$ & & \\
\hline Texas & Fred Hartman Bridge & $\begin{array}{l}\text { The department has } \\
\text { installed an acoustic } \\
\text { monitoring system to } \\
\text { identify possible wire } \\
\text { breaks at the Fred } \\
\text { Hartman Bridge. The } \\
\text { system seems to work } \\
\text { well and has identified } \\
\text { several possible wire } \\
\text { breaks. Prior to its } \\
\text { installation, the system } \\
\text { was tested on a cable } \\
\text { mock-up at the } \\
\text { Ferguson Structural } \\
\text { Lab of the University of } \\
\text { Texas at Austin, where } \\
\text { research is underway to } \\
\text { determine the effects of } \\
\text { stay cable vibrations on } \\
\text { the fatigue life of the } \\
\text { cables. This allowed the } \\
\text { department to test the } \\
\text { monitoring system to } \\
\text { see how accurately it } \\
\text { could identify } \\
\text { occurrence and location } \\
\text { of wire breaks since } \\
\text { numerous wire breaks } \\
\text { were generated. The } \\
\text { correlation between the } \\
\text { monitoring system } \\
\text { results and the } \\
\text { autopsied cables was } \\
\text { very good }\end{array}$ & $\begin{array}{l}\text { Current grouted and } \\
\text { sheathed systems do not } \\
\text { allow for visual } \\
\text { inspection. New stay } \\
\text { systems (perhaps } \\
\text { ungrouted, unsheathed } \\
\text { systems consisting of } \\
\text { bare corrosion resistant } \\
\text { tension members) need } \\
\text { to be developed that } \\
\text { allow for inspection of } \\
\text { the entire stay length. } \\
\text { Research is also needed } \\
\text { to develop rapid, } \\
\text { economical evaluation } \\
\text { (NDE) methods to } \\
\text { determine conditions of } \\
\text { stay cables }\end{array}$ & yes \\
\hline Virginia & $\begin{array}{l}\text { I-295 over James River } \\
\text { (Varina-Enon Bridge) }\end{array}$ & no comments & no comments & yes \\
\hline Washington & $\begin{array}{l}\text { Gum Street-Kennewick, } \\
\text { WA }\end{array}$ & N/A & unknown & yes \\
\hline Washington & Thea-Foss Tacoma, WA & N/A & unknown & yes \\
\hline Wisconsin & $\begin{array}{l}\text { Sixth Street Viaduct, North } \\
\text { Cable Stay }\end{array}$ & not applicable & no answer & yes \\
\hline Wisconsin & $\begin{array}{l}\text { Sixth Street Viaduct, South } \\
\text { Cable Stay }\end{array}$ & not applicable & no answer & yes \\
\hline Alberta/Calgary & Prince's Island (Pedestrian) & $\begin{array}{l}\text { Have not used vibration } \\
\text { monitoring on a long- } \\
\text { term basis. Has only } \\
\text { been used for short } \\
\text { durations to determine } \\
\text { frequency and } \\
\text { magnitude, etc. }\end{array}$ & no answer & yes \\
\hline Alberta/Calgary & Carburn Park (Pedestrian) & $\begin{array}{l}\text { Have not used vibration } \\
\text { monitoring on a long- } \\
\text { term basis. Has only } \\
\text { been used for short } \\
\text { durations to determine } \\
\text { frequency and } \\
\text { magnitude, etc. }\end{array}$ & no answer & yes \\
\hline Alberta/Calgary & McMahon (Pedestrian) & $\begin{array}{l}\text { Have not used vibration } \\
\text { monitoring on a long- } \\
\text { term basis. Has only }\end{array}$ & no answer & yes \\
\hline
\end{tabular}




\section{NCHRP SYNTHESIS TOPIC 35-07-INSPECTION AND MAINTENANCE OF BRIDGE STAY CABLE SYSTEMS}

\begin{tabular}{|c|c|c|c|c|}
\hline State & Bridge & Q8 & Q9 & Q10 \\
\hline & & $\begin{array}{l}\text { been used for short } \\
\text { durations to determine } \\
\text { frequency and } \\
\text { magnitude, etc. }\end{array}$ & & \\
\hline Alberta/Calgary & Fox Hollow (Pedestrian) & $\begin{array}{l}\text { Have not used vibration } \\
\text { monitoring on a long- } \\
\text { term basis. Has only } \\
\text { been used for short } \\
\text { durations to determine } \\
\text { frequency and } \\
\text { magnitude, etc. }\end{array}$ & no answer & yes \\
\hline Alberta/Calgary & Stoney Trail (Pedestrian) & $\begin{array}{l}\text { Have not used vibration } \\
\text { monitoring on a long- } \\
\text { term basis. Has only } \\
\text { been used for short } \\
\text { durations to determine } \\
\text { frequency and } \\
\text { magnitude, etc. }\end{array}$ & no answer & yes \\
\hline British Columbia & Alex Fraser Bridge & $\begin{array}{l}\text { Acoustic monitoring } \\
\text { may be cost-effective } \\
\text { for older structures. For } \\
\text { new structures, cost of } \\
\text { monitoring outweighs } \\
\text { benefits, and may be } \\
\text { compromised by other } \\
\text { noise (rehab, banging, } \\
\text { etc.) on the structure }\end{array}$ & $\begin{array}{l}\text { Our cables are } \\
\text { reasonably accessible, } \\
\text { inspectable. Possibly a } \\
\text { closeable drain at the } \\
\text { lower end of the cable } \\
\text { to allow visual } \\
\text { inspection, sample } \\
\text { collection, testing for } \\
\text { corrosion product of } \\
\text { any water in the cable } \\
\text { sheaths }\end{array}$ & yes \\
\hline Manitoba/Winnipeg & Esplanade Riel & $\begin{array}{l}\text { Not enough experience } \\
\text { to comment at this time }\end{array}$ & $\begin{array}{l}\text { Different corrosion } \\
\text { protection system at the } \\
\text { anchorages that permits } \\
\text { easier visual inspection. } \\
\text { Removable sections of } \\
\text { the HDPE and Vandal } \\
\text { Tubes would make it } \\
\text { easier to inspect strands } \\
\text { near the anchorages }\end{array}$ & yes \\
\hline New Brunswick & Hawkshaw & $\begin{array}{l}\text { Monitoring of } \\
\text { deflection of bridge by } \\
\text { student at Nackawic }\end{array}$ & no answer & yes \\
\hline New Brunswick & Longs Creek \#1 & $\begin{array}{l}\text { Monitoring of } \\
\text { deflection of bridge by } \\
\text { student at Nackawic }\end{array}$ & no answer & yes \\
\hline New Brunswick & Nackawic River & $\begin{array}{l}\text { Monitoring of } \\
\text { deflection of bridge by } \\
\text { student at Nackawic }\end{array}$ & no answer & yes \\
\hline Quebec, Canada & Galipeault & $\begin{array}{l}\text { No long-term } \\
\text { monitoring on our stay } \\
\text { cable bridges at the } \\
\text { present time }\end{array}$ & no answer & yes \\
\hline Quebec, Canada & Papineau & $\begin{array}{l}\text { No long-term } \\
\text { monitoring on our stay } \\
\text { cable bridges at the } \\
\text { present time }\end{array}$ & no answer & yes \\
\hline \multirow[t]{2}{*}{ Quebec, Canada } & Price & & & \\
\hline & Freyssinet & $\begin{array}{l}\text { We believe acoustical } \\
\text { monitoring is an } \\
\text { effective method to } \\
\text { record wire failures. } \\
\text { Permanent load cells } \\
\text { are good for monitoring } \\
\text { loads, especially with } \\
\text { unbonded monostrands } \\
\text { when it can be } \\
\text { established that the load }\end{array}$ & $\begin{array}{l}\text { Ability to detension, } \\
\text { inspect, and retension } \\
\text { individual strands } \\
\text { Ability to detension, } \\
\text { remove, and replace } \\
\text { individual strands. } \\
\text { Ability to add strands to } \\
\text { each cable or cable } \\
\text { group (avg. } 5 \% \text { ) }\end{array}$ & yes \\
\hline
\end{tabular}


NCHRP SYNTHESIS TOPIC 35-07_INSPECTION AND MAINTENANCE OF BRIDGE STAY CABLE SYSTEMS

\begin{tabular}{|c|c|c|c|c|}
\hline State & Bridge & Q8 & Q9 & Q10 \\
\hline & & $\begin{array}{l}\text { is equal in all } \\
\text { individual strands } \\
\text { within reasonable } \\
\text { tolerances such that by } \\
\text { monitoring one strand, } \\
\text { the load in cable is } \\
\text { known }\end{array}$ & & \\
\hline
\end{tabular}




\section{NCHRP SYNTHESIS TOPIC 35-07-INSPECTION AND MAINTENANCE OF BRIDGE STAY CABLE SYSTEMS}

\section{Questions:}

Q11 What do you see as the single most important problem in stay cable maintenance?

Q12 Please comment on any other methods for inspections, testing, monitoring, and repair of stay cable (including conventional methods) that you have found beneficial and are not listed above.

\section{Additional Comments?}

\section{Responses:}

\begin{tabular}{|c|c|c|c|c|}
\hline State & Bridge & Q11 & Q12 & Additional Comments \\
\hline Alabama & Cochrane Africatown & $\begin{array}{l}\text { Stay anchors. (Access } \\
\text { and rain-wind-induced } \\
\text { oscillation) }\end{array}$ & no answer & \\
\hline Alaska & $\begin{array}{l}\text { Sitka Harbor Bridge, Sitka, } \\
\text { Alaska }\end{array}$ & $\begin{array}{l}\text { Access to upper cable } \\
\text { anchorage }\end{array}$ & N/A & no answer \\
\hline Alaska & $\begin{array}{l}\text { Captain William Moore } \\
\text { Bridge, Skagway }\end{array}$ & $\begin{array}{l}\text { Access to upper cable } \\
\text { anchorage }\end{array}$ & N/A & no answer \\
\hline California & $\begin{array}{l}\text { Sacramento River } \\
\text { (Meridian) }\end{array}$ & $\begin{array}{l}\text { Inspection and } \\
\text { condition evaluation of } \\
\text { anchorages }\end{array}$ & $\begin{array}{l}\text { Engineering judgment } \\
\text { and experience seem to } \\
\text { prevail in determining } \\
\text { appropriate inspection } \\
\text { and maintenance } \\
\text { strategies }\end{array}$ & \\
\hline Delaware & $\begin{array}{l}\text { Br. 1-902, SR-1 over the } \\
\text { Chesapeake and Delaware } \\
\text { Canal, St. Georges, New } \\
\text { Castle County, Delaware }\end{array}$ & $\begin{array}{l}\text { Effective corrosion } \\
\text { barriers that do not } \\
\text { interfere with the ability } \\
\text { to adequately inspect } \\
\text { and assess the health of } \\
\text { the cable stay system } \\
\text { on a regular interval } \\
\text { and within practical } \\
\text { means }\end{array}$ & & \\
\hline Florida & Dame Point Bridge & $\begin{array}{l}\text { Accessibility for } \\
\text { inspection and } \\
\text { maintenance }\end{array}$ & Man-lift truck & \\
\hline Georgia & $\begin{array}{l}\text { Talmadge Memorial } \\
\text { Bridge, Savannah }\end{array}$ & $\begin{array}{l}\text { Access to the cable } \\
\text { anchorages }\end{array}$ & $\begin{array}{l}\text { Television endoscope- } \\
\text { type cameras for access } \\
\text { to guide pipes at bridge } \\
\text { deck level is helpful }\end{array}$ & \\
\hline Georgia & $\begin{array}{l}\text { Sidney Lanier Bridge, } \\
\text { Brunswick }\end{array}$ & $\begin{array}{l}\text { Access to the cable } \\
\text { anchorages }\end{array}$ & $\begin{array}{l}\text { Television endoscope- } \\
\text { type cameras for access } \\
\text { to guide pipes at bridge } \\
\text { deck level is helpful }\end{array}$ & \\
\hline Illinois & $\begin{array}{l}\text { Quincy Bayview Bridge at } \\
\text { Quincy, IL }\end{array}$ & $\begin{array}{l}\text { Uncertainty of cable } \\
\text { condition and } \\
\text { anchorages }\end{array}$ & no answer & \\
\hline Illinois & Clark Bridge at Alton, IL & $\begin{array}{l}\text { Uncertainty of cable } \\
\text { condition and } \\
\text { anchorages }\end{array}$ & no answer & \\
\hline Indiana & 46-03-7495 EBL & $\begin{array}{l}\text { Inspection, access, } \\
\text { testing, cost }\end{array}$ & no answer & \\
\hline Indiana & I65-68-7910 & $\begin{array}{l}\text { Inspection, access, } \\
\text { testing, cost }\end{array}$ & no answer & \\
\hline Iowa & Burlington, IA & $\begin{array}{l}\text { The inability to inspect } \\
\text { the elements inside the } \\
\text { cable and the anchorage } \\
\text { areas }\end{array}$ & no answer & \\
\hline Kentucky & $\begin{array}{l}\text { William Natcher Bridge, } \\
\text { Owensboro, KY }\end{array}$ & $\begin{array}{l}\text { Inspecting the cable } \\
\text { anchors. (PB) } \\
\text { Inspecting grout-filled } \\
\text { cables. (DKD) }\end{array}$ & none & $\begin{array}{l}\text { Comments followed by } \\
\text { (DKD) were made by } \\
\text { Darrell Dudgeon of } \\
\text { KYTC. Comments } \\
\text { followed by (PB) were } \\
\text { made by Ruchu Hsu, }\end{array}$ \\
\hline
\end{tabular}




\section{NCHRP SYNTHESIS TOPIC 35-07-INSPECTION AND MAINTENANCE OF BRIDGE STAY CABLE SYSTEMS}

\begin{tabular}{|c|c|c|c|c|}
\hline State & Bridge & Q11 & Q12 & Additional Comments \\
\hline & & & & $\begin{array}{l}\text { P.E. of Parsons } \\
\text { Brinkerhoff Quade and } \\
\text { Douglas, Inc. } \\
\text { Consulting Engineers } \\
\text { who was the lead } \\
\text { design engineer for the } \\
\text { Owensboro Bridge }\end{array}$ \\
\hline Kentucky & $\begin{array}{l}\text { William H. Harsha Bridge, } \\
\text { Maysville, KY }\end{array}$ & $\begin{array}{l}\text { Inspecting the cable } \\
\text { anchors. (PB) } \\
\text { Inspecting grout-filled } \\
\text { cables. (DKD) }\end{array}$ & none & $\begin{array}{l}\text { Comments followed by } \\
\text { (DKD) were made by } \\
\text { Darrell Dudgeon of } \\
\text { KYTC. Comments } \\
\text { followed by (PB) were } \\
\text { made by Ruchu Hsu, } \\
\text { P.E. of Parsons } \\
\text { Brinkerhoff Quade and } \\
\text { Douglas, Inc. } \\
\text { Consulting Engineers } \\
\text { who was the lead } \\
\text { design engineer for the } \\
\text { Owensboro Bridge }\end{array}$ \\
\hline Louisiana & $\begin{array}{l}\text { Mississippi River Bridge at } \\
\text { Luling, LA }\end{array}$ & $\begin{array}{l}\text { The hidden nature of } \\
\text { the system }\end{array}$ & no answer & no answer \\
\hline Mississippi & & $\begin{array}{l}\text { No comment/we do not } \\
\text { have enough experience } \\
\text { in this area to comment }\end{array}$ & N/A and N/A & \\
\hline Massachusetts & $\begin{array}{l}\text { Leonard P. Zakim Bunker } \\
\text { Hill Bridge, Boston, MA }\end{array}$ & Access for inspection & $\begin{array}{l}\text { Stay cable anchorage } \\
\text { design should allow for } \\
\text { accessibility for } \\
\text { inspection. Inspection, } \\
\text { maintenance, and } \\
\text { replacement should be } \\
\text { addressed during design }\end{array}$ & no answer \\
\hline Missouri & $\begin{array}{l}\text { Bill Emerson Memorial } \\
\text { Bridge, Cape Girardeau }\end{array}$ & $\begin{array}{l}\text { The integrity of the } \\
\text { stays. Grouted cables } \\
\text { are impossible to } \\
\text { inspect with a non- } \\
\text { destructive technique } \\
\text { (i.e., one that does not } \\
\text { require removal of } \\
\text { sheathing and grout) } \\
\text { thus, it is impossible to } \\
\text { identify corrosion } \\
\text { problems early }\end{array}$ & $\begin{array}{l}\text { MoDOT has no related } \\
\text { experience }\end{array}$ & \\
\hline Ohio & $\begin{array}{l}\text { Maumee River Bridge, } \\
\text { Toledo }\end{array}$ & $\begin{array}{l}\text { The largest "problem" } \\
\text { with stay cables is that } \\
\text { they are widely } \\
\text { perceived as "a } \\
\text { problem" rather than } \\
\text { just another bridge } \\
\text { member with specific } \\
\text { needs and } \\
\text { characteristics. Stay } \\
\text { cables have been placed } \\
\text { unnecessarily "on a } \\
\text { pedestal." While they } \\
\text { are a very important } \\
\text { bridge member, in } \\
\text { current designs they are } \\
\text { highly redundant, } \\
\text { overtested, and } \\
\text { (relatively) easily } \\
\text { replaced. There is no } \\
\text { other major bridge } \\
\text { member that fits into all } \\
\text { three of these } \\
\text { categories. Let's not }\end{array}$ & no answer & no answer \\
\hline
\end{tabular}




\section{NCHRP SYNTHESIS TOPIC 35-07-INSPECTION AND MAINTENANCE OF BRIDGE STAY CABLE SYSTEMS}

\begin{tabular}{|c|c|c|c|c|}
\hline State & Bridge & Q11 & Q12 & Additional Comments \\
\hline & & $\begin{array}{l}\text { promote the feeling that } \\
\text { Stays are "a } \\
\text { maintenance problem" }\end{array}$ & & \\
\hline South Carolina & Cooper River Bridge & $\begin{array}{l}\text { Provide end caps that } \\
\text { are easily removed and } \\
\text { fully protected against } \\
\text { corrosion }\end{array}$ & no answer & \\
\hline Texas & Veterans Memorial Bridge & $\begin{array}{l}\text { Ability to determine the } \\
\text { effectiveness and } \\
\text { remaining life of } \\
\text { corrosion protection } \\
\text { systems for main } \\
\text { tension elements. The } \\
\text { configuration and } \\
\text { construction techniques } \\
\text { make evaluation and } \\
\text { inspection using non- } \\
\text { destructive techniques } \\
\text { almost impossible }\end{array}$ & no answer & \\
\hline Texas & Fred Hartman Bridge & $\begin{array}{l}\text { Ability to determine the } \\
\text { effectiveness and } \\
\text { remaining life of } \\
\text { corrosion protection } \\
\text { systems for main } \\
\text { tension elements. The } \\
\text { configuration and } \\
\text { construction techniques } \\
\text { make evaluation and } \\
\text { inspection using non- } \\
\text { destructive techniques } \\
\text { almost impossible }\end{array}$ & no answer & \\
\hline Virginia & $\begin{array}{l}\text { I-295 over James River } \\
\text { (Varina-Enon Bridge) }\end{array}$ & $\begin{array}{l}\text { Lack of familiarity with } \\
\text { this type of construction } \\
\text { by the department's } \\
\text { staff which requires } \\
\text { assistance from the } \\
\text { consultant community } \\
\text { in the inspection of } \\
\text { these elements }\end{array}$ & no answer & \\
\hline Washington & $\begin{array}{l}\text { Gum Street-Kennewick, } \\
\text { WA }\end{array}$ & none yet & N/A & \\
\hline Washington & Thea-Foss Tacoma, WA & none yet & N/A & \\
\hline Wisconsin & $\begin{array}{l}\text { Sixth Street Viaduct, North } \\
\text { Cable Stay }\end{array}$ & $\begin{array}{l}\text { Cannot inspect cables } \\
\text { without pulling strand } \\
\text { every } 10 \text { years }\end{array}$ & $\begin{array}{l}\text { Four strands (one at } \\
\text { each pylon) will be } \\
\text { removed every } 10 \text { years } \\
\text { starting in } 2014 \text { to } \\
\text { check for } \\
\text { corrosion/rusting }\end{array}$ & \\
\hline Wisconsin & $\begin{array}{l}\text { Sixth Street Viaduct, South } \\
\text { Cable Stay }\end{array}$ & $\begin{array}{l}\text { Cannot inspect cables } \\
\text { without pulling strand } \\
\text { every } 10 \text { years }\end{array}$ & $\begin{array}{l}\text { Four strands (one at } \\
\text { each pylon) will be } \\
\text { removed every } 10 \text { years } \\
\text { starting in } 2014 \text { to } \\
\text { check for } \\
\text { corrosion/rusting }\end{array}$ & \\
\hline Alberta/Calgary & Prince's Island (Pedestrian) & $\begin{array}{l}\text { Access for inspection } \\
\text { and actual testing }\end{array}$ & no answer & $\begin{array}{l}\text { The five bridges } \\
\text { identified are all } \\
\text { pedestrian structures. } \\
\text { Three over water and } \\
\text { two over roadways }\end{array}$ \\
\hline Alberta/Calgary & Carburn Park (Pedestrian) & $\begin{array}{l}\text { Access for inspection } \\
\text { and actual testing }\end{array}$ & no answer & $\begin{array}{l}\text { The five bridges } \\
\text { identified are all } \\
\text { pedestrian structures. } \\
\text { Three over water and } \\
\text { two over roadways } \\
\end{array}$ \\
\hline Alberta/Calgary & McMahon (Pedestrian) & $\begin{array}{l}\text { Access for inspection } \\
\text { and actual testing }\end{array}$ & no answer & $\begin{array}{l}\text { The five bridges } \\
\text { identified are all }\end{array}$ \\
\hline
\end{tabular}




\section{NCHRP SYNTHESIS TOPIC 35-07-INSPECTION AND MAINTENANCE OF BRIDGE STAY CABLE SYSTEMS}

\begin{tabular}{|c|c|c|c|c|}
\hline State & Bridge & Q11 & Q12 & Additional Comments \\
\hline & & & & $\begin{array}{l}\text { pedestrian structures. } \\
\text { Three over water and } \\
\text { two over roadways }\end{array}$ \\
\hline Alberta/Calgary & Fox Hollow (Pedestrian) & $\begin{array}{l}\text { Access for inspection } \\
\text { and actual testing }\end{array}$ & no answer & $\begin{array}{l}\text { The five bridges } \\
\text { identified are all } \\
\text { pedestrian structures. } \\
\text { Three over water and } \\
\text { two over roadways }\end{array}$ \\
\hline Alberta/Calgary & Stoney Trail (Pedestrian) & $\begin{array}{l}\text { Access for inspection } \\
\text { and actual testing }\end{array}$ & no answer & $\begin{array}{l}\text { The five bridges } \\
\text { identified are all } \\
\text { pedestrian structures. } \\
\text { Three over water and } \\
\text { two over roadways }\end{array}$ \\
\hline British Columbia & Alex Fraser Bridge & $\begin{array}{l}\text { Detecting corrosion in } \\
\text { cables, maintenance of } \\
\text { sheaths and boots }\end{array}$ & no comment & $\begin{array}{l}\text { Have had leakage of } \\
\text { wax blocking } \\
\text { compound at bottom } \\
\text { anchorages during hot } \\
\text { weather }\end{array}$ \\
\hline Manitoba/Winnipeg & Esplanade Riel & $\begin{array}{l}\text { Corrosion at the } \\
\text { anchorages }\end{array}$ & no answer & \\
\hline New Brunswick & Hawkshaw & $\begin{array}{l}\text { Migration of water into } \\
\text { cable strands }\end{array}$ & no answer & \\
\hline New Brunswick & Longs Creek \#1 & $\begin{array}{l}\text { Migration of water into } \\
\text { cable strands }\end{array}$ & no answer & \\
\hline New Brunswick & Nackawic River & $\begin{array}{l}\text { Migration of water into } \\
\text { cable strands }\end{array}$ & no answer & \\
\hline Quebec, Canada & Galipeault & Fatigue & no answer & $\begin{array}{l}\text { We have had a serious } \\
\text { problem on Galipeault } \\
\text { bridge no. } 1-\text { failure of } \\
\text { an anchorage plate at } \\
\text { one abutment } \\
\text { (corrosion and fatigue } \\
\text { failure). Emergency } \\
\text { repairs were performed }\end{array}$ \\
\hline Quebec, Canada & Papineau & Fatigue & no answer & $\begin{array}{l}\text { We have had a serious } \\
\text { problem on Galipeault } \\
\text { bridge no. } 1 \text {-failure of } \\
\text { an anchorage plate at } \\
\text { one abutment } \\
\text { (corrosion and fatigue } \\
\text { failure). Emergency } \\
\text { repairs were performed }\end{array}$ \\
\hline \multirow[t]{2}{*}{ Quebec, Canada } & Price & & & $\begin{array}{l}\text { We also had a failure of } \\
\text { an anchorage plate on } \\
\text { Price bridge (no. 3) } \\
\text { during the } 1988 \\
\text { Saguenay earthquake } \\
(\mathrm{ML}=6.0) \text {. It was the } \\
\text { first documented } \\
\text { structural damage to a } \\
\text { steel bridge caused by } \\
\text { an earthquake in } \\
\text { Canada }\end{array}$ \\
\hline & Freyssinet & $\begin{array}{l}\text { Inspectability in the } \\
\text { anchorage area }\end{array}$ & no answer & \\
\hline
\end{tabular}


Abbreviations used without definitions in TRB publications:

\begin{tabular}{ll} 
AASHO & American Association of State Highway Officials \\
AASHTO & American Association of State Highway and Transportation Officials \\
ADA & Americans with Disabilities Act \\
APTA & American Public Transportation Association \\
ASCE & American Society of Civil Engineers \\
ASME & American Society of Mechanical Engineers \\
ASTM & American Society for Testing and Materials \\
ATA & American Trucking Associations \\
CTAA & Community Transportation Association of America \\
CTBSSP & Commercial Truck and Bus Safety Synthesis Program \\
DHS & Department of Homeland Security \\
DOE & Department of Energy \\
EPA & Environmental Protection Agency \\
FAA & Federal Aviation Administration \\
FHWA & Federal Highway Administration \\
FMCSA & Federal Motor Carrier Safety Administration \\
FRA & Federal Railroad Administration \\
FTA & Federal Transit Administration \\
IEEE & Institute of Electrical and Electronics Engineers \\
ISTEA & Intermodal Surface Transportation Efficiency Act of 1991 \\
ITE & Institute of Transportation Engineers \\
NASA & National Aeronautics and Space Administration \\
NCHRP & National Cooperative Highway Research Program \\
NCTRP & National Cooperative Transit Research and Development Program \\
NHTSA & National Highway Traffic Safety Administration \\
NTSB & National Transportation Safety Board \\
SAE & Society of Automotive Engineers \\
SAFETEA-LU & Safe, Accountable, Flexible, Efficient Transportation Equity Act: \\
& A Legacy for Users (2005) \\
TCRP & Transit Cooperative Research Program \\
TEA-21 & Transportation Equity Act for the 21st Century (1998) \\
TRB & Transportation Research Board \\
TSA & Transportation Security Administration \\
U.S.DOT & United States Department of Transportation \\
& \\
\hline
\end{tabular}

